\title{
YIELD, PEST DENSITY, AND TOMATO FLAVOR EFFECTS OF COMPANION PLANTING IN GARDEN-SCALE STUDIES INCORPORATING TOMATO, BASIL, AND BRUSSELS SPROUT
}

\author{
Michael K. Bomford \\ Dissertation submitted to the \\ Davis College of Agriculture, Forestry and Consumer Sciences \\ at West Virginia University \\ in partial fulfillment of the requirements \\ for the degree of \\ Doctor of Philosophy \\ in \\ Agricultural Science \\ Linda Butler, Ph.D., Chair \\ William Bryan, Ph.D. \\ Sven Verlinden, Ph.D. \\ James Kotcon, Ph.D. \\ Herbert Cole, Ph.D. \\ Division of Plant and Soil Sciences \\ Morgantown, West Virginia \\ 2004
}

Keywords:

intercropping, polyculture, plant competition, plant density, crop ratio, tomato taste, pest dynamics, response surface 


\title{
ABSTRACT \\ Yield, pest density, and tomato flavor effects of companion planting in garden-scale studies incorporating tomato, basil, and Brussels sprout
}

\begin{abstract}
Michael K. Bomford
Companion planting is a small-scale intercropping practice often associated with organic or biodynamic gardening. Two garden-scale studies tested popular companion planting claims by comparing garden beds devoted entirely to one of three or more test crops (monocultures) to all possible two-crop mixtures (dicultures) of the same species. A third study evaluated effects of planting density and crop ratio in three dicultures using a novel experimental design to create gradients in both factors. All studies incorporated basil (Ocimum basilicum L.), Brussels sprout (Brassica oleracea L.), and tomato (Lycopersicum esculentum Mill.). A preliminary study also included snap bean (Phaseolus vulgaris L.), radish (Raphanus sativus L.) before Brussels sprout, and dicultures of tomato and Brussels sprout with a white clover (Trifolium repens L.) living mulch. Double blind taste tests over three years showed no consistent preference for tomatoes grown with companions over those grown in monoculture. An apparent inhibitory effect of companion planting on some pests of Brussels sprout (e.g. imported cabbageworm, Pieris rapae L.; striped flea beetle, Phylollotreta striolata Fab.) in the first study was reversed in the second study when earlier planting of Brussels sprout allowed it to compete more effectively with its companions. Relative yield indices calculated for a range of densities $\left(1.1-47.2 \mathrm{plants} / \mathrm{m}^{2}\right)$ and crop ratios indicated advantages $(\bar{x}=20 \%)$ to planting either tomato or Brussels sprout with basil companions, but no advantage to planting tomato and Brussels sprout together. The highest yields in tomato, basil, and Brussels sprout monocultures occurred at inter-plant spacings of 25, 25 and $40 \mathrm{~cm}$ respectively, suggesting advantages to high-density planting. Yield advantages to diculture were most pronounced at the highest densities tested, and in dicultures incorporating the highest proportions of basil. Canopy light absorption and soil moisture content were inversely correlated, and the use of light and water resources was correlated with plant density and biomass production. I conclude that garden-scale intercropping can offer advantages over monoculture, but these are not achieved simply by combining certain compatible companion species. Crop densty, ratio, and relative planting times all affect the way that companion species interact with one another and their environment.
\end{abstract}




\section{Dedication}

To those who garden for food, peace, and pleasure instead of data.

May we learn from one another in mutually beneficial companionship. 


\section{Table of Contents}

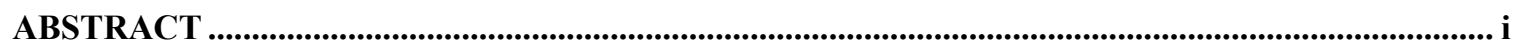

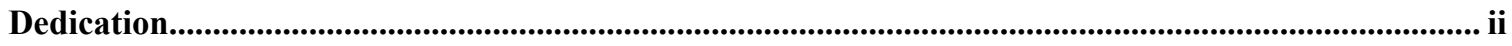

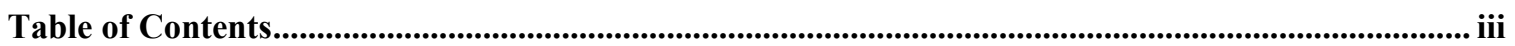

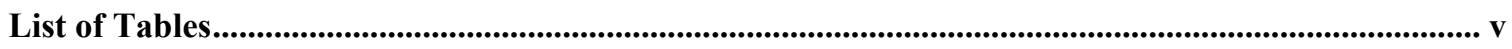

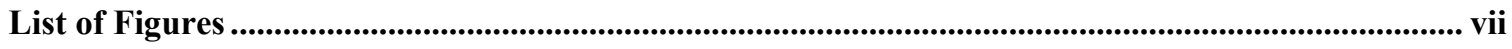

List of Multimedia Files ...............................................................................................................................

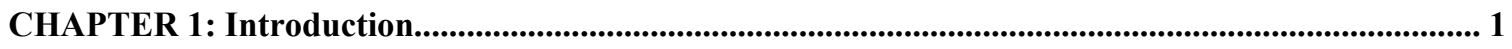

Tracing the Roots of Popular Practice: Carrots Love Tomatoes ........................................................ 1

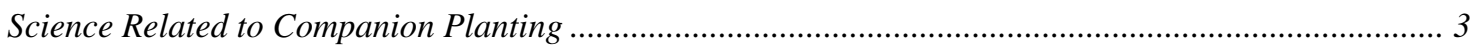

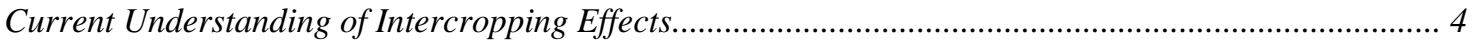

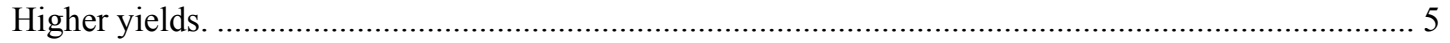



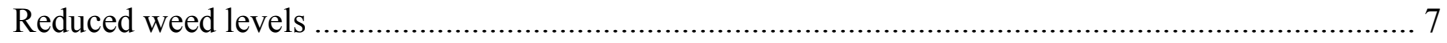

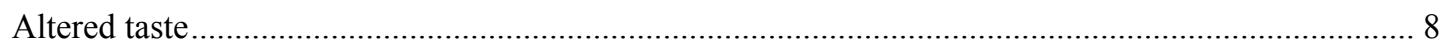

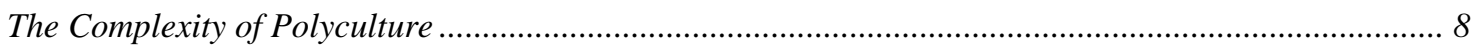

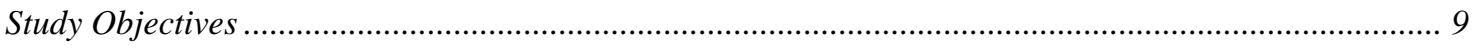

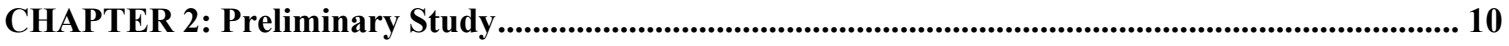

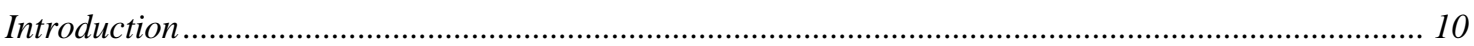

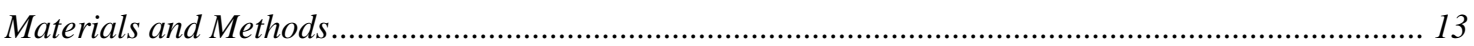

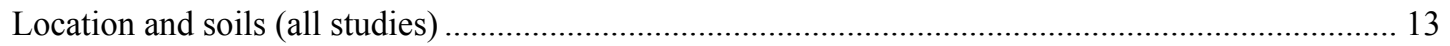

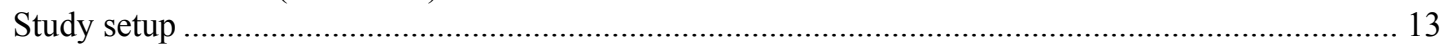

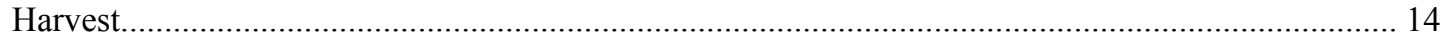

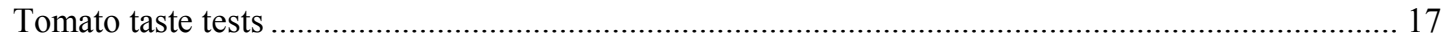

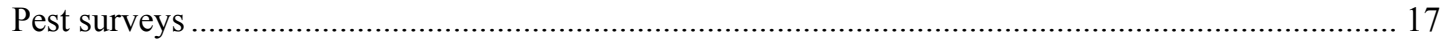

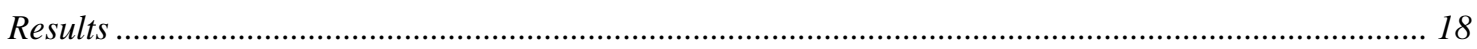

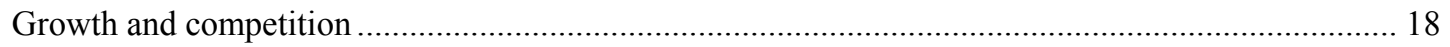

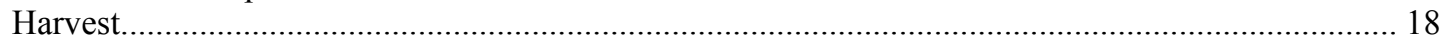

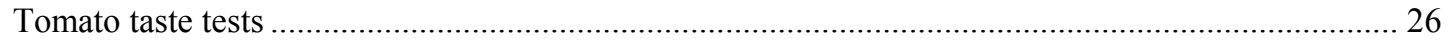

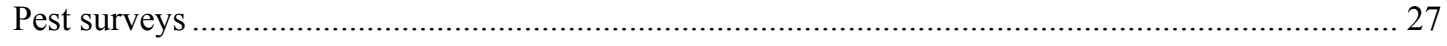

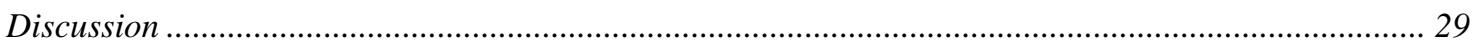

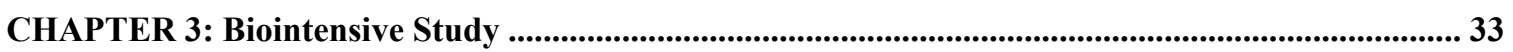

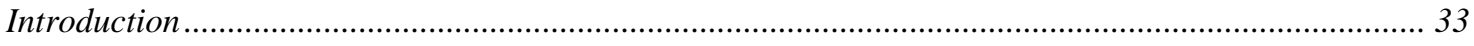

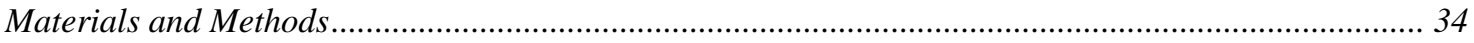

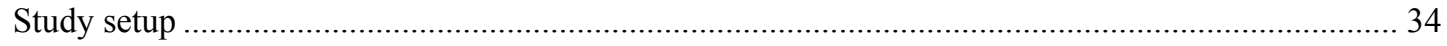

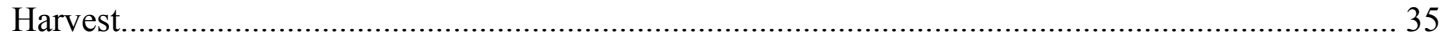

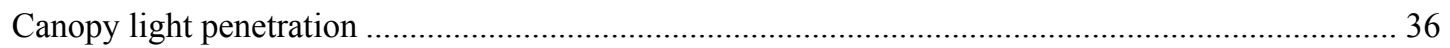

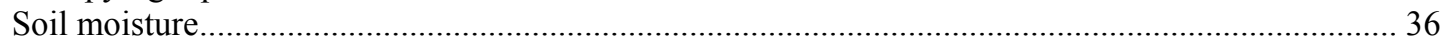

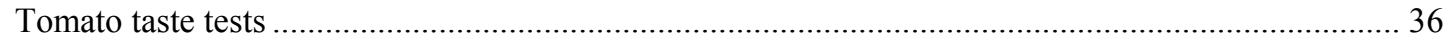




Pest surveys

CHAPTER 4: Tri-fan Circle Study ….............................................................................................................. 51

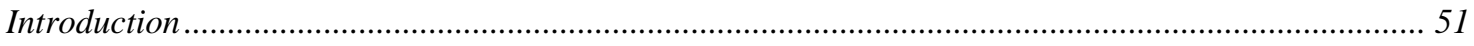

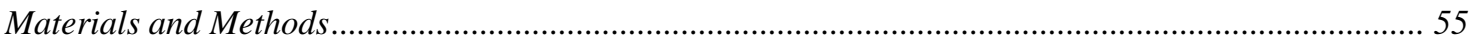

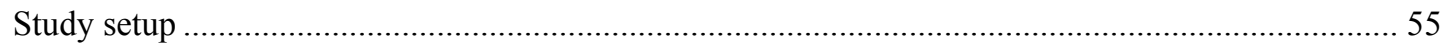

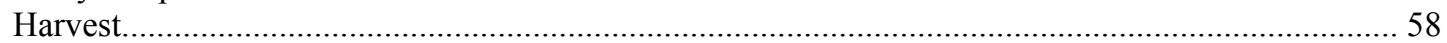

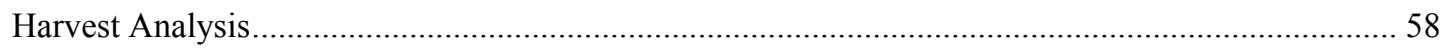

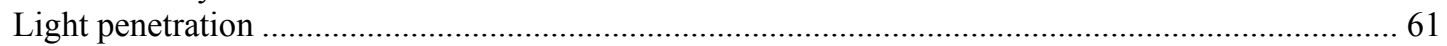

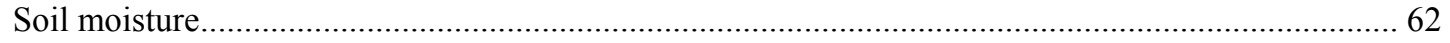

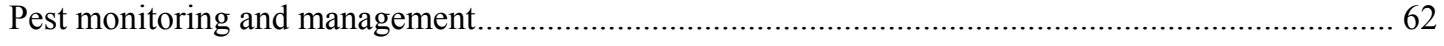

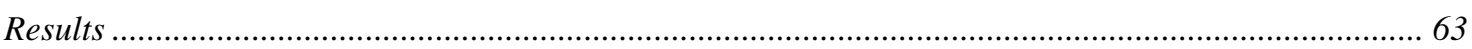

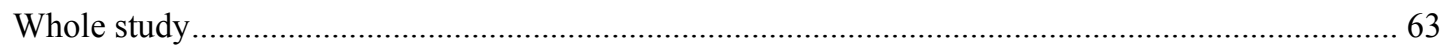

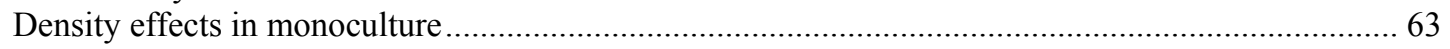

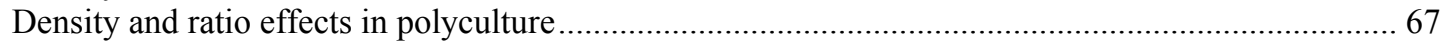

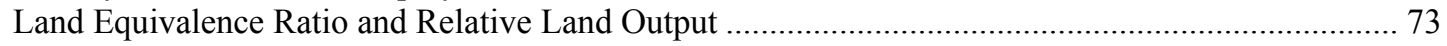

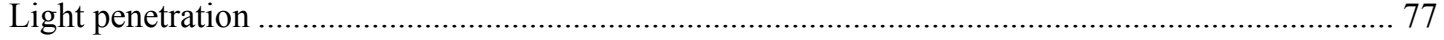

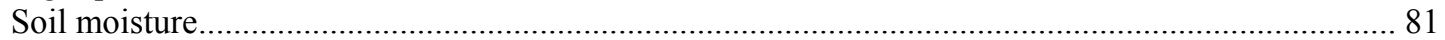

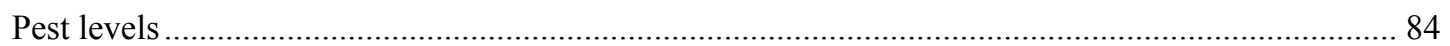

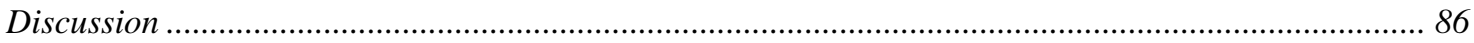

CHAPTER 5: Conclusion .................................................................................................................................... 90

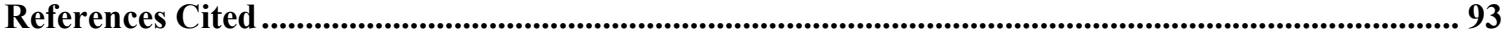

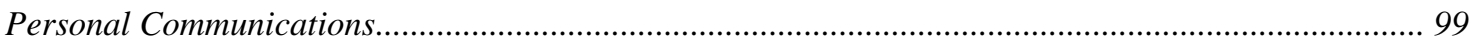

Appendix 1: Maximum polyculture combinations possible for a given number of monocultures.... 100

Appendix 2: Generation of random planting designs for circle studies.................................................. 101

Appendix 3: Weather data.................................................................................................................... 102

Appendix 4: Preliminary study growth photos.................................................................................................. 104

Appendix 5: Scale of selected field studies assessing plant diversity effects .......................................... 105

Appendix 6: Popular companion planting recommendations .................................................................... 106

Appendix 7: Soil test results for all study areas............................................................................................ 107 


\section{List of Tables}

Table 1. Popular recommendations relating to companion combinations examined in the preliminary study

Table 2. Some observations from peer-reviewed studies relating to combinations examined in the preliminary study.

Table 3. Preliminary study treatments and target densities.

Table 4. Above-ground biomass collected from plots of tomatoes grown in monoculture beds, or beds with clover, bean, cabbage, or basil companions. Means followed by the same letter within a column are not significantly different (Tukey's test $P>0.05$ ).

Table 5. Characteristics of tomatoes harvested from monoculture beds, or beds with clover, bean, cabbage, or basil companions. Means followed by the same letter within a column are not significantly different (Tukey's test $P>0.05$ ).

Table 6. Contributions of component crops to total Land Equivalence Ratio (LER) for seven companion plant combinations $(\bar{x} \pm$ S.E.). Upper and lower $95 \%$ confidence intervals are shown for total LER.

Table 7. Tomato taste test ratings by blind tasters comparing fruit grown in monoculture beds or diculture beds to standard fruit grown in monoculture beds. Sweetness, acidity, "true tomato flavor" and personal preference for each test tomato was compared to a standard on a scale of 2 (much less than standard) to 2 (much more than standard).

Table 8. Counts of palestriped flea beetle found on basil leaves during six surveys between June and September $(n=4)$. Means followed by the same letter within a column are not significantly different (Tukey's test, $P<0.05$ ).

Table 9. Counts of three prominent phytophagous insects found on bean leaf triplets during five surveys between June and September $(n=4)$.

Table 10. Counts of three prominent phytophagous insects found on brassica (radish and Brussels sprout) leaves during five surveys between June and September $(n=4)$. Means followed by the same letter within a column are not significantly different (Tukey's test, $P<0.05$ ).................... 28

Table 11. Counts of cross-striped cabbageworm (larvae and eggs) and imported cabbageworm larvae found on Brussels sprout leaves during three surveys between August and September $(n=4)$. Means followed by the same letter within a column are not significantly different (Tukey's test, $P<0.05)$

Table 12. Counts of potato aphids, and two aphid biocontrol organisms, on tomato leaf clusters during six surveys between June and September $(n=4)$.

Table 13. The magnitude of selected differences in survival rate (S) plant weight (P), and fruit yield (F) in dicultures as compared to monocultures. $X$ denotes a monoculture or untested combination.

Table 14. Biointensive study treatments, bed areas, plant spacing, and densities (after Jeavons 1982)

Table 15. Fresh weight of aboveground plant matter removed over the growing season. For each plant type means followed by the same letter within a column are not significantly different, Tukey's test $(P<0.05)$.

Table 16. Contributions of component crops to total Land Equivalence Ratio (LER) for three companion plant combinations $(\bar{x} \pm$ S.E. $)$.

Table 17. Tomato taste test ratings by blind tasters comparing fruit grown in monoculture beds or diculture beds to standard fruit grown in monoculture beds. Sweetness, acidity, "true tomato flavor" and personal preference for each test tomato was compared to a standard on a scale of 2 (much less than standard) to 2 (much more than standard).

Table 18. Total palestriped flea beetles, Systena blanda, found on basil in systematic leaf surveys in 2002. Means followed by the same letter are not significantly different (Tukey's test, $P<0.05$ ).

Table 19. Counts of commonly occurring phytophagous Lepidoptera on Brussels sprout leaves during systematic leaf surveys. Means followed by the same letter within a column are not significantly different (Tukey's test, $P<0.05$ ). 
Table 20. Counts of the striped flea beetle, $P$. striolata, found on Brussels sprout leaves during systematic surveys. Means followed by the same letter within a column are not significantly different (Tukey's test, $P<0.05$ ).

Table 21. Occurrence of the cabbage aphid, $B$. brassicae, on Brussels sprout leaves in the final monitoring session of 2002. Counts of aphid clusters containing up to 50 aphids are reported. Groups larger than 50 were considered multiple clusters (e.g. 125 aphids $=3$ clusters). Individual aphids parasitized by braconid wasps (mummies) are reported separately. Means followed by the same letter within a column are not significantly different (Tukey's test, $P<0.05$ ).

Table 22. Counts of the potato aphid, $M$. euphorbiae, found on tomato leaves during systematic surveys. Means followed by the same letter within a column are not significantly different (Tukey's test, $P<0.05$ ).

Table 23. Proportion of tomato leaves with early blight, $A$. solani, lesions at final harvest. Means followed by the same letter within a column are not significantly different (Tukey's test, $P<0.05$ ).

Table 24. Description of variables from models used to analyze the tri-fan circle study.................... 58

Table 25. Criteria used to assign damage ratings to individual Brussels sprout plants at harvest..... 63

Table 26. Fresh weight, and marketable portion, of all plant matter removed from tri-fan circle study.

Table 27. Fitted values for a linear regression of square root biomass $\left(w^{0.5}\right)$ against arc position $(x)$ where $d$ describes the effect of density (Figure 27 top left).

Table 28. Fitted values for a nonlinear regression of biomass $(w)$ against planting density $(N)$ where $a$ estimates the area required by a plant to grow to its maximum size $\left(w_{\max }\right)$, and $b$ describes the resource use efficiency of the population (Figure 27 top right) (after Watkinson 1980).............. 65

Table 29. Fitted terms in a square root yield-density response surface model $\left(w^{0.5}=i+d x+z q+\operatorname{Rep}\right)$ relating the square root of aboveground fresh weight $\left(w^{0.5}\right)$ of plants grown in diculture at each arc position $(x)$ with varying numbers of neighbors of the same species $(q)$ (c.f. Figure 30). The first and second letters of each diculture code represent the target and companion species, respectively ( $\mathrm{T}=$ tomato, $\mathrm{B}=$ basil, $\mathrm{S}=$ Brussels sprout).

Table 30. Fitted terms in a nonlinear response surface model $\left(w=w_{\max }\left[1+a\left(N_{\mathrm{A}}+\alpha N_{\mathrm{B}}\right)\right]^{-b}\right)$ relating aboveground fresh weight $(w)$ of plants grown in diculture to the density of a target crop $\left(N_{\mathrm{A}}\right)$ and its companion crop $\left(N_{B}\right)$ (c.f. Figure 31). The first and second letters of each diculture code represent the target and companion species, respectively $(T=$ tomato, $B=b a s i l, S=B r u s s e l s$ sprout).

Table 31. Fitted terms in an inverse yield-density response surface model $\left(w^{-1}=1 / w_{\max }+\mathrm{z} N_{\mathrm{A}}+\alpha N_{\mathrm{B}}\right)$ relating inverse aboveground fresh weight $\left(w^{-1}\right)$ of plants grown in diculture to the density of a target crop $\left(N_{\mathrm{A}}\right)$ and its companion crop $\left(N_{\mathrm{B}}\right)$. The first and second letters of each diculture code represent the target and companion species, respectively $(T=$ tomato, $B=b a s i l, S=B r u s s e l s$ sprout).......................................................................................................................................................70 70

Table 32. Segments of the tri-fan circle study ranked by canopy light absorption (100 - Sunfleck \%), moisture deficit (100 - Volumetric Water Content \%), and total aboveground biomass production (g). The mean rank is shown in the final column.

Table 33. The maximum number of potential polycultures relates to the number of component crops. Adding any number to its neighbor in preceding column gives the next number in the series. The series in these four columns correspond to the second to fifth rows of Pascal's triangle (Weisstein 1999). 100

Table 34. A selection of studies demonstrating atypical range of plot sizes to illustrate the scale at which intercropping research has been conducted.

Table 35. Examples of popularly circulated companion planting recommendations (from Primal Seeds 2002).

Table 36. Analysis of composted dairy manure and leaf litter applied to preliminary study plots at approximately $3 \mathrm{~kg} / \mathrm{m}^{2}$ on 27 April, 2000.

Table 37. Soil test results from samples collected from the biointensive study on 15 April 2003, following study completion. Each value is the mean for a single replicate................................ 108

Table 38. Soil test results from samples collected from the tri-fan circle study on 15 April 2003, prior to transplanting crops for the second season. Each value is the mean for a single replicate..... 108 


\section{List of Figures}

Figure 1. Theoretical (left) and actual (right) planting arrangement of a sample companion crop bed containing bean and basil plants.

Figure 2. Temporal overlap of crops in the preliminary study. Black, grey, and white bars denote periods of seeding to emergence or transplant, pre-harvest, and harvest, respectively. Arrows show crop pest monitoring dates.

Figure 3. Total fresh weight of basil leaves removed on each harvest day. Basil plants were grown in monoculture beds (mono) containing five rows of basil, or in beds containing five alternating rows of basil and a companion crop (bean, brassica, or tomato). Dicultures contained two rows of basil and three of the companion crop. All leaves and stems $>15 \mathrm{~cm}$ above the soil surface were removed on each harvest day, except the final harvest, when all remaining leaves were removed.

Figure 4. Aboveground fresh weight of basil harvested per plant (left), and per $\mathbf{m}^{2}$ (right). Points with the same letter for a given harvest are not significantly different (Tukey's test, $P<0.05, n=4$ ). Basil plants were grown in monoculture beds (mono) containing five rows of basil, or in beds containing five alternating rows of basil and a companion crop (bean, brassica, or tomato). Dicultures contained two rows of basil and three of the companion crop.

Figure 5. Fresh weight of beans removed on each harvest day for first planting (left) and second planting (right). Plants were grown in monoculture beds (mono) containing five rows of bean, or in beds containing five alternating rows of bean and a companion crop (basil, brassica, or tomato). Bean dicultures with brassica or tomato companions contained two rows of bean and three of the companion crop. Bean and basil dicultures contained three rows of bean and two of basil. All pods $>10 \mathrm{~cm}$ in length were removed at each harvest.

Figure 6. Fresh weight of bean plants removed per $\mathrm{m}^{2}$ (left), and per row (right). Weight includes total season harvest of beans and aboveground plant parts for two plantings. Plants were grown in monoculture beds (mono) containing five rows of bean, or in beds containing five alternating rows of bean and a companion crop (basil, brassica, or tomato). Bean dicultures with brassica or tomato companions contained two rows of bean and three of the companion crop. Bean and basil dicultures contained three rows of bean and two of basil. Bars within a box labeled with the same letter, or no letter, are not significantly different (Tukey's test, $P<0.05, n=4)$................... 21

Figure 7. Aboveground fresh weight of Brussels sprout plant matter collected per plant (left), and per $\mathbf{m}^{2}$ (right). Brussels sprouts were grown in monoculture beds (mono) containing five rows of Brussels sprouts, or in beds containing five alternating rows of Brussels sprout and a companion crop (basil, bean, clover, or tomato). Basil, bean, and clover beds contained three rows of Brussels sprout and two of the companion crop; tomato beds contained two rows of Brussels sprout and three of tomato. Bars within a box labeled with the same letter are not significantly different (Tukey's test, $P<0.05, n=4)$.

Figure 8. Number of radishes harvested on each harvest day (left) and in all harvests combined (right). Points with the same letter for a given harvest are not significantly different (Tukey's test, $P<0.05, n=4)$. Radishes were grown in monoculture beds (mono) containing five rows of radishes, or in beds containing five alternating rows of radish and a companion crop (basil, bean, clover, or tomato). Basil, bean, and clover beds contained three rows of radish and two of the companion crop; tomato beds contained two rows of radish and three of tomato. Only radishes $>\mathbf{2} \mathbf{~ c m}$ in diameter were removed during the first two harvests; the remainder were removed during the final harvest.

Figure 9. Fresh weight of radish plants removed on each harvest day (left), and in all harvests combined (right). ). Points with the same letter for a given harvest are not significantly different (Tukey's test, $P<0.05, n=4$ ). Radishes were grown in monoculture beds (mono) containing five rows of radishes, or in beds containing five alternating rows of radish and a companion crop (basil, bean, clover, or tomato). Basil, bean, and clover beds contained three rows of radish and two of the companion crop; tomato beds contained two rows of radish and three of tomato. Only radishes $>\mathbf{2 m}$ in diameter were removed during the first two harvests; the remainder were removed during the final harvest. 
Figure 10. Number of ripe tomato fruits picked on each harvest day in tomato monoculture beds (mono), and in beds containing alternating rows of tomato and a companion crop (basil, bean, brassica, or clover). Points within the same oval are not significantly different (Tukey's test, $P>$ 0.05). No significant differences were found between treatments on days where points are not enclosed by ovals.

Figure 11. Mean fresh weight of individual tomato fruits collected from monocultures or dicultures on each harvest day. No significant differences were found between treatments on any harvest day (Tukey's test).

Figure 12. Temporal overlap of crops in the Biointensive study. Black, grey, and white bars denote periods of seeding to transplant, transplant to harvest, and harvest, respectively. Arrows show crop monitoring dates.

Figure 13. Fresh weight of basil removed from monoculture beds (BAS) and Brussels sprout (S\&B) or tomato $(T \& B)$ diculture beds on each harvest day in 2001 (left) and 2002 (right). Error bars denote standard error of each mean.

Figure 14. Relationship between relative relative chlorophyll content (SPAD reading) of basil leaves, measured with a portable chlorophyll meter (SPAD-502, Minolta Camera Co.), and fresh weight per plant at final harvest. Each data point is the mean value for a bed labeled by treatment (BAS=monoculture; $\mathrm{S \& B}=$ Brussels sprout diculture; $\mathrm{T} \& \mathrm{~B}=$ =tomato diculture) and year........... 38

Figure 15. Tomato yield on each harvest day in 2001 (left) and 2002 (right), separated by treatment

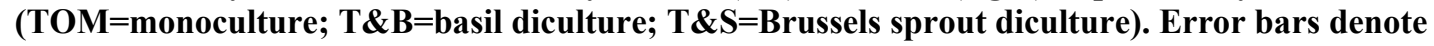
standard error of each mean.

Figure 16. Proportion of soil surface exposed to direct sunlight in monocultures of basil (BAS), Brussels sprout (SPT) and tomato (TOM) and dicultures of Brussels sprout and basil (S\&B), tomato and basil (T\&B), and tomato and Brussels sprout (T\&S) during 2001 (left, $n=3$ ) and 2002 (right, $n=4)$. Means labeled with the same letter for a single monitoring date are not significantly different (Tukey's test, $P<\mathbf{0 . 0 5}$ ). Error bars denote standard errors of each mean. 41

Figure 17. The proportion of the soil surface exposed to direct sunlight (left) and the volumetric soil water content (right) show similar patterns. Treatments were monocultures of basil (BAS), Brussels sprout (SPT) and tomato (TOM) or dicultures of Brussels sprout and basil (S\&B), tomato and basil (T\&B), and tomato and Brussels sprout (T\&S). Bars marked with the same letter are not significantly different (Tukey's test, $P<0.05, n=7$ ). Error bars denote standard error of the mean.

Figure 18. Volumetric soil water content in the top $20 \mathrm{~cm}$ by treatment and sampling date in 2001 (left) and 2002 (right). Points on a single sampling date followed by the same letter, or no letter, are not significantly different (Tukey's test, $P<0.05$ ).

Figure 19. Experimental designs commonly used in competition studies to combine two species at different densities. (a) Single density replacement series, in which total plant density is held constant while species density varies. (b) Simple additive series, in which density of species $i$ is held constant while density of species $\boldsymbol{j}$ and total density vary. (c) Complete binary factorial structure, in which the density of each species is varied along with the total density.

Figure 20. Hexagonal fan array used as a planting design (after Antonovics and Fowler 1985). An array is characterized by the radii of the outer arc $\left(r_{o}\right)$ and inner arc $\left(r_{I}\right)$, angular plant spacing within $\operatorname{arcs}(\theta)$, and angular arc length $\left(\theta\right.$ to $\left.360^{\circ}\right)$. Distance between plants within an arc increases by a constant factor, $C$, with each successive arc, such that $C x_{1}=x_{3}$ and $C x_{3}=x_{5}$. Spacing between arcs is set to reduce the range of distances to neighboring plants; in this study $x_{2}=x_{3}$ and $x_{4}=x_{5}$, but in the first published hexagonal fan design $x_{1}=x_{2}$ and $x_{3}=x_{4}$ (Antonovics and Fowler 1985).

re 21. A single fan, divided into four equal segments of monoculture and diculture. Plants were randomly assigned to arcs in diculture segments under the constraint that a $2: 1$ crop ratio be present in each arc, with the most numerous species matching the species in the nearest monoculture. Here primary colors represent monocultures, and secondary colors consisting of 2:1 blends dominated by the nearest primary color represent dicultures.

Figure 22. Sample planting scheme for tri-fan circle design. Tomatoes (red diamonds), Brussels sprouts (blue triangles), and basil (yellow squares) are arranged in concentric circles, ranging from one to ten meters in diameter. Axes show dimensions in meters. 
Figure 23. Possible density combinations in the tri-fan circle study, displayed on linear and log scales (left and right, respectively). The design does not simultaneously test very high densities of one species and very low densities of the other.

Figure 24. Temporal overlap of crops in the tri-fan circle study. Black, grey, and white bars denote periods of seeding to transplant, transplant to harvest, and harvest, respectively........................ 57

Figure 25. Approximate location of ceptometer samples (grey circles) and soil moisture readings (open diamonds) covering nine of eleven arcs of plants (black dots) in a circle segment in 2003. Each ceptometer sample was the mean of three readings, in which the bar (white line) was rotated approximately $45^{\circ}$ between readings. Sample locations were identical in 2002 except that the innermost ceptometer sample and inner two soil moisture readings were excluded because only the outer eight ares were planted.

Figure 26. Total aboveground fresh weight of tomato, Brussels sprout and basil plant matter collected from each segment of tri-fan circle plots. Monoculture segments contained tomato (TOM), Brussels sprout (SPT), or basil (BAS). Diculture segments contained a 2:1 mixture of the crops grown in the nearest and next nearest monoculture segments, respectively.

Figure 27 (overleaf). Two estimates of the response to density of tomato $(\diamond)$, Brussels sprout $(\times)$, and basil $(O)$ plants grown in monoculture. The first model (top left) is a linear regression of the mean of the square root of aboveground fresh weight $\left(w^{0.5}\right)$ against arc position $(x)\left(w^{0.5}=d x+i\right)$ where $d$ and $i$ are fitted values (Table 27). The second model (top right) is a nonlinear regression of the mean of aboveground fresh weight $(w)$ against plant density $\left(w=w_{\max }(1+a N)^{-b}\right)$ where $w_{\max }, a$, and $b$ are fitted values (Table 28). The relative spacings (arc positions) represent multiplicative increments of 1.26 from a close spacing of $14.4 \mathrm{~cm}\left(47.2 \mathrm{plants} / \mathrm{m}^{2}\right)$ at 2 to a wide spacing of $93.5 \mathrm{~cm}\left(1.1 \mathrm{plants} / \mathrm{m}^{2}\right)$ at 10 . Each data point represents the mean weight of all plants grown at a given density, with standard errors. The same data points and regression lines are shown when fresh weight is plotted against density on a log-log scale (middle left and right), and multipled by plant density to give the relationship between fresh weight per unit area and density (bottom left and right).

Figure 28. Total aboveground fresh weight (kg) of tomato (orange), Brussels sprout (blue) and basil (green) plant matter collected from each arc of each segment of tri-fan circle plots. Each successive arc position represents a $26 \%$ increase in plant spacing, ranging from $14.4 \mathrm{~cm}$ in arc 2 to $93.5 \mathrm{~cm}$ in arc 10. Monoculture segments contained tomato (TOM), Brussels sprout (SPT), or basil (BAS). Diculture segments contained a 2:1 mixture of the crops grown in the nearest and next nearest monoculture segments, respectively.

Figure 29. Aboveground fresh weight per plant of tomato grown with basil (top left), basil grown with tomato (top right), Brussels sprout grown with basil (middle left), basil grown with Brussels sprout (middle right), tomato grown with Brussels sprout (bottom left), and Brussels sprout grown with tomato (bottom right) at a range of densities (arc position) and frequencies (neighbors). The relative spacings (arc positions) represent multiplicative increments of 1.26 from a close spacing of $14.4 \mathrm{~cm}$ at 2 to a wide spacing of $93.5 \mathrm{~cm}$ at 10 . The frequency scale (neighbors) represents the number of a target plant's nearest neighbors that are the same species as that plant.

Figure 30. Response surfaces fit to the data presented in Figure 29 using the linear regression values in Table 29. Labels indicate the target and companion crops ("target with companion")............ 71

Figure 31. Response surfaces fit to the data presented in Figure 29 using the nonlinear model and values presented in Table 30. Labels indicate the target and companion crops ("target with companion")

Figure 32. Relative Land Output (RLO, solid line) and Land Equivalent Ratio (LER, dashed line) for each segment (left) and arc (right) of the combined tri-fan circle plots. Error bars denote standard deviation of the mean of all segments of an arc.

Figure 33. Relative Land Output (RLO, solid line) and Land Equivalence Ratio (LER, dashed line) of each segment for each arc in the tri-fan circle plots. Each successive arc position represents a $26 \%$ increase in plant spacing, ranging from $14.4 \mathrm{~cm}$ in arc 2 to $93.5 \mathrm{~cm}$ in arc 10. Monoculture segments contained tomato (TOM), Brussels sprout (SPT), or basil (BAS), and have a RLO of 1 by definition. Diculture segments contained a 2:1 mixture of the crops grown in the nearest and next nearest monoculture segments, respectively. 
Figure 34. Relative Land Outputs (left) and Land Equivalence Ratios (right) calculated from the linear response surfaces shown in Figure 30 for dicultures of tomato and basil (top), Brussels sprout and basil (middle), and tomato and Brussels sprout (bottom).

Figure 35. Relative Land Outputs (left) and Land Equivalence Ratios (right) calculated from the nonlinear response surfaces shown in Figure 31 for dicultures of tomato and basil (top), Brussels sprout and basil (middle), and tomato and Brussels sprout (bottom)

Figure 36. Relationship between the fractional absorption of Photosynthetically Active Radiation (PAR) by the crop canopy and the proportion of ceptometer sensors exposed to direct sunlight below the crop canopy (Sunfleck \%) in 2003. Fractional absorption was calculated as (1-T/S)(1$R / S$ ) where $T$ is PAR below the canopy, $R$ is PAR reflected from the canopy, and $S$ is PAR above the canopy (Decagon Devices 1989). Each point is the season mean for a tri-fan circle segment in a single replicate at a single plant density $(n=108)$ 77

Figure 37. Mean proportion (\%) of soil surface exposed to direct sunlight in each section of a tri-fan circle study. Monoculture segments contained tomato (TOM), Brussels sprout (SPT), or basil (BAS). Diculture segments contained a 2:1 mixture of the crops grown in the nearest and next nearest monoculture segments, respectively. Actual values labeled with the same letter do not differ significantly (Tukey's test, $n=6, P<0.05$ ). Expected diculture values (dashed line) are $(2 \mathrm{~A} / 3+\mathrm{B} / 3)$ where $A$ and $B$ are the values for the nearest and next nearest monocultures, respectively.

Figure 38. Observed (solid line) and expected (dashed line) sunfleck proportion (\%) beneath diculture canopies. Mean plant densities were 9.13, 3.58, and 1.41 plants $/ \mathrm{m}^{2}$ for the inner, middle, and outer lines, respectively. Stars denote significant differences between observed and expected values $\left(\chi^{2}\right.$ test, $\left.n=6, * P<0.05, * * P<0.05, * * * P<0.005\right)$. Each diculture contained a 2:1 crop mixture of the respective species indicated by letters in the diculture code $(T=$ tomato, $B=$ basil, $S=$ Brussels sprout $)$. 78

Figure 39. Mean proportion (\%) of soil surface exposed to direct sunlight in $2002(\square)$ and $2003(\diamond)$. Data points show replicate means, and trendlines show linear regressions for each year $(2002$ Sunfleck = -26.3 Ln (Density) + 66.6; 2003 Sunfleck = -19.5 Ln (Density) + 75.7).

Figure 40. Mean proportion (\%) of soil surface exposed to sunlight at a range of planting densities for each segment of the tri-fan circle study in 2002 (top) and 2003 (bottom). The difference between the first sample (dashed line) and second sample (solid line) indicates increased light interception due to plant growth between samples.

Figure 41. Penetration of direct sunlight to a range of heights above the soil surface in each segment of the tri-fan circle study on three sampling days in 2003.

Figure 42. The relationship between soil moisture content and canopy light penetration. Each point is the season mean for a unique combination of treatment, density and replicate $(r=0.71, P<$ $0.0001, n=161)$.

Figure 43. Volumetric water content $(\%)$ in each section of a tri-fan circle study. Monoculture segments contained tomato (TOM), Brussels sprout (SPT), or basil (BAS). Diculture segments contained a 2:1 mixture of the crops grown in the nearest and next nearest monoculture segments, respectively. Observed values labeled with the same letter do not differ significantly (Tukey's test, $n=6, P<0.05)$. Expected diculture values (dashed line) are $(2 \mathrm{~A} / 3+B / 3)$ where $A$ and $B$ are the values for the nearest and next nearest monocultures, respectively....................... 82

Figure 44. Observed (solid line) and expected (dashed line) volumetric soil water content (\%) in dicultures. Mean plant densities were 9.13 and 1.41 plants $/ \mathrm{m}^{2}$ for the inner and outer lines, respectively. No differences were found between observed and expected values $\left(\chi^{2}\right.$ test, $n=6, \alpha=$ 0.05).

Figure 45. Mean volumetric soil water content $(\%)$ in $2002(\square)$ and $2003(\diamond)$. Data points show replicate means, and trendlines show linear regressions for each year $(2002 \mathrm{VWC}=-3.77 \mathrm{Ln}$ $($ Density $)+27.76, R^{2}=0.69, n=3 ; 2003 V W C=-1.64$ Ln $($ Density $\left.)+32.35, R^{2}=0.91, n=3\right) \ldots . .83$

Figure 46. The relationships between biomass accumulation and penetration of sunlight through the canopy (left) or volumetric soil water content (right). Each point represents the total fresh weight of all above-ground plant matter removed from all circle segments at one of three densities $(n=27)$.

Figure 47. Effects of density on mean damage rating (0-4) for imported cabbageworm ( $\bullet$ ), cabbage aphid $(\times)$, and groundhog $(+)$ on Brussels sprout plants in a mixed species fan design. The 
relative spacings (arc positions) represent multiplicative increments of 1.26 from a close spacing of $14.4 \mathrm{~cm}$ at 2 to a wide spacing of $93.5 \mathrm{~cm}$ at 10 . The best-fit linear regression lines are shown for imported cabbageworm (solid line, damage $=1.42+0.074 \mathrm{Arc}, \mathrm{R}^{2}=0.73, P=0.003$ ) and cabbage aphid (dashed line, feeding severity $=0.60+0.17$ Arc $, R^{2}=0.88, P=0.0002$ ). Density had no significant effect on groundhog feeding severity.

Figure 48. Proportion of tomato plants expressing symptoms of early blight (black bars) and

Fusarium wilt (white bars) infection at final harvest.

Figure 49. Four points on a circle can be used to determine the maximum number of polycultures that can be created using four crops. There are six possible dicultures, represented by the lines $\mathrm{AB}, \mathrm{AC}, \mathrm{AD}, \mathrm{BC} \mathrm{BD}$, and $\mathrm{CD}$; four possible tricultures, represented by the triangles $\mathrm{ABC}, \mathrm{ABD}$, $A C D$, and $B C D$; and one possible tetraculture, represented by the tetrangle $A B C D$................ 100

Figure 50. The area occupied by a single plant (black circle) in straight offset rows is bordered by the hexagon formed by the Star of David with points at all adjacent plants (white circles) (A). When offset rows are curved this hexagon no longer describes the area available to a plant (B); the actual area is described by a different hexagon (C), or estimated by a four sided figure (D).... 101

Figure 51. Daily maximum and minimum temperatures, and accumulated precipitation, in 2000 (top) and 2001 (bottom). All observations recorded at the Morgantown municipal airport, approximately $1 \mathrm{~km}$ from the study site.

Figure 52. Daily maximum and minimum temperatures, and accumulated precipitation, in 2002 (top) and 2003 (bottom). All observations recorded at the Morgantown municipal airport, approximately $1 \mathrm{~km}$ from the study site.

Figure 53. Soil test results from samples collected from the preliminary study area on 13 November, 2000. Each bar represents a single bed. Study area corners are marked by orthogonal abbreviation. 


\section{List of Multimedia Files}

File 1. Photographs of beds representing each of the preliminary study treatments on 29 June, 20 July, 11 August, and 6 September, 2000 (MS PowerPoint)

File 2. Photographs of beds representing each of the preliminary study treatments on 29 June, 20 July, 11 August, and 6 September, 2000 (PDF)

File 3. Tool used to randomize tri-fan circle study (MS Excel, Analysis Toolpak required) 


\section{CHAPTER 1: Introduction}

Intercropping is the practice of growing two or more crops together so that they interact agronomically (Vandermeer 1989). It lends itself to small-scale agriculture, and has long been used by subsistence farmers in Asia, Latin America, and Africa (Francis 1986, Plucknett and Smith 1986, Altieri 1991). In North America and Europe it is frequently used by backyard gardeners and market gardeners, who do not rely on the capital and energy intensive technologies crucial to much large-scale crop production in the developed world. Small-scale intercropping, or companion planting, is the focus of a wealth of popular books (e.g. Riotte 1975, Cunningham 1998), newspaper and magazine articles (e.g. Organic Gardening), and internet websites targeting small-scale food producers in the developed world. It is often associated with those who embrace organic and biodynamic production philosophies.

\section{Tracing the Roots of Popular Practice: Carrots Love Tomatoes}

Perhaps the best-known work on companion planting is Carrots Love Tomatoes (Riotte 1975), which has sold more than half a million copies, and remains in print a quarter century after its publication. Carrots Love Tomatoes was written by Louise Riotte, the daughter of an astrologist father and herbalist mother (Cunningham 2001). An avid gardener, Riotte wrote articles for Organic Gardening magazine, and scripts for a radio gardening program. She accumulated the material for Carrots Love Tomatoes from personal observation, folklore, horticultural science, and biodynamic methods, treating them all as equally credible.

The year that Riotte died she recounted a story of her experience of placing too much faith in experts:

"My husband was a graduate of the New York State Agricultural College," she said. "When we made our first garden [in Oklahoma], he was accustomed to the New York climate and planted in June and it all burned up" (quoted in Simmons 1998).

Rather than looking to experts, she claimed to write what she knew: "Most of my books are personal experiences and I fill in with info from other authors" (quoted in Simmons 1998).

Although she seldom references these other authors, she repeatedly mentions Ehrenfried Pfeiffer, a protégé of the founder of the biodynamic agriculture movement, Rudolf Steiner. Pfeiffer developed a method of testing companion combinations in the laboratory, called sensitive crystallization (Hill 1975). The method involved adding extracts from plant pairs to a $5 \% \mathrm{CuCl}$ solution, which was allowed to crystallize on a glass plate. The appearance of the crystals was used to predict which plants would be good companions and which would be antagonistic (Hill 1975).

Riotte drew heavily on Pfeiffer's work, as have others famous for disseminating companion planting recommendations (e.g. Jeavons 1982, Cunningham 1998). In using Pfeiffer as a source she opened herself 
up to fire from some in the mainstream scientific community. The following addendum to a Cornell extension service bulletin is an example (Beyfuss \& Pritts 1994):

Unfortunately, much of the popular literature that discusses companion planting is based upon some very bad science, in particular, the "sensitive crystallization method" which was originated by Dr. Ehrenfried E. Pfeiffer in the 1930's[...] The notion that "carrots love tomatoes" but "beans dislike fennel" is based upon an analytical laboratory procedure and not on direct observation of the plants in nature. No legitimate scientist believes that this method can determine compatibility among plant species.

While invoking the power of "legitimate" science Beyfuss and Pritts demonstrate a poor analysis of its meaning. The role of the scientist is to test hypotheses, not to believe them or disbelieve them based on how they are generated. The criticism that Pfeiffer generated predictions based on laboratory procedures rather than direct observation of nature could be leveled against many "legitimate" scientists. Whether a hypothesis is based on theory, hunch, or sensitive crystallization, a scientist should test it before rejecting it.

The larger problem with Pfeiffer's hypotheses is the uncertainty over exactly what they predict. In some cases Riotte suggests specific benefits or drawbacks of particular companion combinations, but anybody wishing to test whether carrots do, in fact, "love tomatoes" has to guess at the meaning of "love" between plants. Riotte's explanation of the companion pair in her book's title does little to clear up the confusion, stating simply that "carrots grow well with" tomatoes, which, in turn, "are compatible with carrot." Is she predicting that a combination of carrots and tomato will have higher yields than either crop grown alone? Will one or both crops suffer fewer pest problems than when they are grown alone? Will susceptibility to disease differ between dicultures and monocultures? Will there be other physiological differences between plants grown in diculture and monoculture?

The uncertainty regarding the meaning of these predictions probably contributes to the disagreement over the meaning of companion planting tests conducted so far. Rodale's All-New Encyclopedia of Organic Gardening claims that "modern research substantiates the effectiveness of some companion plants in repelling pests," citing studies documenting antifeedant effects of plant extracts (Bradley and Ellis 1992). Meanwhile an extension agent at Utah State University claims that "most of the research done at universities on companion planting indicates it is ineffective" (Hinkamp 1999). Two more extension agents, at Ohio State University, offer a scientifically safe statement implying either that companion planting has been tried and found wanting, or that it hasn't been tried (Kerrigan and Nagel 1998):

"Some gardeners believe that certain plants perform better when grown together. However no proven beneficial relationship of this type of interplanting, called companion planting, has been demonstrated under research conditions." 


\section{Science Related to Companion Planting}

Scientists have devoted considerable resources to understanding intercropping effects, using a relatively small set of test crops to contribute to an evolving understanding of plant-environment interactions. A recent review (Hooks and Johnson 2003) cites more than 120 published studies examining effects of intercropping on arthropod pests of brassica alone. The authors note that this family has been well-studied because it contains a number of widely-grown and commercially important crops, and hosts a wide range of insect pests, representing several major insect orders and a selection of both specialists and generalists.

Implicit in scientists' focus on a few test species is the assumption that these are governed by a set of underlying ecological principles that will be applicable to a broader set of organisms once they are understood. Finch and Collier (2000) epitomize this attitude in their discussion of hypotheses proposed to explain the observation that polycultures often have fewer phytophagous pests than monocultures. They dismiss most of the hypotheses already proposed "primarily because no one has used any of them to produce a general theory of host plant selection." They offer their own alternative hypothesis, based largely on observations of the cabbage root fly, in the hopes that it will be shown to be "all-embracing."

Similarly, the scientific literature dealing with interactions between companion plant species tends to consider two species at a time, in highly controlled environments (Firbank and Watkinson 1990, Jolliffe 1997). By understanding simple interactions between a few species, experimenters hope to uncover the laws that govern more complex systems and a much broader range of organisms.

Much of the popular literature on companion planting suggests an underlying belief that nature is inherently idiosyncratic. Instead of seeking simple laws governing species interactions, many of the books, magazine articles, and websites that deal with the topic are notable for their complexity. Charts and tables outline hundreds of different possible combinations that are considered either beneficial or detrimental (e.g. Appendix 6). A delight in complexity is apparent in writings such as this conclusion to a list of companion planting recommendations circulated in the Canadian Organic Growers' newsletter (Fraser 2002):

We as humans cannot possibly know or understand all the deep, dark, velvety secrets of plants. I do know that plants are a delight to my senses. Their medicinal and culinary properties, color and fragrance enhance and restore my physical health and my mental well-being. They are my companions too.

Great Garden Companions (Cunningham 1998), a recent addition to the popular writings on companion planting, suggests a different tactic than most of its predecessors. Calling previous recommendations "very confusing and sometimes unscientific," the author advises gardeners to put members of the same plant family together, since they have similar growing needs. This 'rule of thumb' directly contradicts the advice of Riotte (1975), who suggested that putting plants from different families together confuses pests in search of hosts. 
Writers of popular companion planting literature often claim that their recommendations are backed up by science, yet scientific writing has largely ignored popular recommendations. Finch and Collier (2000) suggest that scientists could learn something from commonly used companion combinations:

There is $[\ldots]$ a need to obtain a better understanding of 'companion planting,' a practice used frequently by organic growers. The earlier data showed that there is no scientific evidence that the odors from highly aromatic plants can actually deter pest insects. This, therefore, brings into question how these aromatic plants produce their effects.

Two recent studies have taken this advice to heart. Several companion plants, including species recommended by Riotte as rose companions, were tested for their ability to deter Japanese beetle, Poppillia japonica (Newman), from feeding on roses (Held et al. 2003). The study found no evidence that any of the companions tested deterred the beetle, but suggested that the volatiles of geranium, a plant said to deter Japanese beetle (Riotte 1975), make roses more attractive to the insect. A second study reports the effects of 24 non-host plants, including popularly recommended companion plants, on cabbage root fly landing and oviposition on cabbage (Finch et al. 2003). All but four of the non-hosts deterred oviposition, but none deterred landing. The non-hosts that did not prevent oviposition had non-green surfaces, or a low, sprawling form. The authors conclude that the green leaves, not the odor or taste of the non-hosts, protected the cabbage from the pest. These papers are as notable for their findings as for their attempts to synthesize information from both popular and scientific sources.

Advocates of companion planting suggest associations between species can offer a wide array of benefits, including yield advantages, pest suppression, natural enemy augmentation, reduced disease incidence, and improved crop flavor. The benefits expected from specific combinations are sometimes clearly stated (e.g. "basil repels flies"), but often vague (e.g. "tomatoes and all members of the brassica family repel each other") (both quotes from Riotte 1975). This creates challenges for anybody hoping to test popular companion planting claims experimentally.

\section{Current Understanding of Intercropping Effects}

Despite its roots in small-scale agriculture, and the readiness with which small-scale temperate zone growers have adopted it, most intercropping research has considered larger, field-scale applications of the technology (e.g. Appendix 5). There are several possible reasons for this focus:

- Funding for agriculture research is often dedicated to large-scale production. Although small-scale production provides $15-20 \%$ of the world's food supply (Altieri 1991), and about $45 \%$ of households in areas as diverse as the city of Vancouver, Canada (City Farmer 2002), and the state 
of West Virginia ${ }^{1}$, USA, grow some of their own food, these growers often lack the organization necessary to command researchers' attention.

- The edge:interior ratio is inherently greater in small plots than in large plots, resulting in greater edge effects, and increased difficulty in interpreting results. Researchers have suggested that studies of mixed stands should occupy a large enough area that edge effects are negligible (Jolliffe 1997). Such a condition precludes garden-scale studies.

- The conversion of large-scale monoculture to polyculture represents a substantial increase in crop diversity, so benefits derived from increasing biodiversity can be easily observed. Small-scale agriculture is usually already more diverse than its large-scale counterpart, so the additional diversity gained through intercropping may offer less pronounced advantages.

Research conducted in field-scale settings attributes a number of advantages to intercropping, including increased yields (Jolliffe1997), reduced arthropod pest levels (Andow 1991), reduced weed competition (Weston 1996), and improved taste (Theunissen 1997). Since small-scale studies are largely unavailable, these same advantages are often ascribed to companion planting. The assumption that conclusions drawn from large-scale studies can be applied to garden scale settings is invalid, but a review of these studies provides important background for the garden-scale studies necessary to draw conclusions about companion planting.

\section{Higher yields.}

A recent review of intercropping studies reported that intercrop yields averaged $13 \%$ higher than in monocultures (Jolliffe 1997). Considerable research has addressed the need for meaningful ways of comparing yields in polyculture and monoculture. Jolliffe's recent review (1997) employed a conservative method to analyze those studies published to date, likely resulting in an understatement of the polyculture yield advantage (Jolliffe 1997).

Intercropping yield advantages observed for reasons other than pest reductions have variously been ascribed to:

a) changes in competition for nutrients, water, and light (Theunissen 1997; Putnam \& Allan 1992; Vandermeer 1989),

b) altered soil conditions in the root zone due to root exudates or allelopathic effects (Theunissen 1997),

\footnotetext{
${ }^{1}$ West Virginia county extension agents report that $45 \%$ (range: $10-80 \%$, by region) of state households grew gardens in 2002, producing an average of $\$ 275$ (range: $\$ 50-\$ 1200$ ) of fruit and vegetables per household (Jett pers. comm.). Given that WV had 736,481 households in 2000 (US Census Bureau 2003), the value of WV's garden production likely exceeded \$91 million in 2002. The state's largest commercial crop sector, the nursery and greenhouse industry, was valued at $\$ 19$ million in 1997, accounting for about $30 \%$ of commercial crop production (Gandee and D'Souza 2001). In other words, the value of food grown in WV's gardens may exceed that of the state's total commercial crop production.
} 
c) stimulation or repression of mycorrhiza and endophytes (Theunissen 1997),

d) beneficial effects of shading in hot environments (Willey 1979),

e) windbreak effects in windy environments (Radke \& Hagstrom 1976), and

f) support of climbing plants or lodging susceptible plants by nearby companions (Stobbe et al., 1990)

The first mechanism, (a), has been termed the "Competitive Production Principle" (Vandermeer 1989).

According to this principle, yield increases occur in polyculture when the sum of inter-crop competition is less than the sum of intra-crop competition (Willey 1979). Different crops are able to draw on different competitive niches, giving polycultures greater access to resources than monocultures. As an example of this phenomenon, Putnam and Allan (1992) showed that mustard has a high water and soil $\mathrm{N}$ requirement early in the season, and sunflower requires these resources late in the season. Yields of both crops increase when they are grown together, due to the complimentary timing of their resource needs (Putnam \& Allan 1992). Two crops might also minimize competition for water and nutrients if they have different rooting depths, or different demands for soil N, as is the case for legumes and non-legumes (Haynes 1980). Light competition is also very important. Two crops that occupy different positions in the canopy may increase light interception efficiency, or one might be shaded out by the other (Clark \& Francis 1985). The Competitive Production Principle is the reason most frequently given for intercropping yield advantages, and the focus of most of the sparse assortment of papers that attempt experimental explanations of differential yields.

The remaining mechanisms (b-f) are grouped under the term "Facilitative Production Principle" (Vandermeer 1989). Broadly speaking, these mechanisms involve a modification of the microenvironment, rather than a competitive effect. Although an array of facilitative production factors has been proposed, little experimental research evaluates the relative importance of these factors in field settings. It is very likely that some of these factors are very important for specific crop combinations, but not for others, making it difficult to incorporate them into general theories of intercropping effects.

\section{Fewer arthropod pests}

The impact of intercropping on arthropod pests has been well documented. A review of 209 studies, examining 287 herbivorous arthropod species, reported that herbivore levels were consistently lower in polyculture than in monoculture for $52 \%$ of the species considered (Andow 1991). In most other cases levels varied, or did not change; in only $15 \%$ of cases did levels increase. Reductions in arthropod pest levels do not always translate directly into higher yields, or better quality crops.

Summarizing previous research, Finch and Collier (2000) reviewed seven hypotheses offered to explain reduced arthropod pest levels in polyculture (see also Smith and McSorely 2000), and offer an eighth suggestion, which discounts or encompasses each of the previous hypotheses: 
1. Physical obstruction of the host crop by larger non-host neighbors may prevent pests from finding their hosts (Perrin 1977);

2. Visual camouflage of the host crop by neighboring plants could make the plant less visually apparent to searching insects;

3. Masking of host odors by neighboring plants emitting non-host volatiles could make host scent more difficult to recognize (Perrin and Phillips 1978);

4. Repellent chemicals emitted by neighboring plants may counterbalance the attractiveness of host scent (Uvah and Coaker 1984);

5. Host odor changes due to host metabolism of compounds emitted by neighboring plants may make hosts more difficult to recognize (Theunissen 1997);

6. Phytophagous insects may stay longer in areas where hosts are concentrated than in areas where they frequently encounter non-hosts (resource concentration hypothesis) (Root 1973);

7. Predators and parasitoids of phytophagous insects may be more common in complex environments than in monoculture (natural enemies hypothesis) (Root 1973).

8. Phytophagous insects, induced to land by a combination of green foliage and host odor, wait until they alight on a green surface to test the suitability of their landing site using chemoreceptors on their feet (appropriate/inappropriate landings hypothesis) (Finch and Collier 2000). Before deciding to feed or oviposit they may take off and land several times more, increasing the likelihood that they will 'lose' a potential host, and land instead on a non-host in polyculture. According to this theory the ideal companion crop for pest management purposes would maximize non-host green surfaces near the crop while minimizing competition with the crop.

\section{Reduced weed levels}

Intercrops that capture a greater share of available resources than sole crops suppress weeds (Liebman \& Dyck 1993). For example, legumes mixed with cereals have been shown to suppress perennial cool-season weed growth (Dyck \& Barnard 1976).

Beyond the competitive effect, some intercrops exude allelopathic chemicals credited for weed suppression. For example, organic acids produced by rye, and glucosinolates found in crucifers can both contribute to weed management (Weston 1996; Vaughn \& Boydston 1997). 


\section{Altered taste}

Many companion plant combinations are reputed to alter the taste of one or more of the crops. For example, basil is said to improve tomato flavor (Riotte 1975, Bradley \& Ellis 1992).

Reporting observations of an intercropping experiment with white clover, cabbage, and leek Theunissen (1997) wrote:

There is no doubt that undersowing cabbage and leek with clover influences the physiology of both vegetable crops. It can be tasted. The question is if and how this affects the pest-host plant relationships and what are the mechanisms behind this.

Although Theunissen apparently viewed his brief claim about the altered taste of cabbage and leek undersown with clover as little more than evidence of underlying physiological effects, the possibility that intercropping could alter taste remains an unexplored area.

\section{The Complexity of Polyculture}

Companion planting systems are extraordinarily complex. A simplified system that considers two crops, six herbivore species, and six natural enemy species has 91 potential two-way, and 364 potential three-way ecological interactions (Andow 1991). Experimental analysis of each potential interaction is unrealistic, and would bog down advancements in the understanding of companion planting.

The knowledge to be gained through reductionist research is complimented by whole-system studies. Isolating individual variables in tightly controlled environments can offer answers to specific questions, but a narrow adherence to this strategy can lead researchers to overlook potentially useful information, or develop a line of questioning divorced from the context of practical application.

In an evaluation of the challenges associated with promoting sustainable agriculture, a report by the National Research Council (1989) stated:

Insufficient numbers of young scientists are pursuing careers in interdisciplinary or systems research [...] As a result agricultural scientists often lack the skills and insights to understand fully on-farm problems.

Viewed from the perspective of a researcher examining the complexity of polyculture, Andow (1991) stated the difference between reductionist and systems research using the analogy of untangling a knot:

Perhaps as a response to the complexity of the problem, two alternate approaches have evolved. The first seeks to unravel the problem by minutely examining each thread of the knot [...] Frequently, no effort is expended toward developing a general understanding of the response of 
arthropods to polyculture. Indeed, while never explicitly stated, one detects an implied commitment to the idea that nature is inherently idiosyncratic and that there is no general understanding to discover.

The second approach seeks to cut the knot of complexity with simple but elegant theory. This theoretical approach clearly seeks general understanding of the response of arthropods to polyculture, and indeed, assumes that such general understanding exists, that regularities await discovery, and that nature is not inherently idiosyncratic.

\section{Study Objectives}

Recognizing their inherent complexity, I undertook a series of garden-scale studies to assess companion planting effects. I began with a single-season preliminary trial, incorporating tomatoes, Brussels sprouts, basil, beans, and white clover in raised beds planted to monocultures or companion pairs. The study was designed to test for differences in yield, land use efficiency, pest density, disease severity, and tomato flavor that might occur between monoculture and diculture garden beds.

Observations from the preliminary study were used to design a two-year study, in which tomatoes, Brussels sprouts and basil were grown as monocultures or companion pairs according to 'Biointensive' planting recommendations (Jeavons 1982). The Biointensive study attempted to satisfy the same objectives as the preliminary study, and examine differences in resource availability between the treatments, using a popularly-recommended gardening system that often incorporates companion planting. Neither the preliminary nor the biointensive study were designed to control for arthropod, disease, and yield effects, but rather to observe and compare whole-system effects in garden-scale plots with, and without, companion planting.

A final two-year study evaluated the effects of crop density and ratio on yield and land use efficiency. The study employed a novel 'tri-fan circle' method to create simultaneous gradients in planting density and crop ratio of tomato, Brussels sprout and basil. The design was intended to be efficient without confounding factors, addressing concerns about experimental designs commonly used in crop density and ratio studies (Jolliffe 2000). Rather than simply compare monocultures (companion crop absent) to dicultures (companion crop present), the tri-fan circle study was designed to identify crop densities and ratios that optimize any yield or land use efficiency benefits derived from companion planting. Once again resource availability measurements were used to better understand the companion planting effects observed. 


\section{CHAPTER 2: Preliminary Study}

\section{Introduction}

Early meetings with the farmer advisory panel at the West Virginia University Organic Research Farm demonstrated considerable local interest, and strongly held convictions, regarding companion planting. Some felt that our research plans were compromised because they didn't incorporate the practice; others felt that the practice offered little benefit.

A garden system study was developed to compare the effects of plant interactions in monoculture and diculture beds. The study was designed to simultaneously evaluate several companion pairs (dicultures), comparing yield, pest and disease incidence, and taste of crops grown in diculture to the same crops grown in monoculture. Multiple dicultures were tested simultaneously to increase efficiency (Appendix 1) and help separate the effects of crop choice from broader effects of diversity.

Crops were selected to represent a variety of species commonly grown in West Virginia's gardens, and to match crops already being studied in market garden and field crop systems trials on the WVU Organic Research Farm. Tomato (Lycopersicon esculentum Mill.), Brussels sprout (Brassica olerecia L.), and bush bean (Phaseolus vulgaris L.) were chosen as representatives of three different families well-represented in West Virginia's small farms and gardens. Basil (Ocimum basilicum L.) was selected as an aromatic herb, frequently recommended as a companion plant. Radish (Raphanus sativus L.) was planted prior to Brussels sprout because it was an alternate brassica with a short maturation time, allowing inter-species interactions to be observed in all treatments before Brussels sprouts were transplanted into the field in late summer. White clover (Trifolium repens L.) was used as a nitrogen-fixing living mulch to observe any single-season effects of living mulch at the garden scale.

Several of the dicultures tested have been referred to in the popular companion planting literature (Table 1). Popular recommendations relating to these species vary, and are occasionally contradictory. Many peer reviewed studies consider brassica polycultures (Table 2), but the other dicultures have not been as well studied. 
Table 1. Popular recommendations relating to companion combinations examined in the preliminary study.

\begin{tabular}{|c|c|}
\hline mbination & opular recommendation \\
\hline $\begin{array}{l}\text { Tomato \& } \\
\text { Brassica }\end{array}$ & $\begin{array}{l}\text { - "Tomatoes and all members of the brassica family repel each other and should be } \\
\text { kept apart." (Riotte 1975) } \\
\text { - "The cabbage family includes not only cabbage but cauliflower, kale, kohlrabi, } \\
\text { broccoli, collards and Brussels sprouts - even rutabaga and turnip. While each plant } \\
\text { of this group has been developed in a special way, they are all pretty much subject to } \\
\text { the same likes and dislikes [...] Cabbages dislike strawberries, tomatoes, and pole } \\
\text { beans." (Riotte 1975) } \\
\text { - Combine tomatoes with cabbage "to control flea beetles, cabbage maggots, white } \\
\text { cabbage butterflies, and imported cabbageworm" (Bradley and Ellis 1992). } \\
\text { - Group tomatoes with peppers, eggplant, and greens. Group brassicas together with } \\
\text { lettuce and root crops. Mix both with aromatic herbs. "There really are no wrong } \\
\text { choices." (Cunningham 1998) } \\
\text { - Cabbage and tomato make "bad companions." (Primal Seeds 2002, Bellamy 2003). } \\
\text { - Cabbage and tomato make "good companions." (GardenGuides 2003). }\end{array}$ \\
\hline $\begin{array}{l}\text { Tomato and } \\
\text { Basil }\end{array}$ & $\begin{array}{l}\text { - “...basil helps tomatoes to overcome both insects and disease, also improving } \\
\text { flavor" (Riotte 1975). } \\
\text { - Interplant basil with vegetables "to repel aphids, mosquitoes and mites" (Bradley } \\
\text { and Ellis 1992). } \\
\text { - "Plant basil among your tomatoes to control tomato hornworms" (Bradley and Ellis } \\
\text { 1992). } \\
\text { - "Basil goes with tomatoes in cooking and in the garden." Basil repels mites, } \\
\text { mosquitoes, and tomato hornworms (Cunningham 1998). } \\
\text { - Basil and tomatoes are "good companions" (Primal Seeds 2002, Bellamy 2003, } \\
\text { GardenGuides 2003). }\end{array}$ \\
\hline $\begin{array}{l}\text { Brassica \& } \\
\text { clover }\end{array}$ & $\begin{array}{l}\text { - Plant cabbage family crops with ground cover in between. Dwarf white clover } \\
\text { recommended (Cunningham 1998). } \\
\text { - "Late-season plantings of broccoli and cauliflower can benefit from underseeding } \\
\text { with a winter-hardy green manure..." White clover is a good living mulch, suitable } \\
\text { for droughty soils (Bradley and Ellis 1992). }\end{array}$ \\
\hline $\begin{array}{l}\text { Radish and } \\
\text { bean }\end{array}$ & $\begin{array}{l}\text { - "Radishes grow well with bush beans." "Radishes and pole beans seem to derive } \\
\text { mutual benefit" (Riotte 1975). }\end{array}$ \\
\hline $\begin{array}{l}\text { Tomato and } \\
\text { clover }\end{array}$ & - Use clover or black plastic as a groundcover beneath tomato (Cunningham 1998). \\
\hline
\end{tabular}


Table 2. Some observations from peer-reviewed studies relating to combinations examined in the preliminary study.

Combination Peer reviewed study observation

Brassica \& - Studies as early as 1915 record reduced pest presence on cabbage grown near tomato tomato (Vostrikov 2003).

- Rutin, a chemical found in tomato, deters oviposition by imported cabbageworm and diamondback moth (Gupta and Thorsteinson 1960).

- Crucifer flea beetle, P. cruciferae, colonizes hosts faster in monoculture than polyculture. Tomato volatiles interfere with host finding by the beetle (Tahvanainen \& Root 1972)

- Tomatoes reduce the number of eggs laid on Brussels sprouts by Plutella xylostella and cabbage whitefly, Aleyrodes brassicae in glasshouse (Phillips 1977)

- Imported cabbageworm densities are greater on cabbages surrounded by tomato than on cabbages grown in monoculture (Bach and Tabishnik 1990, Maguire 1984).

- Cabbage-tomato combinations "produced yields, production costs, and net returns which were comparable to either crop grown alone and... used half the land." (Brown et al 1985)

- Crucifer flea beetles (P. cruciferae) are slower to find hosts and faster to leave hosts in polyculture than in monoculture (Elmstrom et al 1988)

- Ovipositing diamondback moths do not discriminate between cabbage grown alone and cabbage grown with tomato (Bach and Tabishnik 1990).

- Cabbage grown with tomatoes had fewer diamondback larvae and higher rates of parasitism by Cotesia plutellae (Kurdjumov) than cabbage grown in monoculture (Bach and Tabishnik 1990).

Brassica \& clover

- Cabbage intercropped with clover has lower weight but higher quality than in monoculture (Theunissen et al 1995)

- High clover intercrops reduce diamondback moth oviposition on brassica as compared to monoculture, but low clover does not (Asman et al. 2001)

Brassica \& - Cabbage aphid parasitoid Diaeretiella rapae has higher rate of parasitism in tilled weeds than weedy Brussels sprouts monocultures (Smith 1976)

General - Cabbage aphids, Brevicoryne brassica, immigrate at a lower rate in intercrops vs. monoculture (Dempster and Coaker 1974)

- Ground beetles and harvest spiders prey on caterpillars at a higher rate in polycultures (Dempster and Coaker 1974) 


\section{Materials and Methods}

\section{Location and soils (all studies)}

All studies were conducted on a gentle ( $<6 \%$ grade) south-facing slope at the West Virginia University (WVU) horticulture farm, near Morgantown, WV. Soils were clay loams in the Dormont and Guernsey series. Two soil samples were taken from the top $20 \mathrm{~cm}$ of each bed in November of 2000 and April of 2003, and were tested by the WVU soil lab for $\mathrm{pH}$, organic matter, and available $\mathrm{P}, \mathrm{K}$, and $\mathrm{Mg}$ (mean $\mathrm{pH}$, $\mathrm{P}$, and $\mathrm{K}$ were $6.5,124 \mathrm{~kg} / \mathrm{ha}$, and $287 \mathrm{~kg} / \mathrm{ha}$, respectively; see Appendix 7 for detailed test results). Test areas were fertilized with a composted mixture of dairy manure and leaf litter applied at approximately 3 $\mathrm{kg} / \mathrm{m}^{2}\left(12 \mathrm{~g} / \mathrm{m}^{2}\right.$ total $\mathrm{N}, 7.8 \mathrm{~g} / \mathrm{m}^{2}$ total $\mathrm{P}$, and $14 \mathrm{~g} / \mathrm{m}^{2}$ total $\left.\mathrm{K}\right)$ at the beginning of each season (Appendix 7 ).

\section{Study setup}

The preliminary study was conducted in the summer of 2000 . Forty-eight raised beds ( $1.25 \mathrm{~m}$ by $3.0 \mathrm{~m})$ were constructed in a 4 by 12 grid, with a $1 \mathrm{~m}$ alley between beds. The top of each bed was level, creating a terrace effect on the sloping site. Alleys were mulched with straw, to prevent soil compaction and discourage weed seed germination. Each bed had five crop rows, spaced $25 \mathrm{~cm}$ apart, running the length of the bed (east-west orientation). The second and fourth row were planted to a primary crops; the first, third and fifth rows were planted to a secondary crop (Figure 1; Table 3).

Five crops were grown, according to the following procedure:

a) Basil. Six week-old basil (Ocimum basilicum L, cv. 'Nufar') seedlings were transplanted $25 \mathrm{~cm}$ apart on 23 June, and harvested between 11 July and 7 October.

b) Bean. Snap beans (Phaseolus vulgaris L., cv. 'Provider') were inoculated with rhizobium (Nature's Aid, Urban Laboratories, St. Joseph MO) then sown $10 \mathrm{~cm}$ apart on 15 May, and harvested between 5 July and 20 July. A second crop was sown on 26 July, and harvested between 20 September, and 7 October.

c) Brassica. Radishes (Raphanus sativus L., cv. 'Cherry Bell') were seeded at $2.25 \mathrm{~g} / \mathrm{m}$ on 8 June, and harvested between 6 and 19 July. They were replaced with four week-old Brussels sprout (Brassica oleracea L., Gemmifera Group, cv. 'Long Island') seedlings, transplanted $50 \mathrm{~cm}$ apart on 5 August, and harvested on 10 January, 2001.

d) Clover. White clover (Trifolium repens L.) was seeded at $4 \mathrm{~kg} / \mathrm{ha}$ on 10 May. Seed was broadcast evenly across all beds planted with this crop, to establish a uniform understory. A $10 \mathrm{~cm}$ wide strip of clover was removed from rows 2 and 4 of each bed before transplanting the primary crop.

e) Tomato. Four week-old tomato (Lycopersicum esculentum Mill., cv. 'WV 63') seedlings were transplanted $50 \mathrm{~cm}$ apart on 23 May, and harvested between 16 August and 7 October. Plants were not suckered. A trellis held plants off the ground. 
Beds were randomly assigned to one of the twelve treatments listed in Table 3, with each treatment replicated four times in a completely randomized design. Regular hand weeding prevented competition from non-crop plants. No irrigation was provided after transplants were watered in; plants relied on natural precipitation (Appendix 3).

Table 3. Preliminary study treatments and target densities.

\begin{tabular}{|c|c|c|c|c|c|}
\hline \multirow[b]{2}{*}{ Treatment } & \multicolumn{2}{|l|}{ Crop } & \multicolumn{3}{|c|}{ Density (plants $/ \mathrm{m}^{2}$ ) } \\
\hline & $\begin{array}{l}\text { Primary } \\
\text { (Rows } 2 \\
\text { and 4) }\end{array}$ & $\begin{array}{l}\text { Secondary } \\
\text { (Rows 1, } 3 \\
\text { and 5) }\end{array}$ & $\begin{array}{l}\text { Primary } \\
\text { crop }\end{array}$ & $\begin{array}{l}\text { Secondary } \\
\text { crop }\end{array}$ & Overall \\
\hline 1. Basil monoculture & Basil & Basil & 18.5 & 18.5 & 18.5 \\
\hline 2. Bean monoculture & Bean & Bean & 46.2 & 46.2 & 46.2 \\
\hline 3. Brassica monoculture & Brassica & Brassica & $9.2 *$ & $9.2 *$ & 9.2 \\
\hline 4. Tomato monoculture & Tomato & Tomato & 9.2 & 9.2 & 9.2 \\
\hline 5. Tomato and basil & Tomato & Basil & 9.2 & 18.5 & 14.8 \\
\hline 6. Tomato and bean & Tomato & Bean & 9.2 & 46.2 & 31.4 \\
\hline 7. Tomato and brassica & Tomato & Brassica & 9.2 & $9.2 *$ & 9.2 \\
\hline 8. Tomato and clover & Tomato & Clover & 9.2 & - & - \\
\hline 9. Brassica and basil & Brassica & Basil & $9.2 *$ & 18.5 & 14.8 \\
\hline 10. Brassica and bean & Brassica & Bean & $9.2 *$ & 46.2 & 31.4 \\
\hline 11. Brassica and clover & Brassica & Clover & $9.2 *$ & - & - \\
\hline 12. Bean and basil & Bean & Basil & 46.2 & 18.5 & 29.5 \\
\hline
\end{tabular}

*Brussels sprout planting density reported here. Radish planting rate resulted in ca. 75 plants $/ \mathrm{m}^{2}$.

\section{Harvest}

All harvest data are reported as fresh weights. Radishes, beans, basil, and tomatoes were harvested weekly throughout the harvest periods noted in Figure 12.

Radishes exceeding two $\mathrm{cm}$ in diameter were harvested during the first and second harvest. All remaining radishes were harvested during the third (final) harvest. Split, damaged, and misshapen radishes were considered unmarketable. The following data were recorded for each radish-growing bed at each harvest:

- Number and fresh weight of marketable radishes

- Number and fresh weight of unmarketable radishes

- Fresh weight of all radish tops

Beans exceeding $10 \mathrm{~cm}$ in length were harvested each week for three weeks for each of the bean crops planted (Figure 2). The fresh weight of harvested beans was recorded for each bed at each harvest. The fresh weight of the bean plants was recorded after the final harvest of each planting.

Basil leaves and stems more than $15 \mathrm{~cm}$ above the soil surface were harvested each week. The fresh weight of harvested parts was recorded for each bed after each harvest. The fresh weight of the above-ground plant parts was recorded after the final harvest. 


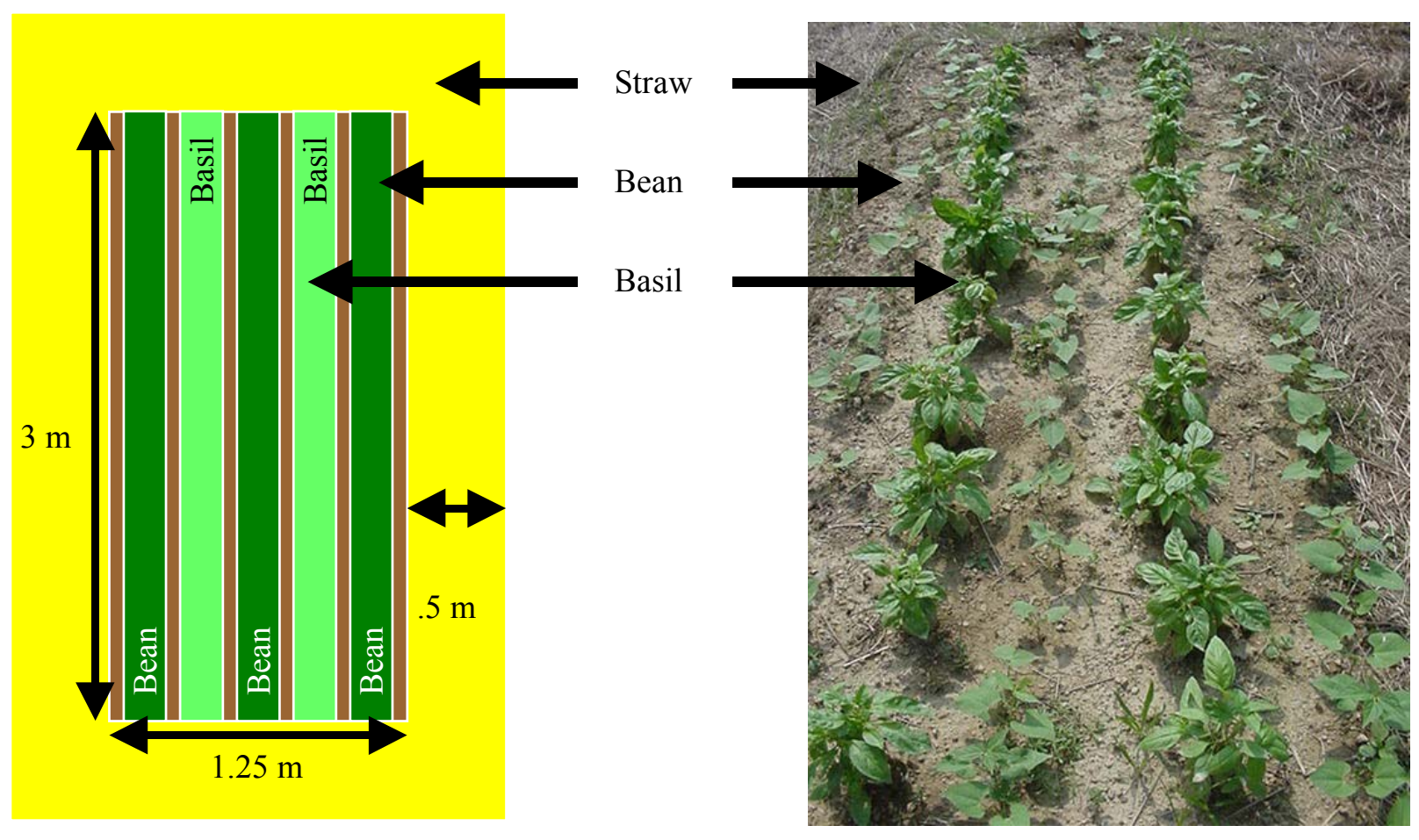

Figure 1. Theoretical (left) and actual (right) planting arrangement of a sample companion crop bed containing bean and basil plants.

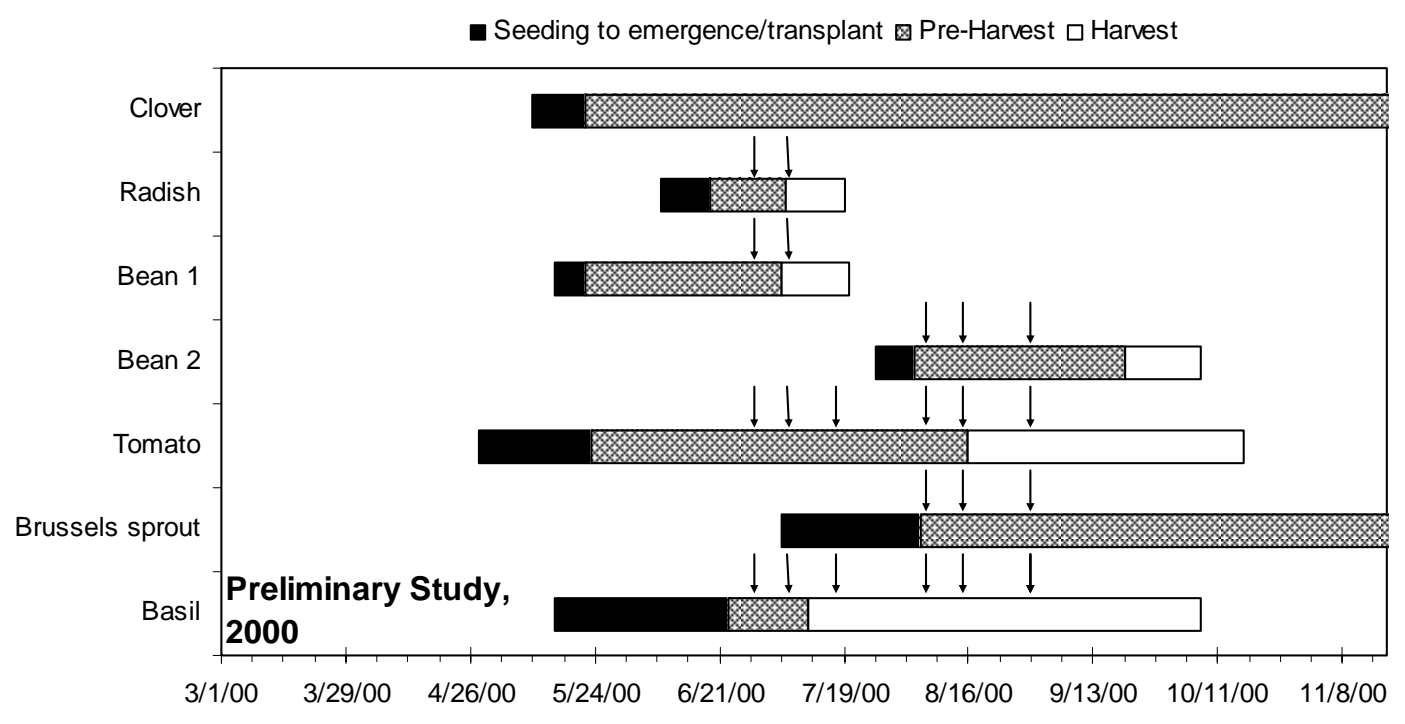

Figure 2. Temporal overlap of crops in the preliminary study. Black, grey, and white bars denote periods of seeding to emergence or transplant, pre-harvest, and harvest, respectively. Arrows show crop pest monitoring dates. 
Tomatoes that had started to change color from green to red were harvested each week. Blemished tomatoes, including those that had split, suffered insect feeding damage, or showed visible rot, were considered unmarketable. The total number and fresh weight of tomatoes harvested from each bed were recorded after each harvest. The numbers of marketable tomatoes, split tomatoes, tomatoes with insect feeding damage, and tomatoes with visible rot were recorded for each bed after each harvest. At the final harvest both red and green tomatoes were harvested, and the following data were recorded for each tomatogrowing bed:

- Red tomato count

- Green tomato count

- Blemish-free red tomato count

- Split red tomato count

- Insect damaged red tomato count

- Red tomatoes exhibiting late blight infection symptoms

- Red tomatoes exhibiting other visible rot symptoms

- Total fruit fresh weight

- Total plant fresh weight

Brussels sprouts were harvested on 11 January, 2001 (not shown in Figure 2). The following data were recorded for each bed:

- Number of surviving plants

- Above-ground fresh weight of plants, including sprouts

- Number of sprouts $>2 \mathrm{~cm}$ in diameter

Yields for each harvest day, and for the entire season, were subjected to ANOVA to test for treatment effects (Zar 1984). Means were separated by Tukey's test when treatment effects were significant $(\alpha=$ 0.05). Separate analyses were conducted for each crop.

A Land Equivalent Ratio (LER) was calculated for each diculture using the formula

$$
\operatorname{LER}=\left[\left(Y_{A}\right)_{\mathrm{p}} /\left(Y_{A}\right)_{\mathrm{m}}\right]+\left[\left(Y_{B}\right)_{\mathrm{p}} /\left(Y_{B}\right)_{\mathrm{m}}\right]
$$

where $Y$ is the total fresh weight of above-ground biomass collected over the season, in grams per square meter (Mead 1986). Subscripts ${ }_{A}$ and ${ }_{B}$ denote the two crops in diculture. Subscripts ${ }_{p}$ and ${ }_{m}$ denote polyculture and monoculture beds, respectively. The standard deviation of each $Y$ value was calculated independently, and the square root of the sum of the squares of all $Y$ values used in the calculation was used as the standard deviation for the index, from which a $95 \%$ confidence interval was calculated for each LER value (Zar 1984). 


\section{Tomato taste tests}

Two double-blind tomato taste tests were conducted to determine whether the crop growing with tomatoes affected tomato taste. Freshly harvested, blemish-free tomatoes were matched by size and degree of ripeness, and divided by treatment. Undergraduate classes, consisting of 20-30 students, served as untrained taste panels. Panelists were instructed on the physical sensations of sweetness and acidity, and told to use provided saltines to clear the palate between tastes. Each panelist was served two tomato quarters from monoculture beds, identified as a "standard." They were instructed to compare these to a quarter tomato from each of the remaining tomato treatments, according to four criteria (sweetness, acidity, "true tomato flavor," and preference). A 5-point rating system was used for each comparison (-2=much less than standard; $0=$ equivalent to standard; $2=$ much more than standard). Results from both panels were pooled. A two-tailed t-test was used to test the mean rating for each criterion for significant difference from zero (Zar 1984).

\section{Pest surveys}

The density of leaf-dwelling arthropods and foliar diseases was estimated in the field during six monitoring sessions between late June and late August (Figure 2). Sessions lasted 2-4 days, during which six plants were inspected in each row of each bed. Plant inspections were conducted on upper leaf clusters, selected according to the following criteria:

- Tomato - inspect both sides of five leaflets at the terminal end of one upper leaf.

- Brussels sprout - inspect both sides of two fully-extended upper leaves.

- Bean - inspect both sides of one upper leaf triplet.

- Basil - inspect both sides of one upper leaf pair.

- Clover - no inspection

Commonly occurring arthropods were identified and enumerated. Counts were summed for the entire season. Data were subjected to ANOVA to test for treatment effects, and means were separated by Tukey's test when effects were significant (Zar 1984). 


\section{Results}

\section{Growth and competition}

Plot photographs that illustrate the following qualitative observations are available in separate files (Appendix 4).

Basil. Basil suffered little competition from radishes. Tomatoes and beans had both started to shade basil by the end of June, and this effect was accentuated by mid-July. The second bean crop was less competitive than the first, so that only tomatoes were obviously overwhelming basil by mid-August. Tomatoes were clearly dominant in the basil and tomato dicultures by September. Brussels sprout and bean did not clearly overwhelm basil, nor were they overwhelmed by basil at season end.

Bean. The first crop of beans dominated all companion crops early in the season. This effect was accentuated by mid-July, just prior to removal of these plants. The second crop of beans was overwhelmed by tomato companions, and suffered some shading from basil and Brussels sprout companions. Bean plants were smaller and leggier in basil and brassica dicultures than in monocultures at season end. They were difficult to find in tomato dicultures.

Brassica. Radishes were shaded by the first bean crop, but did not suffer obvious aboveground competition from other crops. Brussels sprouts suffered some competition from clover living mulch, and were overwhelmed by tomatoes.

Tomato. By mid-July tomatoes had dominated all companions except beans. The removal of the first bean crop allowed tomatoes to overwhelm the second crop of bean companions, resulting in complete dominance by season end.

\section{Harvest}

Basil. All basil plants survived to the final harvest except those in tomato diculture beds $(80.7 \pm 7.5 \%$ survival). Yields tended to increase over the course of the growing season except in tomato diculture beds (Figure 3).

Basil yields were consistently highest in monoculture beds, followed by diculture beds with Brussels sprout, then bean, then tomato (Figure 3, Figure 4). The season yield of individual basil plants grown with Brussels sprouts did not differ significantly from that of plants grown in monoculture (Figure 4). Individual plants grown between tomatoes had the lowest yield, followed by plants grown between beans (Figure 4).

Bean. More beans were harvested in the early planting than the late planting (Figure 5). The final harvest was the largest of the three for the first planting and the smallest of the three for the second (Figure 5). 
Bean plants growing between tomatoes were considerably more stunted in the second planting than the first, resulting in greatly reduced yields (Figure 5).

The bean harvest accounted for $45.0 \pm 0.7 \%$ of the total bean plant biomass removed from the plots. This proportion did not vary significantly between treatments. The total bean plant biomass removed for both plantings was highest in monoculture plots and lowest in bean and tomato dicultures, but beans grown between tomatoes did not produce significantly less biomass than those grown between brassicas when data from both plantings were combined (Figure 6). The biomass removed per bean row did not differ significantly between treatments (Figure 6).

Brussels sprout. Survival of Brussels sprout plants grown between tomatoes was very poor $(56.2 \pm 12.0 \%)$ compared with survival in monoculture $(95.0 \pm 1.7 \%)$, or in other companion combinations $(88.4 \pm 3.6 \%)$. Plants grown in monoculture, or in combination with bean, were significantly heavier than those grown with tomatoes, producing more above-ground biomass per unit area (Figure 7). The average weight of plants grown between basil, bean or clover did not differ significantly from the weight of plants grown in monoculture, but plants grown with basil or clover produced less biomass than those grown in monoculture (Figure 7).

There was a significant linear relationship $\left(r^{2}=0.77, P<0.0001\right)$ between the average plant weight and the number of marketable Brussels sprouts, described by the equation

$$
y=5.22 x+66.5
$$

where $x$ was the number of marketable Brussels sprouts and $y$ was the fresh weight $(\mathrm{g})$ of the above-ground portion of the plant. 


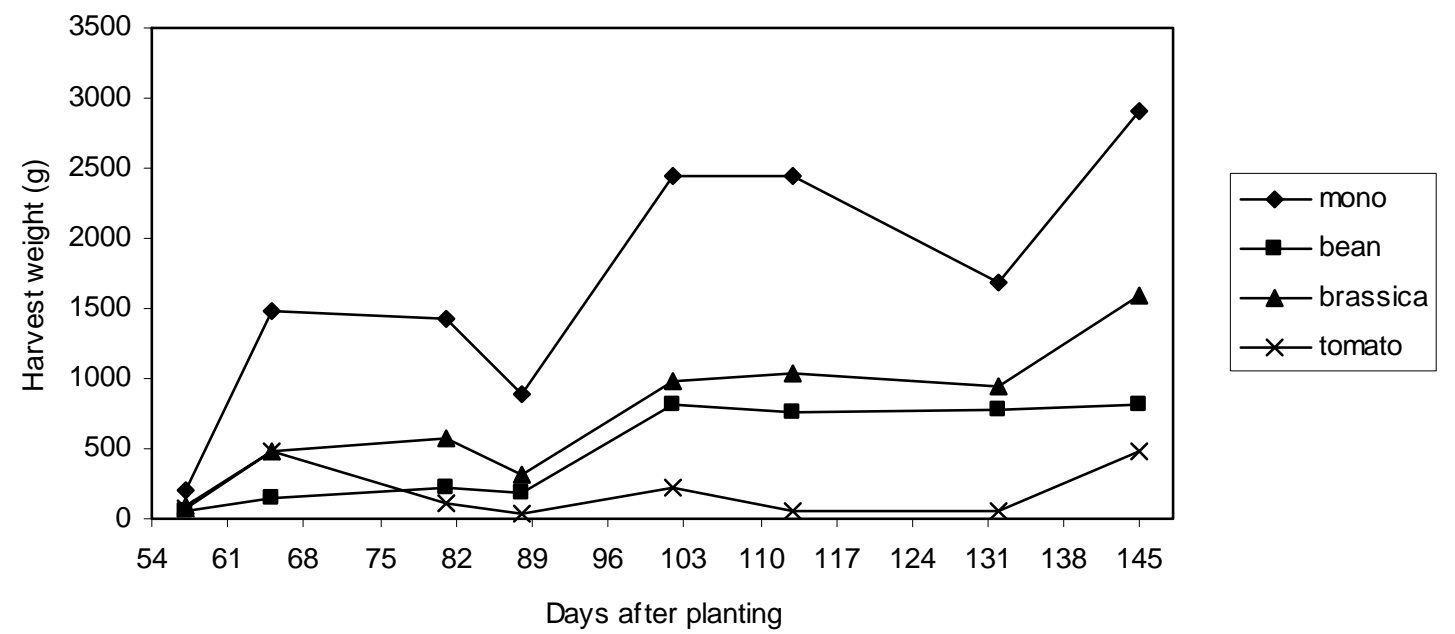

Figure 3. Total fresh weight of basil leaves removed on each harvest day. Basil plants were grown in monoculture beds (mono) containing five rows of basil, or in beds containing five alternating rows of basil and a companion crop (bean, brassica, or tomato). Dicultures contained two rows of basil and three of the companion crop. All leaves and stems $>15 \mathrm{~cm}$ above the soil surface were removed on each harvest day, except the final harvest, when all remaining leaves were removed.
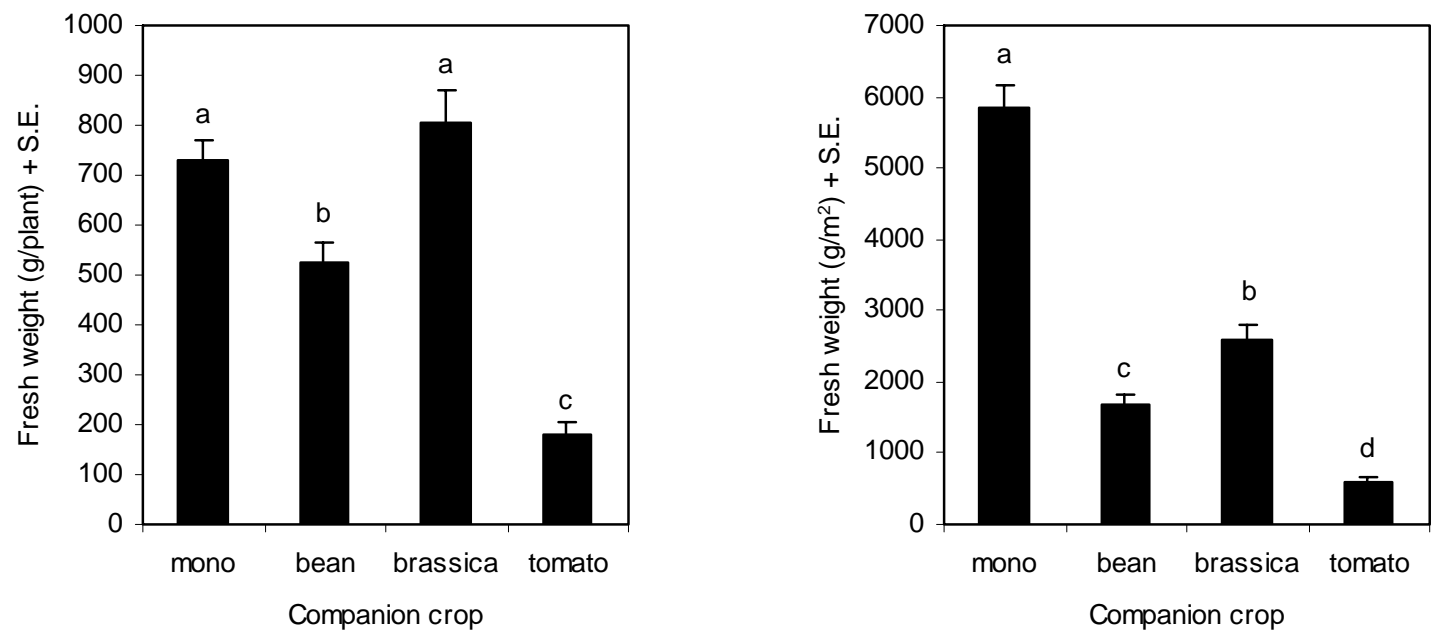

Figure 4. Aboveground fresh weight of basil harvested per plant (left), and per $\mathbf{m}^{2}$ (right). Points with the same letter for a given harvest are not significantly different (Tukey's test, $P<0.05, n=4$ ). Basil plants were grown in monoculture beds (mono) containing five rows of basil, or in beds containing five alternating rows of basil and a companion crop (bean, brassica, or tomato). Dicultures contained two rows of basil and three of the companion crop. 


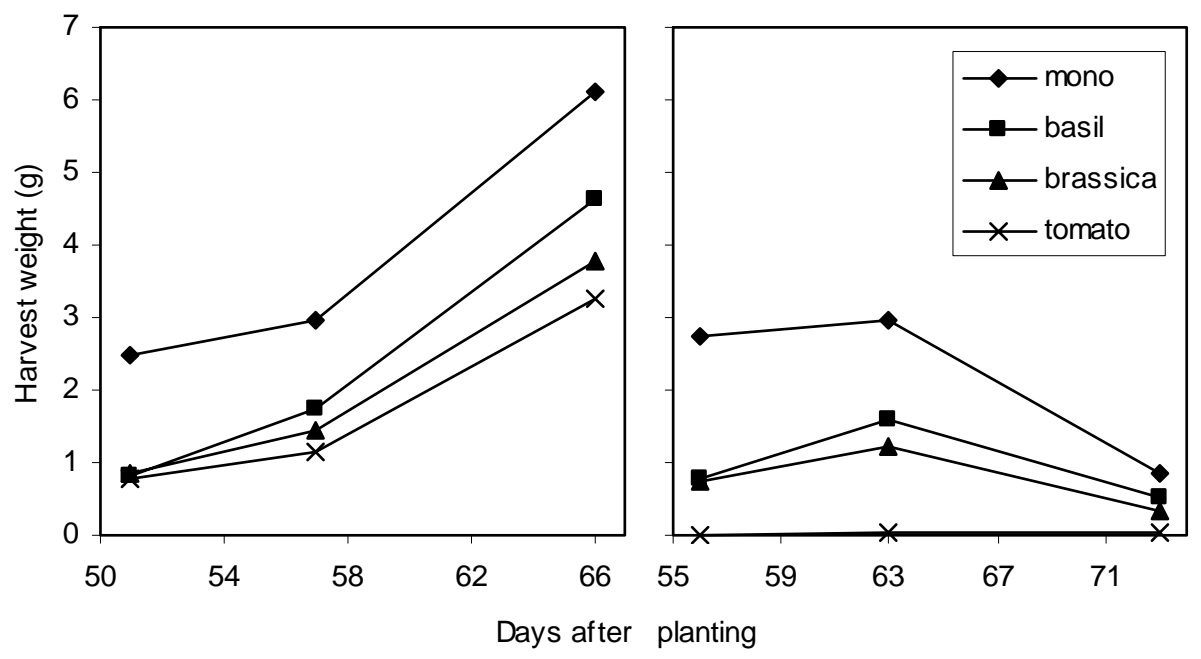

Figure 5. Fresh weight of beans removed on each harvest day for first planting (left) and second planting (right). Plants were grown in monoculture beds (mono) containing five rows of bean, or in beds containing five alternating rows of bean and a companion crop (basil, brassica, or tomato). Bean dicultures with brassica or tomato companions contained two rows of bean and three of the companion crop. Bean and basil dicultures contained three rows of bean and two of basil. All pods $>10 \mathrm{~cm}$ in length were removed at each harvest.
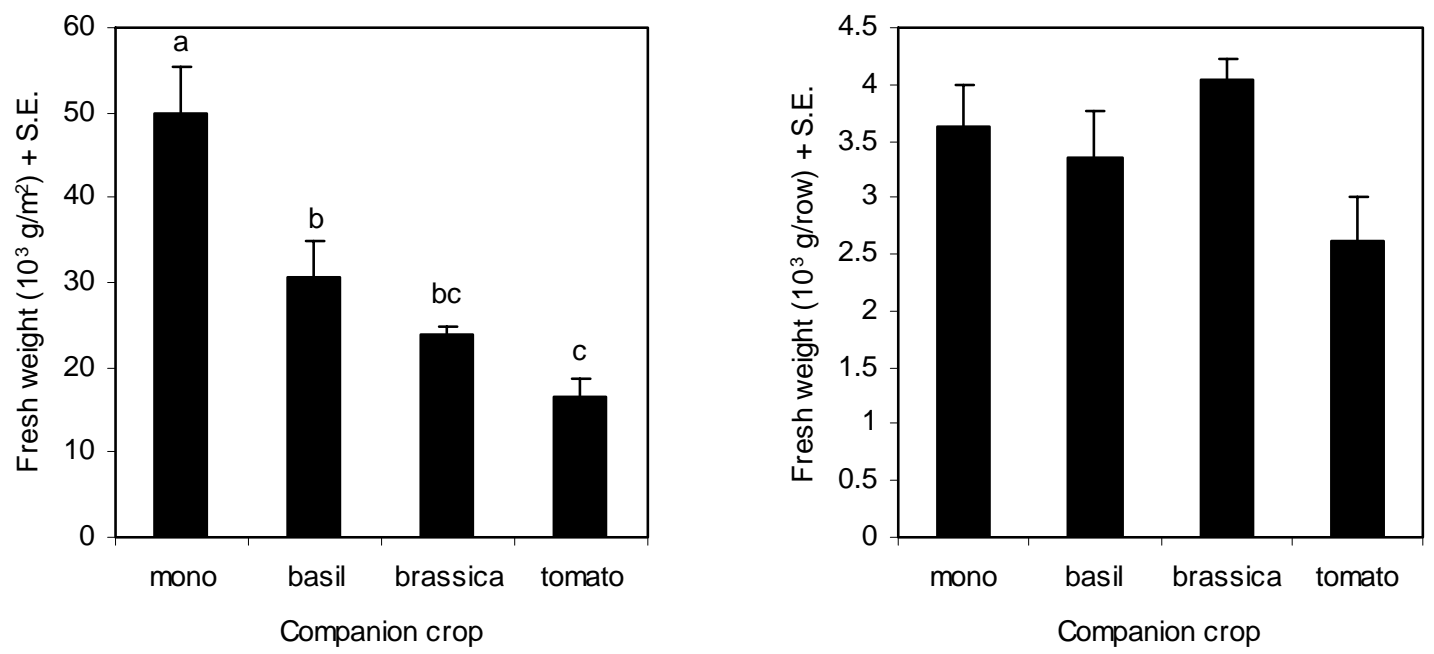

Figure 6. Fresh weight of bean plants removed per $\mathrm{m}^{2}$ (left), and per row (right). Weight includes total season harvest of beans and aboveground plant parts for two plantings. Plants were grown in monoculture beds (mono) containing five rows of bean, or in beds containing five alternating rows of bean and a companion crop (basil, brassica, or tomato). Bean dicultures with brassica or tomato companions contained two rows of bean and three of the companion crop. Bean and basil dicultures contained three rows of bean and two of basil. Bars within a box labeled with the same letter, or no letter, are not significantly different (Tukey's test, $P<0.05, n=4$ ). 

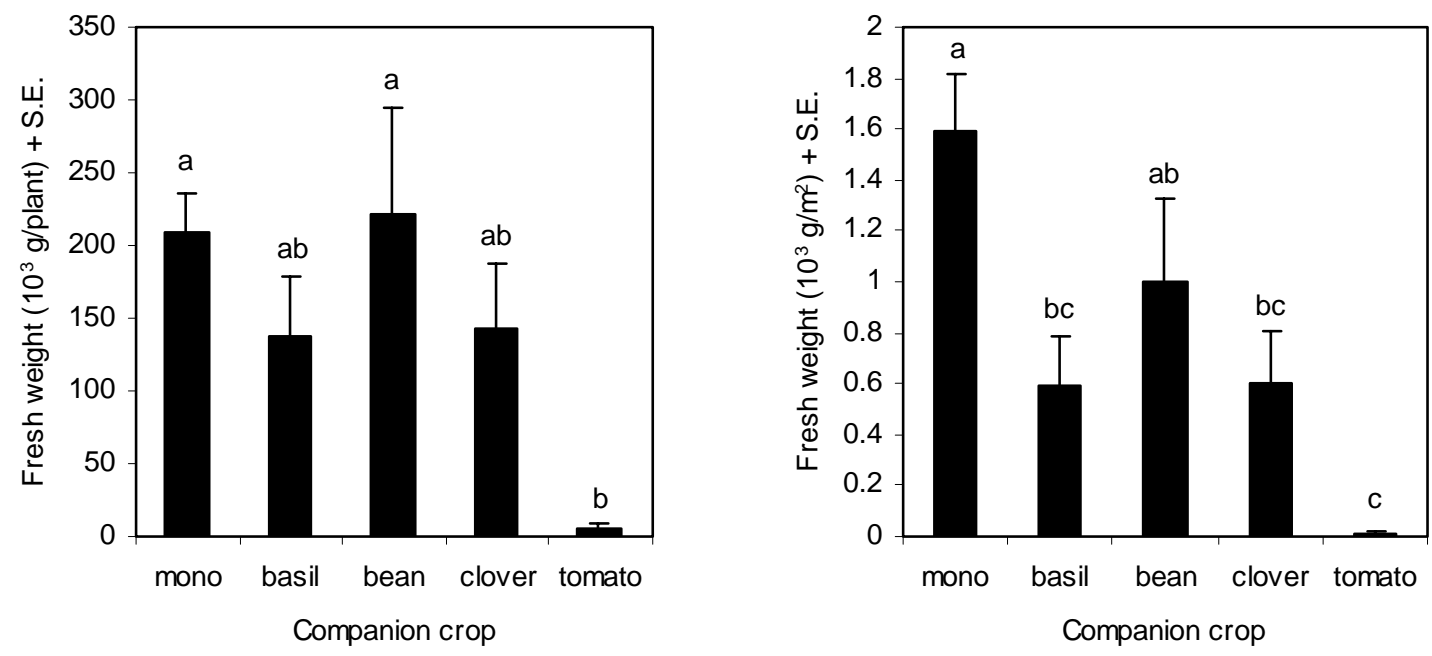

Figure 7. Aboveground fresh weight of Brussels sprout plant matter collected per plant (left), and per $\mathrm{m}^{2}$ (right). Brussels sprouts were grown in monoculture beds (mono) containing five rows of Brussels sprouts, or in beds containing five alternating rows of Brussels sprout and a companion crop (basil, bean, clover, or tomato). Basil, bean, and clover beds contained three rows of Brussels sprout and two of the companion crop; tomato beds contained two rows of Brussels sprout and three of tomato. Bars within a box labeled with the same letter are not significantly different (Tukey's test, $P<0.05$, $n=4)$.

Radish. The number of radishes and the radish biomass harvested from monoculture treatments exceeded that of any polyculture treatments, but differences were not observed between polycultures (Figure 8, Figure 9). The treatments did not affect the mean weight of plants at harvest $(42.7 \pm 3.1 \mathrm{~g}(\bar{x} \pm \mathrm{SEM}))$ or the mean root weight $(20.1 \pm 1.5 \mathrm{~g})$.

About half of the radishes harvested $(51.3 \pm 3.2 \%)$ were deemed unmarketable, usually due to splitting or cracking. The marketable proportion of harvested root weight in the second harvest was significantly lower for radishes planted in clover $(14.2 \pm 0.4 \%)$ than other treatments $(28.8 \pm 2.3 \%)$, but this effect was not significant in other harvests, or for the season harvest. The proportion of marketable root weight fell with each successive harvest $(36.1 \pm 2.6,25.8 \pm 2.3$ and $13.2 \pm 1.8 \%$ in first, second and third harvests, respectively).

Radishes grown in combination with bean were stunted, and slower to mature than those grown in monoculture, or in combination with tomato. Only $25.4 \pm 7.0 \%$ of radishes grown in monoculture, and $28.0 \pm 0.8 \%$ of radishes grown with tomatoes, failed to reach a marketable size by the second harvest, compared to $63.7 \pm 7.7 \%$ of those grown with bean (Figure 8 ). 
Tomato. Tomato biomass removed from plots over the entire season averaged $18.8 \pm 0.9 \mathrm{~kg} \cdot \mathrm{m}^{2}$, and did not differ significantly between treatments (Table 4). Tomato plants grown in monoculture produced significantly less biomass than plants grown with basil or brassica companions (Table 4).

Fruit accounted for $79.6 \pm 0.7 \%$ of the biomass collected. Tomato plants grown in monoculture bore fewer fruits than those grown in bean, cabbage, or basil dicultures (Table 5). There was a non-significant tendency for plants grown in monoculture to produce smaller fruits, and a lower proportion of marketable fruit per plant than plants grown in diculture (Table 5).

The number of ripe tomatoes harvested each week tended to increase as the season progressed, except in late September (Figure 10). Average fruit size declined throughout the season (Figure 11). Differences between treatments were only observed on two harvest dates: Monoculture yields were higher than diculture yields during the second harvest, and tomatoes grown with beans yielded more than tomatoes grown with brassicas in the next-to-last harvest (Figure 10).

Table 4. Above-ground biomass collected from plots of tomatoes grown in monoculture beds, or beds with clover, bean, cabbage, or basil companions. Means followed by the same letter within a column are not significantly different (Tukey's test $P>0.05$ ).

\begin{tabular}{lll}
\hline Tomato companion & $\begin{array}{l}\text { Biomass per plant } \\
(\mathrm{kg}) \pm \text { S.E. }\end{array}$ & $\begin{array}{l}\text { Treatment biomass } \\
\left(\mathrm{kg} \cdot \mathrm{m}^{-2}\right) \pm \text { S.E. }\end{array}$ \\
\hline Monoculture & $2.33 \pm 0.38 \mathrm{a}$ & $18.7 \pm 3.1 \mathrm{a}$ \\
Clover & $3.25 \pm 0.39 \mathrm{ab}$ & $15.6 \pm 1.9 \mathrm{a}$ \\
Bean & $3.88 \pm 0.50 \mathrm{ab}$ & $18.6 \pm 2.4 \mathrm{a}$ \\
Brassica & $4.29 \pm 0.31 \mathrm{~b}$ & $20.6 \pm 1.5 \mathrm{a}$ \\
Basil & $4.31 \pm 0.20 \mathrm{~b}$ & $20.7 \pm 1.0 \mathrm{a}$ \\
\hline
\end{tabular}

Table 5. Characteristics of tomatoes harvested from monoculture beds, or beds with clover, bean, cabbage, or basil companions. Means followed by the same letter within a column are not significantly different (Tukey's test $P>0.05$ ).

\begin{tabular}{llll}
\hline Tomato companion & $\begin{array}{l}\text { Fruits harvested per } \\
\text { plant }(\bar{x} \pm \text { S.E. })\end{array}$ & $\begin{array}{l}\text { Mean fruit weight } \\
(\mathrm{g}) \pm \text { S.E. }\end{array}$ & $\begin{array}{l}\text { Marketable proportion } \\
\text { of fruit }(\%) \pm \text { S.E. }\end{array}$ \\
\hline Monoculture & $15.2 \pm 2.0 \mathrm{a}$ & $124.1 \pm 5.5 \mathrm{a}$ & $59.6 \pm 5.4 \mathrm{a}$ \\
Clover & $17.4 \pm 2.3 \mathrm{ab}$ & $144.1 \pm 3.0 \mathrm{a}$ & $71.4 \pm 2.9 \mathrm{a}$ \\
Bean & $22.8 \pm 1.7 \mathrm{bc}$ & $130.8 \pm 8.5 \mathrm{a}$ & $63.6 \pm 2.2 \mathrm{a}$ \\
Brassica & $23.9 \pm 1.9 \mathrm{bc}$ & $144.8 \pm 3.6 \mathrm{a}$ & $68.9 \pm 2.6 \mathrm{a}$ \\
Basil & $25.8 \pm 0.7 \mathrm{c}$ & $135.6 \pm 7.6 \mathrm{a}$ & $65.4 \pm 3.4 \mathrm{a}$ \\
\hline
\end{tabular}



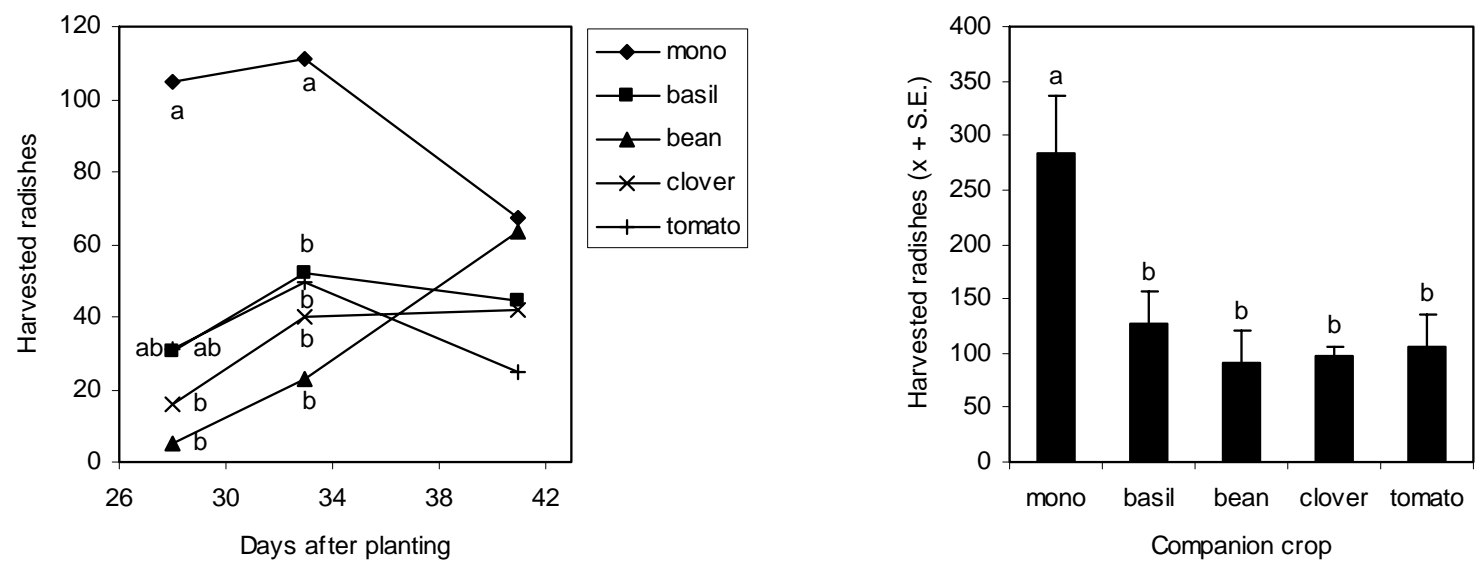

Figure 8. Number of radishes harvested on each harvest day (left) and in all harvests combined (right). Points with the same letter for a given harvest are not significantly different (Tukey's test, $P<0.05, n=4)$. Radishes were grown in monoculture beds (mono) containing five rows of radishes, or in beds containing five alternating rows of radish and a companion crop (basil, bean, clover, or tomato). Basil, bean, and clover beds contained three rows of radish and two of the companion crop; tomato beds contained two rows of radish and three of tomato. Only radishes $>\mathbf{2} \mathbf{c m}$ in diameter were removed during the first two harvests; the remainder were removed during the final harvest.
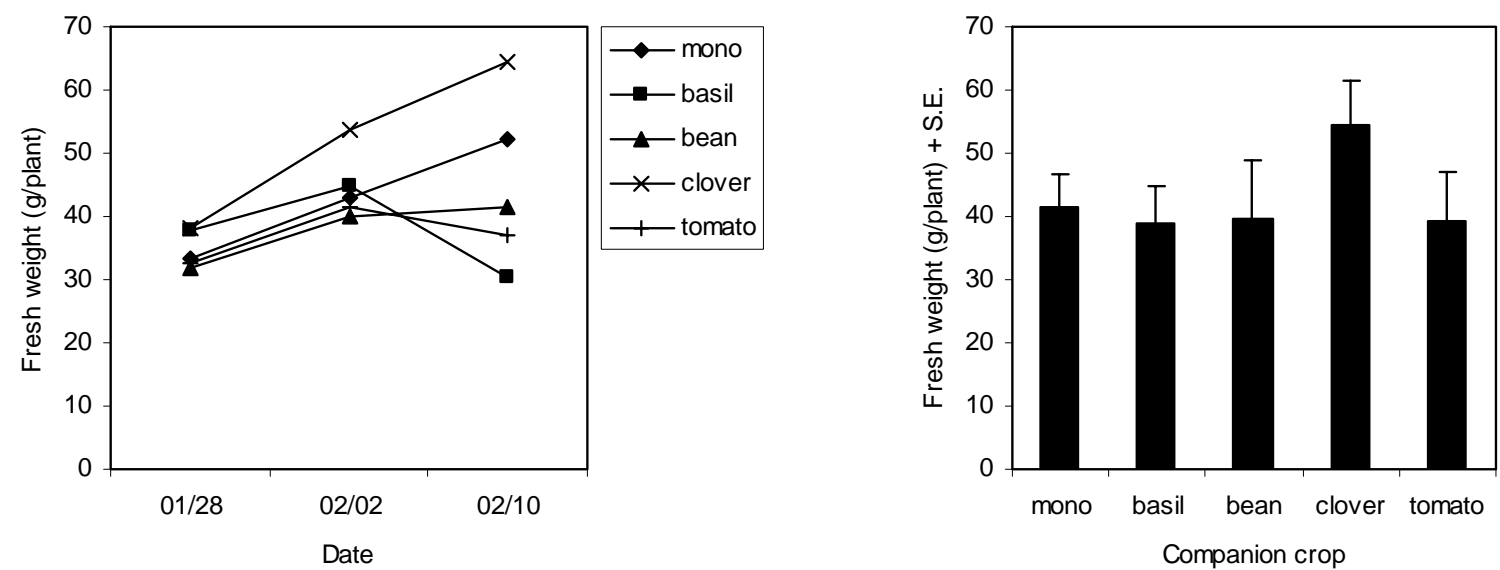

Figure 9. Fresh weight of radish plants removed on each harvest day (left), and in all harvests combined (right). ). Points with the same letter for a given harvest are not significantly different (Tukey's test, $P<0.05, n=4$ ). Radishes were grown in monoculture beds (mono) containing five rows of radishes, or in beds containing five alternating rows of radish and a companion crop (basil, bean, clover, or tomato). Basil, bean, and clover beds contained three rows of radish and two of the companion crop; tomato beds contained two rows of radish and three of tomato. Only radishes $>2$ $\mathrm{cm}$ in diameter were removed during the first two harvests; the remainder were removed during the final harvest. 


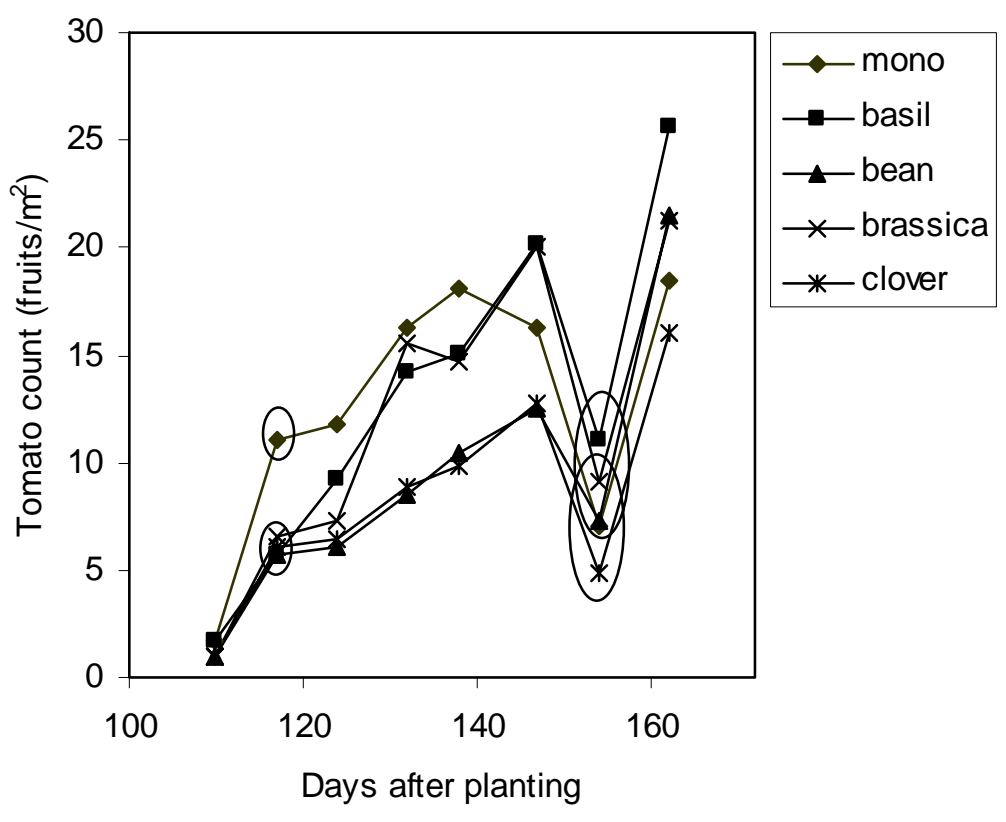

Figure 10. Number of ripe tomato fruits picked on each harvest day in tomato monoculture beds (mono), and in beds containing alternating rows of tomato and a companion crop (basil, bean, brassica, or clover). Points within the same oval are not significantly different (Tukey's test, $P>$ 0.05). No significant differences were found between treatments on days where points are not enclosed by ovals.

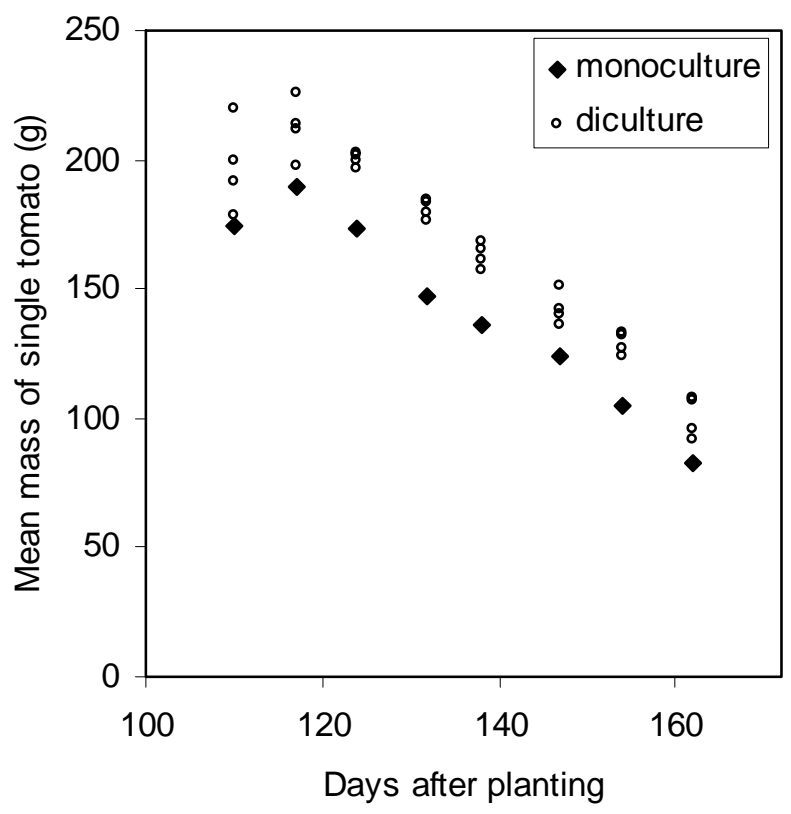

Figure 11. Mean fresh weight of individual tomato fruits collected from monocultures or dicultures on each harvest day. No significant differences were found between treatments on any harvest day (Tukey's test). 
Land Equivalence Ratios (LER). LERs ranged from 0.45 for brassica and clover to 1.33 for tomato and bean (Table 6). Dicultures did not yield significantly more than monocultures. The brassica and clover combination yielded significantly less brassica biomass than the brassica monocultures (Table 6).

Tomatoes accounted for at least $75 \%$ of the LER in all tomato dicultures (Table 6). Yield of the tomato component of dicultures did not differ significantly from yield in monoculture. All other crops had significantly lower yield in diculture than in monoculture; none dominated their companion dicultures.

Table 6. Contributions of component crops to total Land Equivalence Ratio (LER) for seven companion plant combinations $(\bar{x} \pm$ S.E.). Upper and lower $95 \%$ confidence intervals are shown for total LER.

\begin{tabular}{llllll}
\hline \multirow{2}{*}{$\begin{array}{l}\text { Companion } \\
\text { Combination }\end{array}$} & \multicolumn{3}{c}{ Contribution to LER \pm S.E. } & Total \\
\cline { 2 - 5 } & Tomato & Basil & Brassica & Bean & LER \pm S.E. \\
\hline Tomato \& Bean & $1.00 \pm 0.20$ & & & $0.33 \pm 0.18$ & $1.33 \pm 0.27$ \\
Tomato \& Brassica & $1.10 \pm 0.18$ & & $0.20 \pm 0.13$ & & $1.31 \pm 0.22$ \\
Tomato \& Basil & $1.11 \pm 0.17$ & $0.10 \pm 0.15$ & & & $1.21 \pm 0.23$ \\
Brassica \& Bean & & & $0.39 \pm 0.20$ & $0.48 \pm 0.12$ & $0.86 \pm 0.24$ \\
Bean \& Basil & & $0.29 \pm 0.09$ & & $0.61 \pm 0.18$ & $0.90 \pm 0.20$ \\
Tomato \& Clover & $0.84 \pm 0.20$ & & & & $0.84 \pm 0.20$ \\
Brassica \& Basil & & $0.44 \pm 0.10$ & $0.39 \pm 0.15$ & & $0.84 \pm 0.18$ \\
Brassica \& Clover & & & $0.45 \pm 0.17$ & & $0.45 \pm 0.17$ \\
\hline
\end{tabular}

\section{Tomato taste tests}

Tasters found tomatoes grown in brassica and clover dicultures less acidic than those grown in monoculture (Table 7). No significant differences were observed for other companion crops or criteria tested.

Table 7. Tomato taste test ratings by blind tasters comparing fruit grown in monoculture beds or diculture beds to standard fruit grown in monoculture beds. Sweetness, acidity, "true tomato flavor" and personal preference for each test tomato was compared to a standard on a scale of $\mathbf{- 2}$ (much less than standard) to 2 (much more than standard).

\begin{tabular}{lcccc}
\hline \multirow{2}{*}{ Companion crop } & \multicolumn{4}{c}{ Taster rating $(\overline{\boldsymbol{x}} \pm$ S.E. $(\boldsymbol{n}))$} \\
\cline { 2 - 5 } & Sweetness & Acidity & $\begin{array}{c}\text { True tomato } \\
\text { flavor }\end{array}$ & $\begin{array}{c}\text { Personal } \\
\text { preference }\end{array}$ \\
\hline None (monoculture) & $-0.31 \pm 0.19(36)$ & $-0.01 \pm 0.19(36)$ & $-0.19 \pm 0.19(36)$ & $-0.23 \pm 0.21(35)$ \\
Basil & $0.05 \pm 0.15(60)$ & $0.00 \pm 0.14(60)$ & $0.10 \pm 0.12(59)$ & $-0.02 \pm 0.14(59)$ \\
Bean & $-0.08 \pm 0.15(59)$ & $-0.27 \pm 0.14(59)$ & $0.16 \pm 0.13(58)$ & $0.09 \pm 0.17(58)$ \\
Brassica & $0.02 \pm 0.15(60)$ & $-0.36 \pm 0.14(60)^{*}$ & $0.10 \pm 0.15(60)$ & $0.02 \pm 0.16(59)$ \\
Clover & $0.13 \pm 0.16(60)$ & $-0.28 \pm 0.14(60)^{*}$ & $-0.15 \pm 0.13(59)$ & $-0.14 \pm 0.15(59)$ \\
\hline
\end{tabular}

$*$ Different from standard $(P<0.05)$ 


\section{Pest surveys}

Basil. Only one phytophagous insect was routinely found on basil: the palestriped flea beetle, Systena blanda (Melsheimer). It was more often found on plants growing in monoculture than plants growing in diculture with tomato (Table 8).

Table 8. Counts of palestriped flea beetle found on basil leaves during six surveys between June and September $(n=4)$. Means followed by the same letter within a column are not significantly different (Tukey's test, $P<0.05$ ).

\begin{tabular}{lc}
\hline Companion crop & $\begin{array}{l}\text { Palestriped flea beetles } \\
\text { per leaf }(\overline{\boldsymbol{x}} \pm \text { S.E. })\end{array}$ \\
\hline Monoculture & $1.05 \pm 0.20 \mathrm{a}$ \\
Bean & $0.50 \pm 0.29 \mathrm{ab}$ \\
Brassica & $0.85 \pm 0.22 \mathrm{ab}$ \\
Tomato & $0.08 \pm 0.03 \mathrm{~b}$ \\
\hline
\end{tabular}

Bean. Three groups of phytophagous insects were commonly found on beans: thrips, chiefly Frankliniella occidentalis (Pergande); potato leafhopper, Empoasca fabae (Harris); and aphids (Table 9). Differences between treatments were not significant.

A variety of other insects occurred at very low levels $(<0.1$ insects per leaf), including whitefly, flea beetles, ladybeetles, Aphidiid wasps, and Mexican bean beetles. Feeding on leaves by Mexican bean beetle caused significant damage on the first bean crop, but no differences were observed between treatments.

Table 9. Counts of three prominent phytophagous insects found on bean leaf triplets during five surveys between June and September $(n=4)$.

\begin{tabular}{llll}
\hline & \multicolumn{3}{c}{ Insects per leaf triplet $(\overline{\boldsymbol{x}} \pm$ S.E. $)$} \\
\cline { 2 - 4 } Companion crop & Thrips & Leafhoppers & Aphids \\
\hline Monoculture & $3.8 \pm 0.7$ & $1.8 \pm 0.2$ & $0.49 \pm 0.05$ \\
Basil & $2.7 \pm 0.5$ & $1.5 \pm 0.3$ & $1.01 \pm 0.10$ \\
Brassica & $1.9 \pm 0.2$ & $2.4 \pm 0.4$ & $0.63 \pm 0.22$ \\
Tomato & $4.4 \pm 1.3$ & $1.5 \pm 0.3$ & $0.69 \pm 0.21$ \\
\hline
\end{tabular}

Brassica. Many phytophagous insects were commonly found on brassica: striped flea beetle, Phyllotreta striolata (F.); cabbage whitefly, Aleyrodes proletella (L.); green peach aphid, Myzus persicae (Sulzer); cross-striped cabbageworm, Evergestis rimosalis (Guenee); and imported cabbageworm, Pieris rapae (L.). Levels of all of these differed between treatments (Table 10 and Table 11).

More striped flea beetles were found on crucifers growing in monoculture, or with a clover living mulch, than on plants growing with tomato companions (Table 10). Crucifers with tomato companions had fewer cabbage whitefly adults than other crucifers (Table 10). More green peach aphids were found on crucifers 
grown in monoculture than on those grown with a clover living mulch or with tomato companions (Table 10). Cross-striped cabbageworm counts were higher on plants grown in monoculture than those grown with basil, clover or tomato companions, and lower on plants grown with tomato companions than on those grown in monoculture or with bean companions (Table 11). The number of imported cabbageworm eggs did not differ significantly between treatments, but more larvae were found on brassica grown with basil companions than those grown with clover or tomato companions (Table 11).

Most ( $>70 \%)$ of the cabbage flea beetles were found on radish plants. Most $(>80 \%)$ of the green peach aphids were found on Brussels sprout plants. Cabbage whitefly, cross-striped cabbageworm, and imported cabbageworm were found exclusively on Brussels sprout plants.

Table 10. Counts of three prominent phytophagous insects found on brassica (radish and Brussels sprout) leaves during five surveys between June and September $(n=4)$. Means followed by the same letter within a column are not significantly different (Tukey's test, $P<0.05$ ).

\begin{tabular}{llll}
\hline & \multicolumn{3}{c}{ Insects per leaf $(\overline{\boldsymbol{x}} \pm$ S.E. $)$} \\
\cline { 2 - 4 } Companion crop & Striped flea beetle adult & Cabbage whitefly adult & Green peach aphid \\
\hline Monoculture & $4.9 \pm 0.4 \mathrm{a}$ & $3.6 \pm 0.4 \mathrm{a}$ & $11.5 \pm 2.1 \mathrm{a}$ \\
Basil & $2.7 \pm 0.5 \mathrm{ab}$ & $3.1 \pm 0.5 \mathrm{a}$ & $5.6 \pm 0.6 \mathrm{ab}$ \\
Bean & $3.1 \pm 0.8 \mathrm{ab}$ & $3.8 \pm 0.5 \mathrm{a}$ & $6.4 \pm 1.0 \mathrm{ab}$ \\
Clover & $4.4 \pm 0.8 \mathrm{a}$ & $2.0 \pm 0.7 \mathrm{a}$ & $4.6 \pm 0.9 \mathrm{~b}$ \\
Tomato & $1.6 \pm 0.5 \mathrm{~b}$ & $0.1 \pm 0.1 \mathrm{~b}$ & $2.2 \pm 0.8 \mathrm{~b}$ \\
\hline
\end{tabular}

Table 11. Counts of cross-striped cabbageworm (larvae and eggs) and imported cabbageworm larvae found on Brussels sprout leaves during three surveys between August and September $(n=4)$. Means followed by the same letter within a column are not significantly different (Tukey's test, $P<0.05$ ).

\begin{tabular}{llll}
\hline & \multicolumn{3}{l}{ Insects per leaf $(\overline{\boldsymbol{x}} \pm$ S.E. $)$} \\
\cline { 2 - 4 } Companion crop & $\begin{array}{l}\text { Cross-striped } \\
\text { cabbageworm larva }\end{array}$ & $\begin{array}{l}\text { Imported } \\
\text { cabbageworm egg }\end{array}$ & $\begin{array}{l}\text { Imported } \\
\text { cabbageworm larva }\end{array}$ \\
\hline Monoculture & $1.22 \pm 0.12 \mathrm{a}$ & $0.9 \pm 0.2 \mathrm{a}$ & $0.54 \pm 0.09 \mathrm{ab}$ \\
Basil & $0.36 \pm 0.14 \mathrm{bc}$ & $1.2 \pm 0.5 \mathrm{a}$ & $0.71 \pm 0.19 \mathrm{a}$ \\
Bean & $0.97 \pm 0.40 \mathrm{ab}$ & $1.4 \pm 0.1 \mathrm{a}$ & $0.56 \pm 0.11 \mathrm{ab}$ \\
Clover & $0.19 \pm 0.09 \mathrm{bc}$ & $1.2 \pm 0.2 \mathrm{a}$ & $0.25 \pm 0.06 \mathrm{~b}$ \\
Tomato & $0.00 \pm 0.00 \mathrm{c}$ & $1.6 \pm 0.2 \mathrm{a}$ & $0.23 \pm 0.05 \mathrm{~b}$ \\
\hline
\end{tabular}

Tomato. The potato aphid, Macrosiphum euphorbiae (Thomas), was the most commonly found phytophagous insect on tomatoes. Of the 5,846 individuals counted 297 (5.1\%) were winged adults. Season aphid counts ranged from $11.4 \pm 3.5$ aphids per plant in basil diculture beds to $17.9 \pm 3.6$ aphids per plant in clover diculture beds (Table 12). Differences between treatments were not significant.

The aphid midge, Aphidoletes aphidimyza (Rondani), and aphid "mummies," caused by parasitism of aphids by Aphidiid wasps, were both commonly observed in all treatments, but counts did not differ significantly between treatments (Table 12). The aphid:A. aphidimyza ratio was $25.9 \pm 3.2$. 
A variety of insects were recorded on tomato leaves at very low levels ( $<0.1$ insects per leaf), including whitefly, thrips, lady beetle, syrphid, cabbage looper, and lacewing.

Table 12. Counts of potato aphids, and two aphid biocontrol organisms, on tomato leaf clusters during six surveys between June and September $(n=4)$.

\begin{tabular}{llll}
\hline & \multicolumn{3}{c}{ Insects per leaf cluster $(\overline{\boldsymbol{x}} \pm$ S.E. $)$} \\
\cline { 2 - 4 } Companion crop & Potato aphid (unwinged) & Aphidoletes & Aphidiid mummy \\
\hline Monoculture & $12.4 \pm 2.0$ & $0.82 \pm 0.12$ & $0.44 \pm 0.15$ \\
Basil & $11.4 \pm 2.7$ & $0.39 \pm 0.08$ & $0.46 \pm 0.15$ \\
Bean & $13.6 \pm 0.6$ & $0.75 \pm 0.25$ & $0.38 \pm 0.22$ \\
Brassica & $13.4 \pm 3.5$ & $0.64 \pm 0.10$ & $0.17 \pm 0.07$ \\
Clover & $17.9 \pm 3.6$ & $0.83 \pm 0.23$ & $0.30 \pm 0.11$ \\
\hline
\end{tabular}

\section{Discussion}

Plants grown in combination with other species may differ significantly from those grown in monoculture.

This study demonstrated altered survival rates, plant size, and fruit yield in certain diculture combinations as compared to monocultures (Table 13). Tomato plants tended to benefit from polyculture, suggesting lower inter-specific competition than intra-specific competition for tomato plants. Polyculture was detrimental to individual basil and brassica plants, suggesting that inter-specific competition exceeded intra-specific competition for these crops.

Table 13. The magnitude of selected differences in survival rate (S) plant weight (P), and fruit yield $(F)$ in dicultures as compared to monocultures. $X$ denotes a monoculture or untested combination.

\begin{tabular}{lccccc}
\hline Companion & \multicolumn{5}{c}{ Difference from monoculture (\%) } \\
\cline { 2 - 6 } crop & Basil & Bean & Brussels sprout & Radish & Tomato \\
\hline Basil & $\mathrm{X}$ & $-7 \mathrm{P}$ & $-8 \mathrm{~S},-34 \mathrm{P}$ & $+9 \mathrm{~S},-42 \mathrm{P}$ & $+185 \mathrm{P}^{*},+70 \mathrm{~F}^{*}$ \\
Bean & $0 \mathrm{~S},-28 \mathrm{P}^{*}$ & $\mathrm{X}$ & $-1 \mathrm{~S},+6 \mathrm{P}$ & $+57 \mathrm{~S},-21 \mathrm{P}$ & $+67 \mathrm{P},+50 \mathrm{~F}^{*}$ \\
Brassica & $0 \mathrm{~S},+10 \mathrm{P}$ & $+11 \mathrm{P}$ & $\mathrm{X}$ & $\mathrm{X}$ & $+84 \mathrm{P}^{*},+57 \mathrm{~F}^{*}$ \\
Clover & $\mathrm{X}$ & $\mathrm{X}$ & $-12 \mathrm{~S},-32 \mathrm{P}$ & $+4 \mathrm{~S},+23 \mathrm{P}$ & $+39 \mathrm{P},+14 \mathrm{~F}$ \\
Tomato & $-19 \mathrm{~S}^{*},-75 \mathrm{P}^{*}$ & $-28 \mathrm{P}$ & $-41 \mathrm{~S}^{*},-97 \mathrm{P}^{*}$ & $-9 \mathrm{~S},-29 \mathrm{P}$ & $\mathrm{X}$ \\
\hline
\end{tabular}

*Significant difference from monoculture (Tukey's test, $P<0.05$ )

Yield advantages occur in polyculture when inter-specific competition is less than intra-specific competition overall (Joliffe and Wanjau 1999). In this study LERs suggested yield advantages to dicultures incorporating tomato and other harvested companion crops (Table 6). Although companion crops suffered from their association with tomato, the magnitude of their disadvantage was less than that of the diculture advantage to tomato.

Competition between plants is greater at high densities than low densities. The observation that tomato yields were as high in dicultures as in monoculture (Table 4, Table 6), despite higher monoculture tomato densities, suggests that tomato density in the monoculture treatments exceeded the yield-optimizing density. Apparent yield advantages to companion planting with tomato (Table 6) were probably largely 
due to reduced competition between tomato plants. The same effect might not have been observed if tomato monocultures were planted at a lower density. The observed effects, therefore, were related to crop density, not just companion choice. Future studies are necessary to evaluate possible interactions between density and companion planting effects.

Any conclusion that a particular companion plant combination is beneficial or detrimental may only be valid for the particular combination of conditions tested in this study; the same crops combined at a different density or planted at different times could interact differently. The difference between the early and late bean plantings demonstrates the obvious and important effect of relative planting time on crop interactions (Figure 5). Early beans dominated their companions; late beans were dominated by the same companions. The discussion of companion crop interactions is incomplete without an awareness of how relative planting time alters these interactions, leading to size inequalities that are reinforced through competition between plants (Connolly et al. 1990). Several plant competition indices have been proposed to incorporate the element of time into competition studies (e.g. Connolly 1987, Goldberg 1994, Grace 1995).

The white clover living mulch proved to be a strong competitor to both tomatoes and brassicas. Since clover was considered a mulch, not a crop, its weight was not incorporated into LER calculations, resulting in low LERs in beds containing clover. A similar competitive effect of a clover living mulch beneath cabbage was reported by Brandsaeter et al. (1998), who found that roto-tilling between the cabbage rows increased yields by reducing clover competetiveness. Although the clover living mulch reduced cabbage yields in the Brandsaeter et al. study, its nitrogen fixing ability improved oat yields in the same plots the following year. The results of the single-year study reported here show only a yield reduction due to clover living mulch. Any advantage that might have occurred in the second year was not observed because the study was terminated.

Untrained, double-blind taste panels reported that tomato fruit grown in diculture with clover or brassica was less acidic than fruit grown in monoculture (Table 7). These results suggest that companion crops may alter tomato flavor, but does not support the popular assertion that basil companions improve tomato taste (Riotte 1975). Since t-tests were performed for each of 20 samples there was a high likelihood of a Type I error; the probability of finding a significant difference where no difference existed was less than $5 \%$ for any individual sample, but may have been as high as $62 \%$ after the test was repeated 20 times. The taste test results should therefore be interpreted with caution. Further taste studies are necessary to determine whether plant companions have a consistent and reproducible effect on crop flavor.

Taste tests usually have one of three objectives: a) to determine if products differ in any way, b) to determine how products differ, or c) to determine which products are preferred (Lawless and Heymann 1998a). Trained panelists are usually used for the first two types of test, and untrained panels for the third. The test used in this study asked untrained panelists how tomatoes grown in diculture differed from those grown in monoculture (sweetness and acidity comparisons, objective b) and which tomatoes were preferred 
(preference and true tomato flavor comparisons, objective c). Untrained panelists were used because resources were not available to hire or train panelists, but such panels are best suited to answer questions relating to consumer preference (Lawless and Heymann 1998a), for which no significant differences were found between treatments. An absence of consistent preference does not mean that no differences existed between treatments. A proper evaluation of the relevant question "Do tomatoes grown in diculture taste different from those grown in diculture?" would require trained panelists and a study designed simply to discriminate between tomatoes grown in different ways (Peryam 1958).

Leaf surveys showed only one case in which phytophagous pest counts were lower in dicultures with basil than in monocultures (Table 12, Table 10, Table 11), despite routine assertions of basil's efficacy as a pest repellent in popular literature. Cross-striped cabbageworm counts were lower on Brussels sprouts grown with basil than on those grown in monoculture, but imported cabbageworm counts were actually higher in basil dicultures than in clover or tomato dicultures (Table 11). Further research is necessary to determine if basil is indeed a useful companion for cross-striped cabbageworm management, and if it attracts imported cabbageworms. If these effects are observed in repeated trials they would indicate that basil could be recommended as a Brussels sprout companion to deter cross-striped cabbageworms but should be avoided in situations where imported cabbageworm is a significant pest.

Companion planting may have reduced pest presence in other combinations: the palestriped flea beetle on basil, and all of the pests commonly found on Brussels sprout except the imported cabbageworm, were more numerous in monoculture than in some diculture beds (Table 10, Table 11, Table 8). Where differences existed between monoculture and diculture beds pest counts were always lower in dicultures with tomato than in monoculture. Counts of green peach aphid and lepidopteron pests feeding on Brussels sprout were also lower in bean dicultures than in Brussels sprout monoculture.

Pests of Brussels sprout showed the most consistent treatment-related differences. In most cases pest incidence appeared to be inversely related to the competition faced by Brussels sprout plants. Fewer pests were found on small, stunted Brussels sprouts growing with a more dominant crop than on larger Brussels sprouts that were themselves dominant. It seems likely that the smaller host size and shielding effects of dominant companions could make it more difficult for pests to find their Brussels sprout hosts in diculture than in monoculture, as predicted by the disruptive crop hypothesis. A similar study of cabbage growing in white clover living mulch found that cabbage suffered considerable competition from the living mulch, but also suffered less pest damage than cabbage in monoculture (Brandsaeter et al. 1998). Likewise, cabbage plants grown in monocultures had more diamondback larvae than those grown with tomatoes, leading to the suggestion that diamondback moths had more difficulty finding their hosts among tomato plants than in monoculture (Bach and Tabashnik 1990). Both of these studies concluded that the advantage of reducing pest damage outweighed the disadvantages associated with competition from companion crops. Such was not the case in this study; the stunting of Brussels sprouts due to competition from companions had a more 
negative impact on final yields than the higher pest damage observed in monocultures. Producers may not always benefit from pest reductions due to companion planting. In cases such as this, the cure may be worse than the disease. 


\section{CHAPTER 3: Biointensive Study}

\section{Introduction}

A test of popular companion planting claims should replicate commonly used companion planting techniques. Some of the most widely-read publications promoting companion planting (e.g. Riotte 1975, Hill 1975) offer many recommendations related to specific crop combinations but do not recommend specific planting methods or arrangements. An exception is How to Grow More Vegetables... (Jeavons 1982), which offers detailed planting schemes as part of its discussion of a set of high-density growing methods that Jeavons terms "biointensive" agriculture.

Biointensive agriculture is a small-scale production method, involving the use of double-dug raised beds fertilized with composts to support high-density plantings (Jeavons 1982). The system was introduced to North America by Rudolf Steiner's student Alan Chadwick, who managed the student garden at UC Santa Cruz from 1967 to 1972 (Brown 2000). Biointensive production systems are now widely used worldwide, owing in part to the popularity of How to Grow More Vegetables..., which has gone through six editions and sold more than 600,000 copies in seven languages (Jeavons 2003). Jeavons has devoted most of his career to promoting the system, and has been widely recognized for his work (Jeavons 2003).

Companion planting is considered a vital component of biointensive systems (Jeavons 1982). Plants are said to grow better when near certain other plants, an advantage partly attributed to situations in which properly selected companions reduce pest problems. Jeavons' nonprofit organization, Ecology Action, claims that the suite of biointensive methods results in average vegetable yields that are four times higher than in conventional systems (Ecology Action 2003).

With the exception of Jeavons' publications in the Journal of Sustainable Agriculture (Jeavons 2001), in which he calls for formal academic analysis of biointensive systems, there has been little discussion of biointensive production methods in the scientific press. A study on double digging found that the practice significantly altered the soil profile, but did not enhance bean or beet yield (Holt \& Smith 1998). Numerous studies have demonstrated a yield benefit from polyculture (reviewed by Jolliffe 1997), but have not considered specific combinations used by biointensive practitioners.

I set out to compare monocultures and dicultures in biointensive beds. I chose two crops that were already being grown in other research trials on the same research farm: tomato (Lycopersicon esculentum Mill) and Brussels sprout (Brassica olerecia L.). Popular recommendations predict yield reductions when these crops are mixed (Table 1, Riotte 1975, Jeavons 1982). I used basil (Ocimum basilicum L.) as a companion crop for both. Basil planted with tomato is reputed to improve tomato growth, reduce pest pressure on tomatoes, and improve fruit flavor. Aromatic plants, such as basil, planted among brassicas are said to reduce brassica pest problems (Riotte 1975, Bradley \& Ellis 1992). I planned to test these recommendations by monitoring 
in-season and end-of-season yields and pest and beneficial insect populations and damage throughout two growing seasons.

To better understand any relationship between yield differences and plant competition I planned to monitor the availability of two crucial resources - water and light - at several points during the growing season.

\section{Materials and Methods}

\section{Study setup}

The Biointensive Study was conducted in 2001 and 2002. Three crops from the preliminary study were selected for their potential as companions: tomato (L. esculentum cv. 'WV 63'), Brussels sprout (B. oleracea, Gemmifera Group, cv. 'Long Island'), and basil (O. basilicum, cv. 'Nufar'). Crops were transplanted into beds double dug to a depth of $0.4 \mathrm{~m}$, and arranged in offset rows, so that interplant spacing within and between rows was held constant within each bed (Jeavons, 1982). Spacing between companion crops within a bed was the mean of the target spacing for each component crop (Jeavons, 1982) (Table 14). Thirty-five plants were grown in each bed; dicultures had 12 primary crop plants and 23 secondary crop plants. Beds were 1.6 times as long as wide, but bed area varied with interplant spacing (Table 14).

The study was conducted in four blocks of six treatments, using a randomized complete block design. Blocks were re-randomized between growing seasons. Crop seeding, transplant, and harvest dates are shown in Figure 12.

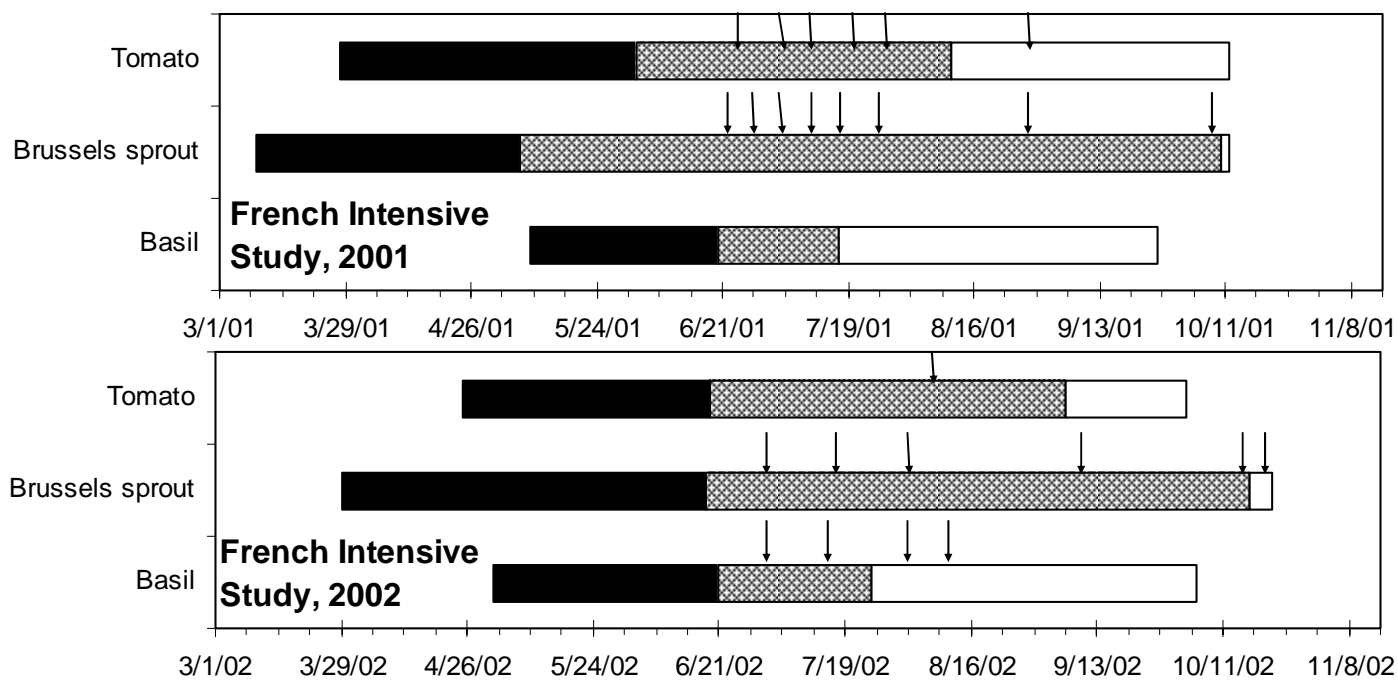

Figure 12. Temporal overlap of crops in the Biointensive study. Black, grey, and white bars denote periods of seeding to transplant, transplant to harvest, and harvest, respectively. Arrows show crop monitoring dates. 
Table 14. Biointensive study treatments, bed areas, plant spacing, and densities (after Jeavons 1982)

\begin{tabular}{llccccc}
\hline & & & Interplant & \multicolumn{3}{c}{ Density $\left(\right.$ plants $\left.\mathrm{m}^{-2}\right)$} \\
\cline { 5 - 7 } Treatment & Code & $\begin{array}{c}\text { Bed area } \\
\left(\mathrm{m}^{2}\right)\end{array}$ & $\begin{array}{c}\text { spacing } \\
(\mathrm{cm})\end{array}$ & $\begin{array}{c}\text { Primary } \\
\text { crop }\end{array}$ & $\begin{array}{c}\text { Secondary } \\
\text { crop }\end{array}$ & Overall \\
\hline 1. Basil monoculture & BAS & 2.7 & 30 & 12.8 & - & 12.8 \\
2. Brussels sprout monoculture & SPT & 6.1 & 45 & 5.7 & - & 5.7 \\
3. Tomato monoculture & TOM & 7.6 & 50 & 4.6 & - & 4.6 \\
4. Tomato and basil & T\&B & 6.8 & 40 & 2.5 & 4.7 & 7.2 \\
5. Tomato and Brussels sprout & T\&S & 6.1 & 48 & 1.7 & 3.4 & 5.1 \\
6. Brussels sprout and basil & S\&B & 4.3 & 38 & 2.8 & 5.4 & 8.2 \\
\hline
\end{tabular}

\section{Harvest}

Tomato and basil harvests were conducted according to the protocols described for the preliminary study.

The following data were collected during the final tomato harvest:

- Above-ground plant weight;

- Ripe fruit count and weight;

- Green fruit count and weight;

- Count of fruits damaged by splitting, vertebrate pests, arthropod pests, and rot;

- Main stem length (soil to growing tip);

- Fruit clusters (2001 only);

- Relative chlorophyll content of a single, healthy mature tomato leaf near the top of the plant, measued with a portable chlorophyll meter (SPAD-502, Soil-Plant Analysis Development (SPAD), Minolta Camera Co., Osaka, Japan) (2001 only) (Watanabe et al. 1980).

Following the final basil harvest the fresh weight of all above-ground portions of each of three plants per row was recorded. The relative chlorophyll content of one apparently healthy mature leaf near the top of each of these plants was recorded using a portable chlorophyll meter (Watanabe et al. 1980). Overall plant survival, and the total fresh weight of the above ground portions of the remaining plants were recorded for each bed.

Brussels sprouts were harvested only once each year. Plant survival was recorded for each bed. The following data were recorded for each plant:

- Total above-ground fresh weight

- Number and total weight of marketable sprouts (tight, $>2 \mathrm{~cm}$ in diameter, no visible pest damage)

- Stem length, from soil surface to growing tip

- Relative chlorophyll content of a single, healthy mature leaf near the top of the plant, measured with a portable chlorophyll meter (Watanabe et al. 1980). 
The correlation between relative chlorophyll content and final plant weight was tested by bivariate analysis. Harvest data were subjected to ANOVA to test for treatment and replicate effects, and means were separated by Tukey's test where significant differences were found (Zar 1984).

\section{Canopy light penetration}

A Sunfleck Ceptometer (Decagon, Pullman WA) was used to measure canopy light penetration between $1000 \mathrm{~h}$ and $1500 \mathrm{~h}$ on several cloudless days during each growing season (26 June, 2, 9 and 21 July, and 15 August, 2001; 12 July, 5 August and 9 September, 2002). Eight readings were taken at soil level in each bed. The upright meter was rotated $45^{\circ}$ with each reading, to eliminate effects due to row orientation. Readings were taken above the crop canopy before and after the soil level readings with the meter held upright, to measure direct solar radiation, and the meter inverted, to measure reflected solar radiation. Each reading recorded photosynthetically active radiation (PAR) and the proportion of ceptometer sensors exposed to direct sunlight (Sunfleck proportion). The mean of all eight readings was used as the sample reading for each bed. Samples from all dates were pooled, and the effects of treatment and replicate on light penetration were tested by ANOVA. Means were separated by Tukey's test where significant effects were observed.

\section{Soil moisture}

A HydroSense Soil Moisture Meter (Spectrum Technologies, Plainfield IL) was used to measure volumetric water content (VWC) (\%) in the top $20 \mathrm{~cm}$ of soil on three days in the latter portion of each growing season (7 and 24 August and 5 September, 2001; 17 July, 8 August and 9 September, 2002). Readings were taken between plants, approximately $50 \mathrm{~cm}$ from the east end of the second and fourth row of each bed. Readings were also taken approximately $50 \mathrm{~cm}$ from the west end of the same rows, and in the center of each bed, in 2003 only. The mean of all readings taken within each bed was used as the sample value for that bed. Samples from all dates were pooled, and the effects of treatment and replicate on VWC were tested by ANOVA. Means were separated by Tukey's test where significant effects were observed.

\section{Tomato taste tests}

A double-blind tomato taste test was conducted according to the protocol described for the preliminary study.

\section{Pest surveys}

Systematic Brussels sprout leaf checks were conducted eight times between mid June and mid October in 2001, and six times between early July and late October in 2002 (Figure 12). The second, fourth, and sixth plant in each row containing Brussels sprouts was checked, except in Brussels sprout and basil 
combinations, in which all plants were checked. Both sides of three fully extended upper leaves were inspected on each plant.

Systematic tomato leaf checks were conducted six times between late June and early August in 2001, and on 8 August, 2002 (Figure 12). All tomato plants were inspected in diculture beds, and the second, fourth, and sixth plants of each row were checked in tomato monoculture beds. Both sides of five leaflets at the terminal end of a fully extended upper leaf were inspected. Early blight lesions were inspected on a lower leaflet of the second tomato plant in each row. The number of lesions on the five leaflets nearest the terminal end of the leaf was recorded. All lesion diameters were recorded if there were fewer than five lesions; otherwise diameters of the five lesions nearest the terminal end of the leaf were recorded. The proportion of early blight infected leaves was recorded for each plant following the final tomato harvest in both years.

Systematic basil leaf checks conducted in 2002 only because weekly scans showed few arthropod pests or diseases in 2001. Systematic checks were conducted four times between early July and mid August in 2002. The second, fourth, and sixth plant in each row was inspected in all beds containing basil. Inspections consisted of a 10-second, whole-plant scan, followed by a detailed examination of both sides of a fully extended upper leaf pair.

Commonly occurring arthropods found on inspected plants were identified and enumerated. Data were subjected to ANOVA to test for treatment and replicate effects, and means were separated by Tukey's test where significant differences were found (Zar 1984).

\section{Results}

\section{Harvest}

Basil. Basil yields averaged 1.4 and $3.4 \mathrm{~kg} / \mathrm{m}^{2}$ in 2001 and 2002, respectively, demonstrating a significant difference between years. Individual basil plants yielded more in monoculture beds than in beds with Brussels sprout companions (Table 15). Basil plants with tomato companions were smaller than plants in monoculture in 2001, but differences were not significant in 2002, or when all data were pooled (Table 15). Differences between treatments became more pronounced towards the end of each season (Figure 13). Monocultures yielded at least five times as much plant material per unit area as dicultures (Table 15). 

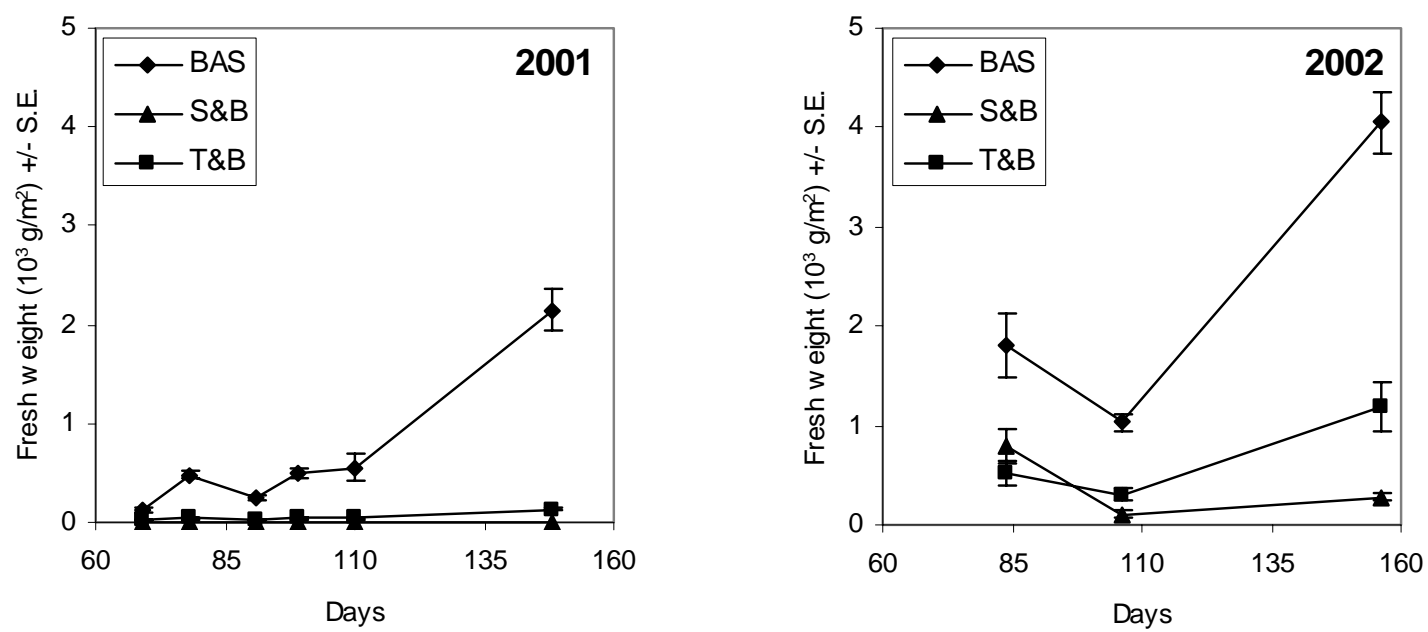

Figure 13. Fresh weight of basil removed from monoculture beds (BAS) and Brussels sprout (S\&B) or tomato (T\&B) diculture beds on each harvest day in 2001 (left) and 2002 (right). Error bars denote standard error of each mean.

Mean values for relative leaf chlorophyll content, measured in SPAD units at season end $(C)$, was correlated with the mean yield, in $\mathrm{g}(Y)$, of the final basil harvest when both seasons were pooled (Figure 14) $\left(C=3.5 \log _{10} Y+17.9, r^{2}=0.82, n=23, P<0.001\right)$. Similar relationships were found when data from 2001 $\left(C=3.4 \log _{10} Y+17.8, r^{2}=0.81, n=11, P<0.001\right)$ and $2002\left(C=3.0 \log _{10} Y+21.4, r^{2}=0.67, n=12, P<0.002\right)$ were analyzed independently. Fresh weight and SPAD values gathered from a single bed tended to cluster according to treatment within each year (Figure 14).

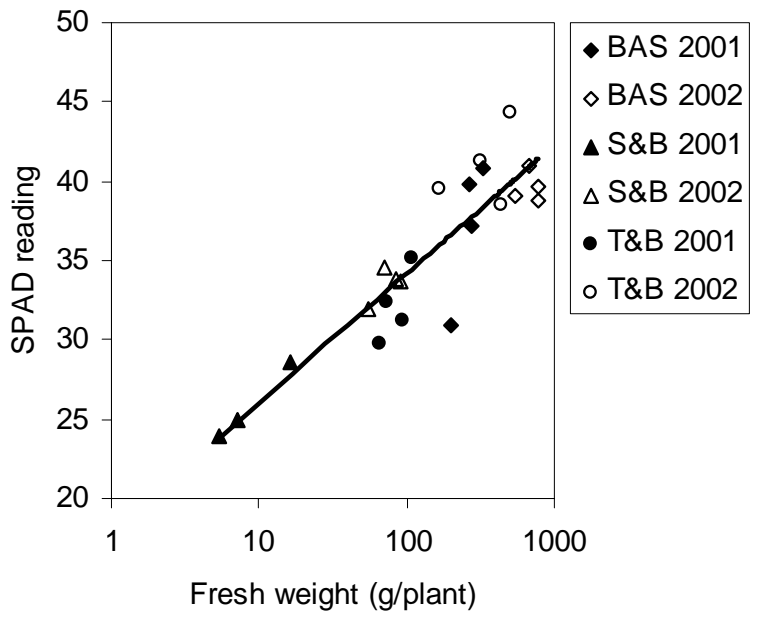

Figure 14. Relationship between relative relative chlorophyll content (SPAD reading) of basil leaves, measured with a portable chlorophyll meter (SPAD-502, Minolta Camera Co.), and fresh weight per plant at final harvest. Each data point is the mean value for a bed labeled by treatment (BAS=monoculture; $S \& B=B$ russels sprout diculture; $T \& B=$ tomato diculture) and year.

Brussels sprout. Above-ground Brussels sprout biomass removed at season end averaged 9.5 and 5.5 $\mathrm{kg} / \mathrm{m}^{2}$ in 2001 and 2002, respectively. The marketable proportion of this biomass was very low because most auxiliary buds (sprouts) did not reach a marketable size, or were too loose. Marketable sprout weight 
in 2001 averaged $6.6 \%$ of plant biomass, resulting in a linear correlation $\left(r^{2}=0.44, n=147, P<0.001\right)$ between the two quantities. Marketable weight in 2002 was $<0.3 \%$ of plant biomass.

Plants grown with basil tended to be larger than those grown in monoculture, or with tomato companions (Table 15). This tendency was significant when all data were pooled, but not for individual seasons (Table 15). Biomass produced per unit area did not differ significantly between treatments (Table 15).

No relationship was observed between plant weight and leaf chlorophyll content at season end.

Table 15. Fresh weight of aboveground plant matter removed over the growing season. For each plant type means followed by the same letter within a column are not significantly different, Tukey's test $(P<0.05)$.

\begin{tabular}{|c|c|c|c|c|c|c|}
\hline & \multicolumn{3}{|c|}{ Biomass (kg/plant \pm S.E.) } & \multicolumn{3}{|c|}{ Fresh weight $\left(\mathrm{kg} / \mathrm{m}^{2} \pm\right.$ S.E. $)$} \\
\hline & $2001(n=3)$ & $2002(n=4)$ & Pooled $(n=7)$ & $2001(n=3)$ & $2002(n=4)$ & Pooled $(n=7)$ \\
\hline \multicolumn{7}{|l|}{ Basil } \\
\hline BAS & $0.31 \pm 0.03 \mathrm{a}$ & $0.54 \pm 0.05 \mathrm{a}$ & $0.44 \pm 0.06 \mathrm{a}$ & $4.06 \pm 0.42 \mathrm{a}$ & $6.89 \pm 0.69 \mathrm{a}$ & $5.20 \pm 0.67 \mathrm{a}$ \\
\hline S\&B & $0.00 \pm 0.00 \mathrm{~b}$ & $0.22 \pm 0.03 \mathrm{~b}$ & $0.13 \pm 0.05 b$ & $0.36 \pm 0.00 \mathrm{~b}$ & $1.19 \pm 0.15 b$ & $0.69 \pm 0.25 b$ \\
\hline $\mathrm{T} \& \mathrm{~B}$ & $0.05 \pm 0.00 \mathrm{~b}$ & $0.42 \pm 0.09 \mathrm{ab}$ & $0.35 \pm 0.06 \mathrm{a}$ & $0.30 \pm 0.03 \mathrm{~b}$ & $2.00 \pm 0.40 \mathrm{~b}$ & $0.96 \pm 0.37 \mathrm{~b}$ \\
\hline \multicolumn{7}{|c|}{ Brussels sprout } \\
\hline SPT & $1.98 \pm 0.25 \mathrm{a}$ & $0.94 \pm 0.14 \mathrm{ab}$ & $1.38 \pm 0.24 b$ & $11.25 \pm 1.39 \mathrm{a}$ & $5.33 \pm 0.79 \mathrm{a}$ & $7.87 \pm 1.37 \mathrm{a}$ \\
\hline S\&B & $3.60 \pm 0.49 \mathrm{a}$ & $2.32 \pm 0.05 \mathrm{a}$ & $2.87 \pm 0.32 \mathrm{a}$ & $10.15 \pm 1.36 \mathrm{a}$ & $6.54 \pm 0.15 \mathrm{a}$ & $8.09 \pm 0.90 \mathrm{a}$ \\
\hline $\mathrm{T} \& \mathrm{~S}$ & $2.14 \pm 0.12 \mathrm{a}$ & $1.41 \pm 0.15 \mathrm{~b}$ & $1.73 \pm 0.17 b$ & $7.19 \pm 0.41 \mathrm{a}$ & $4.74 \pm 0.51 \mathrm{a}$ & $5.79 \pm 0.59 \mathrm{a}$ \\
\hline \multicolumn{7}{|c|}{ Tomato } \\
\hline TOM & $3.36 \pm 0.32 b$ & $1.58 \pm 0.09 \mathrm{ab}$ & $2.47 \pm 0.43 b$ & $13.38 \pm 2.47 \mathrm{a}$ & $7.30 \pm 0.43 \mathrm{a}$ & $10.92 \pm 1.76 \mathrm{a}$ \\
\hline $\mathrm{T} \& \mathrm{~B}$ & $5.67 \pm 0.41 \mathrm{a}$ & $2.77 \pm 0.21 \mathrm{a}$ & $3.92 \pm 0.58 \mathrm{a}$ & $16.41 \pm 1.18 \mathrm{a}$ & $6.88 \pm 0.53 \mathrm{a}$ & $11.70 \pm 1.90 \mathrm{a}$ \\
\hline $\mathrm{T} \& \mathrm{~S}$ & $2.65 \pm 0.62 b$ & $1.45 \pm 0.16 \mathrm{~b}$ & $1.96 \pm 0.35 b$ & $5.42 \pm 1.27 \mathrm{~b}$ & $2.54 \pm 0.28 b$ & $3.77 \pm 0.77 b$ \\
\hline
\end{tabular}

Tomato. More tomato plant biomass was removed in $2001\left(12.3 \mathrm{~kg} / \mathrm{m}^{2}\right)$ than in $2002\left(5.7 \mathrm{~kg} / \mathrm{m}^{2}\right)$. Fruit accounted for most ( $88 \%$ in $2001 ; 77 \%$ in 2002) of this biomass. The mean weight of individual tomatoes did not differ significantly between years (134 \pm 4 and $121 \pm 3 \mathrm{~g}$ /fruit in 2001 and 2002, respectively), but each plant produced more fruits in $2001(28.3 \pm 3.0)$ than in $2002(15.8 \pm 1.4)$, reflecting a shorter harvest period, and a lower yield per harvest in 2002 (Figure 15).

Tomato plants grown with basil produced more fruits per plant $(27.7 \pm 3.4)$, than those grown in monoculture (20.6 \pm 3.3$)$ or with Brussels sprout companions (15.2 \pm 2.1$)$. Plants grown with basil companions produced more biomass per plant than those grown in monoculture, or with Brussels sprout companions (Table 15). Those grown with Brussels sprout companions produced less biomass per unit area than those grown in monoculture, or with basil companions (Table 15). Differences between treatments tended to be most pronounced when overall yields were comparatively high (Figure 15).

No significant relationship was found between leaf chlorophyll content and biomass removed during 2001 . Chlorophyll content was not measured at harvest in 2002. 

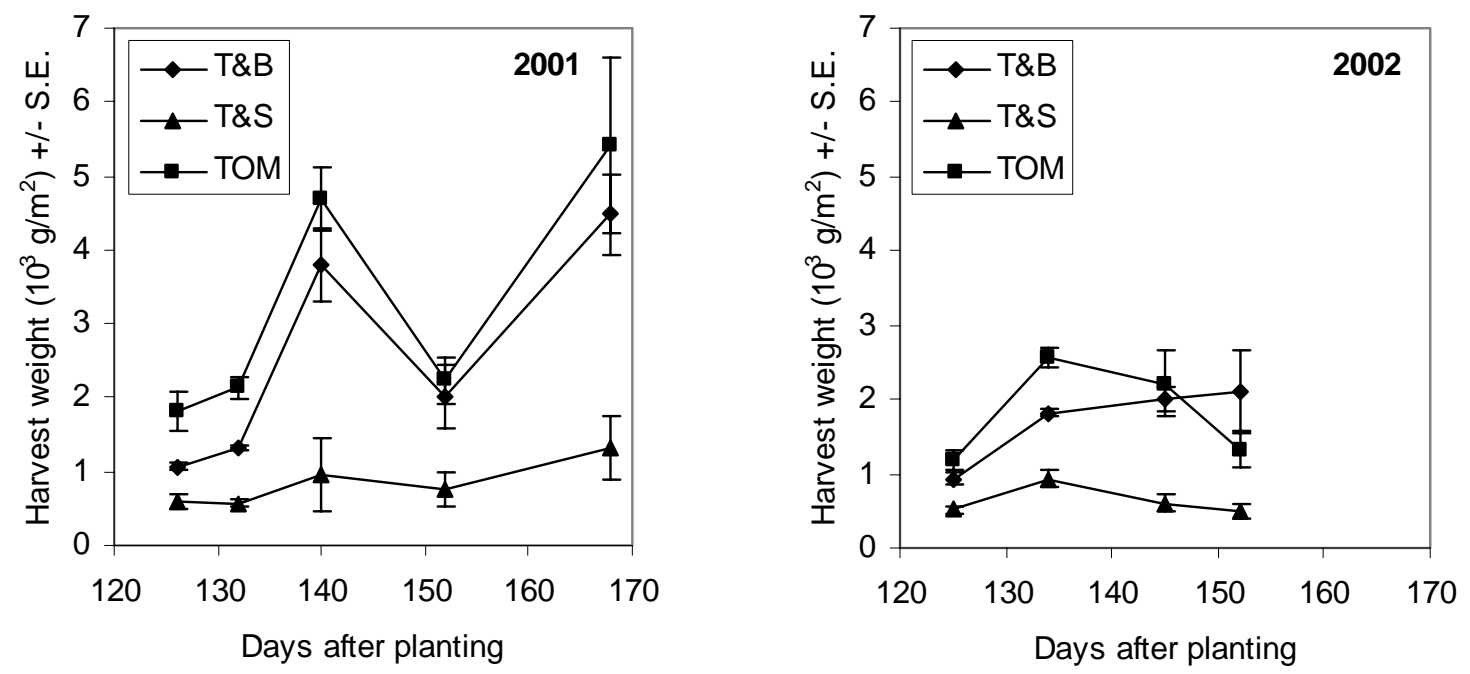

Figure 15. Tomato yield on each harvest day in 2001 (left) and 2002 (right), separated by treatment (TOM=monoculture; $T \& B=b a s i l$ diculture; $T \& S=B r u s s e l s ~ s p r o u t ~ d i c u l t u r e)$. Error bars denote standard error of each mean.

\section{Land equivalence ratios}

Land equivalence ratios ranged from 1.08, for tomato and Brussels sprout dicultures, to 1.16 for the other dicultures (Table 16). Although these ratios all exceeded 1.0, diculture yields were not significantly greater than monoculture yields (Table 16). Neither tomato nor Brussels sprout yields were reduced by intercropping with basil companions, but basil yields were lower in diculture than in monoculture (Table 16). When tomato and Brussels sprout were combined in diculture the yields of both component crops were lower than in monoculture (Table 16).

Table 16. Contributions of component crops to total Land Equivalence Ratio (LER) for three companion plant combinations $(\bar{x} \pm$ S.E. $)$.

\begin{tabular}{lcccc}
\hline Companion & \multicolumn{2}{c}{ Contribution to LER $(\overline{\boldsymbol{x}} \pm$ S.E. $)$} & LER \\
\cline { 2 - 4 } Combination & Tomato & Basil & Brussels sprout & \pm S.E. \\
\hline S\&B & - & $0.13 \pm 0.39$ & $1.03 \pm 0.21$ & $1.16 \pm 0.44$ \\
T\&B & $0.98 \pm 0.24$ & $0.18 \pm 0.41$ & - & $1.16 \pm 0.47$ \\
T\&S & $0.35 \pm 0.26$ & - & $0.74 \pm 0.20$ & $1.08 \pm 0.33$ \\
\hline
\end{tabular}

\section{Canopy light penetration}

Measurements of sunfleck proportions gave an indication of plants' potential to intercept

photosynthetically active radiation in the treatments tested. As each growing season progressed plant canopies tended to cover more of the soil surface, reducing the sunfleck proportion. This trend was 
apparent in basil monocultures in both seasons, but was more evident in 2002 than in 2001 for the other treatments (Figure 16).

In 2001 differences between treatments were most pronounced during the first monitoring session, on 26 June. Sunflecks covered almost twice as much of the soil surface in basil monocultures (96\%) as in tomato and basil dicultures (55\%). The canopies of tomato monocultures and Brussels sprout and basil dicultures already covered most of the soil surface, allowing only 18 and $26 \%$ of direct sunlight to penetrate, respectively. Canopies of Brussels sprout monocultures and tomato and Brussels sprout dicultures offered almost complete cover, with just 3 and $4 \%$ of sunlight reaching the soil surface (Figure 16). As the season progressed the treatments containing Brussels sprouts and the tomato monocultures filled in, so that no differences could be detected between them. The basil monocultures also filled in, but continued to allow more light to penetrate the canopy than other treatments until the final monitoring session, when they did not differ from the tomato monocultures or the tomato and basil dicultures. The tomato and basil dicultures did not fill in as substantially as the other crops, so that one-third of the soil surface was still exposed to direct sunlight by mid-August (Figure 16).

When all sampling dates were pooled basil monocultures and tomato and basil dicultures were found to allow more direct sunlight to reach the soil surface than other treatments (Figure 17, left).
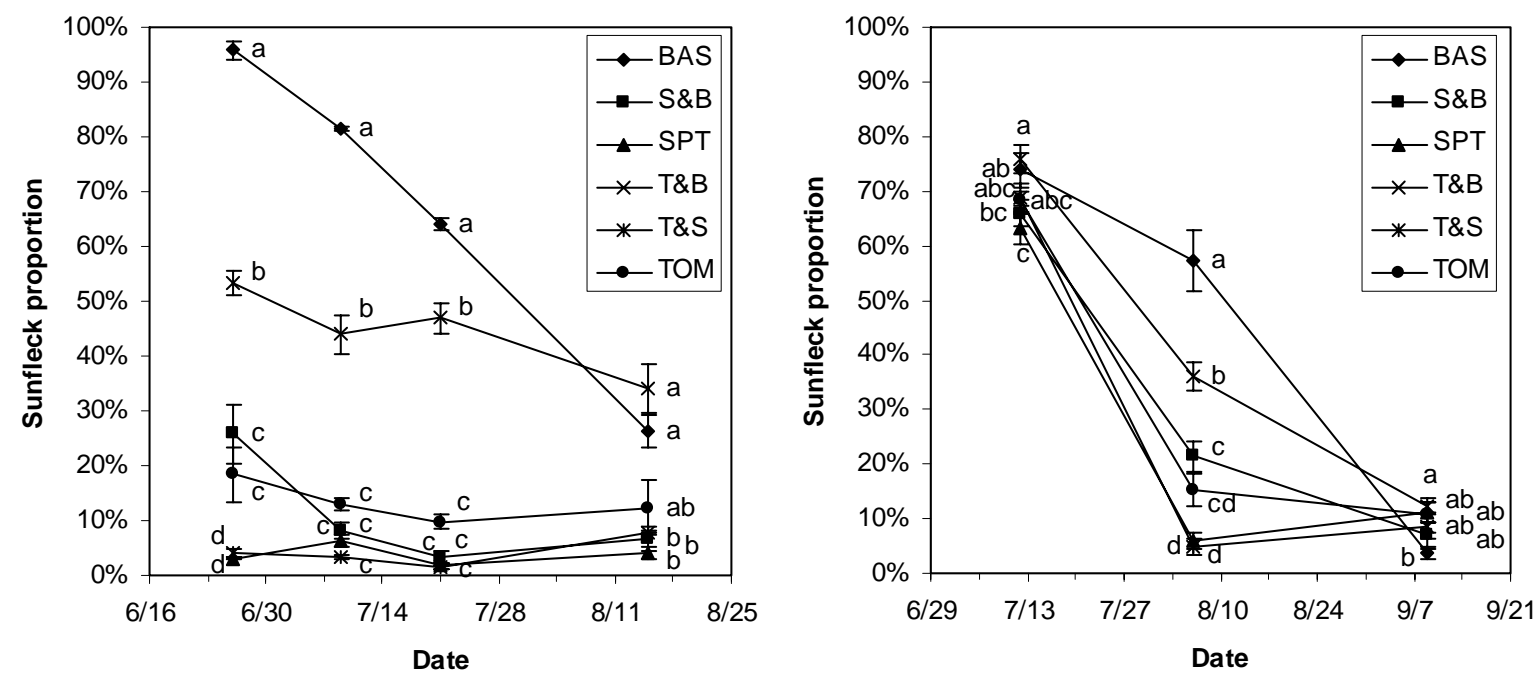

Figure 16. Proportion of soil surface exposed to direct sunlight in monocultures of basil (BAS), Brussels sprout (SPT) and tomato (TOM) and dicultures of Brussels sprout and basil (S\&B), tomato and basil (T\&B), and tomato and Brussels sprout (T\&S) during 2001 (left, $n=3$ ) and 2002 (right, $n=4)$. Means labeled with the same letter for a single monitoring date are not significantly different (Tukey's test, $P<0.05$ ). Error bars denote standard errors of each mean. 

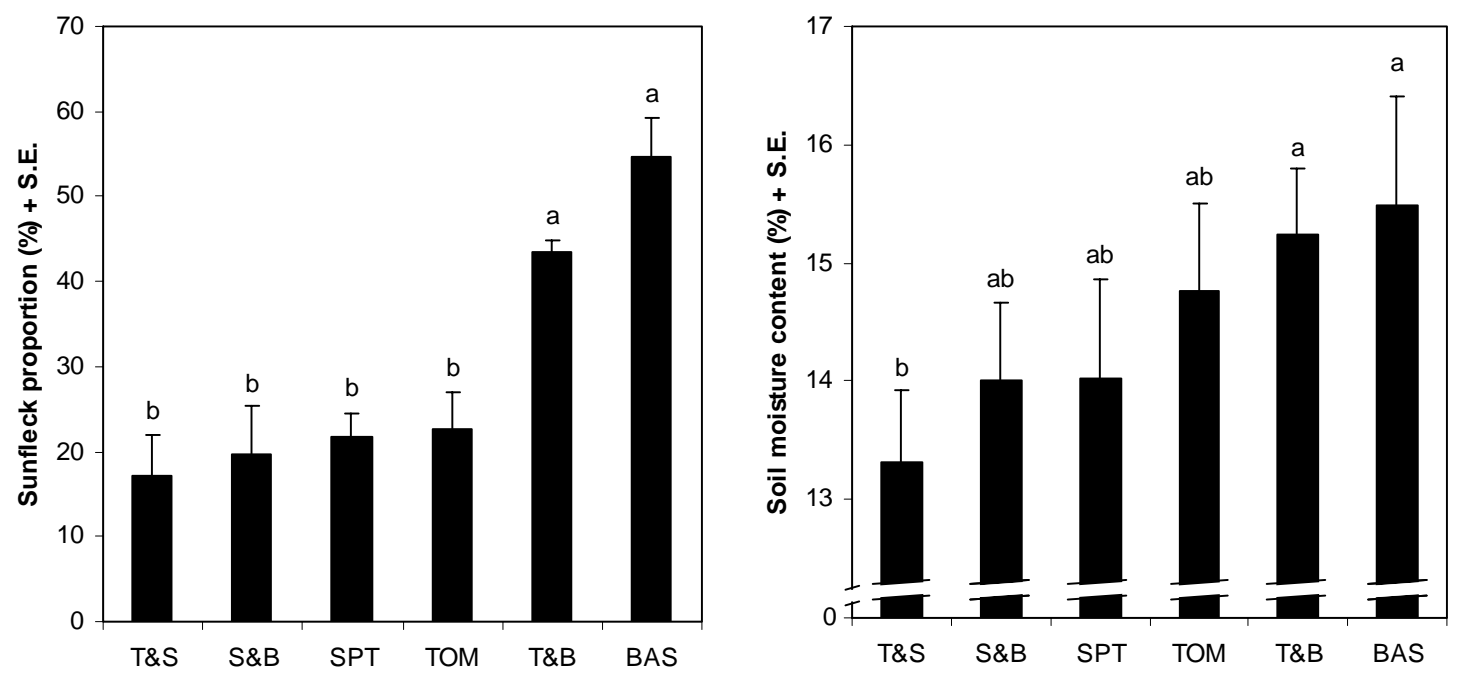

Figure 17. The proportion of the soil surface exposed to direct sunlight (left) and the volumetric soil water content (right) show similar patterns. Treatments were monocultures of basil (BAS), Brussels sprout (SPT) and tomato (TOM) or dicultures of Brussels sprout and basil (S\&B), tomato and basil $(T \& B)$, and tomato and Brussels sprout $(T \& S)$. Bars marked with the same letter are not significantly different (Tukey's test, $P<0.05, n=7$ ). Error bars denote standard error of the mean.

All but the basil monocultures filled in later in 2002 than in 2001. The soil surface exposed to direct sunlight when monitoring began (13 July) ranged from 63 to 74\% (Figure 16). Differences became more pronounced mid-season (6 August), reflecting the trends observed early in the season of 2001: Brussels sprout monocultures and tomato and Brussels sprout dicultures allowed the least sunlight to penetrate their canopies, tomato and basil dicultures intercepted just over half of the direct sunlight, and the most sunlight penetrated basil monoculture canopies (Figure 16). Monitoring extended into September of 2002, by which point all canopies had filled in substantially, basil monocultures allowed significantly less sunlight to penetrate than tomato and basil dicultures (Figure 16).

\section{Soil moisture}

Due to equipment problems in 2001, no soil moisture readings were taken before all canopies filled in. Between early August and early September of 2001 soil moisture content tended to increase. A significant treatment effect $(P=0.02)$ was detected on 7 August, 2001, with basil monocultures and tomato and basil dicultures appearing to have higher soil moisture levels than the treatments with Brussels sprouts, but the Tukey's test did not detect significant differences between any two means (Figure 18). No treatment effect was found on the remaining monitoring days in 2001.

Soil moisture content fell between mid-July and mid-September of 2002. Significant treatment effects were detected on 8 August $(P<0.001)$ and 8 September $(P=0.007)$ (Figure 18). 

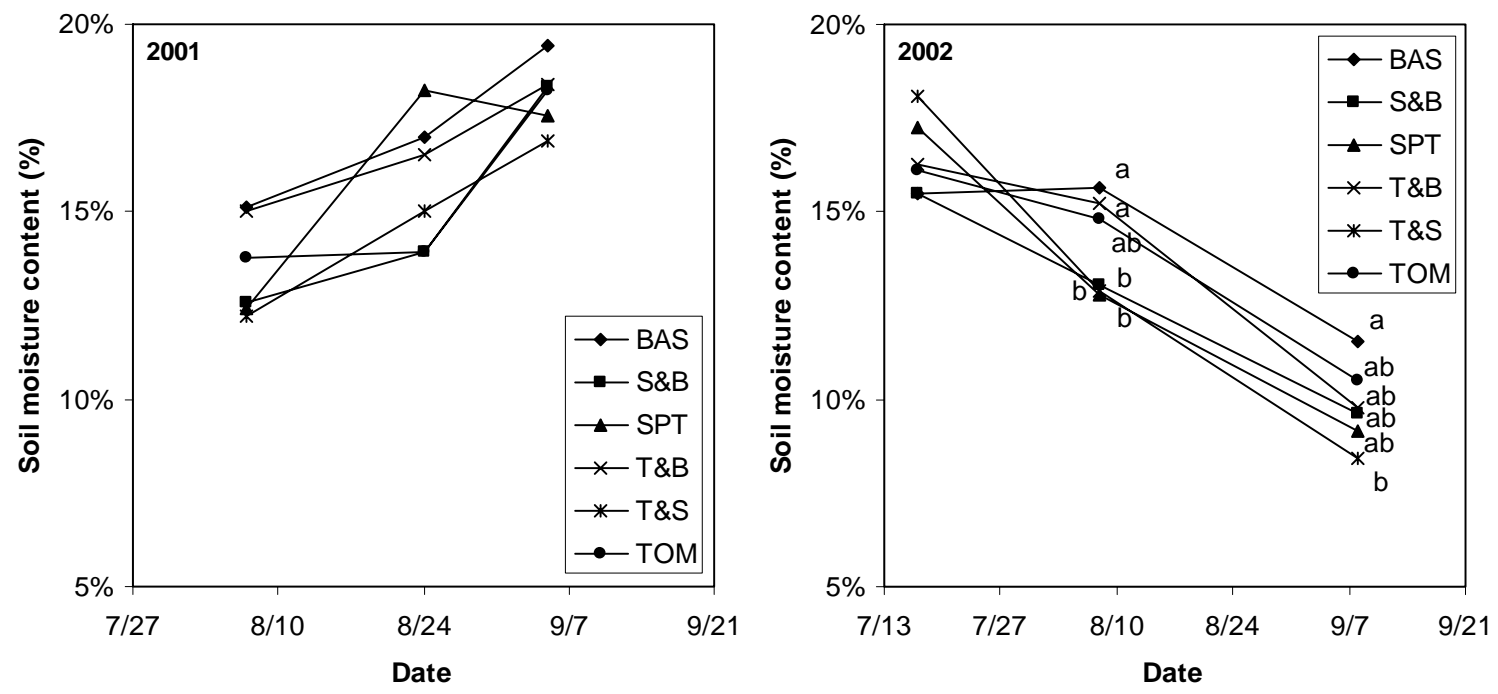

Figure 18. Volumetric soil water content in the top $20 \mathrm{~cm}$ by treatment and sampling date in 2001 (left) and 2002 (right). Points on a single sampling date followed by the same letter, or no letter, are not significantly different (Tukey's test, $P<0.05$ ).

When all sampling dates were pooled basil monocultures and tomato and basil dicultures were found to have a higher volumetric soil water content than tomato and Brussels sprout dicultures (Figure 17, right). Treatments ranked by volumetric soil water content fell in the same order as treatments ranked by sunlight penetration through the canopy (Figure 17).

\section{Tomato taste tests}

Companion planting did not alter tomato taste, and refrigeration had inconsistent effects on taste. In 2001 tasters found refrigerated tomatoes sweeter than unrefrigerated tomatoes; in 2002 they found refrigerated tomatoes less sweet (Table 17). In 2002 tasters found test tomatoes grown in monoculture less acidic than the standard tomatoes grown in the same beds (Table 17). No treatment effect was detected when data from both years were pooled (Table 17). 
Table 17. Tomato taste test ratings by blind tasters comparing fruit grown in monoculture beds or diculture beds to standard fruit grown in monoculture beds. Sweetness, acidity, "true tomato flavor" and personal preference for each test tomato was compared to a standard on a scale of -2 (much less than standard) to 2 (much more than standard).

\begin{tabular}{|c|c|c|c|c|}
\hline \multirow[b]{2}{*}{ Companion crop } & \multicolumn{4}{|c|}{ Taster rating $(\bar{x} \pm$ S.E. $(n))$} \\
\hline & Sweetness & Acidity & True tomato flavor & Personal preference \\
\hline \multicolumn{5}{|l|}{2001} \\
\hline None & $0.16 \pm 0.21(32)$ & $0.13 \pm 0.18(32)$ & $0.09 \pm 0.16(32)$ & $0.25 \pm 0.19(32)$ \\
\hline Basil & $-0.13 \pm 0.21(32)$ & $-0.31 \pm 0.16(32)$ & $0.13 \pm 0.14$ & $0.13 \pm 0.19$ \\
\hline Brussels sprout & $0.25 \pm 0.21(32)$ & $0.09 \pm 0.18(32)$ & $0.16 \pm 0.15(32)$ & $0.19 \pm 0.23(32)$ \\
\hline None (refrigerated) & $0.45 \pm 0.19(32)^{* *}$ & $-0.19 \pm 0.19(32)$ & $0.28 \pm 0.17(32)$ & $0.25 \pm 0.18(32)$ \\
\hline \multicolumn{5}{|l|}{2002} \\
\hline None & $0.30 \pm 0.22(30)$ & $-0.33 \pm 0.15(30)^{*}$ & $-0.10 \pm 0.22(30)$ & $0.13 \pm 0.22(30)$ \\
\hline Basil & $0.23 \pm 0.19(30)$ & $0.21 \pm 0.19(29)$ & $0.21 \pm 0.17(29)$ & $0.27 \pm 0.22(30)$ \\
\hline Brussels sprout & $0.20 \pm 0.23(30)$ & $-0.13 \pm 0.20(30)$ & $0.03 \pm 0.23(30)$ & $0.07 \pm 0.20(29)$ \\
\hline None (refrigerated) & $-0.57 \pm 0.22(30)^{*}$ & $0.07 \pm 0.23(30)$ & $-0.07 \pm 0.20(30)$ & $-0.30 \pm 0.22(30)$ \\
\hline \multicolumn{5}{|l|}{ Pooled } \\
\hline None & $0.23 \pm 0.15(62)$ & $-0.01 \pm 0.12(62)$ & $0.00 \pm 0.13(62)$ & $0.19 \pm 0.14(62)$ \\
\hline Basil & $0.05 \pm 0.14(62)$ & $-0.07 \pm 0.13(61)$ & $0.16 \pm 0.11(61)$ & $0.20 \pm 0.14(61)$ \\
\hline Brussels sprout & $0.23 \pm 0.15(62)$ & $-0.02 \pm 0.14(62)$ & $0.10 \pm 0.13(62)$ & $0.13 \pm 0.15(62)$ \\
\hline None (refrigerated) & $-0.04 \pm 0.16(62)$ & $-0.06 \pm 0.15(62)$ & $0.11 \pm 0.13(62)$ & $-0.02 \pm 0.14(62)$ \\
\hline
\end{tabular}

*Different from standard $(P<0.05), * *(P<0.01)$

\section{Pest surveys}

Basil. Only one phytophagous insect was routinely found on basil: the palestriped flea beetle, Systena blanda (Melsheimer). It was not found in significant numbers in 2001, but occurred more frequently on basil in monoculture than in diculture in 2002 (Table 18).

Table 18. Total palestriped flea beetles, Systena blanda, found on basil in systematic leaf surveys in 2002. Means followed by the same letter are not significantly different (Tukey's test, $P<0.05$ ).

\begin{tabular}{ll}
\hline $\begin{array}{l}\text { Companion } \\
\text { crop }\end{array}$ & $\begin{array}{l}\text { Insects per plant } \\
(\bar{x} \pm \text { S.E. })\end{array}$ \\
\hline Monoculture & $0.88 \pm 0.21 \mathrm{a}$ \\
Brussels sprout & $0.40 \pm 0.19 \mathrm{~b}$ \\
Tomato & $0.33 \pm 0.15 \mathrm{~b}$ \\
\hline
\end{tabular}

Brussels sprout. Phytophagous insects commonly found on Brussels sprouts included moth and butterfly larvae, flea beetles, and aphids.

Larvae of the imported cabbageworm, Pieris rapae (L.), cross-striped cabbageworm, Evergestis rimosalis (Guenee), and diamondback moth, Plutella xylostella (L.) all occurred frequently in both years (Table 19), causing considerable feeding damage. Only the imported cabbageworm showed a significant response to treatment, occurring more commonly on Brussels sprouts grown with basil than on those grown in 
monoculture when data in 2001, and when egg and larval counts were added and both years were pooled (Table 19). Imported cabbageworm adults were often seen feeding on flowering basil plants.

Table 19. Counts of commonly occurring phytophagous Lepidoptera on Brussels sprout leaves during systematic leaf surveys. Means followed by the same letter within a column are not significantly different (Tukey's test, $P<0.05$ ).

\begin{tabular}{|c|c|c|c|c|c|}
\hline \multirow{3}{*}{$\begin{array}{l}\text { Companion } \\
\text { crop }\end{array}$} & \multicolumn{5}{|c|}{ Insects per leaf $(\bar{x} \pm$ S.E. $)$} \\
\hline & \multirow{2}{*}{$\begin{array}{c}\text { Cross-striped } \\
\text { cabbageworm } \\
\text { larva }\end{array}$} & \multicolumn{3}{|c|}{ Imported cabbageworm } & \multirow{2}{*}{$\begin{array}{l}\text { Diamond- } \\
\text { back larva }\end{array}$} \\
\hline & & egg & larva & egg+larva & \\
\hline \multicolumn{6}{|l|}{$2001(n=3)$} \\
\hline Monoculture & $0.76 \pm 0.02 \mathrm{a}$ & $3.80 \pm 0.38 \mathrm{a}$ & $3.36 \pm 0.17 \mathrm{a}$ & $7.15 \pm 0.27 \mathrm{a}$ & $0.36 \pm 0.12 \mathrm{a}$ \\
\hline Basil & $1.44 \pm 0.28 \mathrm{a}$ & $3.81 \pm 0.31 \mathrm{a}$ & $5.22 \pm 0.15 b$ & $9.02 \pm 0.39 \mathrm{a}$ & $0.61 \pm 0.39 \mathrm{a}$ \\
\hline Tomato & $1.24 \pm 0.71 \mathrm{a}$ & $4.11 \pm 1.21 \mathrm{a}$ & $4.53 \pm 0.17 \mathrm{ab}$ & $8.64 \pm 1.37 \mathrm{a}$ & $0.49 \pm 0.39 \mathrm{a}$ \\
\hline \multicolumn{6}{|l|}{$2002(n=4)$} \\
\hline Monoculture & $0.83 \pm 0.03 \mathrm{a}$ & $1.70 \pm 0.20 \mathrm{a}$ & $1.88 \pm 0.40 \mathrm{a}$ & $3.58 \pm 0.40 \mathrm{a}$ & $0.06 \pm 0.12 \mathrm{a}$ \\
\hline Basil & $1.50 \pm 0.17 \mathrm{a}$ & $2.70 \pm 0.54 \mathrm{a}$ & $1.68 \pm 0.33 \mathrm{a}$ & $5.48 \pm 0.57 \mathrm{a}$ & $0.56 \pm 0.54 \mathrm{a}$ \\
\hline Tomato & $1.15 \pm 0.39 \mathrm{a}$ & $2.73 \pm 1.84 \mathrm{a}$ & $2.65 \pm 0.37 b$ & $4.30 \pm 0.43 \mathrm{a}$ & $0.22 \pm 0.09 \mathrm{a}$ \\
\hline \multicolumn{6}{|l|}{ Pooled $(n=7)$} \\
\hline Monoculture & $0.80 \pm 0.16 \mathrm{a}$ & $2.60 \pm 0.46 \mathrm{a}$ & $2.51 \pm 0.37 \mathrm{a}$ & $5.11 \pm 0.76 \mathrm{a}$ & $0.33 \pm 0.20 \mathrm{a}$ \\
\hline Basil & $1.48 \pm 0.14 \mathrm{a}$ & $3.17 \pm 0.38 \mathrm{a}$ & $3.20 \pm 0.74 \mathrm{a}$ & $7.00 \pm 0.79 b$ & $0.58 \pm 0.08 \mathrm{a}$ \\
\hline Tomato & $1.19 \pm 0.34 \mathrm{a}$ & $3.32 \pm 0.59 \mathrm{a}$ & $3.45 \pm 0.46 \mathrm{a}$ & $6.16 \pm 1.06 \mathrm{ab}$ & $0.33 \pm 0.16 \mathrm{a}$ \\
\hline
\end{tabular}

The striped flea beetle, Phylollotreta striolata (Fabricius) occurred more frequently on Brussels sprouts grown with basil than on plants grown in monoculture, or with tomato companions (Table 20). This effect was significant in 2002, and when data from both years were pooled, but not in 2001 (Table 20).

Table 20. Counts of the striped flea beetle, $P$. striolata, found on Brussels sprout leaves during systematic surveys. Means followed by the same letter within a column are not significantly different (Tukey's test, $P<0.05$ ).

\begin{tabular}{lccc}
\hline & \multicolumn{3}{c}{ Insects per leaf $(\overline{\boldsymbol{x}} \pm$ S.E.) } \\
\cline { 2 - 4 } Companion crop & $\mathbf{2 0 0 1}(\boldsymbol{n}=\mathbf{3})$ & $\mathbf{2 0 0 2}(\boldsymbol{n}=\mathbf{4})$ & Pooled $(\boldsymbol{n}=\mathbf{7})$ \\
\hline Monoculture & $0.24 \pm 0.08 \mathrm{a}$ & $1.25 \pm 0.21 \mathrm{a}$ & $0.82 \pm 0.23 \mathrm{a}$ \\
Basil & $0.39 \pm 0.23 \mathrm{a}$ & $3.50 \pm 0.50 \mathrm{~b}$ & $2.17 \pm 0.69 \mathrm{~b}$ \\
Tomato & $0.07 \pm 0.04 \mathrm{a}$ & $1.12 \pm 0.43 \mathrm{a}$ & $0.67 \pm 0.31 \mathrm{a}$ \\
\hline
\end{tabular}

Cabbage aphids, Brevicoryne brassicae (L.), were rarely seen during 2001, but were more common in 2002, particularly towards the end of the growing season. A detailed cabbage aphid survey at the end of 2002 showed no difference in infestation rates between treatments (Table 21). Aphids parasitized by braconid wasps could be found in all treatments, but the level of parasitism did not differ between treatments (Table 21). 
Table 21. Occurrence of the cabbage aphid, B. brassicae, on Brussels sprout leaves in the final monitoring session of 2002. Counts of aphid clusters containing up to 50 aphids are reported. Groups larger than 50 were considered multiple clusters (e.g. 125 aphids $=3$ clusters). Individual aphids parasitized by braconid wasps (mummies) are reported separately. Means followed by the same letter within a column are not significantly different (Tukey's test, $P<0.05$ ).

\begin{tabular}{lcc}
\hline & \multicolumn{2}{c}{ Insects per leaf $(\overline{\boldsymbol{x}} \pm$ S.E. $)$} \\
\cline { 2 - 3 } Companion crop & Cabbage aphid cluster & Mummies \\
\hline Monoculture & $0.52 \pm 0.20 \mathrm{a}$ & $1.53 \pm 0.91 \mathrm{a}$ \\
Basil & $0.79 \pm 0.63 \mathrm{a}$ & $0.33 \pm 0.25 \mathrm{a}$ \\
Tomato & $1.87 \pm 0.98 \mathrm{a}$ & $1.37 \pm 0.78 \mathrm{a}$ \\
\hline
\end{tabular}

Tomato. The potato aphid, Macrosiphum euphorbiae (Thomas), was the only phytophagous pest consistently seen on tomatoes in both seasons (Table 22). The higher counts in 2001 than 2002 reflects more intensive monitoring in 2001 (Figure 12), not necessarily a difference in infestation rates between years.

Table 22. Counts of the potato aphid, M. euphorbiae, found on tomato leaves during systematic surveys. Means followed by the same letter within a column are not significantly different (Tukey's test, $P<0.05)$.

\begin{tabular}{lccc}
\hline & \multicolumn{3}{c}{ Insects per leaf $(\overline{\boldsymbol{x}} \pm$ S.E. $)$} \\
\cline { 2 - 4 } Companion crop & $\mathbf{2 0 0 1}(\boldsymbol{n}=\mathbf{3})$ & $\mathbf{2 0 0 2}(\boldsymbol{n}=\mathbf{4})$ & Pooled $(\boldsymbol{n}=\mathbf{7})$ \\
\hline Monoculture & $5.58 \pm 2.04 \mathrm{a}$ & $0.77 \pm 0.35 \mathrm{a}$ & $2.83 \pm 1.25 \mathrm{a}$ \\
Basil & $4.81 \pm 2.14 \mathrm{a}$ & $0.90 \pm 0.30 \mathrm{a}$ & $2.57 \pm 1.14 \mathrm{a}$ \\
Tomato & $5.13 \pm 1.18 \mathrm{a}$ & $0.97 \pm 0.38 \mathrm{a}$ & $2.75 \pm 0.97 \mathrm{a}$ \\
\hline
\end{tabular}

The aphid midge, Aphidoletes aphidimyza (Rondani), and aphids "mummies," caused by parasitism of aphids by Aphidiid wasps, were found occasionally in all treatments in both years, but counts did not differ significantly between treatments (data not shown). During the single survey in 2002 the ratio of $M$. euphorbiae:A. aphidimyza was $4.6 \pm 1.0$, down sharply from $17.9 \pm 4.4$ in 2001 and $25.9 \pm 3.2$ in the preliminary study in 2000

Early blight of tomato, Alternaria solani (Ellis \& Martin), was the only disease that routinely damaged any of the crops. The proportion of tomato leaves infected with the fungus differed between replicates in 2001 $(P<0.01)$, but did not differ between treatments in either year (Table 23). When data from both years were pooled tomatoes grown with Brussels sprout companions were found to have more infected leaves than those grown with basil companions (Table 23). Infection rates of tomatoes grown in monoculture did not differ from those grown with companion crops (Table 23). In-season monitoring detected no treatment effect on the number of early blight lesions per leaf or the average lesion size. 
Table 23. Proportion of tomato leaves with early blight, $A$. solani, lesions at final harvest. Means followed by the same letter within a column are not significantly different (Tukey's test, $P<0.05$ ).

\begin{tabular}{lccc}
\hline & & Infected leaves $(\%)(\overline{\boldsymbol{x}} \pm$ S.E.) & Pooled (n=7) \\
\cline { 2 - 4 } Companion crop & $\mathbf{2 0 0 1}(\boldsymbol{n}=\mathbf{3})$ & $\mathbf{2 0 0 2}(\boldsymbol{n}=\mathbf{4})$ & $50 \pm 7 \mathrm{ab}$ \\
\hline Monoculture & $55 \pm 15 \mathrm{a}$ & $34 \pm 6 \mathrm{a}$ & $41 \pm 6 \mathrm{~b}$ \\
Basil & $50 \pm 14 \mathrm{a}$ & $58 \pm 7 \mathrm{a}$ & $58 \pm 6 \mathrm{a}$ \\
Brussels sprout & $59 \pm 11 \mathrm{a}$ & & \\
\hline
\end{tabular}

\section{Discussion}

The dicultures tested were $8-16 \%$ more productive than monocultures, but these differences were not significant. This observation fits with the report that average diculture yields are $12-13 \%$ greater than monoculture yields (Jolliffe 1997). Dicultures consisting of popularly recommended companions (i.e. tomato or Brussels sprout with basil) did not offer a substantial yield advantage over a diculture consisting of a popularly discouraged combination (tomato and Brussels sprout).

Since basil was clearly dominated by its companions (Table 16), it would be considered the subordinate crop in the dominant/subordinant mixtures it occupied in this study. Polycultures offer yield advantages over monocultures when the competition between species is weaker than the competition among species (Joliffe and Wanjau 1999). This is generally the case for the dominant species in a dominant/subordinate mixture, but not for the subordinate species. The overall polyculture effect is due to the net advantage or disadvantage when the effects on both the dominant and subordinate species are considered together. In this study the disadvantage to basil - caused by the fact that its tomato and Brussels sprout companions competed more vigorously than other basil plants - was outweighed by the advantage its companions gained from basil's relatively low competetiveness. From a practical perspective a grower who wishes to maximize land use efficiency might consider planting basil with tomatoes or Brussels sprouts, but a grower solely interested in maximizing basil yield would not.

The observation that tomato and Brussels sprout dicultures make at least as efficient use of land as tomato or Brussels sprout monocultures challenges the popular notion that tomatoes should not be planted with brassicas. This result compliments the observation that cabbage-tomato intercrops produce yields, production costs, and net returns comparable to either crop grown alone (Brown et al. 1985).

Sunfleck proportion and soil moisture content measurements gave some indication of the degree of competition for light and water, two fundamental resources for plant growth. Differences between treatments were similar for both resources, with basil competing least vigorously for light and moisture and Brussels sprouts competing most vigorously (Figure 17).

This study demonstrated a relationship between SPAD readings and basil yield, with mean values clustered by treatment within each year (Figure 14), but no relationship between SPAD readings and tomato or 
Brussels sprout yield. The SPAD-502 chlorophyll meter measures the transmission through a leaf of red light at a wavelength absorbed by chlorophyll $(650 \mathrm{~nm})$ and infra-red light at a wavelength not absorbed by chlorophyll $(940 \mathrm{~nm})$. On the basis of these readings it computes a SPAD (Soil Plant Analysis

Development) value as

$$
\mathrm{SPAD}=\log \left[\left(\mathrm{I}_{940}^{\prime} / \mathrm{I}_{940}\right) /\left(\mathrm{I}_{650}^{\prime} / I_{650}\right)\right]=\log \left[\left(\mathrm{I}_{940}^{\prime} I_{650}\right) /\left(\mathrm{I}_{650}^{\prime} \mathrm{I}_{940}\right)\right]
$$

where $\mathrm{I}_{650}$ and $\mathrm{I}_{940}$ are the currents produced by the red and infrared light beams respectively, and $\mathrm{I}_{650}$ and $\mathrm{I}^{\prime}{ }_{940}$ are the currents produced by the transmitted beams (Markwell et al. 1995). SPAD readings have been correlated with leaf chlorophyll content, on an area basis, in grain crops including rice (Jiang and Vergara 1986), corn (Dwyer et al. 1991), wheat, barley, and triticale (Giunta et al. 2002).

Because leaf chlorophyll content is closely related to leaf nitrogen content, SPAD readings have been highly correlated with leaf nitrogen content and yield of several crops, including corn (Blackmer and Schepers 1994), potato (Gianquinto et al. 2003) and cabbage (Westerveld et al. 2003). Other crops, such as carrot and onion, have not demonstrated such correlations, and the correlation for cabbage was not consistent between years (Westerveld et al. 2003). When nitrogen deficiency is not a growth-limiting factor leaf nitrogen content is not correlated with yield. For example, a comparison of organic and conventional tomatoes reports higher leaf $\mathrm{N}$ content, and SPAD readings, for the conventional plants, but superior yields from the organic plants (Martini et al. 2004). Since previous studies have shown SPAD readings to correlate with yields of both tomato and cabbage, I suggest that the lack of a relationship in this study indicated that tomato and Brussels sprout yields were not limited by nitrogen. The qualitative observation that Brussels sprouts tended to be bitter and produce elongated sprouts supports this suggestion, since these Brussels sprout characteristics are associated with excess nitrogen (Rahn et al. 1993).

The competitiveness of Brussels sprout plants observed in this study contrasted with the poor ability of Brussels sprout to compete for resources in the preliminary study. Although planting densities and spatial arrangements differed somewhat between the two studies, planting time was the most substantial difference. In the preliminary study Brussels sprout plants were transplanted into the field in August, well after their companion crops. In this study Brussels sprouts were planted before their companion crops. Given the head start the crop was able to compete well. The interaction between companion crops, therefore, is likely related to both crop choice and relative planting time (Connolly et al. 2001).

Untrained blind taste panels did not find any differences between tomatoes grown in monoculture and those grown in diculture (Table 17). The differences found in the preliminary study were not noticed in this study, suggesting that the preliminary study differences were not due to interactions between tomato plants and their companions. The differences observed in this study were all differences between monoculture treatments. Tasters found refrigerated tomatoes to be sweeter than unrefrigerated tomatoes in 2001, but 
reported that refrigerated tomatoes were sweeter in 2002. The apparent contradiction may suggest a random statistical error, but might also be due to differing degrees of tomato ripeness at the time of harvest or refrigeration. Tomato flavor is largely determined by the ratio of sugars (fructose and glucose) to acids (citric and malic acid), which increases during the ripening process after acid peaks at the mature green stage (Rick 1978). Tasters are usually unable to determine absolute sweetness (sugar content) or acidity (acid content). A balance between the two factors is perceived as a mild flavor, while the sweetness of two tomatoes with the differing acid contents can be judged differently even if sugar contents are equivilent (Lawless and Heymann 1998b). Tomatoes provided to taste panels were matched for size and ripeness prior to each taste test, but variability between years may have contributed to the apparently contradictory results. Untrained panels are more reliably used to evaluate preference, for which there was no difference recorded between treatments, rather than to find or describe differences between products (Lawless and Heymann 1998a).

There was no evidence that basil deters the pests of tomato and brassica commonly found in this study. On the contrary, imported cabbageworm and striped flea beetle counts were higher on Brussels sprouts grown with basil than on those grown in monoculture when data from both years were pooled (Table 19, Table 20). The reduction in cross-striped cabbageworm numbers associated with basil and tomato companions in the preliminary study (Table 11) was not observed in this study (Table 19).

Brussels sprout plants with basil companions tended to be larger than plants in other beds, indicating that they suffered less competition from their neighbors (Table 15). This observation could lead to the hypothesis that imported cabbageworms and striped flea beetles found large plants more attractive than small plants. Tests for a correlation between plant weight and pest incidence shows no significant effect for striped flea beetle counts, but a significant effect for imported cabbageworm counts $\left(R^{2}=0.31, n=21, P=\right.$ 0.008 ). This effect is not significant for individual treatments. The original analysis, treating treatment and replicate as the independent variables, does a better job of explaining the variability in imported cabbageworm incidence $\left(R^{2}=0.88, n=21, P=0.0002\right)$, indicating that treatment and replicate had a stronger effect on imported cabbageworm incidence than plant weight.

Basil plants were not harvested for more than a month before the final harvest in each season (Figure 13). Some plants flowered during this period, and imported cabbageworm adults could be seen feeding on nectar from these plants. The observed treatment effect may be due to the attractiveness of flowering basil plants to imported cabbageworm adults, which then used neighboring Brussels sprout plants as oviposition sites. This hypothesis is supported by the observation of Zhao et al. (1992) that imported cabbageworm eggs were more common on broccoli intercropped with nectar-bearing plants than on broccoli grown in monoculture. Diamondback moth oviposition was also higher on plants grown among nectar-bearing companions in Zhao's study, but the number of diamondback larvae found on Brussels sprouts growing with basil companions in this study was not significantly higher than that found in monoculture (Table 19). 
Tomato companions had no significant effect on brassica pests in this study. A previous study has shown that rutin, a volatile released by tomato plants, deters oviposition by diamondback moth and imported cabbageworm adults (Tabashnik 1987). Nonetheless, two studies have reported higher imported cabbageworm counts on brassicas intercropped with tomato than on brassicas grown in monoculture (Bach and Tabisknik 1990, Maguire 1984). Though not significant, this study also showed a trend towards higher imported cabbageworm counts on Brussels sprouts with tomato companions than on those grown in monoculture beds (Table 19).

The palestriped flea beetle, which feeds on basil, was the only pest to be found in consistently lower numbers in diculture beds than in monocultures (Table 18). This is a minor pest of basil, which has not been discussed in previous intercropping studies.

Pooled data showed lower early blight incidence in tomato plants grown with basil than those grown with Brussels sprouts (Table 23). A similar reduction in early blight reported for tomato plants grown with a hairy vetch living mulch was attributed to reduced splash dispersal and leaf wetness (Mills et al. 2002). Regular basil harvests during this study maintained bushy, low-growing basil plants that opened the upper tomato canopy for improved air circulation, while covering the soil below. Leaf wetness and splash dispersal were not monitored in this study, but qualitative comparisons of the treatments suggest that basil companions had the characteristics that Mills et al. (2002) ascribe to an early blight-reducing companion, but Brussels sprout did not. The difference between early blight incidence on tomatoes with basil and Brussels sprout companions underscores the importance of canopy architecture, since both companion crops are non-hosts of early blight, and both would have offered the inoculum reductions that Smith (2002) found to be chiefly responsible for reducing early blight incidence when susceptible tomato varieties are intercropped with a resistant varieties. Although this study confounded the effects of tomato density and companion choice (Table 14) tomatoes grown with Brussels sprout companions were planted at the lowest density but had the highest incidence of early blight, suggesting that the observed differences could not be attributed sole to tomato spacing effects. 


\section{CHAPTER 4: Tri-fan Circle Study}

\section{Introduction}

The Preliminary and Biointensive studies suggested that the impact of companion planting with basil, Brussels sprout and tomato is more heavily influenced by competition than by pest dynamics. Clearly, an understanding of the competitive interactions between tomatoes, basil, and Brussels sprouts is necessary to evaluate their potential as companions.

Inter-plant competition is "the tendency of neighboring plants to utilize the same quantum of light, ion of mineral nutrient, molecule of water, or volume of space" (Grime 1977). By definition competition for a resource only occurs when that resource is limiting; there is no competition where there is excess.

The study of plant competition is actively pursued by ecologists and agronomists alike; indeed multiple cropping system studies can serve to unite the often-divergent field of ecology and agronomy (Hart 1986). Recent studies suggest that plants are able to sense the presence of neighbors before the onset of competition by distinguishing the characteristic spectrum of light reflected by nearby foliage (Ballaré et al. 1990). They respond to the information that potential competitors are nearby with rapid above-ground growth, to "get ahead" of the competition. Similarly, plants allocate more energy to root growth when other roots are nearby than when they have the soil to themselves (Maina et al. 2002).

Although each plant strives to maximize its own fitness, the result of all individuals trying to out-compete one other can be decreased community fitness, or a "tragedy of the commons" (Maina et al. 2002). The Green Revolution was largely spurred by the development of dwarf grain crops that sacrificed individual plants' competitive ability to increase whole-field yields. This strategy was successful in an environment of similarly uncompetitive plants, but has been criticized by those growing crops in polyculture (e.g. Fukuoka 1982). Nonetheless, Maina et al. (2002) recently suggested "breeding more 'docile' cultivars that do not overproduce roots in response to inter-plant competition," essentially proposing a repeat of the breeding efforts of the Green Revolution with a below-ground focus.

Polycultures also show an inverse relationship between inter-plant competition and productivity (Joliffe and Wanjau 1999). According to the ecological concept of niche differentiation, polycultures are more productive than monocultures when intra-specific competition is greater than inter-specific competition. This situation occurs when different species are able to make complementary use of slightly different environmental resources, rather than competing for the same resources.

Studies of inter-species competition using two different species commonly use one of three different experimental designs (Freckleton and Watkinson 2000, Jolliffe 2000): 
a) the single density replacement series, in which the proportion of species within mixtures is varied, and total plant density is held constant (Figure 19a);

b) the simple additive series, in which the density of one species is held constant and the density of another is varied (Figure 19b); and

c) the full additive, or complete factorial structure, in which the density of each species is varied within a range of densities (Figure 19c).
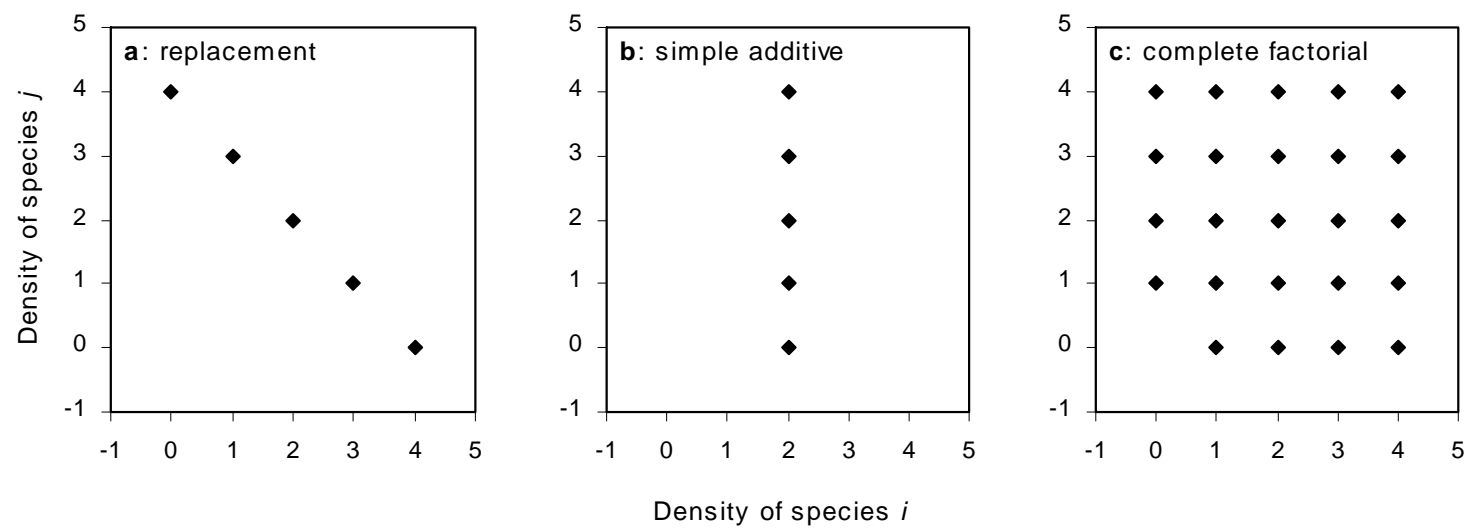

Figure 19. Experimental designs commonly used in competition studies to combine two species at different densities. (a) Single density replacement series, in which total plant density is held constant while species density varies. (b) Simple additive series, in which density of species $i$ is held constant while density of species $j$ and total density vary. (c) Complete binary factorial structure, in which the density of each species is varied along with the total density.

Each design has advantages and disadvantages, and the debate in the scientific press about which is most appropriate "has become emotionally charged" (Jolliffe 2000). The replacement series has been the most widely used, accounting for $50 \%$ of the competition studies published in 11 leading journals between 1984 and 1993 (Gibson et al. 1999). A replacement series can determine which of two species is the superior competitor with relatively few sampling units, and can be used to calculate several commonly used indices comparing yields of polyculture to monoculture (Weigelt and Jolliffe 2003). The design confounds species density and proportion, so it is impossible to tell whether a change in yield is due to the decline in density of one species or the increase in density of the other, and impossible to distinguish between inter-species and intra-species competition (Jolliffe 2000). The total constant planting density used in replacement series is often arbitrary. According to Gibson et al. (1999), "the tendency to misuse the method is so pervasive that its continued use should be discouraged."

Simple additive series have often been used by weed scientists, who examine the effect of weed competition on crops by holding crop density constant while varying weed density within the crop. The effects of species ratio and overall density are confounded: Some argue that these are not meaningful parameters (e.g. Snaydon 1991); others disagree (e.g. Sackville-Hamilton 1994). Since only one species is 
tested in monoculture it is impossible to compare polyculture and monoculture yields in situations where both species are considered desirable crop plants. According to Freckleton and Watkinson (2000), "the most that a simple additive approach can achieve is to demonstrate that competition is taking place."

The complete factorial design addresses many of the shortcomings of simple additive and replacement series: It allows experimenters to distinguish between inter-species and intra-species competition; it does not confound crop density and ratio; and it allows regression analysis, which is considered the most robust statistical method for analyzing competition studies (Freckleton and Watkinson 2000). The technique has been little used, however, due to the sheer size of complete factorial experiments. As Figure 19 demonstrates, a full factorial design covering five crop densities requires 24 experimental units; a replacement or simple additive designs covering the same range of densities require only 5 experimental units. Complete factorial designs simultaneously measure effects of density and crop ratio, requiring multifactor analysis. This is seen as an advantage by some, because "it is much more efficient to ask several questions in a single experiment through the use of factorial structure than by the previous philosophy of controlling all factors except one in each experiment" (Mead 1986). Others see danger in the complexity of factorial designs. Cousens (1991), for example, cautions "we are only just managing to clear up mistakes made in two dimensions without encouraging everyone into three dimensions."

Plant response to density is often tested using plant spacing gradients, or 'fan designs' (Nelder 1962), in which plants are arranged in an expanding lattice (e.g. hexagonal fan array, Figure 20). Similarly, crop ratio gradients can be used to study the effects of species composition in diculture (Boffey and Veevers 1977). Gradients are useful because plants are affected only by near neighbors, not by overall density (Antonovics and Fowler 1985). They are amenable to regression analysis, and are considerably more economical than testing distinct plots.

Researchers in North Wales first proposed that density and ratio gradients could be combined into a single design (Antonovics and Fowler 1985). Two studies conducted at the University College of North Wales demonstrated the efficiency and usefulness of such designs (Antonovics and Fowler 1985, Schmid and Harper 1985). A greenhouse study with 285 sage (Salvia splendens, Sello) and flax (Linum grandifolium, Desf.) plants arranged in $50 \times 75 \mathrm{~cm}$ semi-circles was conducted "to illustrate the usefulness of hexagonal fan designs for studying two-species interactions under a range of densities and frequencies" (Antonovics and Fowler 1985). The authors concluded that "such designs do give consistent and meaningful information." They also commented on the economy of such a design, noting that their study used only one-quarter the number of plants and one-tenth the area that would be required to examine the same range of frequencies and densities using separate plots (Antonovics and Fowler 1985). A second study looked at interactions between lawn daisy (Bellis perennis L.) and selfheal (Prunella vulgaris L.), noting that the daisy was more aggressive than the herb at high densities, but the difference was reversed at low densities (Schmid and Harper 1985). This observation not only demonstrated the importance of conducting plant 
competition studies at a range of densities, but also showed that designs incorporating both density and species competition gradients could provide unexpected results, and advance understanding of inter-plant competition.

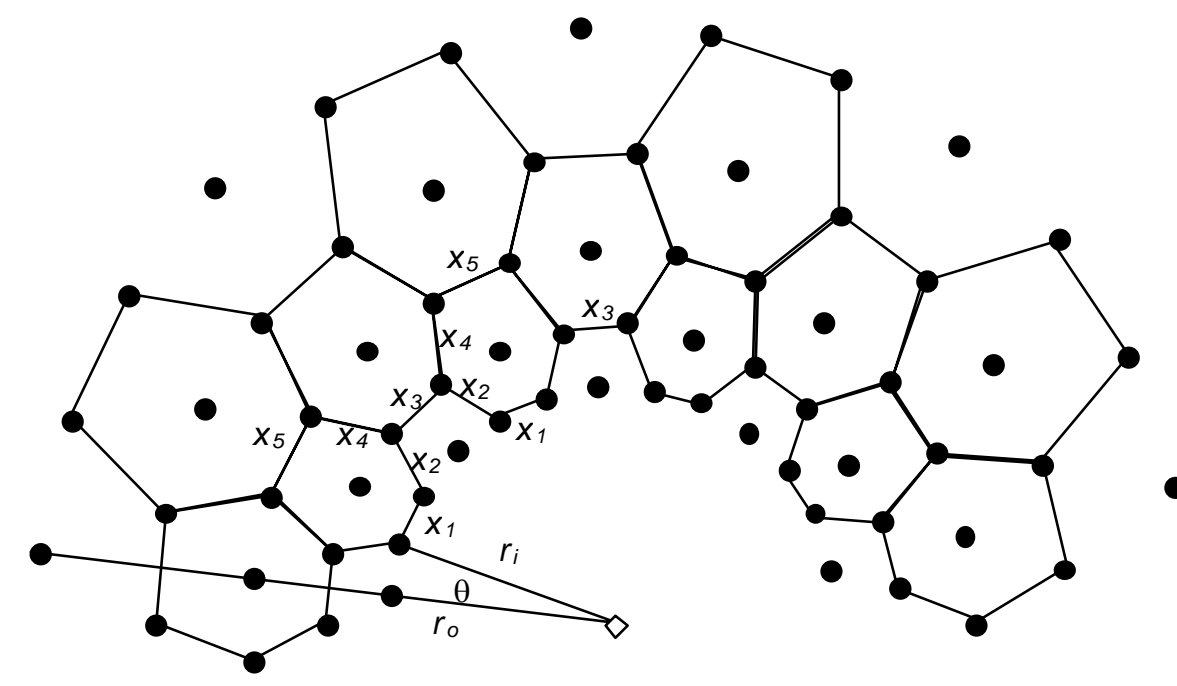

Figure 20. Hexagonal fan array used as a planting design (after Antonovics and Fowler 1985). An array is characterized by the radii of the outer $\operatorname{arc}\left(r_{o}\right)$ and inner $\operatorname{arc}\left(r_{I}\right)$, angular plant spacing within $\operatorname{arcs}(\theta)$, and angular arc length $\left(\theta\right.$ to $\left.360^{\circ}\right)$. Distance between plants within an arc increases by a constant factor, $C$, with each successive arc, such that $C x_{1}=x_{3}$ and $C x_{3}=x_{5}$. Spacing between arcs is set to reduce the range of distances to neighboring plants; in this study $x_{2}=x_{3}$ and $x_{4}=x_{5}$, but in the first published hexagonal fan design $x_{1}=x_{2}$ and $x_{3}=x_{4}$ (Antonovics and Fowler 1985).

A review of designs used to study inter-plant interactions summarized the advantages and disadvantages of hexagonal fan designs, based on the only two published reports of their use (Gibson et al. 1999):

The primary advantages of hexagonal fan designs are their focus on neighborhood interactions, their efficiency in use of space and plants, and their ability to allow assessment of interspecific interactions across a range of densities or plant spacing patterns. However there are statistical problems associated with the analysis of such designs: they are unrandomized and so may be biased due to underlying trends in fans, the correlated responses in neighborhood plants may require a more complex analysis, and they may have limitations in situations in which second or third nearest neighbor effects and more diffuse interactions are significant.

Many of the problems associated with hexagonal fan designs relate to the complexity of analysis, which was a more serious hindrance in 1979, when the first design was analyzed, than it would be today. No randomization was incorporated into the original design in order to ensure that the output would be balanced, since the computer facilities available to the researchers in 1979 could not have coped with an unbalanced design (Antonovics and Fowler 1985). The fact that the first applications of the design only looked at nearest neighbor effects on target plants was also a function of the computing power that would be necessary to evaluate more diffuse interactions, not a limitation of the design itself. After a quarter 
century of advancement in computer technology many of the limitations originally associated with the hexagonal fan design no longer exist.

Given the problems and inefficiencies associated with commonly-used designs for crop competition studies I chose to modify a hexagonal fan design to assess the effects of density and species composition in monocultures and dicultures of tomato, basil, and Brussels sprouts. Randomization was incorporated into the design to satisfy statistical assumptions. Further efficiencies were afforded by combining three fans into a complete circle, so that each monoculture could be compared to two dicultures.

\section{Materials and Methods}

\section{Study setup}

The tri-fan circle study was replicated three times in 2002 and again in 2003. Each replicate was a full circle, $10 \mathrm{~m}$ in diameter. Compost prepared from dairy manure and leaf litter was roto-tilled into the soil of each circle at a target rate of $100 \mathrm{~kg} \mathrm{~N} / \mathrm{ha}$ before drip irrigation lines were laid at $60 \mathrm{~cm}$ intervals. Each circle was covered with $50 \mu \mathrm{m}$ black plastic, to prevent weed growth, and straw mulch, to anchor the plastic and protect the soil from heat and compaction. Seedlings were transplanted in hexagonal fan arrangements, with the following values for the variables described in Figure 20: $r_{o}=5 \mathrm{~m} ; r_{i}=1.0 \mathrm{~m}$ in 2002 and $0.5 \mathrm{~m}$ in $2003 ; \theta=13.33^{\circ}$ (12 plants per arc); and angular arc length $=160^{\circ}$ (Figure 21). The formula used to determine the radius, $r$, of sequentially numbered $\operatorname{arcs}(1 \ldots x)$ was

$$
r_{x}=\left(r_{i} / 1.26\right) \mathrm{e}^{0.2338 x}
$$

so that plant spacing increased by a factor of 1.26 with each successive arc. In order to standardize arc numbering between years the sequential numbering of arcs began at 4 in 2002 and 1 in 2003.

Each fan was divided into four $40^{\circ}$ segments: two diculture segments sandwiched between two monoculture segments (Figure 21). Plant species within each arc in the diculture segments was randomized under the constraint that a 2:1 crop ratio be maintained, with the most numerous species matching the nearest monoculture (Appendix 2). To economize on monoculture segments three fans were combined into a single circle, with each fan sharing monoculture segments with the adjacent fans. This overlapping design allowed three $160^{\circ}$ fans to fit in a $360^{\circ}$ circle, and required only three monocultures, not six, to test three polycultures. The orientation and fan sequence of each circle was randomized within the constraints already described (Appendix 2). The three crops planted were tomato, basil, and Brussels sprout. Potential densities in diculture using this design are shown in Figure 23. Planting dates and seedling age at transplant are shown in Figure 24. A sample planting scheme, randomized by computer (Appendix 2), is shown in Figure 22 . 
Tomatoes were tied to stakes and suckered regularly to maintain a single dominant stem. Plants were watered by drip irrigation as needed.

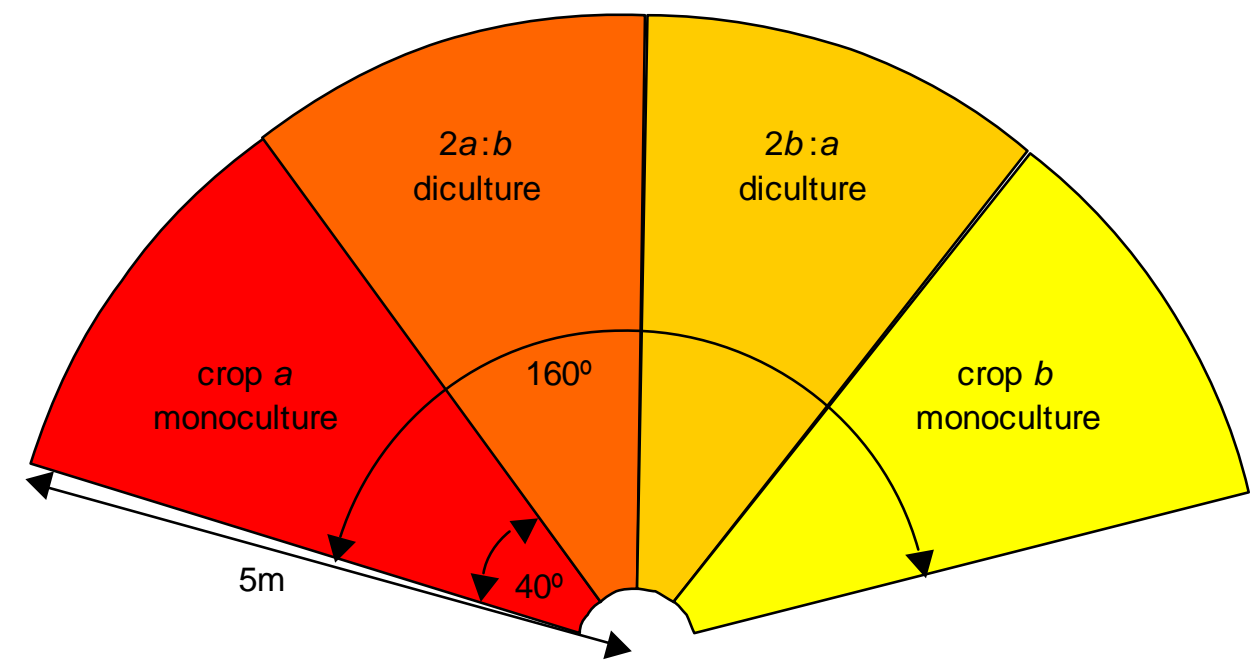

Figure 21. A single fan, divided into four equal segments of monoculture and diculture. Plants were randomly assigned to arcs in diculture segments under the constraint that a 2:1 crop ratio be present in each arc, with the most numerous species matching the species in the nearest monoculture. Here primary colors represent monocultures, and secondary colors consisting of 2:1 blends dominated by the nearest primary color represent dicultures.

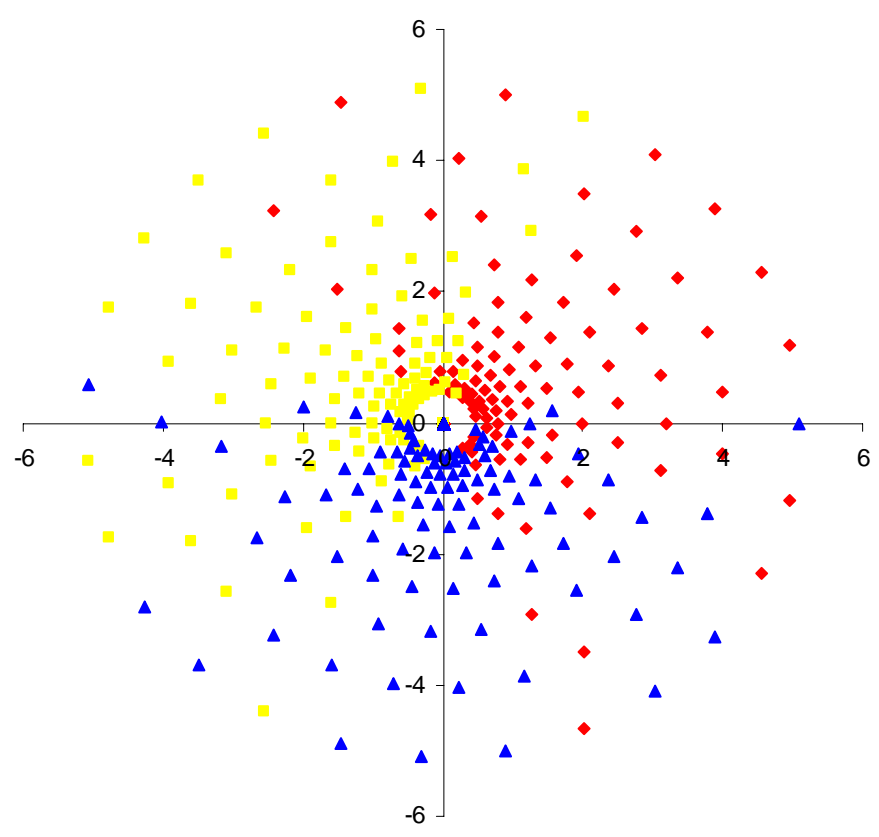

Figure 22. Sample planting scheme for tri-fan circle design. Tomatoes (red diamonds), Brussels sprouts (blue triangles), and basil (yellow squares) are arranged in concentric circles, ranging from one to ten meters in diameter. Axes show dimensions in meters. 

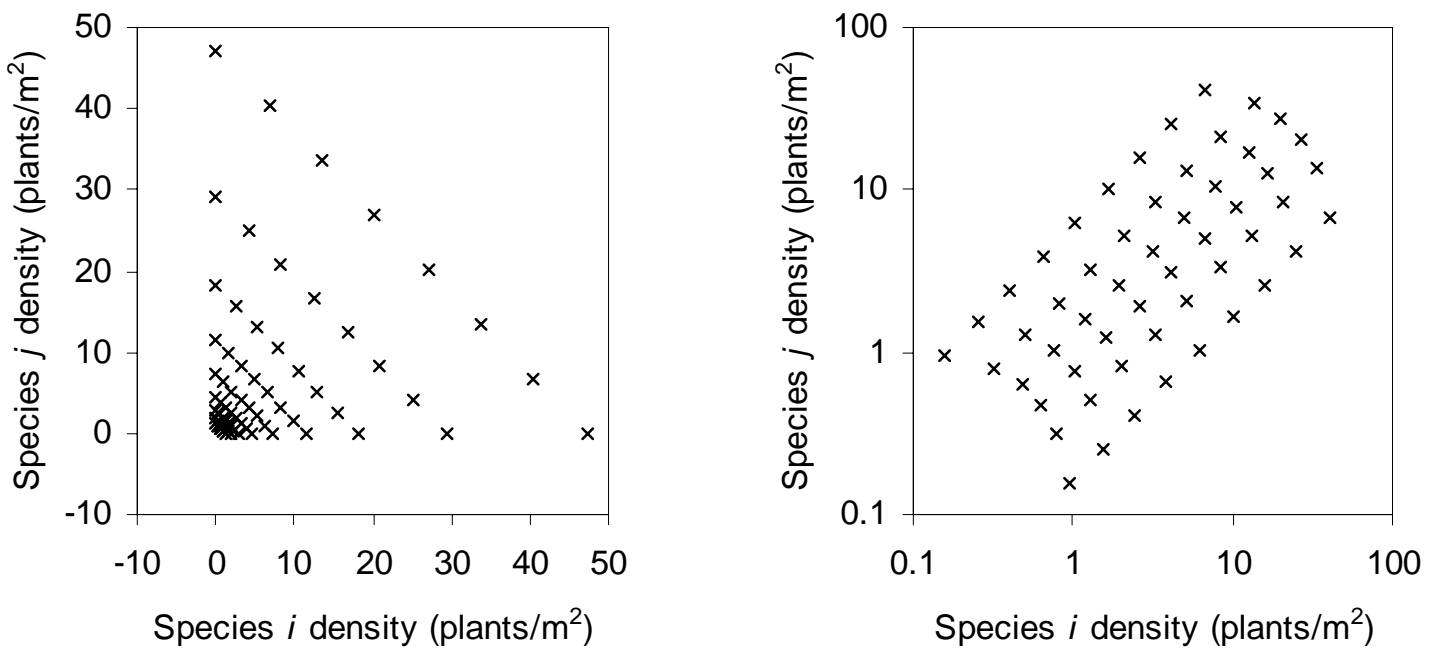

Figure 23. Possible density combinations in the tri-fan circle study, displayed on linear and log scales (left and right, respectively). The design does not simultaneously test very high densities of one species and very low densities of the other.

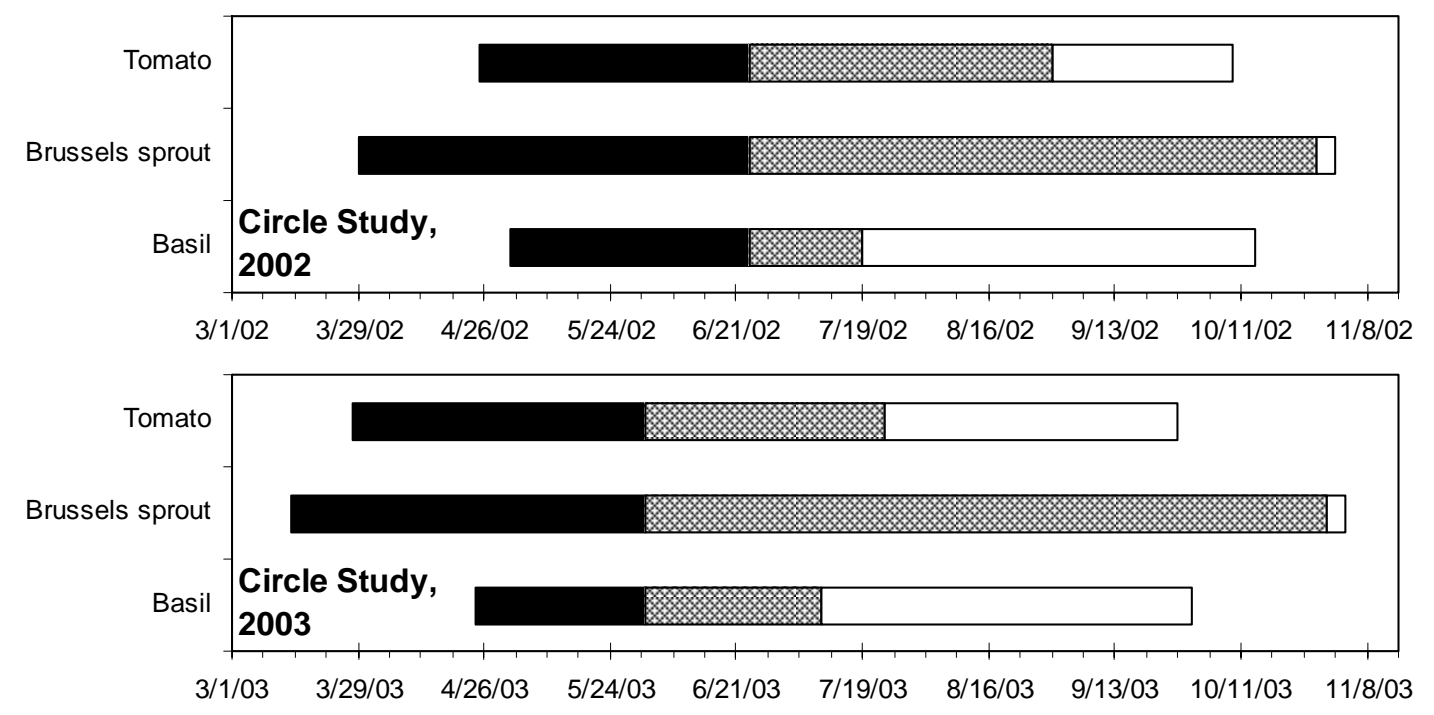

Figure 24. Temporal overlap of crops in the tri-fan circle study. Black, grey, and white bars denote periods of seeding to transplant, transplant to harvest, and harvest, respectively. 


\section{Harvest}

The inner and outer arcs were excluded from all data collection.

Tomatoes that had started to change color from green to red were harvested weekly throughout the harvest periods shown in Figure 24. All remaining tomatoes were picked during the final harvest. Blemished tomatoes, including those that had split, suffered insect feeding damage, or showed visible rot, were considered unmarketable. The total number and fresh weight of marketable and unmarketable fruits removed from each plant was recorded at each harvest. The fresh weight of above-ground vines and the length of the dominant stem was recorded for each plant after the final harvest.

Basil leaves and stems more than $15 \mathrm{~cm}$ above the soil surface were harvested four times during each season's harvest period (mean harvest interval $=27.9 \pm 3.5$ days) (Figure 24). All remaining above-ground plant matter was removed during the final harvest. The fresh weight of all material removed was recorded for each plant at each harvest.

At the end of each season above-ground Brussels sprout plant matter was removed and weighed, marketable sprouts ( $>2 \mathrm{~cm}$ in diameter with tight heads) were counted and weighed, and the length of the dominant stem was recorded for each plant.

\section{Harvest Analysis}

Table 24 summarizes the symbols used for variables discussed in this section.

Table 24. Description of variables from models used to analyze the tri-fan circle study.

\begin{tabular}{ll}
\hline Symbol & Description \\
\hline$a$ & Area $\left(\mathrm{m}^{2} /\right.$ plant) required for plants to reach $w_{\max }$ \\
$b$ & Population resource use efficiency \\
$d$ & Effect of decreasing density on plant weight \\
$i$ & Intercept (square root yield-density model) \\
$N$ & Plant density (plants $/ \mathrm{m}^{2}$ ) \\
$q$ & Number of nearest neighbors of the same species as a the target plant \\
$w$ & Aboveground fresh weight $(\mathrm{g} /$ plant) \\
$w_{\max }$ & Theoretical aboveground fresh weight ( $\mathrm{g} / \mathrm{plant}$ ) of isolated plants \\
$X$ & Arc number \\
$Y$ & Yield $\left(\mathrm{g} / \mathrm{m}^{2}\right)$ \\
$Z$ & Marginal effect of an additional neighbor of the target species on target plant weight \\
$\alpha$ & Marginal effect of an additional neighbor of the companion species on target plant weight \\
$A$ & Target species \\
$B$ & Companion species \\
$m$ & Monoculture \\
$p$ & Polyculture \\
\hline
\end{tabular}


The total fresh weight ( $w$ ), in grams, of all plant matter collected from each plant throughout each season was recorded along with the arc number $(x)$ and number of neighboring plants of the same species $(q)$. Arc numbers from 2002 were standardized to correspond to numbers used in 2003 by adding 3. Plant density $(N)$, in plants $/ \mathrm{m}^{2}$, was calculated from arc number using the formula

$$
N=119.6 \mathrm{e}^{-0.468 x}
$$

The densities of the target crop $\left(N_{A}\right)$ and companion crop $\left(N_{B}\right)$ at a given target plant location were estimated as

$$
\begin{gathered}
N_{A}=N(q+1) / 7 \\
\text { and } \\
N_{B}=N(6-q) / 7 .
\end{gathered}
$$

Linear and nonlinear regressions were used to relate density to plant weight in monoculture. All plants with six neighbors of the same species as the target plant $\left(q=6 ; \mathrm{N}_{\mathrm{A}}=N ; N_{B}=0\right)$ were included in the monoculture analysis. Data for plants grown at the same density within each replicate were pooled. Linear regression was performed on square root transformed data to find the slope $(d)$ and intercept $(i)$ of the equation

$$
w^{0.5}=d x+i
$$

where $d$ describes the effect of decreasing density on aboveground fresh weight of plants grown in monoculture. Nonlinear regression was performed on untransformed data to estimate the aboveground fresh weight of plants grown in isolation $\left(w_{\max }\right)$, the area required to achieve this weight $(a)$, and the resource use efficiency of the population (b), using the relationship derived by Watkinson (1980),

$$
w=w_{\max }(1+a N)^{-b}
$$

Three models were used to estimate response surfaces for the relationship between crop ratio, density and aboveground biomass collected from target plants in diculture. These are referred to as a) the square root yield-density model, b) the nonlinear model, and c) the inverse yield-density model.

Square root yield-density model. Square-root transformed yield data for plants grown at the same target species density $\left(N_{A}\right)$ and companion species density $\left(N_{B}\right)$ within a replicate were pooled. A linear multiple regression model was used to estimate the effects of replicate (Rep), arc number $(x)$, and number of identical neighbors $(q)$ on square root transformed biomass of target plants $\left(w^{0.5}\right)$ using the equation

$$
w^{0.5}=i+d x+z q+\operatorname{Rep}
$$


where $d$ describes the effect of decreasing density and $z$ describes the effect of an increasing number of identical neighbors on aboveground biomass.

Nonlinear model (Firbank and Watkinson 1990). All data for plants grown at the same target and companion densities were pooled. A nonlinear multiple regression analysis was used to fit parameters in the model

$$
w=w_{\max }\left[1+a\left(N_{\mathrm{A}}+\alpha N_{\mathrm{B}}\right)\right]^{-b}
$$

where $\alpha$ describes the average effect of a companion species individual on an individual from the target species and the other parameters have the characteristics already described.

Inverse yield-density model (Suehiro and Ogawa 1980). All data for plants grown at the same target and companion densities were pooled. A linear multiple regression analysis was used to fit parameters to the model

$$
w^{-1}=1 / w_{\max }+z N_{\mathrm{A}}+\alpha N_{\mathrm{B}}
$$

where $z$ describes the effect of each neighbor of the target species on a target individual and $\alpha$ is again the effect of a companion species individual on a target individual.

All models were fit using JMP software (JMP, Version 4).

Yield $(Y)$, in grams per square meter, was estimated for each plant as $Y=w N$.

Relative land outputs (RLOs) were calculated from the actual yield data and from the square root yielddensity and nonlinear response surface models as

$$
\mathrm{RLO}=\left(Y_{A}+Y_{B}\right)_{\mathrm{p}} /\left(Y_{A}+Y_{B}\right)_{\mathrm{m}}=\left[\left(w_{A}\right)_{p}(q+1)+\left(w_{B}\right)_{p}(6-q)\right] /\left[\left(w_{A}\right)_{m}(q+1)+\left(w_{A}\right)_{m}(6-q)\right]
$$

where subscripts $A$ and $B$ refer to the target and companion species, respectively, and subscripts $m$ and $p$ refer to monoculture and polyculture, respectively (Jolliffe 1997). Land Equivalence Ratios (LERs) were calculated from the square root yield-density and nonlinear response surface models as

$$
\operatorname{LER}=\left[\left(Y_{A}\right)_{\mathrm{p}} /\left(Y_{A}\right)_{\mathrm{m}}\right]+\left[\left(Y_{B}\right)_{\mathrm{p}} /\left(Y_{B}\right)_{\mathrm{m}}\right]
$$

where

$$
\left(Y_{A}\right)_{\mathrm{p}}=\left(w_{A}\right) N(q+1) / 7
$$




\section{Light penetration}

A Sunfleck ceptometer (Decagon, Pullman WA), consisting of a series of light meters along a $1 \mathrm{~m}$ bar, was used to measure canopy light penetration to the soil surface on two cloudless days in 2002 (1 August and 5 September) and three cloudless days in 2003 (17 July, 19 August, and 17 September). All samples were taken between $1000 \mathrm{~h}$ and $1500 \mathrm{~h}$. Each sample consisted of three readings, for which the ceptometer bar was rotated approximately $45^{\circ}$ between readings. Each reading recorded photosynthetically active radiation (PAR) and the proportion of ceptometer sensors exposed to direct sunlight (Sunfleck proportion). Three and four samples were taken in each circle segment in 2002 and 2003, respectively. Sample locations were evenly spaced along the centerline of each segment to cover the range of plant densities (excluding the inner and outer arcs) without overlapping (Figure 25). Two readings were taken above the crop canopy in each segment to measure incoming and reflected solar radiation. Samples were also taken at $20 \mathrm{~cm}$ intervals between the soil surface and the crop canopy at the innermost sampling location (Figure 25) of each segment in 2003.

Sample values, each consisting of the mean of three readings, were recorded along with sample location information (replicate, circle segment, mean planting density, height above soil surface). Fractional interception $(f)$ of PAR by the plant canopy was calculated for all samples collected in 2003 as

$$
f=(1-t)\left(1-r_{c}\right)
$$

where $t$ and $r_{c}$ are the fraction of incident radiation transmitted by the canopy and the canopy reflectance, respectively (Decagon Devices 1989). The relationship between fractional interception of PAR and Sunfleck \% was tested by simple linear regression. Multiple regression analysis (JMP, Version 4) was used to test the effects of replicate, circle segment, and planting density on sample readings taken at the soil surface for each sampling date, then data from all sampling dates were pooled and the analysis was repeated. A similar analysis was used to test the effects of circle segment and sample height on sample readings taken at a range of heights in the plant canopy. Where significant effects of replicate or segment were found means were separated by Tukey's test. 'Expected' Sunfleck readings were calculated for several densities in the diculture circle segments as $(2 \mathrm{~A}+\mathrm{B}) / 3$, where $\mathrm{A}$ and $\mathrm{B}$ were mean readings from equivalent densities in the nearest and next nearest monoculture segments. The difference between observed and expected values was evaluated by Chi square test (Zar 1984). 


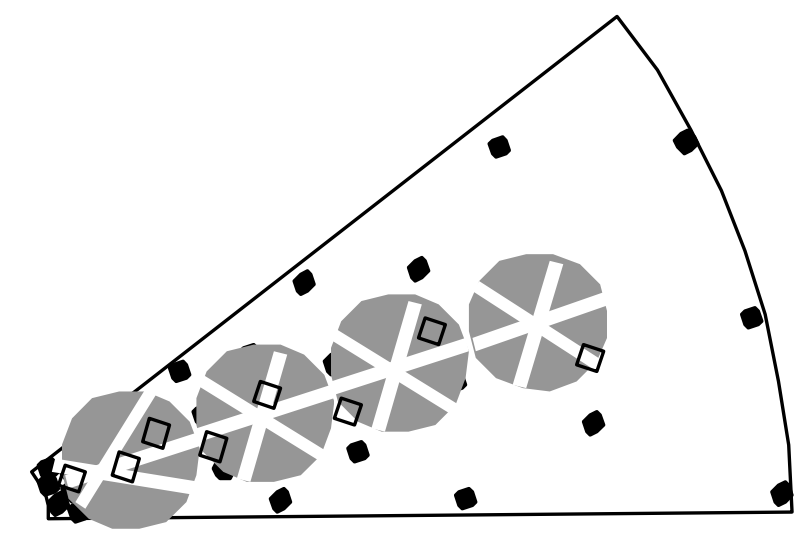

Figure 25. Approximate location of ceptometer samples (grey circles) and soil moisture readings (open diamonds) covering nine of eleven arcs of plants (black dots) in a circle segment in 2003. Each ceptometer sample was the mean of three readings, in which the bar (white line) was rotated approximately $45^{\circ}$ between readings. Sample locations were identical in 2002 except that the innermost ceptometer sample and inner two soil moisture readings were excluded because only the outer eight arcs were planted.

\section{Soil moisture}

A HydroSense Soil Moisture Meter (Spectrum Technologies, Plainfield IL) was used to measure volumetric water content (VWC) (\%) in the top $20 \mathrm{~cm}$ of soil on two days in 2002 (1 August and 5 September) and three days in 2003 (21 July, 15 August, and 18 September). Readings were taken between plants near the centerline of each circle segment in every arc except the inner and outer arcs (both years) and the $3^{\text {rd }}$ arc from the center (2003 only) (Figure 25). Multiple regression analysis (JMP, Version 4) was used to test the effects of replicate, circle segment, and planting density on VWC for each sampling date, then data from all dates were pooled and the analysis was repeated. Where significant effects of replicate or segment were found means were separated by Tukey's test. 'Expected' mean VWC readings were calculated for several densities in the diculture circle segments as $(2 \mathrm{~A}+\mathrm{B}) / 3$, where $\mathrm{A}$ and $\mathrm{B}$ were mean readings from equivalent densities in the nearest and next nearest monoculture segments. The difference between observed and expected values was evaluated by Chi square test (Zar 1984).

\section{Pest monitoring and management}

Plots were surrounded by a $90 \mathrm{~cm}$ high poultry wire fence to protect plants from groundhogs and rabbits. No systematic pest monitoring was conducted during the growing season, but regular field visits for crop management indicated a need to control Lepidoptera feeding on Brussels sprouts. A commercial formulation of Bacillus thuringiensis var. kurstaki was applied three times in each growing season (1 July, 1 August and 19 September 2002; 11 July, 21 August, and 17 September 2003).

During the final harvest of 2003 the proportion of tomato leaves killed by early blight was estimated for each tomato plant. Damage severity values were assigned to each Brussels sprout plant, recording cabbage 
aphid (Brevicoryne brassicae L.) infestation, imported cabbageworm (Pieris rapae L.) feeding, and groundhog (Marmota monax L.) feeding on a four-point scale (Table 25), based on whole-plant scans at harvest. Index values were subject to multiple regression analysis (JMP, Version 4) to test for replicate, circle segment, and density effects.

Table 25. Criteria used to assign damage ratings to individual Brussels sprout plants at harvest.

\begin{tabular}{|c|c|c|c|}
\hline $\begin{array}{l}\text { Damage } \\
\text { rating }\end{array}$ & $\begin{array}{l}\text { Severity } \\
\text { index } \\
\text { value }\end{array}$ & Cabbage aphid infestation & $\begin{array}{l}\text { Groundhog and imported } \\
\text { cabbageworm feeding damage }\end{array}$ \\
\hline None & 0 & No aphids found & No feeding damage found \\
\hline Low & 1 & $\begin{array}{l}\text { Clusters present on a minority of leaves, } \\
\text { with no cluster }>20 \text { aphids }\end{array}$ & $\begin{array}{l}\text { Damage found on a minority of } \\
\text { leaves, with }<25 \% \text { of any single leaf } \\
\text { lost to feeding }\end{array}$ \\
\hline Medium & 2 & $\begin{array}{l}\text { Small clusters present on most leaves, or } \\
\text { at least one cluster }>20 \text { aphids }\end{array}$ & $\begin{array}{l}\text { Damage to most leaves, or at least one } \\
\text { leaf with }>25 \% \text { of area lost to feeding }\end{array}$ \\
\hline High & 3 & Clusters $>20$ aphids on most leaves & $\begin{array}{l}>25 \% \text { of leaf area lost to feeding on } \\
\text { most leaves }\end{array}$ \\
\hline
\end{tabular}

\section{Results}

\section{Whole study}

A total of $1.9 \times 10^{6} \mathrm{~g}$ of aboveground plant matter was collected during the entire study (Table 26, Figure 26). Although tomato plants occupied only one-third of the study area they produced $58 \%$ of the biomass collected (Table 26, Figure 26). About three-quarters ( $74 \pm 1 \%$ ) of the tomato biomass was fruit, but only half $(55 \pm 6 \%)$ of this fruit was deemed marketable. Brussels sprouts produced almost half as much aboveground biomass as tomatoes (Table 26), but most of this was stems and leaves. The majority of sprouts that formed were too small or too loose to market, resulting in a very low marketable portion of aboveground biomass (Table 26). Basil plants produced only $15 \%$ of the plant matter collected, but had the highest proportion of marketable biomass (Table 26).

As would be expected, yields of each crop were highest in monoculture segments and lowest in those diculture segments predominantly planted to a companion species (Figure 26).

\section{Density effects in monoculture}

The tri-fan circle design revealed significant effects of density on the aboveground fresh weight of all crops in monoculture (Figure 27). Density effects $(m)$ were strongest in tomato and weakest in basil (Figure 27, Table 27). Resource utilization efficiency (b) did not differ significantly between crops (Table 28). 
Table 26. Fresh weight, and marketable portion, of all plant matter removed from tri-fan circle study.

\begin{tabular}{lccc}
\hline Weight $\left(\mathbf{k g} / \mathbf{m}^{2}\right)$ & $\begin{array}{c}\text { Total weight from } \\
\text { all replicates } \\
(\mathbf{1 0} \mathbf{~} \mathbf{g})\end{array}$ & $\begin{array}{c}\text { Marketable } \\
\text { portion (\%) } \\
\pm \text { S.E. }(\boldsymbol{n}=\mathbf{6})\end{array}$ \\
\hline Basil & $1.8 \pm 0.2$ & 2.8 & $86.7 \pm 2.6$ \\
Brussels sprout & $3.4 \pm 0.2$ & 5.2 & $1.2 \pm 0.5$ \\
Tomato & $7.1 \pm 0.7$ & 11.0 & $41.5 \pm 5.0$ \\
\hline
\end{tabular}

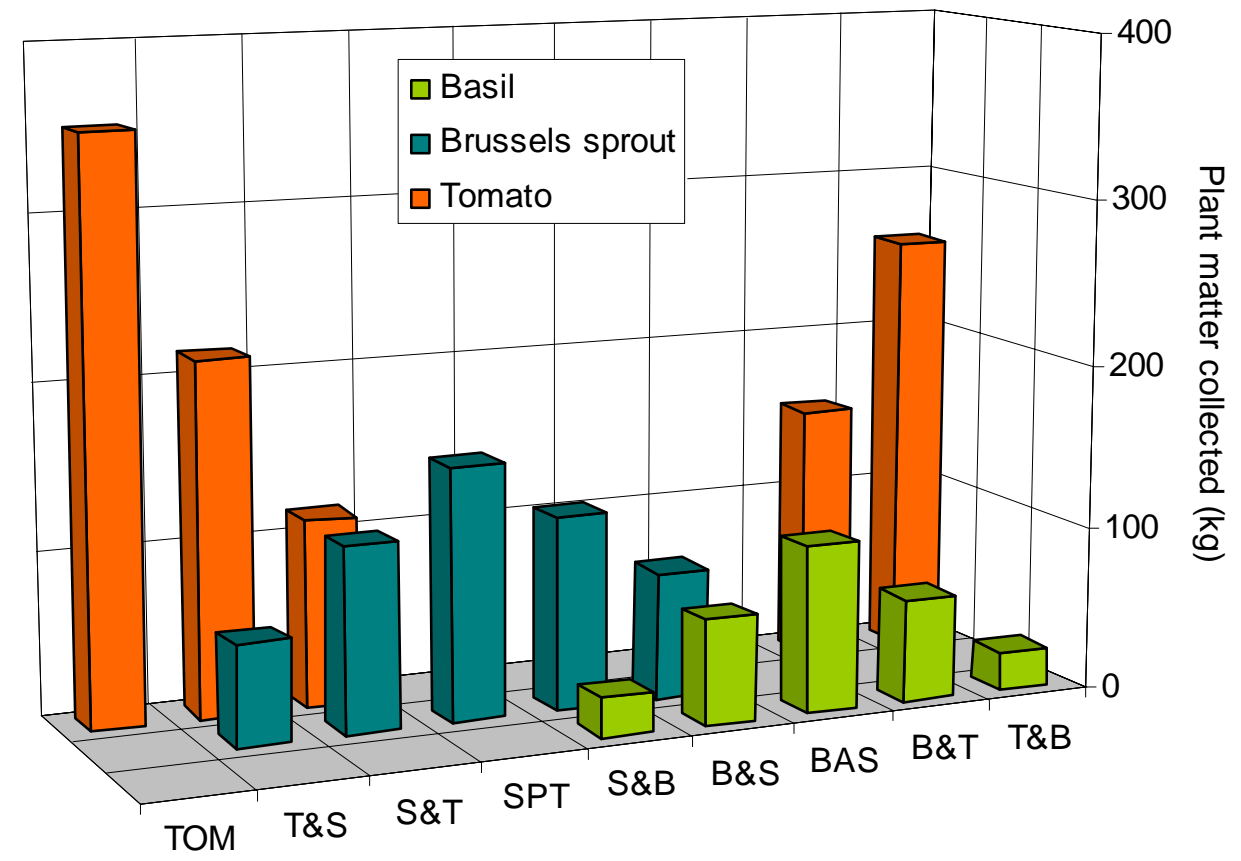

Figure 26. Total aboveground fresh weight of tomato, Brussels sprout and basil plant matter collected from each segment of tri-fan circle plots. Monoculture segments contained tomato (TOM), Brussels sprout (SPT), or basil (BAS). Diculture segments contained a 2:1 mixture of the crops grown in the nearest and next nearest monoculture segments, respectively.

Linear and non-linear models both gave a good fit to the data (Table 27, Table 28, $P<0.0001$ for all models), but the two model types predicted very different responses to densities beyond the range tested (Figure 27). The linear models predicted a more rapid decline in yield per unit area at high densities than the non-linear models (Figure 27 bottom). Both models showed mean Brussels sprout weight exceeding basil weight at low densities, but falling below basil weight at high densities (Figure 27). All models showed a better fit to the data at low densities than at the highest densities tested.

According to ecological theory increasing plant density does not result in increased biomass per unit area if the slope of the line relating log yield to log density is steeper than -1 (Westoby 1984, Sackville Hamilton et al. 1995). This threshold was reached at 7.3 plants $/ \mathrm{m}^{2}$ in the Brussels sprout monocultures, and at 18.2 plants $/ \mathrm{m}^{2}$ in the tomato and basil monocultures, according to the linear model, but at a density of $4.5,18.2$, and 47.2 plants $/ \mathrm{m}^{2}$ in the Brussels sprout, basil, and tomato monocultures, respectively, according to the 
non-linear model. Self-thinning, or the death of weaker individuals, can be expected if the slope of this same line is steeper than $-3 / 2$ (Westoby 1984, Sackville Hamilton et al. 1995). This second threshold was exceeded at 29 plants $/ \mathrm{m}^{2}$ in Brussels sprouts and 47 plants $/ \mathrm{m}^{2}$ in tomato and basil monocultures according to the linear model, but would not be reached at any density of basil or tomato according to the non-linear model.

No self thinning was observed in this study: only $19(6.0 \%)$ of the 317 plants transplanted into monoculture sections of the study died before the final harvest, and deaths were not concentrated in the highest density areas. Most of the Brussels sprout and basil deaths (55\% and 71\%, respectively) occurred in a single replicate (Reps 6 and 4, respectively). The concentration of Brussels sprout deaths was attributed to infection by Rhizoctonia solani (Kotcon, pers. comm.), but no cause was identified for the concentrated basil mortality.

Table 27. Fitted values for a linear regression of square root biomass $\left(w^{0.5}\right)$ against arc position $(x)$ where $d$ describes the effect of density (Figure 27 top left).

\begin{tabular}{lcccc}
\hline & \multicolumn{2}{c}{ Fitted values \pm S.E. for $\boldsymbol{w}^{\mathbf{0 . 5}}=\boldsymbol{d} \boldsymbol{x}+\boldsymbol{i}$} & & \\
\cline { 2 - 3 } Crop & $\boldsymbol{d}$ & $\boldsymbol{i}$ & $\boldsymbol{n}$ & $\boldsymbol{R}^{\mathbf{2}}$ \\
\hline Basil & $3.80 \pm 0.29$ & $0.69 \pm 1.61$ & 45 & 0.80 \\
Brussels sprout & $5.49 \pm 0.43$ & $-6.95 \pm 3.03$ & 44 & 0.79 \\
Tomato & $6.85 \pm 0.43$ & $1.27 \pm 3.00$ & 45 & 0.86 \\
\hline
\end{tabular}

Table 28. Fitted values for a nonlinear regression of biomass $(w)$ against planting density $(N)$ where $a$ estimates the area required by a plant to grow to its maximum size $\left(w_{\max }\right)$, and $b$ describes the resource use efficiency of the population (Figure 27 top right) (after Watkinson 1980).

\begin{tabular}{|c|c|c|c|c|c|}
\hline \multirow[b]{2}{*}{ Crop } & \multicolumn{3}{|c|}{ Fitted values \pm S.E. for $w=w_{\max }(1+a N)^{-b}$} & \multirow[b]{2}{*}{$\boldsymbol{n}$} & \multirow[b]{2}{*}{$R^{2}$} \\
\hline & $w_{\max }$ & $a$ & $b$ & & \\
\hline Basil & $1.82 \pm 0.31 \times 10^{3}$ & $2.03 \pm 2.45 \times 10^{-1}$ & $1.28 \pm 0.84$ & 45 & 0.74 \\
\hline Brussels sprout & $3.73 \pm 9.11 \times 10^{3}$ & $2.31 \pm 3.23 \times 10^{-1}$ & $1.76 \pm 1.40$ & 44 & 0.64 \\
\hline Tomato & $6.95 \pm 1.42 \times 10^{3}$ & $3.48 \pm 3.69 \times 10^{-1}$ & $1.07 \pm 0.51$ & 45 & 0.80 \\
\hline
\end{tabular}

Figure 27 (overleaf). Two estimates of the response to density of tomato $(\diamond)$, Brussels sprout $(X)$, and basil $(O)$ plants grown in monoculture. The first model (top left) is a linear regression of the mean of the square root of aboveground fresh weight $\left(w^{0.5}\right)$ against arc position $(x)\left(w^{0.5}=d x+i\right)$ where $d$ and $i$ are fitted values (Table 27). The second model (top right) is a nonlinear regression of the mean of aboveground fresh weight $(w)$ against plant density $\left(w=w_{\max }(1+a N)^{-b}\right)$ where $w_{\max }, a$, and $b$ are fitted values (Table 28). The relative spacings (arc positions) represent multiplicative increments of 1.26 from a close spacing of $14.4 \mathrm{~cm}\left(47.2 \mathrm{plants} / \mathrm{m}^{2}\right)$ at 2 to a wide spacing $0 \mathrm{c3.5} \mathrm{cm}$ $\left(1.1\right.$ plants $\left./ \mathrm{m}^{2}\right)$ at 10 . Each data point represents the mean weight of all plants grown at a given density, with standard errors. The same data points and regression lines are shown when fresh weight is plotted against density on a log-log scale (middle left and right), and multipled by plant density to give the relationship between fresh weight per unit area and density (bottom left and right). 
Square root yield-density model
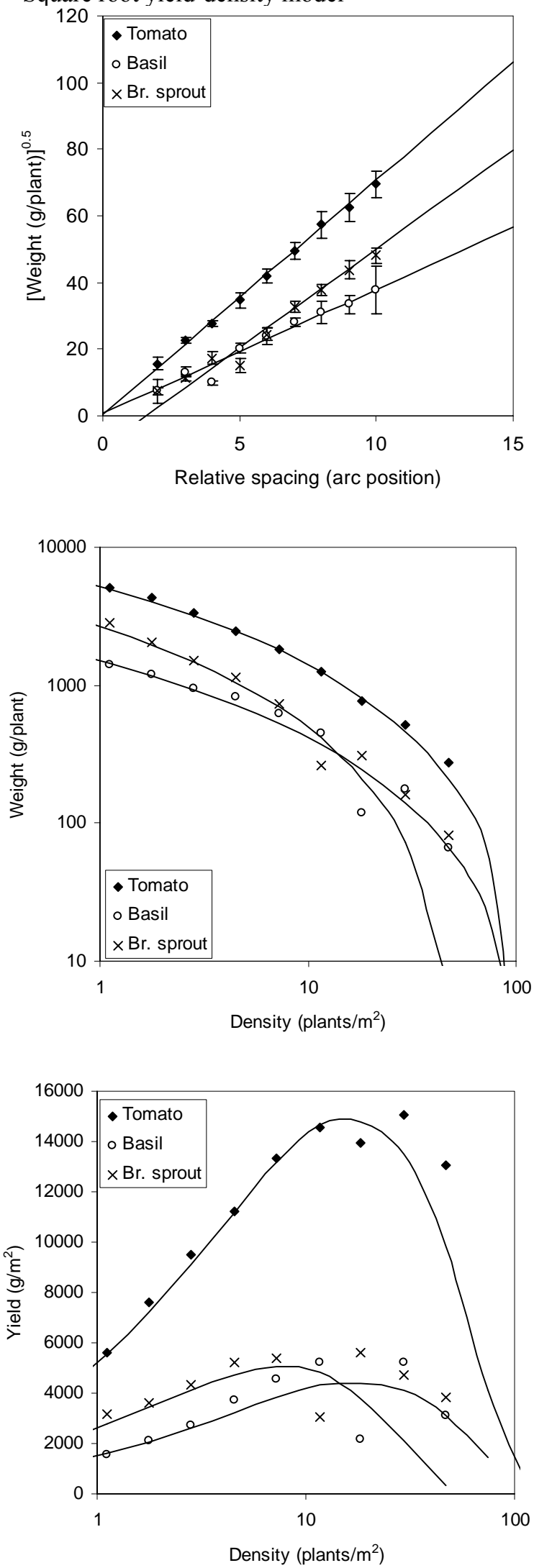

Nonlinear model
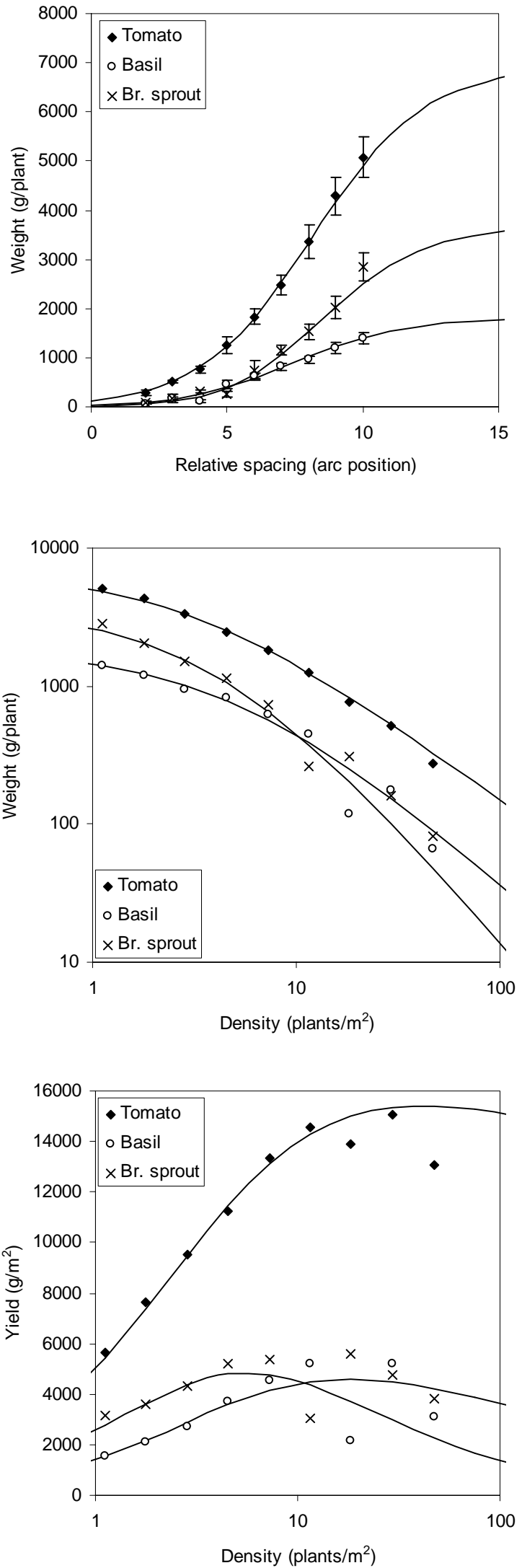


\section{Density and ratio effects in polyculture}

Figure 28 shows the total weight of plant matter collected for each crop, circle segment, and arc position in the tri-fan circles study. The figure shows the dominance of tomato decline at lower densities, as Brussels sprouts make up a larger portion of the total harvest. No similar shift is observed for basil.

Figure 29 shows aboveground plant weight of each crop at all crop ratios and densities tested. Parameters of the square root yield-density, nonlinear yield-density, and inverse yield-density models used to fit response surfaces to these data are shown in Table 29, Table 30 and Table 31, respectively. Response surfaces derived from the first two models are shown in Figure 30 and Figure 31.

All models showed plant weight to be inversely related to density. The square root yield-density model showed the density effect, $d$, to be strongest in tomato dicultures and weakest in basil dicultures (Table 29, Figure 30). Tomato grown with basil had a stronger response to density than tomato grown with Brussels sprouts, but density effects were not altered by companion species when basil or Brussels sprout were target crops (Table 29, Figure 30). Since two terms, $a$ and $b$, contributed to the density effect in the nonlinear yield-density model the magnitude of the effect could not be estimated by looking at a single number. Both terms were always positive, indicating an inverse relationship between yield and density (Table 30). The terms $a$ and $\alpha$ determined the density effects in the inverse yield-density model (Table 31 ). All values for both estimates were positive, except for a non-significant estimate of the effect of basil companions on Brussels sprouts (Table 31). This effect was outweighed by the strong effect of other Brussels sprout neighbors, resulting in a strong inverse relationship between yield and density for all terms (Table 31).

The species of the nearest neighbor of a target plant affected target plant weight under all models. The square root yield-density model showed the nearest neighbor effect, $z$, to be significant for all combinations except the tomato/Brussels sprout dicultures (Table 29, Figure 30). Basil showed a positive response to increasing numbers of basil neighbors; tomato and Brussels sprouts grown with basil companions showed a negative response to increasing numbers of same-species neighbors (Table 29, Figure 30). In other words, all of the crops tested 'preferred' basil companions to tomato or Brussels sprout neighbors. The nonlinear model involved a competition coefficient, $\alpha$, which estimated the average effect of the companion crop on the target crop. This estimate was highest when basil was the target crop, and lowest when basil was the companion crop (Table 30, Figure 31). The estimate was much closer to 1 in the tomato/Brussels sprout dicultures, indicating that the effect of companions on target individuals did not differ greatly from the effect of same-species neighbors, but that Brussels sprouts were slightly more competitive than tomatoes (Table 30, Figure 31). The inverse yield-density model showed that the effects of neighbors of the same species ( $a$ ) were always significant, and the companion effects, $\alpha$, were significant except when basil was a companion to Brussels sprout or Brussels sprout was a companion to tomato (Table 31). A comparison of 
the effects of target and companion crops in each diculture indicated relative dominance ( $a>\alpha$ when target species dominates). Tomato dominated both its companions and Brussels sprout dominated basil.

The linear model showed replicate effects to be significant in all combinations, but no replicate had a consistently positive or negative effect on all crops (Table 29). Differences between replicates suggested a compensatory effect between tomato and basil: Basil plants tended to be larger when tomatoes were smaller and vice-versa (Table 29). This compensatory effect was not observed for other combinations. The replicate effect was not tested by the other models.
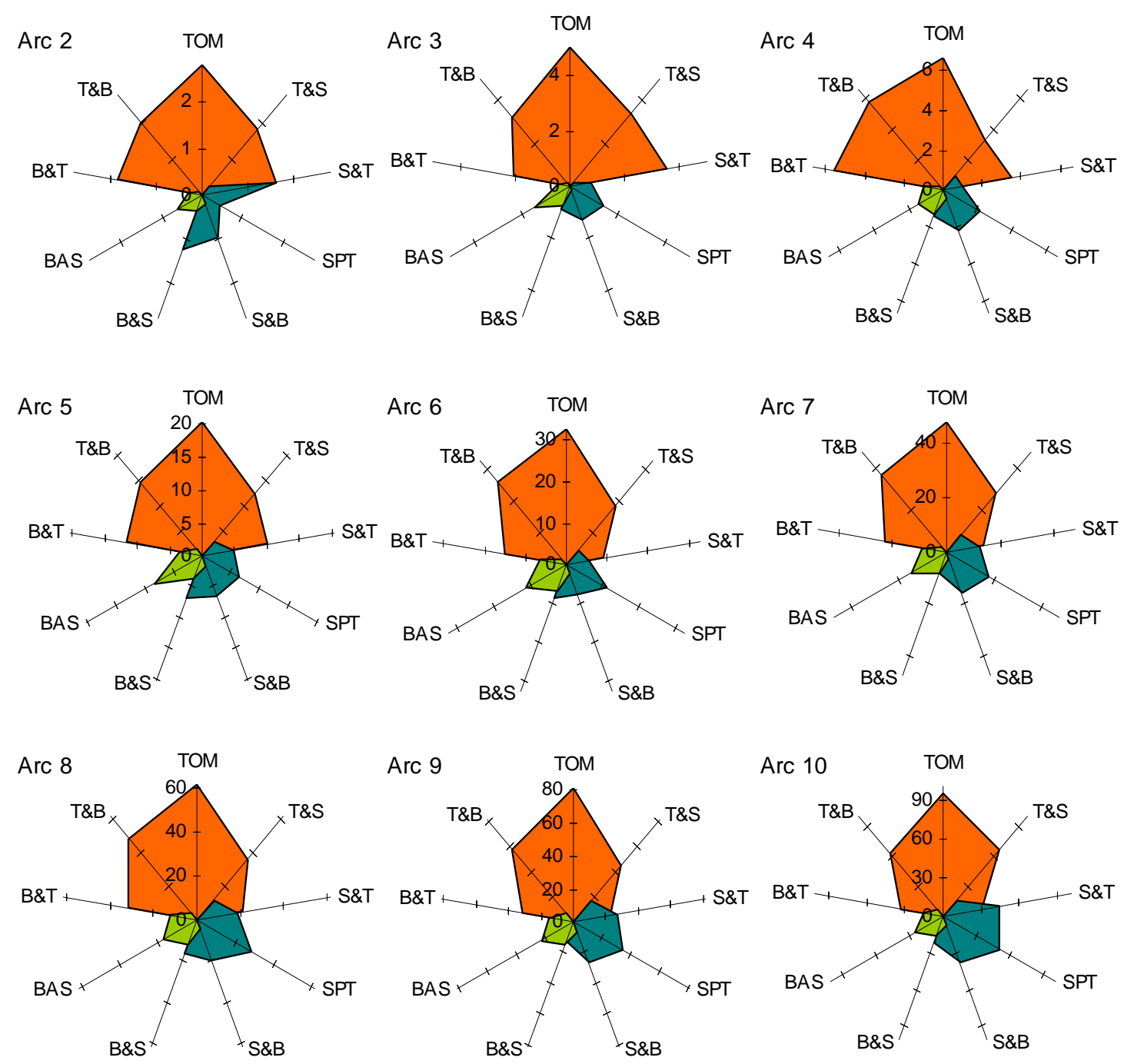

Figure 28. Total aboveground fresh weight (kg) of tomato (orange), Brussels sprout (blue) and basil (green) plant matter collected from each arc of each segment of tri-fan circle plots. Each successive arc position represents a $26 \%$ increase in plant spacing, ranging from $14.4 \mathrm{~cm}$ in arc 2 to $93.5 \mathrm{~cm}$ in arc 10. Monoculture segments contained tomato (TOM), Brussels sprout (SPT), or basil (BAS). Diculture segments contained a 2:1 mixture of the crops grown in the nearest and next nearest monoculture segments, respectively. 

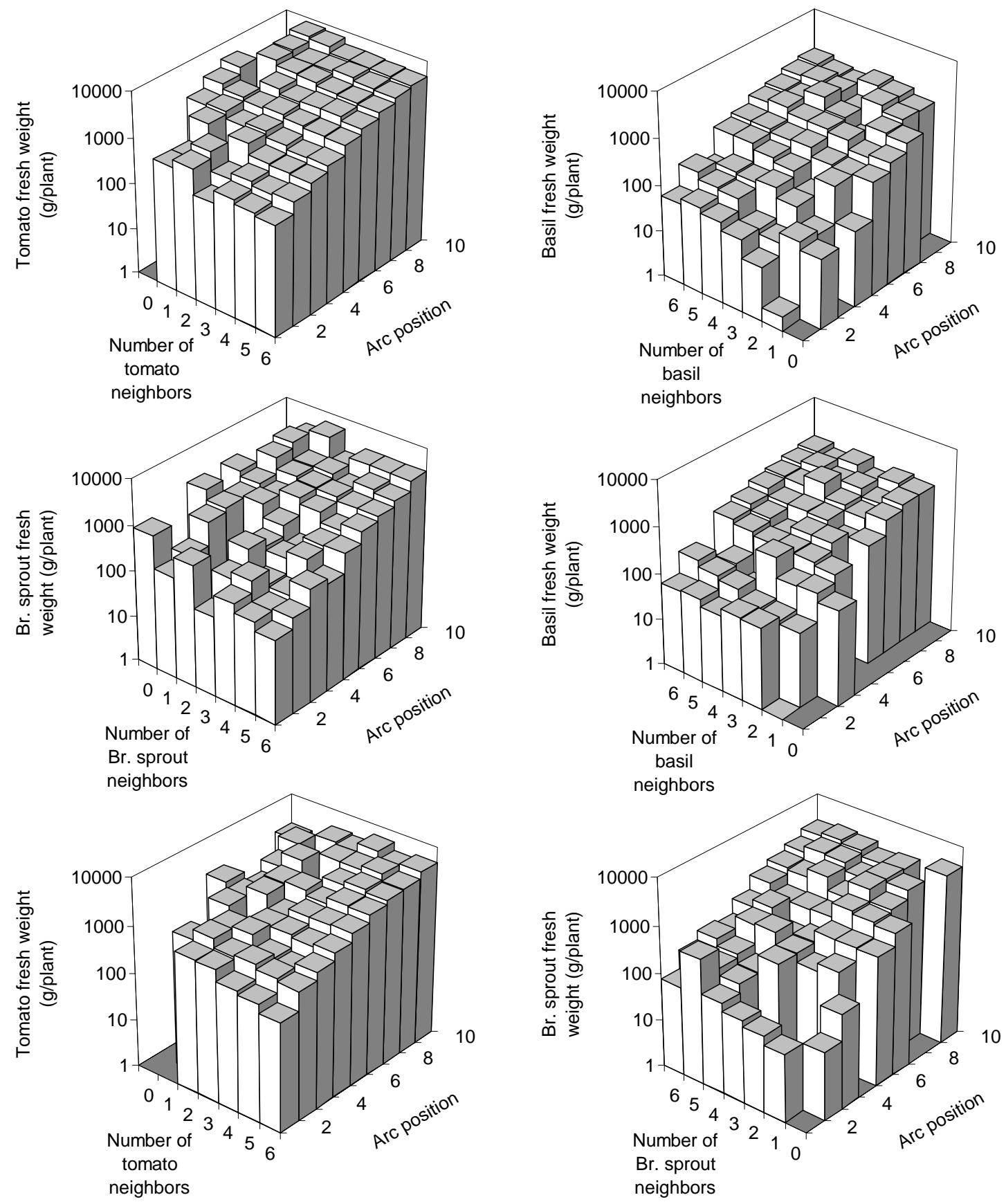

Figure 29. Aboveground fresh weight per plant of tomato grown with basil (top left), basil grown with tomato (top right), Brussels sprout grown with basil (middle left), basil grown with Brussels sprout (middle right), tomato grown with Brussels sprout (bottom left), and Brussels sprout grown with tomato (bottom right) at a range of densities (arc position) and frequencies (neighbors). The relative spacings (arc positions) represent multiplicative increments of 1.26 from a close spacing of $14.4 \mathrm{~cm}$ at 2 to a wide spacing of $93.5 \mathrm{~cm}$ at 10 . The frequency scale (neighbors) represents the number of a target plant's nearest neighbors that are the same species as that plant. 
Table 29. Fitted terms in a square root yield-density response surface model $\left(w^{0.5}=i+d x+z q+R e p\right)$ relating the square root of aboveground fresh weight $\left(w^{0.5}\right)$ of plants grown in diculture at each arc position $(x)$ with varying numbers of neighbors of the same species $(q)$ (c.f. Figure 30). The first and second letters of each diculture code represent the target and companion species, respectively ( $\mathrm{T}=$ tomato, $\mathrm{B}=$ basil, $\mathrm{S}=$ Brussels sprout).

\begin{tabular}{|c|c|c|c|c|c|c|c|c|c|c|c|}
\hline \multirow{2}{*}{$\begin{array}{l}\text { Dicult- } \\
\text { ure }\end{array}$} & \multicolumn{9}{|c|}{ Estimate \pm S.E. } & \multirow[b]{2}{*}{$n$} & \multirow[b]{2}{*}{$\boldsymbol{R}^{2}$} \\
\hline & i & $d$ & $\mathbf{Z}$ & $\operatorname{Rep} 1$ & Rep 2 & Rep 3 & $\operatorname{Rep} 4$ & Rep 5 & Rep 6 & & \\
\hline $\mathrm{T} \& \mathrm{~B}$ & $\begin{array}{l}5.80 \pm \\
1.94^{* *}\end{array}$ & $\begin{array}{l}8.01 \pm \\
0.22 * * *\end{array}$ & $\begin{array}{l}-2.31 \pm \\
0.28 * * *\end{array}$ & $\begin{array}{l}-6.36 \pm \\
1.32 * * *\end{array}$ & $\begin{array}{c}-1.74 \pm \\
1.20 \mathrm{~ns}\end{array}$ & $\begin{array}{l}-5.21 \pm \\
1.28 * * *\end{array}$ & $\begin{array}{l}8.10 \pm \\
1.06^{* * *}\end{array}$ & $\begin{array}{l}3.77 \pm \\
1.06 * * *\end{array}$ & $\begin{array}{l}1.45 \pm \\
1.09 \mathrm{~ns}\end{array}$ & 179 & 0.89 \\
\hline T\&S & $\begin{array}{l}0.30 \pm \\
2.94 \mathrm{~ns}\end{array}$ & $\begin{array}{l}6.63 \pm \\
0.33^{* * *}\end{array}$ & $\begin{array}{l}0.32 \pm \\
0.43 \mathrm{~ns}\end{array}$ & $\begin{array}{c}-3.89 \pm \\
1.59 \mathrm{~ns}\end{array}$ & $\begin{array}{r}-4.14 \pm \\
1.54^{*}\end{array}$ & $\begin{array}{l}0.64 \pm \\
1.61 \mathrm{~ns}\end{array}$ & $\begin{array}{l}1.77 \pm \\
1.38 \mathrm{~ns}\end{array}$ & $\begin{array}{l}5.62 \pm \\
1.41 * * *\end{array}$ & - & 149 & 0.75 \\
\hline $\mathrm{B} \& \mathrm{~T}$ & $\begin{array}{r}-2.39 \pm \\
1.02 *\end{array}$ & $\begin{array}{l}3.36 \pm \\
0.12 * * *\end{array}$ & $\begin{array}{l}1.09 \pm \\
0.15^{* * *}\end{array}$ & $\begin{array}{l}4.14 \pm \\
0.70 * * *\end{array}$ & $\begin{array}{l}5.19 \pm \\
0.69 * * *\end{array}$ & $\begin{array}{l}0.60 \pm \\
0.68 \mathrm{~ns}\end{array}$ & $\begin{array}{l}-3.43 \pm \\
0.57 * * *\end{array}$ & $\begin{array}{c}-1.70 \pm \\
0.59 * *\end{array}$ & $\begin{array}{l}-4.80 \pm \\
0.57 * * *\end{array}$ & 181 & 0.89 \\
\hline $\mathrm{B} \& \mathrm{~S}$ & $\begin{array}{c}-1.74 \pm \\
1.36 \mathrm{~ns}\end{array}$ & $\begin{array}{l}3.27 \pm \\
0.16^{* * *}\end{array}$ & $\begin{array}{l}1.21 \pm \\
0.21 * * *\end{array}$ & $\begin{array}{l}3.26 \pm \\
0.79 * * *\end{array}$ & $\begin{array}{l}2.23 \pm \\
0.76^{* *}\end{array}$ & $\begin{array}{l}1.44 \pm \\
0.81 \mathrm{~ns}\end{array}$ & $\begin{array}{l}-4.09 \pm \\
0.73 * * *\end{array}$ & $\begin{array}{l}-2.84 \pm \\
0.64 * * *\end{array}$ & - & 155 & 0.83 \\
\hline S\&B & $\begin{array}{l}4.06 \pm \\
3.04 \mathrm{~ns}\end{array}$ & $\begin{array}{l}6.01 \pm \\
0.36^{* * *}\end{array}$ & $\begin{array}{l}-2.61 \pm \\
0.42 * * *\end{array}$ & $\begin{array}{l}2.66 \pm \\
1.63 \mathrm{~ns}\end{array}$ & $\begin{array}{l}-5.02 \pm \\
1.69 * *\end{array}$ & $\begin{array}{r}-1.84 \pm \\
1.65 \mathrm{~ns}\end{array}$ & $\begin{array}{l}4.42 \pm \\
1.55^{* *}\end{array}$ & $\begin{array}{c}-0.22 \pm \\
1.49 \mathrm{~ns}\end{array}$ & - & 136 & 0.72 \\
\hline S\&T & $\begin{array}{c}-10.52 \pm \\
2.72 * * *\end{array}$ & $\begin{array}{l}6.10 \pm \\
0.32 * * *\end{array}$ & $\begin{array}{l}0.04 \pm \\
0.38 \mathrm{~ns}\end{array}$ & $\begin{array}{l}0.69 \pm \\
1.46 \mathrm{~ns}\end{array}$ & $\begin{array}{r}-4.15 \pm \\
1.47 *\end{array}$ & $\begin{array}{l}0.91 \pm \\
1.50 \mathrm{~ns}\end{array}$ & $\begin{array}{l}2.94 \pm \\
1.37 *\end{array}$ & $\begin{array}{c}-0.40 \pm \\
1.28 \mathrm{~ns}\end{array}$ & - & 145 & 0.75 \\
\hline
\end{tabular}

ns=not significant; $* P<0.05 ; * * P<0.005 ; * * * P<0.0005$

Table 30. Fitted terms in a nonlinear response surface model $\left(w=w_{\max }\left[1+a\left(N_{\mathrm{A}}+\alpha N_{\mathrm{B}}\right)\right]^{-b}\right)$ relating aboveground fresh weight $(w)$ of plants grown in diculture to the density of a target crop $\left(N_{\mathrm{A}}\right)$ and its companion crop $\left(N_{B}\right)$ (c.f. Figure 31). The first and second letters of each diculture code represent the target and companion species, respectively ( $T=$ tomato, $B=$ basil, $S=$ Brussels sprout).

\begin{tabular}{|c|c|c|c|c|c|c|}
\hline \multirow[b]{2}{*}{ Diculture } & \multicolumn{4}{|c|}{ Estimate \pm S.E. } & \multirow[b]{2}{*}{$n$} & \multirow[b]{2}{*}{$R^{2}$} \\
\hline & $w_{\max }$ & $a$ & $\alpha$ & $b$ & & \\
\hline $\mathrm{T} \& \mathrm{~B}$ & $(9.08 \pm 1.43) \times 10^{3}$ & $(5.74 \pm 4.08) \times 10^{-1}$ & $(3.13 \pm 1.03) \times 10^{-1}$ & $1.04 \pm 0.31$ & 62 & 0.85 \\
\hline $\mathrm{T} \& \mathrm{~S}$ & $(7.51 \pm 1.98) \times 10^{3}$ & $(6.11 \pm 6.20) \times 10^{-1}$ & $1.64 \pm 0.43$ & $0.76 \pm 0.22$ & 55 & 0.81 \\
\hline $\mathrm{B} \& \mathrm{~T}$ & $(1.51 \pm 0.12) \times 10^{3}$ & $(3.82 \pm 4.15) \times 10^{-2}$ & $2.43 \pm 0.50$ & $3.38 \pm 2.83$ & 64 & 0.87 \\
\hline $\mathrm{B} \& \mathrm{~S}$ & $(1.59 \pm 0.20) \times 10^{3}$ & $(1.33 \pm 1.07) \times 10^{-1}$ & $2.33 \pm 0.60$ & $1.43 \pm 0.62$ & 60 & 0.83 \\
\hline S\&B & $(5.49 \pm 0.80) \times 10^{3}$ & $(7.91 \pm 5.44) \times 10^{-1}$ & $(4.00 \pm 6.08) \times 10^{-2}$ & $1.19 \pm 0.40$ & 59 & 0.82 \\
\hline S\&T & $(5.39 \pm 0.94) \times 10^{3}$ & $(4.38 \pm 2.94) \times 10^{-1}$ & $(6.98 \pm 1.66) \times 10^{-1}$ & $1.64 \pm 0.54$ & 62 & 0.91 \\
\hline
\end{tabular}

Table 31. Fitted terms in an inverse yield-density response surface model $\left(w^{-1}=1 / w_{\max }+z N_{\mathrm{A}}+\alpha N_{\mathrm{B}}\right)$ relating inverse aboveground fresh weight $\left(w^{-1}\right)$ of plants grown in diculture to the density of a target crop $\left(N_{\mathrm{A}}\right)$ and its companion crop $\left(N_{\mathrm{B}}\right)$. The first and second letters of each diculture code represent the target and companion species, respectively $(T=$ tomato, $B=$ basil, $S=B$ russels sprout $)$.

\begin{tabular}{lllllc}
\hline & \multicolumn{3}{c}{ Estimate \pm S.E. } & & \\
\cline { 2 - 5 } Diculture & \multicolumn{1}{c}{$\mathbf{1} / \boldsymbol{w}_{\max }$} & \multicolumn{1}{c}{$\boldsymbol{Z}$} & $\boldsymbol{\alpha}$ & $\boldsymbol{n}$ \\
\hline $\mathrm{T} \& \mathrm{~B}$ & $(9.28 \pm 5.9) \times 10^{-5} \mathrm{~ns}$ & $(7.23 \pm 0.5) \times 10^{-5} * * *$ & $(3.05 \pm 0.7) \times 10^{-5} * * *$ & 62 & 0.86 \\
$\mathrm{~T} \& \mathrm{~S}$ & $(2.65 \pm 0.43) \times 10^{-4} * * *$ & $(5.56 \pm 0.3) \times 10^{-5} * * *$ & $(1.11 \pm 0.6) \times 10^{-5} \mathrm{~ns}$ & 55 & 0.88 \\
$\mathrm{~B} \& \mathrm{~T}$ & $(1.12 \pm 3.30) \times 10^{-4} \mathrm{~ns}$ & $(2.42 \pm 0.25) \times 10^{-4} * * *$ & $(6.89 \pm 0.59) \times 10^{-4} * * *$ & 58 & 0.86 \\
$\mathrm{~B} \& \mathrm{~S}$ & $(3.28 \pm 3.21) \times 10^{-4} \mathrm{~ns}$ & $(2.74 \pm 0.25) \times 10^{-4} * * *$ & $(4.51 \pm 0.46) \times 10^{-4} * * *$ & 58 & 0.86 \\
$\mathrm{~S} \& \mathrm{~B}$ & $(3.48 \pm 1.54) \times 10^{-4} *$ & $(2.06 \pm 0.14) \times 10^{-4} * * *$ & $(-3.0 \pm 16) \times 10^{-6} \mathrm{~ns}$ & 59 & 0.80 \\
$\mathrm{~S} \& \mathrm{~T}$ & $(-4.63 \pm 6.65) \times 10^{-4} \mathrm{~ns}$ & $(1.32 \pm 0.50) \times 10^{-4} *$ & $(8.87 \pm 0.71) \times 10^{-4} * * *$ & 62 & 0.77 \\
\hline
\end{tabular}

ns=not significant; ${ }^{*} P<0.05 ; * * P<0.005 ; * * * P<0.0005$ 
A: Tomato with basil

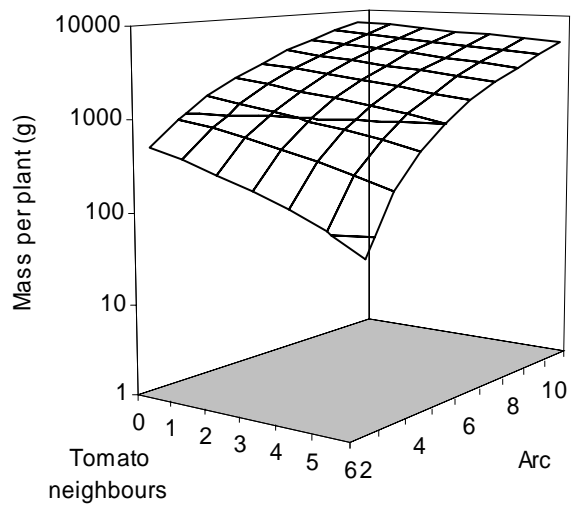

C: Br. sprout with basil

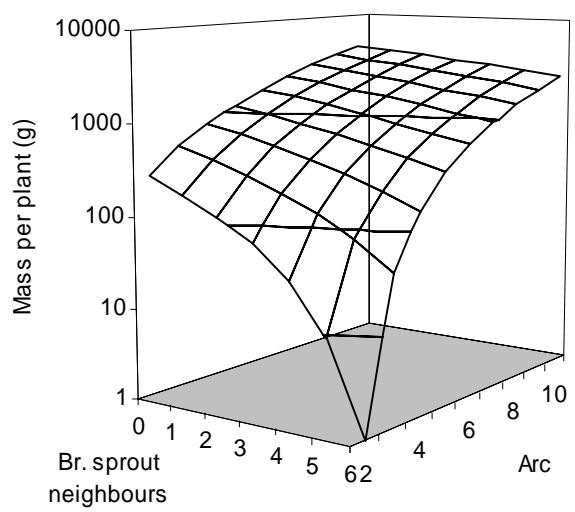

$\mathrm{E}$ : Tomato with $\mathrm{Br}$. sprout

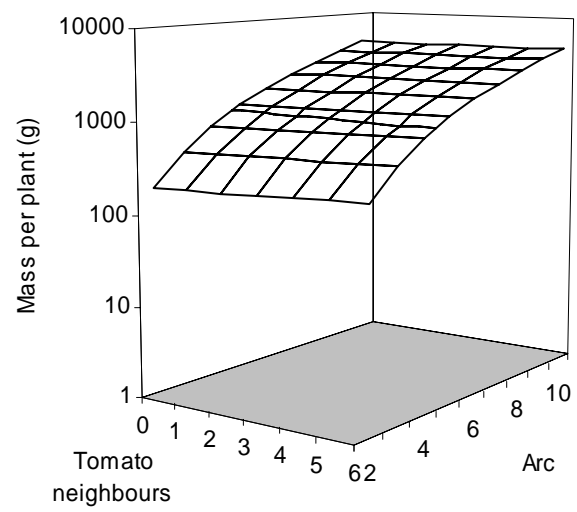

B: Basil with tomato

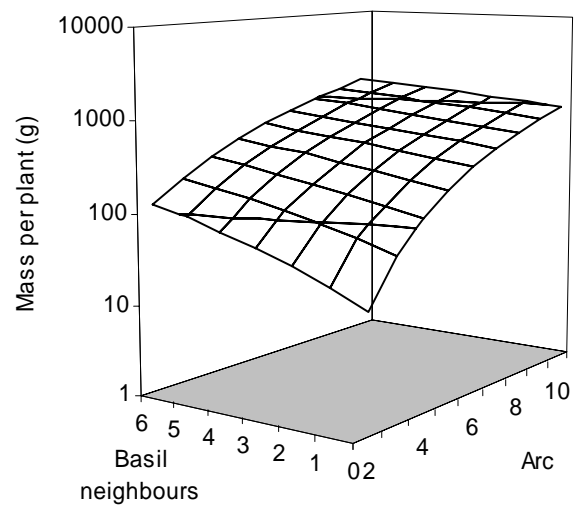

D: Basil with Br. sprout

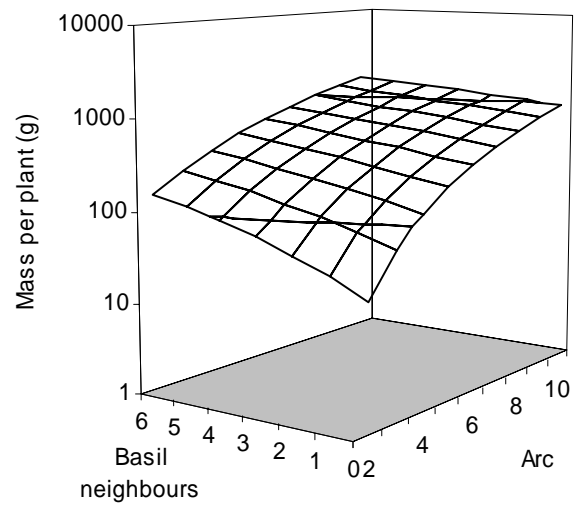

F: Br. sprout with tomato

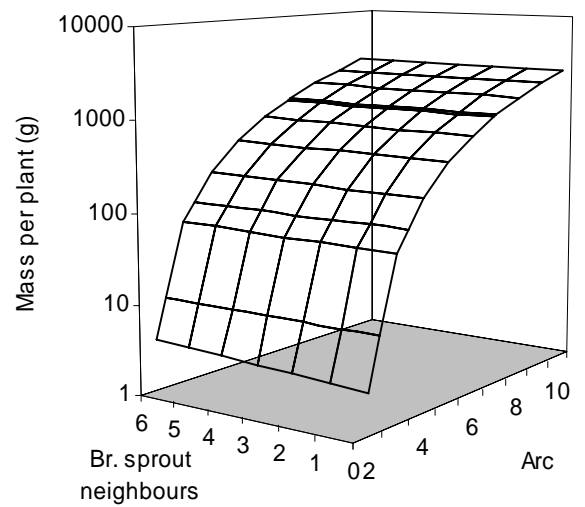

Figure 30. Response surfaces fit to the data presented in Figure 29 using the linear regression values in Table 29. Labels indicate the target and companion crops ("target with companion"). 
A: Tomato with basil

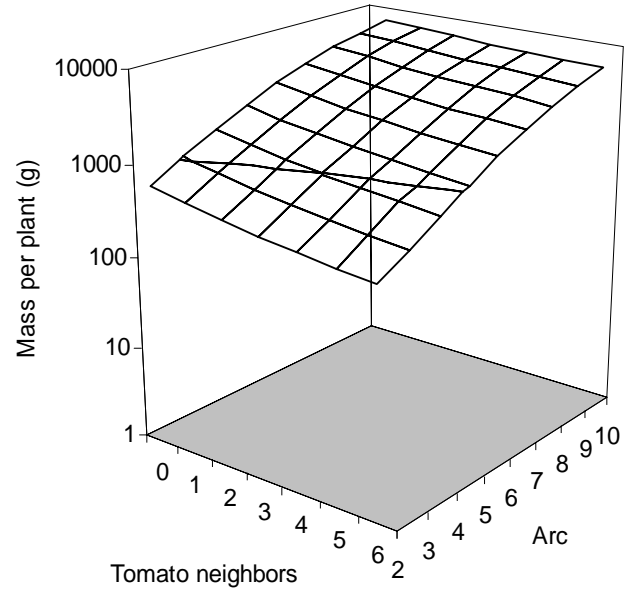

C: Br. sprout with basil

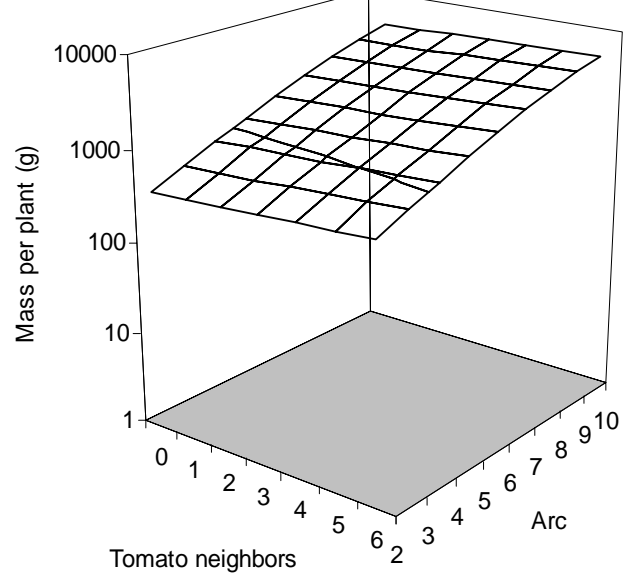

E: Tomato with $\mathrm{Br}$. sprout

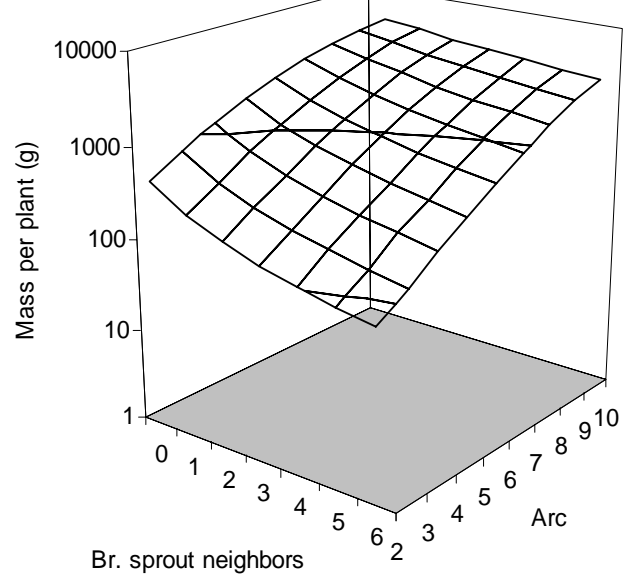

B: Basil with tomato

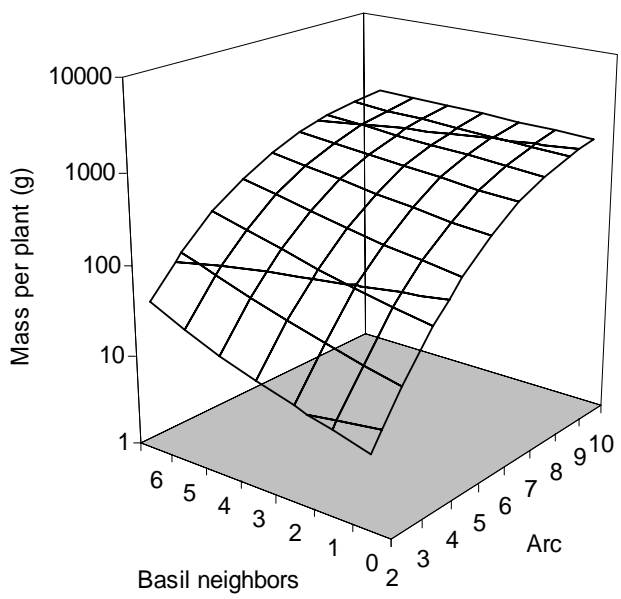

D: Basil with Br. sprout

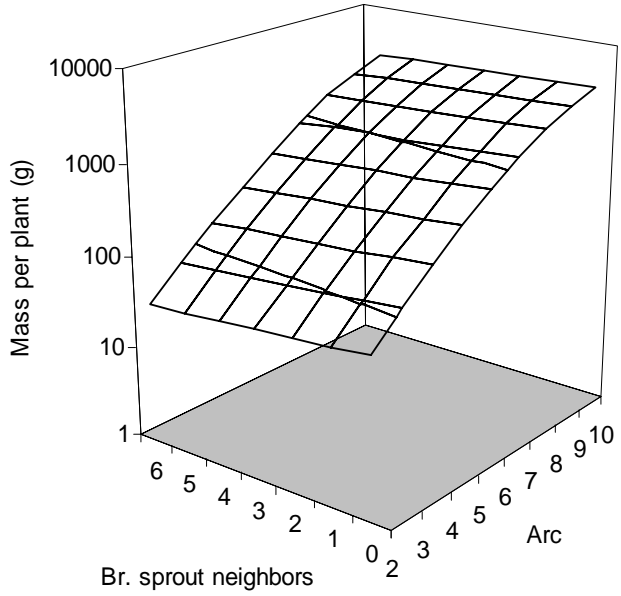

$\mathrm{F}$ : Br. sprout with tomato

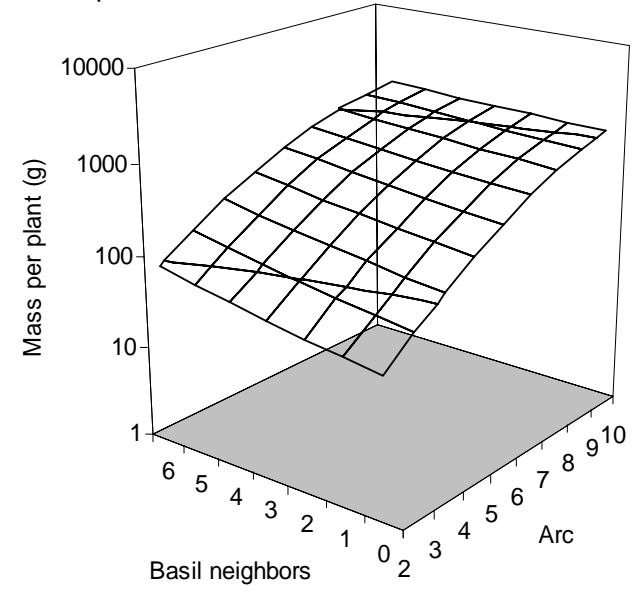

Figure 31. Response surfaces fit to the data presented in Figure 29 using the nonlinear model and values presented in Table 30. Labels indicate the target and companion crops ("target with companion"). 


\section{Land Equivalence Ratio and Relative Land Output}

Figure 32 shows RLO and LER, obtained by direct calculation, for each segment and arc of the tri-fan circles. Most values were greater than one, indicating a yield advantage to polyculture (RLO: 69\% of values $>1$, mean $=1.22$, range $=0.77$ to $3.04, n=54$; LER: $63 \%$ of values $>1$, mean $=1.20$, range $=0.72$ to $4.51, n=54)$. The largest yield advantage were observed in the B\&S segments, where total yields were $19 \%$ and $13 \%$ higher than in monoculture segments, according to the RLO and LER indices, respectively (Figure 32 left). The B\&T segments showed a 17\% advantage over monoculture according to the RLO index, but only a 5\% advantage according to the LER index. All other index values calculated for total yield of a single segment were within $6 \%$ of the monoculture yield. The $B \& S$ and $B \& T$ segments showed some yield advantage at most densities, but trends were not consistent between densities (Figure 33).

Mean yield advantages to polyculture were highest, and most variable, at high densities (Figure 32 right). As density fell the variability in RLO and LER index values decreased and the values approached 1 (no intercropping effect) (Figure 32 right, Figure 33). The yield advantage calculated at the highest density of the S\&T segment was $351 \%$. An examination of Figure 28 shows that this value was related to an uncharacteristic distribution of Brussels sprout weight accumulation at the highest density.

Predictions of RLO and LER from response surface models are shown in Figure 34 and Figure 35. The two models and the two indices each give different predictions, but both show the greatest yield advantages occurring in dicultures that include basil, with no yield advantage in tomato/Brussels sprout dicultures. RLOs calculated from the nonlinear model predicted yield advantages in tomato/basil dicultures, but LERs calculated from the same model did not (Figure 35). The square root yield-density model predicts that the greatest yield advantages occur when the tomato:basil ratio is near 1:1 (Figure 34), but the nonlinear model predicts that a ratio of 1:6 offers the greatest advantage (Figure 35). Both models show the greatest advantages occurring at high densities (Figure 34, Figure 35). 

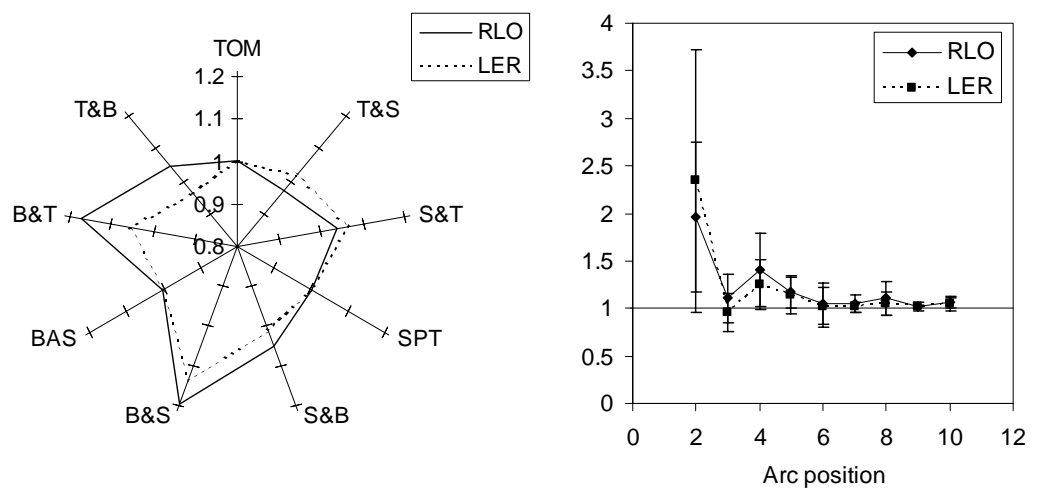

Figure 32. Relative Land Output (RLO, solid line) and Land Equivalent Ratio (LER, dashed line) for each segment (left) and arc (right) of the combined tri-fan circle plots. Error bars denote standard deviation of the mean of all segments of an arc.
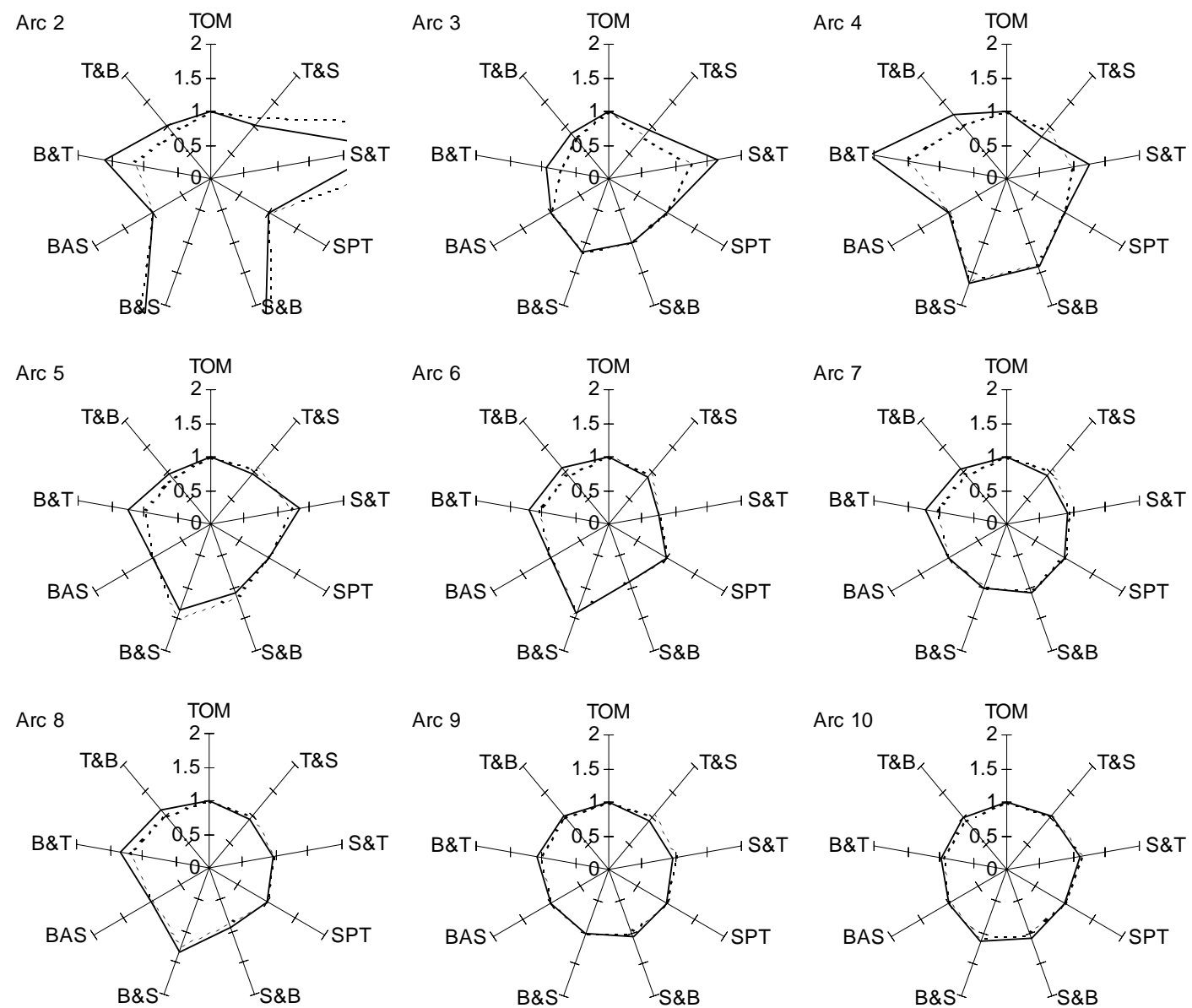

Figure 33. Relative Land Output (RLO, solid line) and Land Equivalence Ratio (LER, dashed line) of each segment for each arc in the tri-fan circle plots. Each successive arc position represents a $26 \%$ increase in plant spacing, ranging from $14.4 \mathrm{~cm}$ in arc 2 to $93.5 \mathrm{~cm}$ in arc 10 . Monoculture segments contained tomato (TOM), Brussels sprout (SPT), or basil (BAS), and have a RLO of 1 by definition. Diculture segments contained a 2:1 mixture of the crops grown in the nearest and next nearest monoculture segments, respectively. 

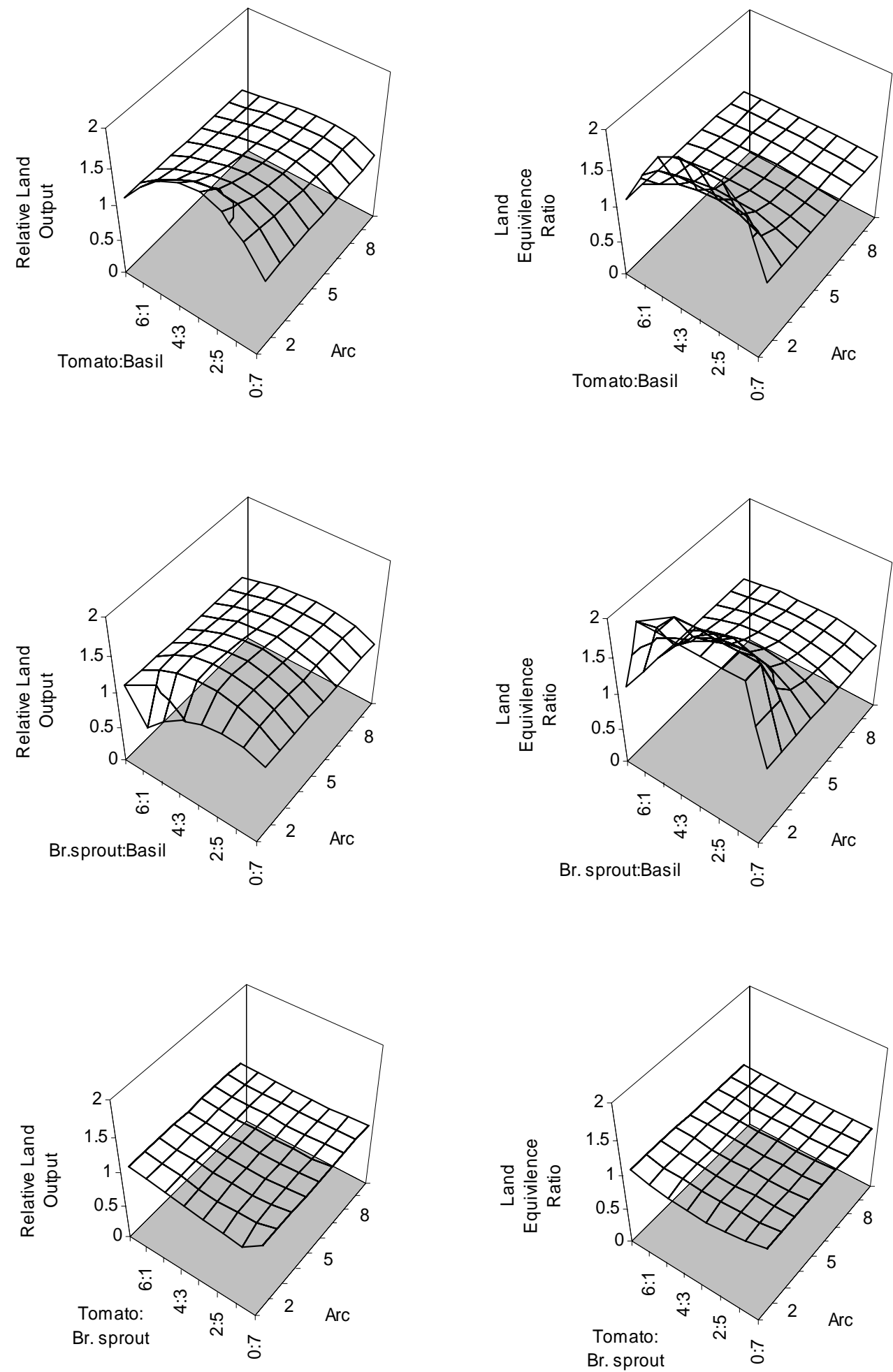

Figure 34. Relative Land Outputs (left) and Land Equivalence Ratios (right) calculated from the linear response surfaces shown in Figure 30 for dicultures of tomato and basil (top), Brussels sprout and basil (middle), and tomato and Brussels sprout (bottom). 

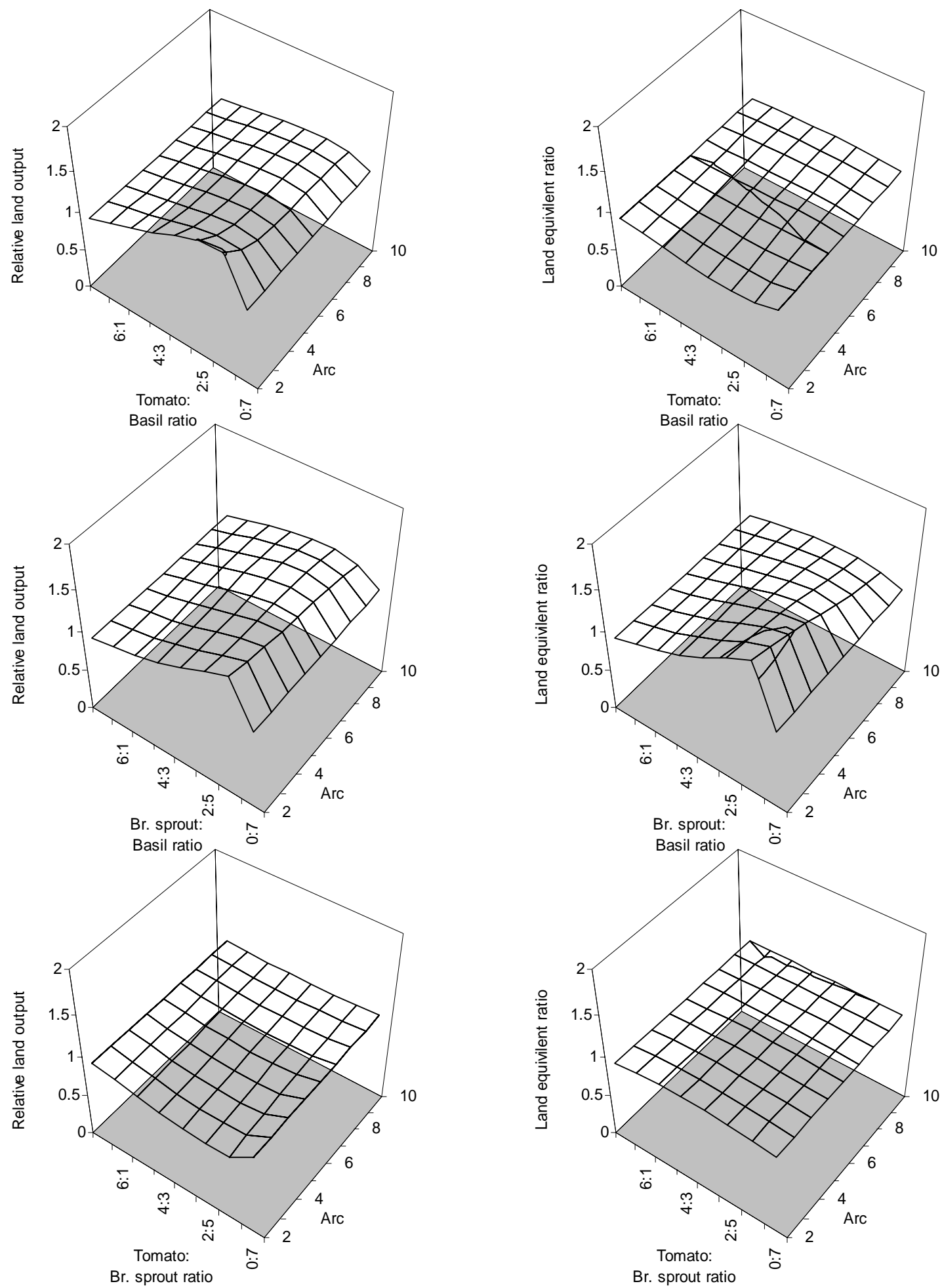

Figure 35. Relative Land Outputs (left) and Land Equivalence Ratios (right) calculated from the nonlinear response surfaces shown in Figure 31 for dicultures of tomato and basil (top), Brussels sprout and basil (middle), and tomato and Brussels sprout (bottom). 


\section{Light penetration}

In 2003 the proportion of ceptometer sensors exposed to direct sunlight below the crop canopy (Sunfleck $\%$ ) was inversely correlated with the fractional PAR absorption by the crop canopy (Figure 36).

More light penetrated basil canopies than tomato or Brussels sprout canopies (Figure 37). As expected, light penetration through dicultures was between that of the component crop monocultures (Figure 37); actual values did not differ significantly from expected values when all densities were pooled. Observed values often differed from expected values when data were separated by plant density (Figure 38). At the lowest density $\left(\bar{x}=1.41\right.$ plants $\left./ \mathrm{m}^{2}\right)$ only dicultures dominated by tomato (T\&S, T\&B) absorbed more light than expected (Figure 38). Other significant differences at low and moderate density were due to less light absorption than expected (Figure 38 ). At the highest density tested in both years $\left(\bar{x}=9.13\right.$ plants $\left./ \mathrm{m}^{2}\right) \mathrm{S} \& \mathrm{~T}$, $\mathrm{S} \& \mathrm{~B}$, and B\&T absorbed more light than expected (Figure 38). At the highest density tested in $2003(\bar{x}=$ 23.3 plants $\left./ \mathrm{m}^{2}\right)$ all dicultures except T\&S absorbed more light than expected ( $\chi^{2}$ test, $P<0.05, n=3$ ).

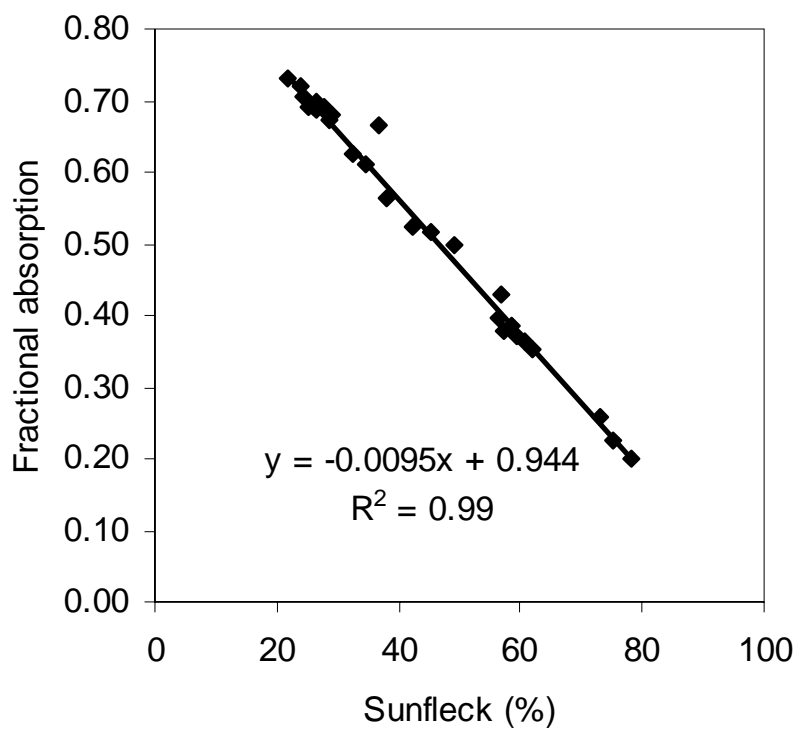

Figure 36. Relationship between the fractional absorption of Photosynthetically Active Radiation (PAR) by the crop canopy and the proportion of ceptometer sensors exposed to direct sunlight below the crop canopy (Sunfleck \%) in 2003. Fractional absorption was calculated as $(1-T / S)(1-R / S)$ where $T$ is PAR below the canopy, $R$ is PAR reflected from the canopy, and $S$ is PAR above the canopy (Decagon Devices 1989). Each point is the season mean for a tri-fan circle segment in a single replicate at a single plant density $(n=108)$. 


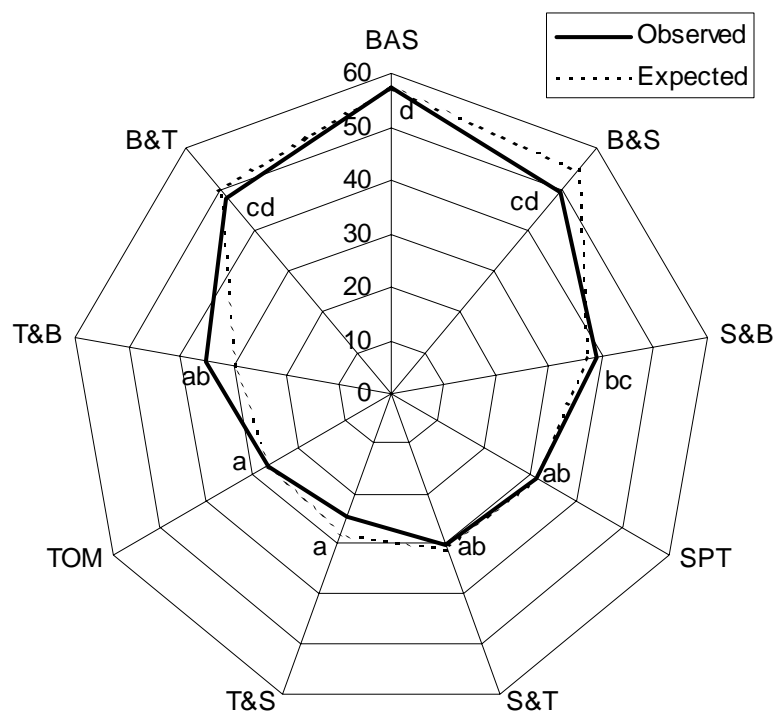

Figure 37. Mean proportion (\%) of soil surface exposed to direct sunlight in each section of a tri-fan circle study. Monoculture segments contained tomato (TOM), Brussels sprout (SPT), or basil (BAS). Diculture segments contained a 2:1 mixture of the crops grown in the nearest and next nearest monoculture segments, respectively. Actual values labeled with the same letter do not differ significantly (Tukey's test, $n=6, P<0.05)$. Expected diculture values (dashed line) are $(2 \mathrm{~A} / 3+\mathrm{B} / 3)$ where $A$ and $B$ are the values for the nearest and next nearest monocultures, respectively.

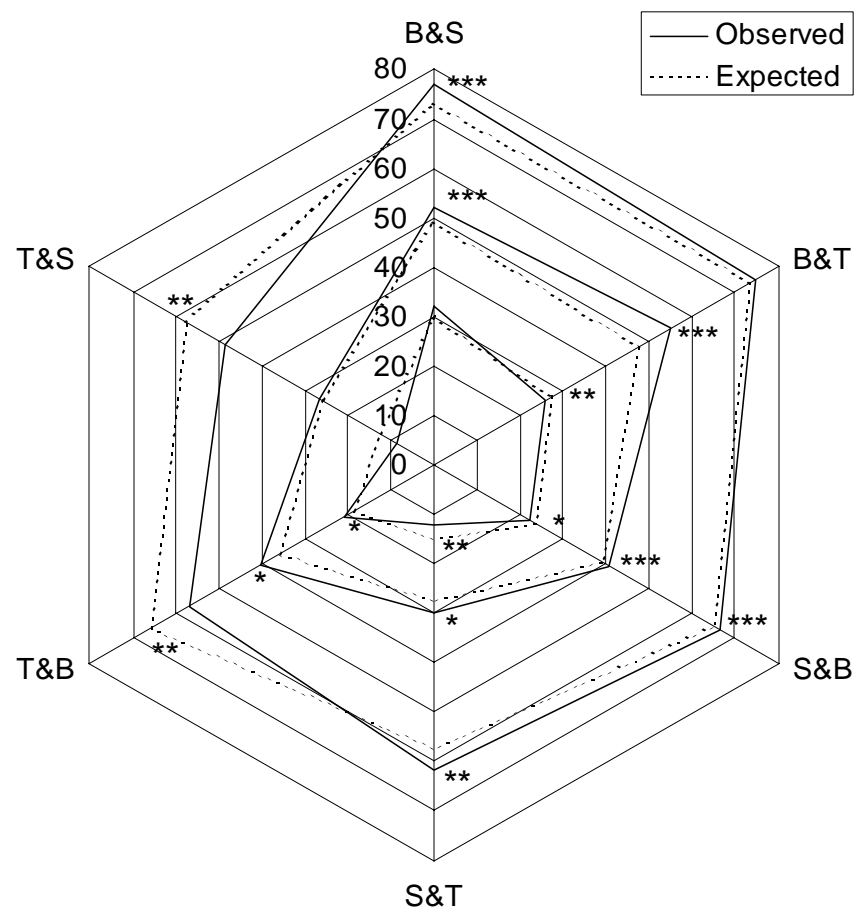

Figure 38. Observed (solid line) and expected (dashed line) sunfleck proportion (\%) beneath diculture canopies. Mean plant densities were $9.13,3.58$, and $1.41 \mathrm{plants} / \mathrm{m}^{2}$ for the inner, middle, and outer lines, respectively. Stars denote significant differences between observed and expected values $\left(\chi^{2}\right.$ test, $\left.n=6, * P<0.05, * * P<0.05, * * * P<0.005\right)$. Each diculture contained a 2:1 crop mixture of the respective species indicated by letters in the diculture code $(T=$ tomato, $B=b a s i l$, $\mathrm{S}=$ Brussels sprout). 
The relationship between plant density and canopy light penetration differed between the two growing seasons (Figure 39). The effect of density on light penetration was stronger, and sunfleck proportion was lower, in 2002 than in 2003 (Figure 39).

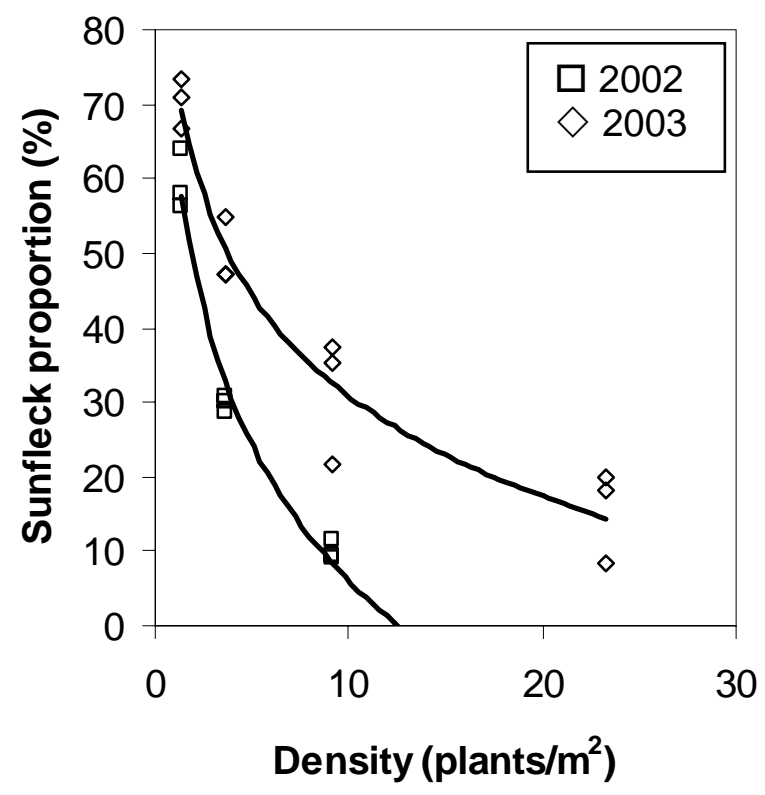

Figure 39. Mean proportion (\%) of soil surface exposed to direct sunlight in $2002(\square)$ and $2003(\diamond)$. Data points show replicate means, and trendlines show linear regressions for each year $(2002$ Sunfleck = -26.3 Ln (Density) + 66.6; 2003 Sunfleck = -19.5 Ln (Density) + 75.7).

Figure 40 shows how density effects on light penetration changed over time during 2002 and 2003. In both years sections dominated by basil absorbed less light than sections dominated by tomato or Brussels sprout (Figure 37, Figure 40). This effect was more pronounced at low densities and early in the season of 2002, but can be seen at all densities throughout the season of 2003 (Figure 40). The basil canopy filled in more completely in 2002 than in 2003 (Figure 40).

The sunfleck proportion increased with increasing height above the soil surface (Figure 41). This height effect was particularly pronounced in combinations dominated by Brussels sprout (Figure 41). In all sections except the basil monoculture more foliage was added between 17 July and 19 August than between 19 August and 17 September, 2003 (Figure 41). 


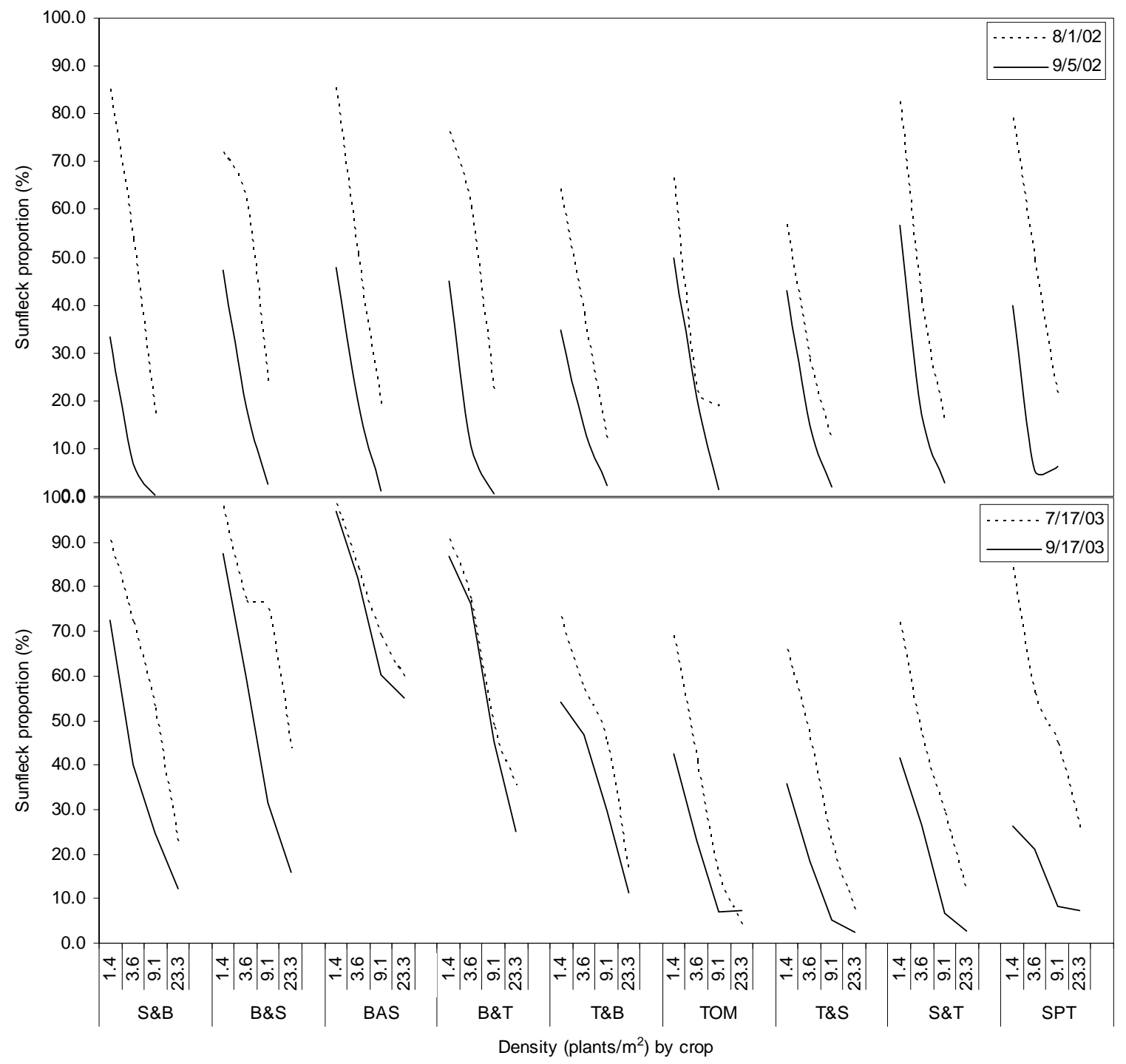

Figure 40. Mean proportion (\%) of soil surface exposed to sunlight at a range of planting densities for each segment of the tri-fan circle study in 2002 (top) and 2003 (bottom). The difference between the first sample (dashed line) and second sample (solid line) indicates increased light interception due to plant growth between samples. 


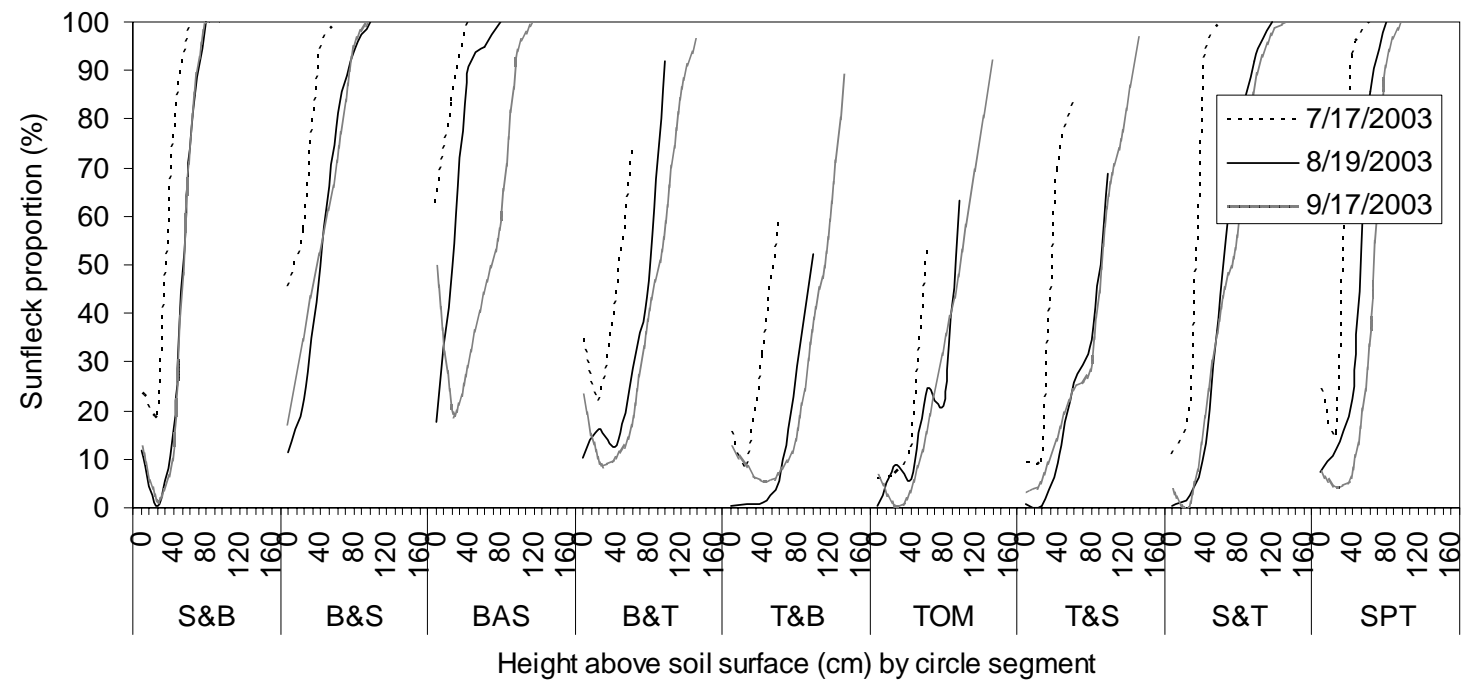

Figure 41. Penetration of direct sunlight to a range of heights above the soil surface in each segment of the tri-fan circle study on three sampling days in 2003.

\section{Soil moisture}

Soil moisture content was correlated with canopy light penetration (Figure 42). Sections dominated by basil had wetter soils than other sections (Figure 43). As expected, soil moisture content in dicultures was between that of the component crop monocultures (Figure 43); actual values did not differ significantly from expected values when all densities were pooled, or when single densities were analyzed independently (Figure 44). Density and replicate both had strong effects on soil moisture content $(P<0.001$, Figure 44 , Figure 45), and the density effect was more pronounced in 2002, when soils were dryer than in 2003 (Figure 45).

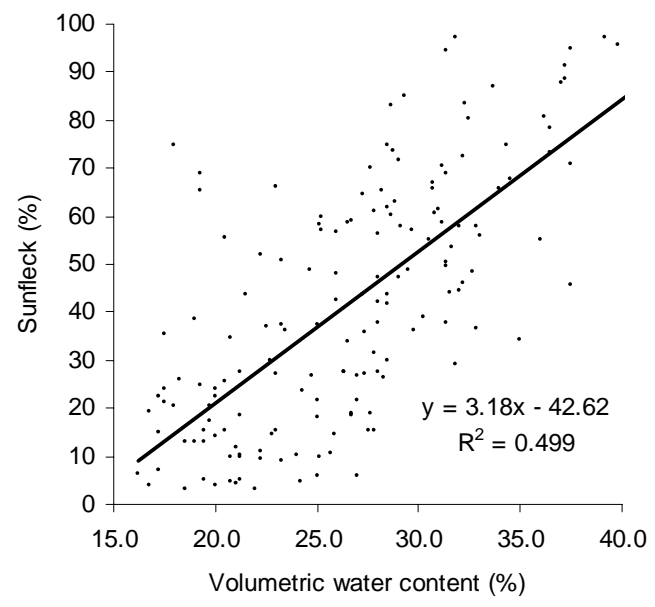

Figure 42. The relationship between soil moisture content and canopy light penetration. Each point is the season mean for a unique combination of treatment, density and replicate $(r=0.71, P<0.0001, n$ =161). 


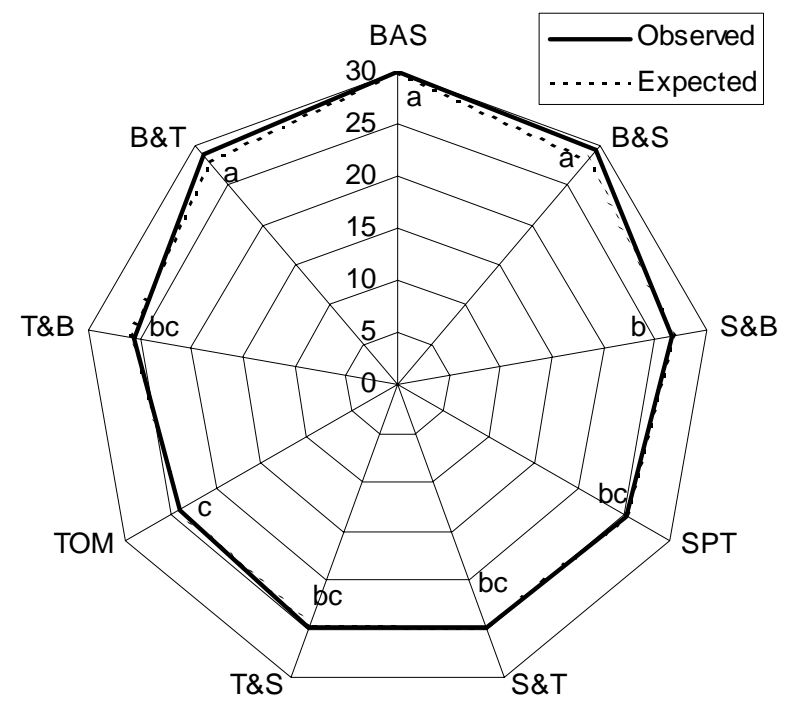

Figure 43. Volumetric water content (\%) in each section of a tri-fan circle study. Monoculture segments contained tomato (TOM), Brussels sprout (SPT), or basil (BAS). Diculture segments contained a 2:1 mixture of the crops grown in the nearest and next nearest monoculture segments, respectively. Observed values labeled with the same letter do not differ significantly (Tukey's test, $n$ $=6, P<0.05)$. Expected diculture values (dashed line) are $(2 \mathrm{~A} / 3+\mathrm{B} / 3)$ where $\mathrm{A}$ and $\mathrm{B}$ are the values for the nearest and next nearest monocultures, respectively.

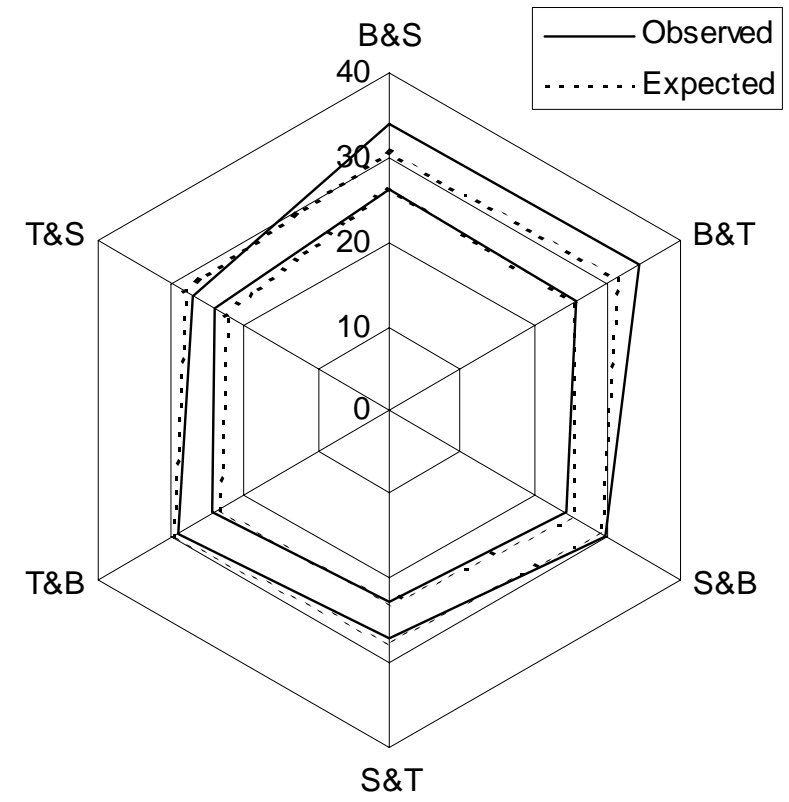

Figure 44. Observed (solid line) and expected (dashed line) volumetric soil water content (\%) in dicultures. Mean plant densities were 9.13 and $1.41 \mathrm{plants} / \mathrm{m}^{2}$ for the inner and outer lines, respectively. No differences were found between observed and expected values $\left(\chi^{2}\right.$ test, $n=6, \alpha=$ 0.05). 


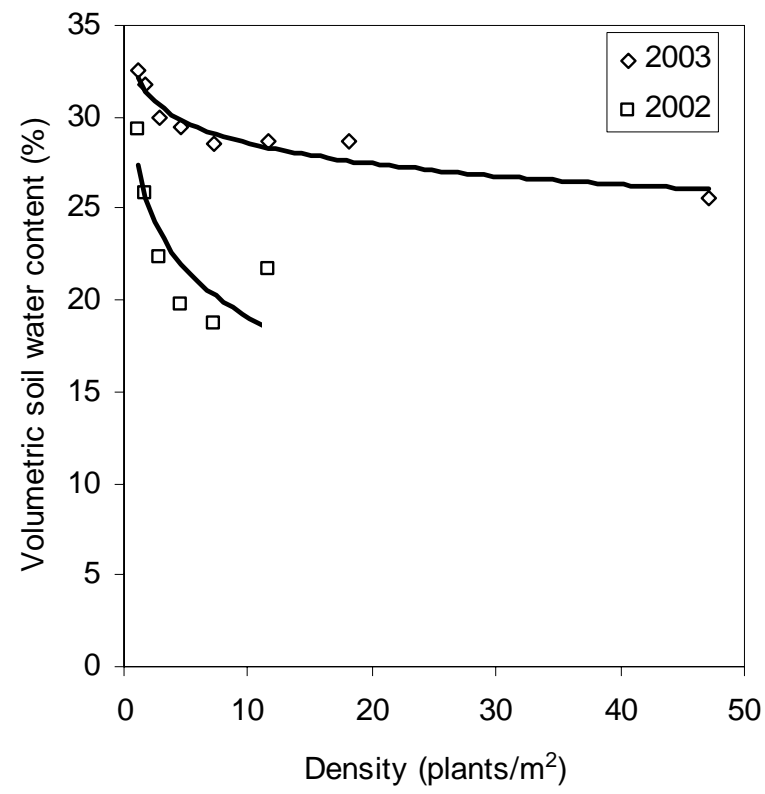

Figure 45. Mean volumetric soil water content $(\%)$ in $2002(\square)$ and $2003(\diamond)$. Data points show replicate means, and trendlines show linear regressions for each year $(2002$ VWC $=-3.77 \mathrm{Ln}$ (Density) $+27.76, R^{2}=0.69, n=3 ; 2003 V W C=-1.64 \operatorname{Ln}($ Density $\left.)+32.35, R^{2}=0.91, n=3\right)$.

Soil moisture and canopy light penetration were both inversely correlated with above-ground biomass accumulation (Figure 46). The relationship between canopy light penetration and biomass accumulation was stronger than soil moisture and biomass accumulation.
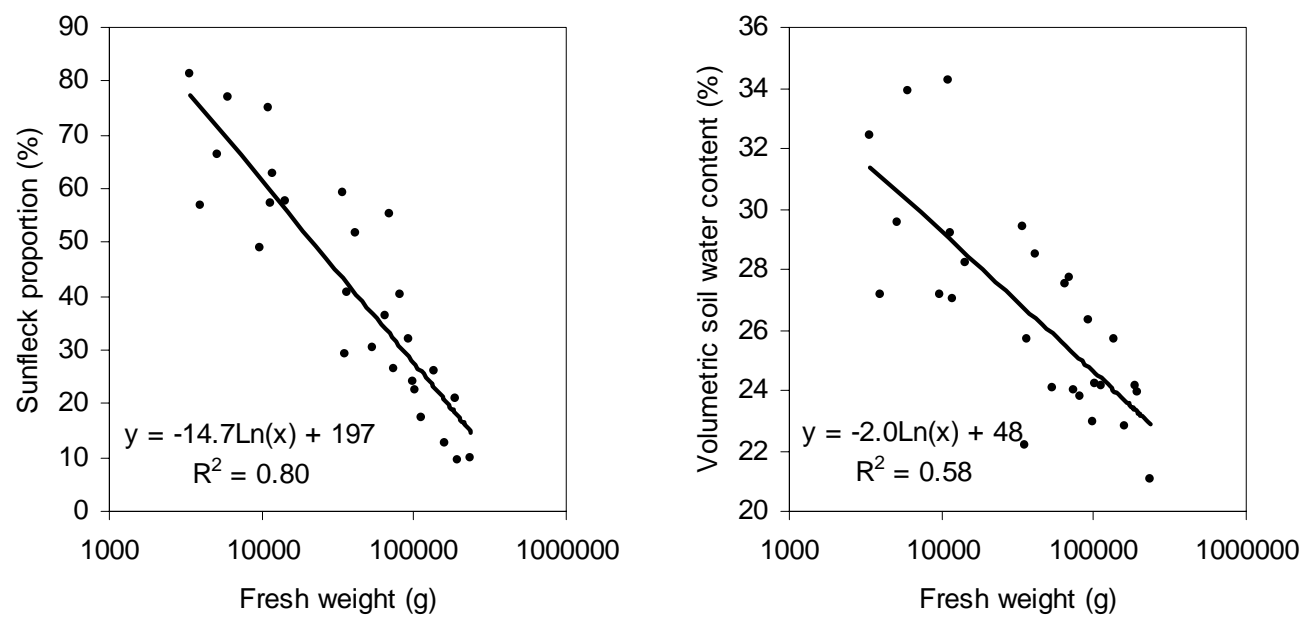

Figure 46. The relationships between biomass accumulation and penetration of sunlight through the canopy (left) or volumetric soil water content (right). Each point represents the total fresh weight of all above-ground plant matter removed from all circle segments at one of three densities $(n=27)$. 


\section{Pest levels}

Aphid infestation and imported cabbageworm damage severity indices were both inversely related to plant density in 2003 (Figure 47). Plant density did not affect groundhog damage severity. Replicate had a significant effect on all Brussels sprout pests, with Rep 3 suffering more damage from all pests than Rep 1, and Rep 2 having more severe aphid infestations and groundhog feeding than Rep 1 (Tukey's test, $P<$

0.03). Circle sections with a 2:1 tomato:Brussels sprout ratio suffered more groundhog damage than other sections (Tukey's test, $P<0.0001$ ) and more imported cabbageworm damage than all sections except those with a 1:2 Brussels sprout:tomato ratio (Tukey's test, $P=0.03$ ). Treatment had no effect on aphid infestation rates.

All tomato plants showed symptoms of early blight infection by the final harvest (Figure 48). Higher levels of early blight infection were observed in Rep 3 than in other replicates (Tukey's test, $P<0.0001$ ), but neither density nor treatment affected early blight severity. Fusarium wilt symptoms were found on $<25 \%$ of tomato plants (Figure 48). Neither density nor replicate affected the incidence or severity of Fusarium wilt.

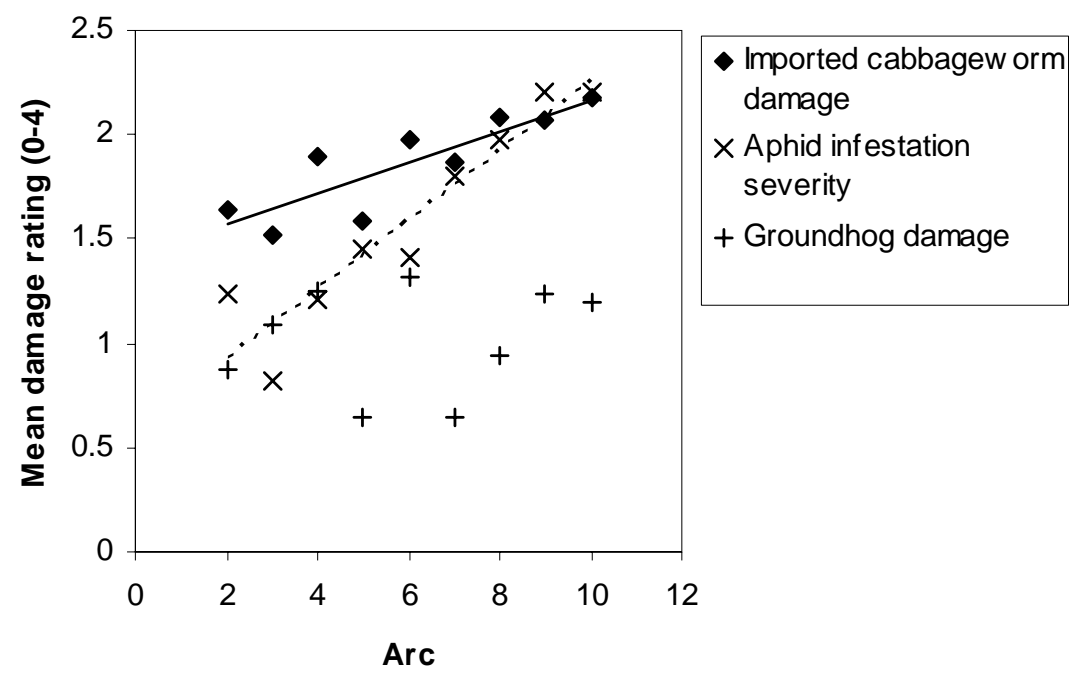

Figure 47. Effects of density on mean damage rating (0-4) for imported cabbageworm (•), cabbage aphid $(\times)$, and groundhog $(+)$ on Brussels sprout plants in a mixed species fan design. The relative spacings (arc positions) represent multiplicative increments of 1.26 from a close spacing of $14.4 \mathrm{~cm}$ at 2 to a wide spacing of $93.5 \mathrm{~cm}$ at 10 . The best-fit linear regression lines are shown for imported cabbageworm (solid line, damage $=1.42+0.074 \mathrm{Arc}, \mathrm{R}^{2}=0.73, P=0.003$ ) and cabbage aphid (dashed line, feeding severity $=0.60+0.17$ Arc $\left., R^{2}=0.88, P=0.0002\right)$. Density had no significant effect on groundhog feeding severity. 


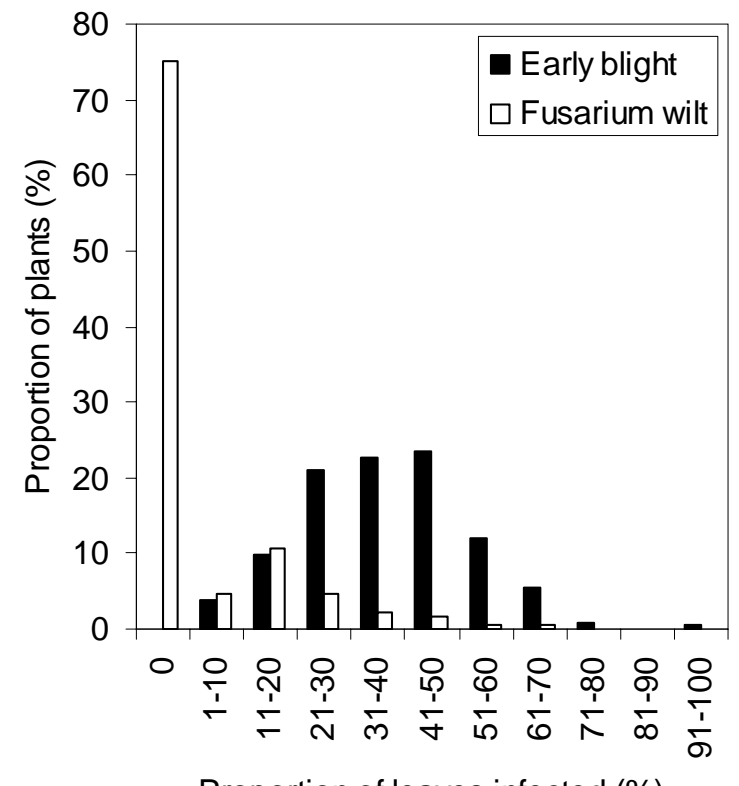

Proportion of leaves infected (\%)

Figure 48. Proportion of tomato plants expressing symptoms of early blight (black bars) and Fusarium wilt (white bars) infection at final harvest. 


\section{Discussion}

The tri-fan circle design allowed analyses of the effects of crop density, crop ratio, and competitive effects within and between species. It answered the objectives of both replacement series and additive series designs, and allowed both regression and full response surface analyses. It demonstrated consistent and reproducible effects under field conditions meeting organic certification requirements.

A similar design, the mixed hexagonal fan design, has been previously employed in a 10-week greenhouse study (Antonovics and Fowler 1985), but this is the first use of the design in a multi-season field study. Antonovics and Fowler (1985) used 255 plants in each of two replicates to test density $(1.0$ to $7.1 \mathrm{~cm}$ spacing) and frequency effects of a single diculture. They reported a four-fold economy of seeds and a tenfold economy of space using the design. By comparison, this study used up to 297 plants in each of six replicates to test density (14.4 to $93.5 \mathrm{~cm}$ spacing) and frequency effects in three dicultures. This study used about the same number of plants per diculture tested as the previous study, but drew data from a broader range of environmental conditions, allowing more robust conclusions.

Several models were used to analyze the results from this design. The first used square-root transformed data to correct for heterogeneity of variance. This model had evenly distributed residuals and came the closest to meeting statistical assumptions, but was biologically suspect because it predicted a dramatic drop in yield at very high densities and no maximum plant size at low densities (Figure 27 left). Nonetheless, it offered a good match to the data over the range of densities tested, and produced easily-interpreted parameter estimates (Table 29). This model showed the density response was strongest in tomato, followed by Brussels sprout, then basil, regardless of companion crop. Tomato and Brussels sprout both responded positively to increasing numbers of basil neighbors, and basil responded negatively to increasing numbers of tomato or Brussels sprout neighbors. The response of tomato and Brussels sprout to one another did not differ significantly from their response to individuals of the same species.

The second model was a nonlinear model that has previously been used to analyze additive designs (Firbank and Watkinson 1990). This model gave a more biologically realistic fit to the data (Figure 27 right), with plant weight reaching a maximum at high densities, and unit per unit area falling more gradually at high densities. It violated the assumption of homogeneity of variance, however, because variability in plant weight tended to increase with weight. The interpretation of some of the model's parameters was ambiguous. The nonlinear model tended to give a higher estimate of plant weight in the absence of competition for dicultures (Table 30) than for monocultures (Table 28), even though this estimate should have depended only on the target species, not the companion species. Two terms, $a$ and $b$, contributed to the total density effect, making it difficult to compare density effects simply by looking at component values. This model also offered a good fit to the data, and some agreement with the first model. The model involved a competition coefficient, $\alpha$, which estimated the effect of individuals of the 
companion species on individuals of the target species (Table 30). This value was very low $(<0.3)$ when basil was the companion species, and high $(>2.3)$ when basil was the target species, indicating that basil offered little competition to tomato or Brussels sprout but suffered severe competition from these species. The values for dicultures of tomato and Brussels sprout were 1.6 and 0.7 for tomato and Brussels sprout targets, respectively, suggesting that Brussels sprout was a stronger competitor than tomato.

The third model, which related inverse yield to the density of each species in diculture, has been criticized for its assumption that yield and density are inversely proportional at high densities (Firbank and Watkinson 1990). Jolliffe (1997) showed that it offered a strong fit to published data for studies of 32 different binary mixtures, noting "I have been repeatedly impressed with the ability of the models to conform to experimental data." The data set for this model also failed to satisfy the assumption of homogenous variances, with variance being inversely related to yield. Very small plants had a disproportionate effect on estimates, making it necessary to pool replicates and exclude the smallest plants from the data set before analysis. This model gave very different estimates of plant weight in the absence of competition for the same species, and most of these estimates were not significant (Table 31). The model separated the intra-specific and inter-specific competition effects ( $a$ and $\alpha$, respectively, Table 31), assigning the smallest values to the strongest competition effects. According to both parameters tomato was the strongest competitor, followed by Brussels sprout, then basil. Under this model the target species is dominant when $a>\alpha$. Tomato was always dominant and basil was always subordinate, but Brussels sprout dominated basil companions and was subordinate to tomato companions.

Different models suggested different monoculture densities to optimize yield (Figure 27). Both the square root yield-density model and the nonlinear model predicted optimum basil yields at 18.2 plants $/ \mathrm{m}^{2}(25 \mathrm{~cm}$ spacing) in monoculture, but Brussels sprout and tomato yields, respectively, were highest at $7.3(40 \mathrm{~cm}$ spacing) and 18.2 plants $/ \mathrm{m}^{2}$ (25 cm spacing) according to first model, and at 4.5 (50 cm spacing) and 47.2 plants $/ \mathrm{m}^{2}$ (16 cm spacing) according to the second. These are much higher densities than are normally recommended. Rodale's All-New Encyclopedia of Organic Gardening (Bradley and Ellis 1992) suggests inter-plant spacings of 60,60 , and $45 \mathrm{~cm}\left(3.2,3.2\right.$ and $\left.5.7 \mathrm{plants} / \mathrm{m}^{2}\right)$ for tomato, Brussels sprout, and basil respectively. Jeavons (1982), who advocates high density plantings, recommends inter-plant spacings of 50,45 , and $30 \mathrm{~cm}\left(4.6,5.7\right.$ and 12.8 plants $\left./ \mathrm{m}^{2}\right)$ for the same crops. The regular pruning of basil, and suckering of all but the primary stem of tomato vines probably contributed to the optimum yields at higherthan-usual densities.

Planning plant spacings solely to maximize yield is only practical if land is the only limiting resource to production. Harvest, pruning, and other field operations were very difficult for plants grown at the yieldoptimizing densities because there was little space to maneuver between the plants. Although yields were high, tomato fruits and basil leaves were smaller at the highest densities, so quality may have been 
compromised. Individual plants were larger, and produced more, at lower planting densities. Lower densities would be most appropriate if plant material or labor is more limiting than land.

The dominant species in a diculture should always perform better than in monoculture because the stronger effect of within-species competition has been replaced by a weaker between-species competition effect (Joliffe and Wanjau 1999). An advantage to diculture only occurs when the magnitude of the positive effect on the dominant species exceeds that of the negative effect on the subordinate species. Model parameters can predict this possibility. For example, the parameter $z$ in the square root yield-density model is negative and $a>\alpha$ in the inverse yield-density model when competition from companion neighbors is less than competition from other neighbors of the target species (Table 29, Table 31) (Jolliffe 1997).

Many previous studies have compared dicultures to monocultures using LER, which Jolliffe (1997) suggests is an unsatisfactory index because it does not compare "equal populations and areas allocated to mixtures and pure stands." Jolliffe (1997) proposed the RLO index as a more useful alternative, comparing mixtures to monocultures grown at the same total density. The use of multiple indices has been recommended as a means of determining pattern robustness and reproducibility (Goldberg et al. 1999); comparing RLO and LER response surfaces in Figure 34 and Figure 35 demonstrate similarities and differences between the two indices. Surfaces predicted by the square root yield-density model and the nonlinear model showed that LER was often higher than RLO at the highest densities, but lower than RLO at lower densities (Figure 34, Figure 35). This same phenomenon was observed when RLO and LER were calculated directly from the data collected.

The highest LER and RLO values were consistently seen at the highest densities, indicating that yield advantages to diculture were greatest when density was high, but not necessarily that the highest densities led to optimal yields. The total decline in biomass harvested from the highest density regions was accompanied by a decline in crop quality (e.g. tomato size, sprout formation) and increasing difficulty in managing the crops.

A relationship between biomass production, light absorption, and moisture uptake is suggested by ranking the circle segments by resource use and biomass production (Table 32). Yield advantages in polyculture may occur when a combination of crops is able to use more of the available resources than a single crop. This hypothesis was tested by looking for differences between the observed resource use of dicultures and that expected from the resource use of adjoining monocultures. Differences were indeed observed between the expected and observed light absorption by dicultures (Figure 38), but not between the observed and expected volumetric water content of soils (Figure 44). Most cases where more light was absorbed than expected occurred at the highest densities, where the greatest advantages to polyculture were also observed (Figure 32). The T\&S segment stands out as the only segment in which RLO did not exceed 1 at the highest densities and no difference was observed between observed and expected light absorption at the highest 
density tested. The segments dominated by tomato were the only ones to absorb more light than expected at the lowest density, however.

The relationship between water and light absorption is further supported by the similar effects of year and planting density on light and water use (Figure 39, Figure 45), and by Figure 42. Future analyses of these data could further explore the relationships between biomass production and utilization of light and water, perhaps offering further insight into the physical reasons for polyculture yield advantages.

The changing patterns of light absorption over time (Figure 40, Figure 41) suggest another avenue to explore using the data collected for this study. Analysis of yield data presented here has considered only the total yields for each season. Tomato and basil harvests were conducted several times throughout the season, generating a time-series yield response. These data could allow analyses of the response to polyculture over time, which have been lacking from the published studies on plant interactions (Weigelt and Jolliffe 2003). Weigelt and Jolliffe (2003) have called for the use of competition indices to track competition effects over time to further the understanding of the processes that lead to the end results observed in most competiton studies.

Arthropod and disease monitoring was not a focus of this study, but the end-of-season monitoring conducted suggested an inverse response to density in both cabbage aphid, and imported cabbageworm (Figure 47).

Table 32. Segments of the tri-fan circle study ranked by canopy light absorption (100 - Sunfleck \%), moisture deficit (100 - Volumetric Water Content \%), and total aboveground biomass production (g). The mean rank is shown in the final column.

\begin{tabular}{lcccc}
\hline \multirow{2}{*}{$\begin{array}{l}\text { Circle } \\
\text { segment }\end{array}$} & $\begin{array}{c}\text { Light } \\
\text { absorption }\end{array}$ & $\begin{array}{c}\text { Moisture } \\
\text { deficit }\end{array}$ & $\begin{array}{c}\text { Biomass } \\
\text { production }\end{array}$ & Mean \\
\hline TOM & 1 & 1 & 1 & 1.00 \\
T\&S & 2 & 3 & 3 & 2.67 \\
T\&B & 3 & 5 & 2 & 3.33 \\
S\&T & 5 & 2 & 4 & 3.67 \\
SPT & 4 & 4 & 6 & 4.67 \\
S\&B & 6 & 6 & 7 & 6.33 \\
B\&T & 7 & 7 & 5 & 6.33 \\
B\&S & 8 & 8 & 8 & 8.00 \\
BAS & 9 & 9 & 9 & 9.00 \\
\hline
\end{tabular}




\section{CHAPTER 5: Conclusion}

Popular literature relating to companion planting (e.g. Riotte 1975) claims that certain combinations can increase yields, reduce pest or disease problems, and even improve flavor. Combinations such as tomato and basil have been encouraged for the benefits they are said to offer the gardener, while other combinations, such as tomato and Brussels sprout, are discouraged because they are said to offer a net disadvantage. Benefits attributed to good companion planting combinations include improved crop flavor, reduced pest and disease damage, and increased yields.

Here I report two studies comparing differences between plants sharing garden beds with companions of a different species (dicultures) and plants growing in beds devoted to a single species (monocultures). A third study looks more closely at how the competitive effects of plants' nearest neighbors varies according to species composition and density when two species are mixed. I conclude that beneficial companion combinations are not simply derived from selecting the right companions, but depend on planting density, plant ratios, and relative planting times.

Untrained tasters have no preference for tomatoes grown with the companion crops tested over those grown in monoculture, regardless of companion choice (Table 7, Table 17). Flavor differences may have existed between treatments, but these were not consistant between studies, and would require trained tasters for proper evaluation (Lawless and Heymann 1998).

Early blight of tomato was common in all studies. The proportion of infected leaves was higher for plants grown with Brussels sprout companions than plants with basil companions in a study in which plants were grown in bare soil (Table 23), but no effects of companion planting or density were seen in a study using black plastic mulch. Recent studies have shown both plastic mulches and living mulches to reduce early blight incidence (Abdul-Baki et al. 2002, Mills et al. 2002). I suggest that basil offered some of the advantage of a living mulch in the study conducted in bare soil, but no advantage when a plastic mulch was present to reduce early blight infection by soil splashing. This hypothesis was not directly tested by the experiments reported here.

Commonly occurring insect pests in these studies included the potato aphid on tomato, the palestriped flea beetle on basil, and the striped flea beetle and imported cabbageworm on Brussels sprout. Of these, only palestriped flea beetle densities were consistently higher in basil monoculture beds than in mixed plantings (Table 8, Table 18). Potato aphid on tomato showed no response to companion planting (Table 12, Table 22). The response of Brussels sprout pests was not consistent across studies, with flea beetles and imported cabbageworms tending to have higher densities in monoculture in the preliminary study (Table 10, Table 11), but lower densities in monoculture in the biointensive study (Table 19, Table 20). The popular claim 
that aromatic herbs such as basil deter pests of brassica was not borne out by these data; insect pest densities were often higher on Brussels sprouts planted with basil companions than in monocultures.

Considering the pest density data divorced from the context of yield data could lead to the invalid conclusion that Brussels sprouts benefited from their association with companions in the preliminary study, but not in the biointensive study. The yield data suggest otherwise. Association with tomato resulted in a lower pest density, but severe yield reductions for Brussels sprout in the preliminary study (Figure 7). The weight of Brussels sprout plants at season end was almost ten times higher in the biointensive study than in the preliminary study (Figure 7, Table 15), but pest densities were often highest in the beds with the largest plants. Even when companion planting reduces herbivore populations no practical benefit is derived if yield reductions from companion competition exceed the losses avoided from herbivore feeding. Competition effects of companion planting usually had a greater impact on yield than the indirect effect of differing pest densities.

Dicultures usually had a dominant species, but dominance was not necessarily maintained between studies. The design of the tri-fan circle study allowed separation of the competitive effects of companion species from target species, and a mathematical indicator of dominance (Table 31). When all species were transplanted at the same time, as in the tri-fan circle study, tomato dominated Brussels sprout, which dominated basil. The order of dominance was the same in the biointensive study (planting times in Figure 12), but neither basil nor Brussels sprout clearly dominated the other in the preliminary study, in which Brussels sprout was planted much later than its companions.

When total plant density is held constant dominant crops should perform better in diculture than in monoculture because competition with the companion species is less than competition with same-species neighbors (Joliffe and Wanjau 1999). Conversely, subordinate crops will not perform as well in diculture because competition with companions is more severe than competition with same-species neighbors. The gardener benefits from companion planting when the improvement in performance of the dominant crop is greater than the reduction in the performance of the subordinate crop. This proved to be the case when tomato or Brussels sprout plants were grown with basil companions, but not when tomato and Brussels sprout were grown together (Figure 34, Figure 35). This suggests that tomato and Brussels sprout occupied much the same niche in their demand for resources, but basil required a slightly different resource set.

Riotte (1975) used the metaphor of 'love' to describe beneficial relationships between companion plants. At its best, human love offers mutual benefits to equal, but different, partners in a relationship. This is not necessarily the case for the relationships between companion plants, even when the end result benefits the gardener. The studies reported here showed the relationship of tomato to basil to be one of domination, with a net benefit accruing to the gardener from basil's ability to survive and produce some yield without compromising tomato yield. When competitive interactions were more equal, as was the case for tomato and Brussels sprout in the tri-fan circle study, diculture offered no yield advantage. The metaphor shifts 
from a warm and fuzzy image of 'love' to a harsher image of domination and submission, with the gardener benefiting from the submissive's struggle. I take comfort in the fact that we are dealing with plants, and not people.

Competition occurs when two or more plants need the same resources to reach their full growth potential. Light and water are two crucial resources for plant growth, requiring investments in leaves and roots for a plant to access them. Soil moisture content and the penetration of photosynthetically active radiation through the canopy were both used as indicators of the plants' ability to access resources. These factors were correlated with each other (Figure 42) and inversely correlated with biomass accumulation (Figure 46). The conclusion that plants use light and water to grow is hardly ground breaking, but the clear correlations demonstrated by the tri-fan circle study suggest that further analysis of these results could use resource use patterns to estimate biomass accumulation over time, even in segments that included Brussels sprouts, which were only harvested once each year.

The tri-fan circle study allowed analysis of companion planting effects over a range of densities and crop ratios. Yield effects of companion planting were most pronounced at the highest densities tested (Figure 34, Figure 35). One model showed the greatest advantages when the dominant:subordinate ratio was near one (Figure 34), but a more biologically realistic model suggested that higher proportions of the subordinate crop offered greater advantages (Figure 35). These models suggested optimum yields at densities even higher than those recommended by Jeavons (1983), an advocate of high-density plantings.

To summarize, companion plant choice, planting density, crop ratio, and relative planting times all contribute to inter-species interactions in companion planting systems. Although companion planting has significant effects on some insect pests at the garden scale, these effects are not simply due to the combination of certain companion species. High density plantings can optimize land use efficiency and diculture advantages, but may lead to reductions in crop quality, or management difficulties. The combination of a dominant and subordinate crop results in larger dominant plants and smaller subordinate plants than in equivalent monocultures grown at the same density. Such combinations offer yield advantages when the increase in dominant plant weights exceeds the reduction in subordinate plant weights, suggesting that the two crops draw on slightly different resource sets. Combinations with high subordinate crop proportions may offer the greatest yield advantages. 


\section{References Cited}

Abdul-Baki, A.A., J.R. Teasdale, R.W. Goth, and K.G. Haynes. 2002. Marketable yields of fresh-market tomatoes grown in plastic and hairy vetch mulches. HortScience 37: 878-881.

Altieri, Miguel A. 1991. How best can we use biodiversity in agroecoysytems?. Outlook on Agriculture 20: $15-23$.

Altieri, Miguel A. 1994. Insect manipulation through weed management. In Biodiversity and Pest Management in Agroecosystems. 25-38. New York, NY: Food Products Press.

Andow, D.A. 1991. Vegetational diversity and arthropod population response. Annual Review of Entomology 36: 561-86.

Antonovics, J., and N.L. Fowler. 1985. Analysis of frequency and density effects on growth in mixtures of Salvia spendens and Linum grandiflorum using hexagonal fan designs. Journal of Ecology 73: 219234.

Asman, Karolina, Barbara Ekbom, and Birgitta Ramert. 2001. Effect of intercropping on oviposition and emigration behavior of the leek moth (Lepidoptera: Acrolepiidae) and the diamondback moth (Lepidoptera: Plutellidae). Environmental Entomology 30: 288-294.

Bach, C.E. 1980. Effect of plant density and diversity in the populations of a specialist herbivore, the striped cucumber beetle, Acalymma vittata. Ecology 51: 1515-1530.

Bach, C.E., and B.E. Tabashnik. 1990. Effects of nonhost plant neighbors on population densities and parasitism rates of the diamondback moth (Lepidoptera: Plutellidae). Environmental Entomology 19: 987-994.

Ballaré, C.L., Ana L. Scopel, and R.A. Sanchez. 1990. Far-red radiation reflected from adjacent leaves: an early signal of competition in plant canopies. Science 247: 329-332.

Bellamy, David. 2003. Companion plants. Backyard organic gardening. Http://home.vtown.com.au/dbellamy/contents.html

Bender, D.A., W.P. Morrison and R.E. Frisbie.1999. Intercropping cabbage and Indian mustard for potential control of Lepidopterous and other insects. HortScience 34: 275-279.

Beyfuss, Robert, and Marvin Pritts. 1994. Ecogardening Factsheet \#10 - Companion Planting. Ecogardening. http://www.hort.cornell.edu/gardening/fctsheet/egfactsh/complant.html: Cornell Cooperative Extension.

Blackmer, T.M., and J.S. Schepers. 1994. Techniques for monitoring crop nitrogen status in corn. Communications in Soil Science and Plant Analysis 25:1791-1800.

Boffey, T.B., and A. Veevers. 1977. Balanced designs for two component competition experiments. Euphytica 26: 481-484.

Bradley, F.M. \& B.W. Ellis 1992. All-New Encyclopedia of Organic Gardening. Rodale Press, Emmaus, PA.

Brandsaeter, L.O., J. Netland, and R. Meadow. 1998. Yields, weeds, pests and soil nitrogen in a white clover-cabbage living mulch system. Biological Agriculture and Horticulture 16: 291-309.

Brown, Martha. 2000. The Farm and Garden Projects at the University of California, Santa Cruz. Chronicle of the University of California 3 (Spring 2000). Http://zzyx.ucsc.edu/casfs/about/fgstory.html: Berkley Center for Studies in Higher Education.

Brown, J.E., W.E. Splittstoesser, and J.M. Gerber. 1985. Production and economic returns of vegetable intercropping systems. Journal of the American Society of Horticultural Science 110, 3: 350-353.

City Farmer. 2002. 44\% of Vancouver Households Grow Food, Says City Farmer. Urban Agriculture Notes. Http://www.cityfarmer.org/44percent.html\#44percent 
Clark, E.A. and C.A. Francis 1985. Transgressive yielding in bean:maize intercrops; interference in time and space. Field Crops Research 11:37-53.

Connolly, J. 1987. On the use of responsive models in mixture experiments. Oecologia 72: 95-103.

Connolly, J., P. Wayne, and R. Murray. 1990. Time course of plant-plant interactions in experimental mixtures of annuals: Density, frequency, and nutrient effects. Oecologia 82: 513-526.

Cousens, Roger. 1991. Aspects of the design and interpretation of competition (interference) experiments. Weed Technology 5: 664-673.

Cunningham, D. 2001. Louise Riotte 1909-1998. Louise Riotte, Gardening by Astrology. Http://www.solsticepoint.com/astrologersmemorial/riotte.html: Solstice Point.

Cunningham, S.J. 1998. Great Garden Companions: A Companion-Planting System for a Beautiful, Chemical-Free Vegetable Garden. Emmaus, PA: Rodale Press.

Decagon Devices. 1989. Sunfleck Ceptometer User's Manual. Pullman, WA.

Dempster, J. P. and T. H. Coaker. 1974. Diversification of crop ecosystems as a means of controlling pests, pp. 106-114. In D. Price-Jones and M. E. Solomon (eds.), Biology in pest and disease control, Blackwell, Oxford.

De Wit, C.T. 1960. On competition. Versl. Landbk Ondea No. 66.S. Eriksson, O.19S6. Mobility and space capture in the stoloniferous plant Fotenrilla anserina. Oikos 46:82-87

Dwyer, L.M., M. Tollenaar, and L. Houwing. 1991. A nondestructive method to monitor leaf greenness in corn. Canadian Journal of Plant Science 71:505-509.

Dyck, G.V. \& A.J. Barnard 1976. Suppression of couchgrass by Italian ryegrass and broad red clover undersown in barley and field beans. Journal of Agricultural Science, Cambridge 87: 93-108.

Ecology Action. 2003. Grow Biointensive. Ecology Action. Http://www.growbiointensive.org/biointensive/GROW-BIOINTENSIVE.html

Elmstrom, K.M., D.A. Andow, and W.W. Barclay. 1988. Flea beetle movement in a broccoli monoculture and diculture. Environmental Entomology 17: 299-305.

Finch, S., and R.H. Collier. 2000. Host-plant selection by insects -- a theory based on 'appropriate/inappropriate landings' by pest insects of cruciferous plants. Entomologia Experimentalis et Applicata 96: 91-102.

Finch, S., H. Billiald, and R.H. Collier. 2003. Companion planting - do aromatic plants disrupt host-plant finding by the cabbage root fly and the onion fly more effectively than non-aromatic plants? Entomologia Experimentalis et Applicata 109: 183-195.

Firbank, L.G., and A.R. Watkinson. 1990. On the effects of competition: from monocultures to mixtures. In Perspectives on Plant Competition, J.B. Grace \& D. Tilman (eds.). 165-192. London: Academic Press.

Francis, Charles A.. 1986. Introduction: Distribution and Importance of Multiple Cropping. In Multiple Cropping Systems, Charles A. Francis (ed.). 1-19. New York: Macmillan.

Fraser, Tina. 2002. Companion planting: Relationships in plant communities. Eco-Farm and Garden (newsletter of the Canadian Organic Growers). Spring 2002.

Freckleton, R.P., and A.R. Watkinson. 2000. Designs for greenhouse studies of interactions between plants: an analytical perspective. Journal of Ecology 88: 386-391.

Fukuoka, Masanobu, 1982. The Plowboy Interview: 40 Years of Natural Farming. Mother Earth News July/August, 1982. The Fukuoka Farming Website. Http://www.fukuokafarmingol.net/faplow.html:July/August.

Gandee, Jesse and Gerard D'Souza. 2001. Agriculture in the West Virginia Economy. Electronic Publications. Http://www.caf.wvu.edu/gdsouzawww/agricultureinWVeconomy.pdf: West Virginia University. 
GardenGuides. 2003. Tips and techniques: Vegetable companion chart. GardenGuides. Http://www.gardenguides.com/TipsandTechniques/vcomp.htm

Garrett, K.A. and C.C. Mundt. 2000. Host diversity can reduce potato late blight severity for focal and general patterns of primary inoculum. Phytopathology 12:1307-1312.

Goldberg, D.E. 1994. Influence of competition at the community level: an experimental version of the null models approach. Ecology 75: 1503-1506.

Goldberg, D.E., T. Rajaniemi, J. Gurevitch, and A. Stewart-Oaten. 1999. Empirical approaches to quantifying interaction intensity competition and facilitation along productivity gradients. Ecology 80: 1118-1131.

Gianquinto, G., P. Sambo and S. Bona. 2003. The use of SPAD-502 chlorophyll meter for dynamically optimizing the nitrogen supply in potato crop: A methodological approach. Acta Horticulturae 627:217-224

Gibson, D.J., J. Connolly, D.C. Hartnett, and J.D. Weidenhamer. 1999. Designs for greenhouse studies of interaction between plants. Journal of Ecology 87: 1-16.

Giunta, F., R Motzo, and M. Deidda. 2002. SPAD readings and associated leaf traits in durum wheat, barley and triticale cultivars. Euphytica 125: 197-205.

Grace, J.B. 1995. On the measurement of plant competition intensity. Ecology 76: 152-156.

Grime, J.P. 1977. Evidence for the existence of three primary strategies in plants and its relevance to ecological and evolutionary theory. American Naturalist 111: 1169-1194.

Gupta, P.D., Thorsteinson, A.J.. 1960. Food plant relationships of the diamond-back moth (Plutella maculipennis (Curt.)). II Sensory regulation of oviposition of the adult female. Entomologia Experimentalis et Applicata 3: 305-314.

Hart, Robert D. 1986. "Ecological framework for multiple cropping systems." In Multiple Cropping Systems, Charles A Francis (ed.). 40-56. New York: Macmillan.

Held, D.W., P. Gonsiska, and D.A. Potter. 2003. Evaluating companion planting and non-host masking odors for protecting roses from the Japanese Beetle (Coleoptera: Scarabaeidae). Environmental Entomology 96: 81-87.

Haynes, R.J. 1980. Competitive aspects of the grass-legume association. Advances in Agronomy 33: 227261.

Hill, Stuart B. 1975. Companion Plants. Ecological Agriculture Projects. Http://eap.mcgill.ca/Publications/EAP55.htm: McGill University.

Hinkamp, Dennis. 1999. "Do Organic Watchdogs Work?." http://www2.ext.usu.edu/coop/garden/garden/organic.htm: Utah State University Extension.

Hokkanen, H.M.T 1991. Trap cropping in pest management. Annual Review of Entomology 36: 119-138.

Holt, B.F., and I.K. Smith. 1998. Small-scale intensive cultivation methods: the effects of deep hand tillage on the productivity of bush beans and red beets. American Journal of Alternative Agriculture 13: 2939.

Hooks, C.R.R., and M.W. Johnson. 2003. Impact of agricultural diversification on the insect community of cruciferous crops. Crop Protection 22: 223-238.

Jeavons, John 1982. How to grow more vegetables than you ever thought possible on less land than you can imagine. Ten Speed Press, Berkeley, CA.

Jeavons, J.C. 2001. Biointensive sustainable mini-farming III. System Performance - initial trials. Journal of Sustainable Agriculture 19: 77-83.

Jeavons, John. 2003. Meet John Jeavons. Grow Biointensive Workshops. Http://www.johnjeavons.info/john-jeavons.html 
Jiang, X.X., and B.S. Vergara. 1986. Chlorophyll meter (SPAD-501) to quantify relative cold tolerance in rice. International Rice Research Newsletter 11:10-11.

JMP, Version 4. SAS Institute Inc., Cary, NC, 1989-2001.

Jolliffe, P.A. 1997. Are mixed populations of plant species more productive than pure stands? Oikos 80: 595-602.

Jolliffe, P.A. 2000. The replacement series. Journal of Ecology 88: 371-385.

Joliffe, P.A., and F.M. Wanjau. 1999. Competition and productivity in crop mixtures: some properties of productive intercrops. Journal of Agricultural Science 132: 425-435.

Kennedy, J.S., C.O. Booth \& W.J.S. Kershaw 1959. Host finding by aphids in the field. II. Aphis fabae (gynoparae) and Brevicorne brassicae; with a re-appraisal of the role of host-finding behavior and virus spread. Annals of Applied Biology 47: 424-444.

Kerrigan, Jack, and Margaret Nagel. 1998. Vegetables: Planning. Ohio Master Gardener Online Manual. Http://www.hcs.ohio-state.edu/mg/manual/veg2.htm: Ohio State University Extension.

Lambert, J.D.H., J.T. Arnason, A. Serratos, B.J.R. Philogene, and M.A. Faris. 1987. Role of intercropped red clover in inhibiting European corn borer (Lepidoptera: Pyralidae) damage to corn in Eastern Ontario. Journal of Economic Entomology 80: 1192-1196.

Lamp, W.O. 1991. Reduced Empoasca fabae (Homoptera: Cicadellidae) density in oat-alfalfa intercrop systems. Environmental Entomology 20: 118-126.

Lawless, H.T. and H. Heymann. 1998a. Introduction and overview. In Sensory Evaluation of Food: Principles and Practices. 1-28. New York: Chapman \& Hall.

Lawless, H.T. and H. Heymann. 1998b. Context effects and biases in sensory judgement. In Sensory Evaluation of Food: Principles and Practices. 301-340. New York: Chapman \& Hall.

Liebman, M. \& E. Dyck 1993. Crop rotation and intercropping strategies for weed management. Ecological Applications 3: 92-122.

Maguire, L.A.. 1984. Influence of surrounding plants on densities of Pieris rapae (L.) eggs and larvae (Lepidoptera: Pieridae) on collards. Environmental Entomology 13: 464-468.

Maina, Godfrey G., Joel S. Brown, and Mordechai Gersani. 2002. Intra-plant versus inter-plant root competition in beans: Avoidance, resource matching, or tragedy of the commons. Plant Ecology 160: 235-247.

Markwell, J., J.C. Osterman and J.L. Mitchell. 1995. Calibration of the Minolta SPAD-502 leaf chlorophyll meter. Photosynthesis Research 46: 467-472.

Martini, E.A., J.S. Buyer, D.C. Bryant, T.K. Hartz, and R.F. Denison. 2004. Yield increases during the organic transition: Improving soil quality, or increasing experience? Field Crops Research 86: 255266.

Mead, Roger. 1986. Statistical methods for multiple cropping systems. In Multiple Cropping Systems, Francis, Charles A. (ed.). 317-350. New York: Macmillan.

Mills, D.J., C.B. Coffman, J.R. Teasdale, K.L. Everts, and J.D. Anderson. 2002. Factors associated with foliage disease of staked fresh market tomatoes grown under different bed strategies. Plant Disease 86: 356-361.

National Research Council, 1989. Alternative Agriculture. National Academy Press, Washington, DC, 447 $\mathrm{pp}$

Nelder, J.A, 1962. New kinds of systematic designs for spacing experiments. Biometrics 18:283-307

Perrin, R.M. \& M.L. Phillips, 1978. Some effects of mixed cropping on the population dynamics of insect pests. Entomologia Experimentalis et Applicata 24:385-393.

Perrin, R.M. 1977. Pest management in multiple cropping systems. Agroecosystems 3: 93-118. 
Peryam, D.R. 1958. Sensory difference tests. Journal of Food Technology 12: 231-236.

Phillips, M.L. 1977. Some effects of inter-cropping Brussels sprouts and tomatoes on infestations of Plutella maculipennis (Curt.) and Alerodes brassicae (Walk.). Unpublished MSc thesis, University of London.

Plucknett, D.L., and Nigel J.H. Smith. 1986. Historical Perspectives on Multiple Cropping. In Multiple Cropping Systems, Charles A. Francis. 20-39. New York, NY: Macmillan.

Primal Seeds. 2002. Companion Planting. Primal Seeds. http://primalseeds.nologic.org/companionplanting.htm

Putnam, D.H and D.L. Allan 1992. Mechanisms for overyielding in a sunflower/mustard intercrop. Agronomy Journal 84: 188-195.

Radke, J.K. and R.T. Hagstrom 1976. Strip intercropping for wind protection. p. 201-222 in M. Stelley (Ed.) Multiple Cropping. ASA Special Publication 27. ASA, CSSA, and SSSA, Madison, WI.

Rahn, C.R., C.D. Paterson, and L.V.V. Vaidyanathan. 1993. Improving the use of nitrogen in Brassicae rotations. Acta Horticulturae 339: 207-218.

Rick, C.M. 1978. The Tomato. Scientific American 239: 76-87.

Riotte, Louise 1975. Carrots Love Tomatoes: Secrets of Companion Planting for Successful Gardening. Storey Books, Pownel, VT.

Root, R.B.. 1973. Organization of plant-arthropod association in simple and diverse habitats: the fauna of collards (Brassica oleracea). Ecological Monograph 43: 95-124.

Sackville Hamilton, N.R. 1994. Replacement and additive designs for plant competition studies. Journal of Applied Ecology 31: 599-603.

Sackville Hamilton, N.R., C. Matthew and G. Lemnaire. 1995. In defense of the $-3 / 2$ boundary rule: a reevaluation of self-thinning concepts and status. Annals of Botany 76: 569-577.

Schmid, B., and J.L. Harper. 1985. Clonal growth in grassland perennials 1 . density and pattern-dependent competition between plants with different growth forms. Journal of Ecology 73: 793-808.

Singh, D. and S.K. Kothari. 1997. Intercropping effects on mustard aphid (Lipaphis erysimi Kaltenback) populations. Crop Science 37: 1263-1264.

Simmons, Leah J. 1998. Riotte sows seeds of success. The Daily Ardmoreite. Http://www.ardmoreite.com/stories/090998/liv_riotte.shtml

Smith, J.G.1976. Influence of crop background on natural enemies of aphids on Brussels sprouts. Annals of Applied Biology 83: 15-29.

Smith, H.A. and R. McSorley, 2000. Intercropping and pest management: A review of major concepts. American Entomologist 46: 154-161

Smith, H.A., R. McSorley, and J.A.S. Izaguirre. 2001. Effect of intercropping common bean with poor hosts and nonhosts on numbers of immature whiteflies (Homoptera:Aleyrodidae) in the Salamá Valley, Guatemala. Environmental Entomology 30: 89-100.

Smith, L.J. 2002. Intercropping with resistant cultivars reduces early blight and root knot disease on susceptible cultivars of tomato (Lycopersicon esculentum). MSc thesis, West Virginia Unversity.

Snaydon, R.W. 1991. Replacement or additive designs for competition studies? Journal of Applied Ecology 28: 930-946.

Stobbe, E.H., A.T. Iverson, A. Kumaragamaga, and J. Dean 1990. Intercrop peas with yellow mustard or canola, it pays. p. 159 in Agronomy Abstracts. ASA, Madison, WI.

Suehiro, K. and Ogawa, H. 1980. Competition between two annual herbs, Atriplex gmelini C.A. Mey and Chenopodium album L., in mixed cultures irrigated with seawater of various concentrations. Oecologia 45: 167-177. 
Tabashnik, B.E. 1987. Plant secondary compounds as oviposition deterrents for cabbage butterfly, Pieris rapae (Lepidoptera: Pieridae). Journal of Chemical Ecology 13: 309-316.

Tahvanainen, J.O. and R.B. Root. 1972. The influence of vegetational diversity on the population ecology of a specialized herbivore, Phyllotreta cruciferae. Oecologia 10: 321-346.

Theunissen, J. and H. Den Ouden. 1980. Effects of intercropping with Spergula arvensis on pests of Brussels sprouts. Entomologia Exeperimentalis et Applicata 27: 260-268.

Theunissen, J., C.J.H. Booij, and L.A.P. Lotz. 1995. Effects of intercropping white cabbage with clovers on pest infestation and yield. Entomologia Experimentalis et Applicata 74:7-16.

Theunissen, J. 1997. Intercropping in field vegetables as an approach to sustainable horticulture. Outlook on Agriculture 26: 95-99.

Uvah, I.I.I. and T.H. Coaker. 1984. Effect of mixed cropping on some insect pests of carrots and onions. Entomologia Experimentalis et Applicata 36: 159-167.

US Census Bureau. 2003. West Virginia. State and County Quick Facts. Http://quickfacts.census.gov/qfd/states/54000.html: US Census Bureau.

Vandermeer, J. 1989. The Ecology of Intercropping. Cambridge University Press, Cambridge.

Vaughn, S.F. and R.A. Boydston. 1997. Volatile allelochemicals released from crucifer green manures. The Journal of Chemical Ecology 23:2107-2116.

Vostrikov, P. 1915. Tomatoes as insecticides: The importance of solanaceae in the control of pests of agriculture. Novotcherkassk 10: 9-12.

Watanabe, S., Y. Hatanaka, and K. Inada. 1980. Development of a digital chlorophyll meter: I. Structure and performance. Japanese Journal of Crop Science 49: 89-90.

Watkinson, A.R. 1980. Density-dependence in single-species populations of plants. Journal of Theoretical Biology 83: 345-357.

Weigelt, Alexandra, and Peter Jolliffe. 2003. Indices of plant competition. Journal of Ecology 91: 707-720.

Weiss, M.J., B.G. Schatz, J.C. Gardner, and B.A. Nead. 1994. Flea beetle (Coleoptera: Chrysomelidae) populations and crop yield in field pea and oilseed rape intercrops. Environmental Entomology 23: 654-658.

Weisstein, E. W. 1999. Pascal's Triangle. MathWorld. Http://mathworld.wolfram.com/PascalsTriangle.html: Wolfram Research Inc.

Westerveld, S.M., A.W. McKeown, M.R. McDonald, and C.D. Scott-Dupree. 2003. Chlorophyll and nitrate meters as nitrogen monitoring tools for selected vegetables in southern Ontario. Acta Horticulturae 627: 259-266

Weston, L.A. 1996. Utilization of allelopathy for weed management in agroecosystems. Agronomy Journal 88: 860-866.

Westoby, M. 1984. The self-thinning rule. Advances in Ecological Research 14: 167-225.

Willey, R.W. 1979. Intercropping - its importance and research needs. Part 1. Competition and yield advantages. Field Crops Abstracts 32: 1-10.

Zar, J.H. 1984. Biostatistical Analysis. Simon and Schuster: New Jersey.

Zhao, J.Z., G.S. Ayers, E.J. Grafius, and F.W. Stehr. 1992. Effects of neighboring nectar-producing plants on populations of pest Lepidoptera and their parasitoids in broccoli plantings. Great Lakes Entomologist 25: 253-258. 


\section{Personal Communications}

Jett, John. Extension Specialist - Horticulture. Center for Agriculture, Natural Resources, and Community Development. West Virginia University. 2088 Agricultural Sciences Building, P.O. Box 6108

Morgantown, WV 26506-6108. Phone: 304-293-6131. Email: John.Jett@mail.wvu.edu

Kotcon, James. Associate Professor, Division of Plant and Soil Sciences. West Virginia University. 401

Brooks Hall. P.O. Box 6058. Morgantown, WV 26506-6058. Phone: 293-3911 ext. 2230. Email:

James.Kotcon@mail.wvu.edu 


\section{Appendix 1: Maximum polyculture combinations possible for a given number of monocultures}

A comparison of a polyculture with its constituent monocultures (e.g. calculation of Land Equivalence Ratios) requires a monoculture control for each crop represented in the polyculture. When multiple polycultures containing the same crop are tested simultaneously the monoculture control for that crop can be used for each. Testing multiple polycultures containing the same crop simultaneously is therefore more efficient than testing each polyculture independently.

The number of possible dicultures that can be produced from $x$ crops is equivalent to the number of lines that can be drawn between $x$ points on a circle (Figure 49, Table 33, Weisstein 1999). Similarly, the number of possible tricultures that can be produced from $x$ crops is equivalent to the number of triangles that can be drawn using $x$ points on a circle, and the number of possible tetracultures equals the number of tetrangles that can be drawn using $x$ points on a circle (Figure 49, Table 33, Weisstein 1999).

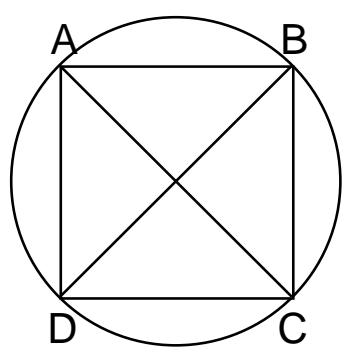

Figure 49. Four points on a circle can be used to determine the maximum number of polycultures that can be created using four crops. There are six possible dicultures, represented by the lines $A B$, $A C, A D, B C B D$, and $C D$; four possible tricultures, represented by the triangles $A B C, A B D, A C D$, and BCD; and one possible tetraculture, represented by the tetrangle $A B C D$.

Table 33. The maximum number of potential polycultures relates to the number of component crops. Adding any number to its neighbor in preceding column gives the next number in the series. The series in these four columns correspond to the second to fifth rows of Pascal's triangle (Weisstein 1999).

\begin{tabular}{cccc}
\hline \multirow{2}{*}{$\begin{array}{c}\text { Crops } \\
\text { (points) }\end{array}$} & $\begin{array}{c}\text { Dicultures } \\
\text { (lines) }\end{array}$ & $\begin{array}{c}\text { Tricultures } \\
\text { (triangles) }\end{array}$ & $\begin{array}{c}\text { Tetracultures } \\
\text { (tetrangles) }\end{array}$ \\
\hline 1 & 0 & 0 & 0 \\
2 & 1 & 0 & 0 \\
3 & 3 & 1 & 0 \\
4 & 6 & 4 & 1 \\
5 & 10 & 10 & 5 \\
6 & 15 & 20 & 15 \\
7 & 21 & 35 & 35 \\
8 & 28 & 56 & 70 \\
$x$ & $1 / 2 x^{2}-1 / 2 x$ & $1 / 6 x^{3}-1 / 2 x^{2}+1 / 3 x$ & $1 / 24 x^{4}-1 / 4 x^{3}+0.4583 x^{2}-1 / 4 x$ \\
\hline
\end{tabular}




\section{Appendix 2: Generation of random planting designs for circle studies}

Circle size. Each replicate consisted of several circles, numbered consecutively from the inside (1...arc). After setting the radius of the inner circle $\left(\mathrm{r}_{1}\right)$, a formula was used to determine the radius of the remaining circles:

$$
\mathrm{r}_{\text {arc }}=\left(\mathrm{r}_{1} / 1.26\right)^{0.2338 \text { arc }}
$$

The inner circle radius was $1.0 \mathrm{~m}$ in 2002 and $0.5 \mathrm{~m}$ in 2003 . The outer circle radius was $5.0 \mathrm{~m}$ in both years. There were a total of 8 circles in 2002 and 11 in 2003.

Randomization. Each circle (27 plants) was divided into nine equal segments of three plants. Every third segment was a monoculture, in which all three plants were the same species. In the zones between monocultures two plants were the same as those in the closest monoculture and one plant was the same as those in the next closest monoculture. The position of the odd plant out in each zone was determined at random.

A spreadsheet was developed to create randomized planting arrangements. It is available here.

Plant spacing. In an offset planting arrangement with straight rows the area occupied by a plant is defined by the hexagon within the 'Star of David' formed when each point touches a neighboring plant (Figure 50A). The midpoint of each edge of the hexagon is halfway between two plants (Figure 50A).

In an offset planting arrangement with arced rows a similar 'Star of David' forms a skewed hexagon (Figure 50B). A slightly larger hexagon of the same proportions describes the area occupied by the plant (Figure 50C). The midpoint between any two plants should fall on an edge of this hexagon (Figure 50C). The area of this hexagon can be more easily estimated by a four-sided figure bounded by lines dissecting the midpoint between adjacent plant on the same arc and arcs dissecting the midpoint between adjacent arcs (Figure 50D).
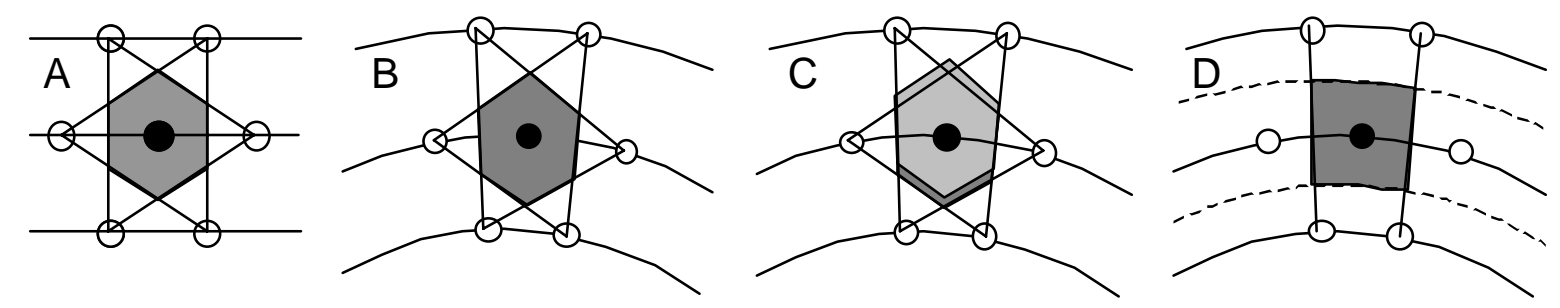

Figure 50. The area occupied by a single plant (black circle) in straight offset rows is bordered by the hexagon formed by the Star of David with points at all adjacent plants (white circles) (A). When offset rows are curved this hexagon no longer describes the area available to a plant (B); the actual area is described by a different hexagon (C), or estimated by a four sided figure (D). 


\section{Appendix 3: Weather data}
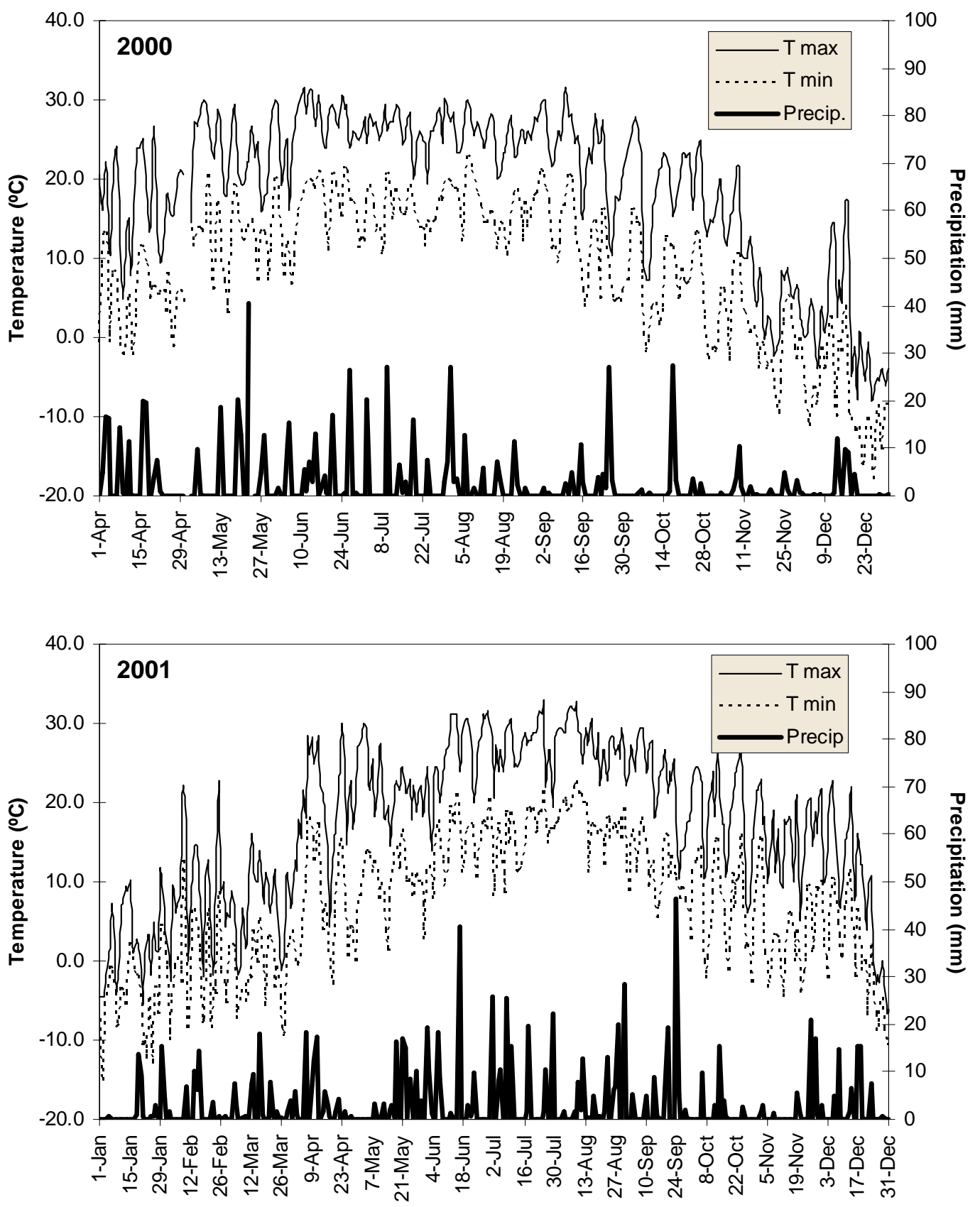

Figure 51. Daily maximum and minimum temperatures, and accumulated precipitation, in 2000 (top) and 2001 (bottom). All observations recorded at the Morgantown municipal airport, approximately 1 $\mathrm{km}$ from the study site. 

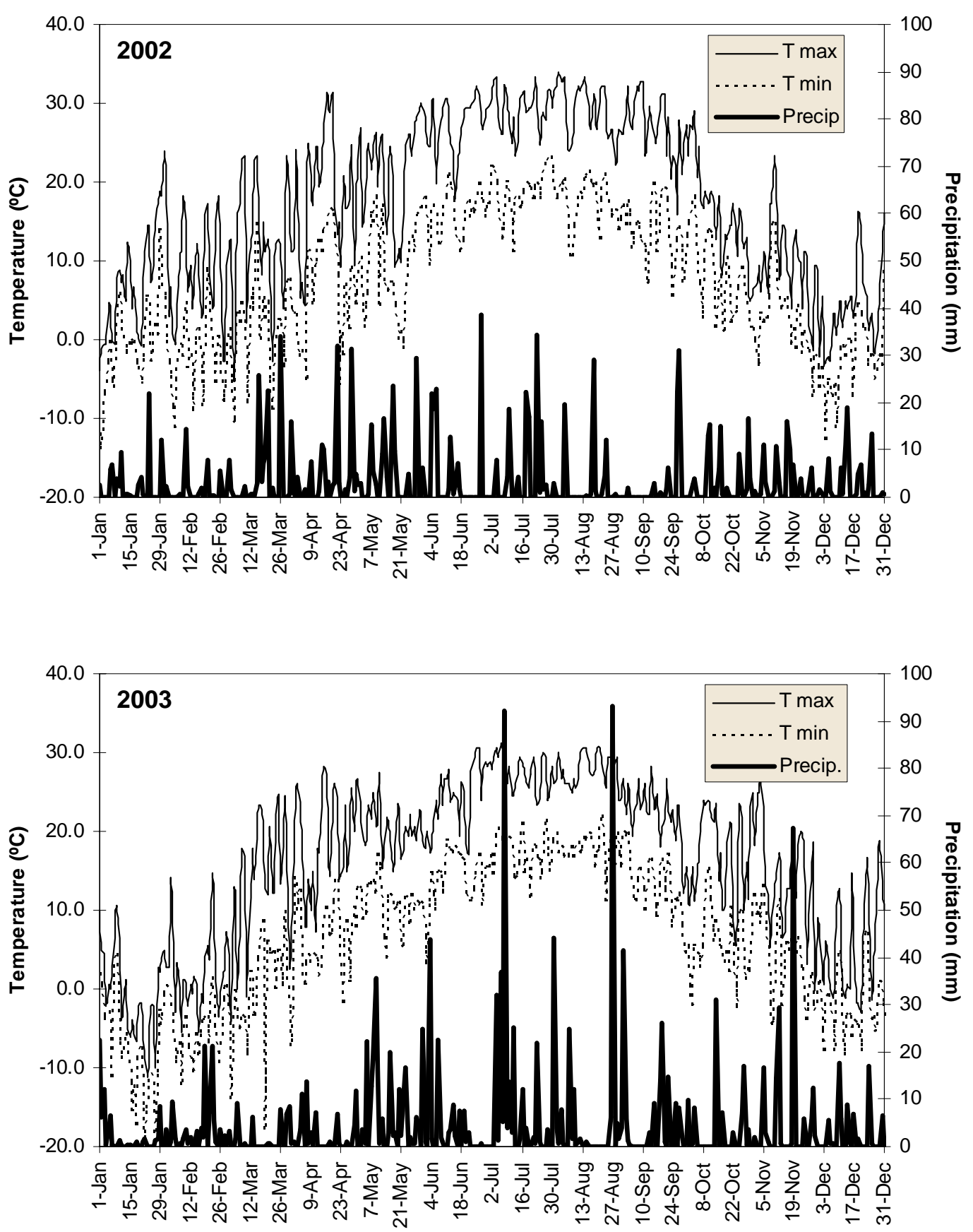

Figure 52. Daily maximum and minimum temperatures, and accumulated precipitation, in 2002 (top) and 2003 (bottom). All observations recorded at the Morgantown municipal airport, approximately 1 $\mathrm{km}$ from the study site. 


\section{Appendix 4: Preliminary study growth photos}

Photographs of beds containing basil, bean, brassica and tomato were taken $1.8 \mathrm{~m}$ above the center of beds representing each of the preliminary study treatments on 29 June, 20 July, 11 August, and 6 September, 2000. These photographs can be examined in an interactive PowerPoint presentation or a separate Word document available with this file. 


\section{Appendix 5: Scale of selected field studies assessing plant diversity effects}

Table 34. A selection of studies demonstrating atypical range of plot sizes to illustrate the scale at which intercropping research has been conducted.

\begin{tabular}{|c|c|c|c|c|}
\hline Title & Reference & Location & Reps & $\begin{array}{c}\text { Plot size } \\
\left(\mathbf{m}^{2}\right)\end{array}$ \\
\hline $\begin{array}{l}\text { Host diversity can reduce potato late blight } \\
\text { severity for focal and general patterns of primary } \\
\text { inoculum }\end{array}$ & $\begin{array}{l}\text { Garrett and } \\
\text { Mundt } 2000\end{array}$ & Oregon & 7 & 7.1 \\
\hline $\begin{array}{l}\text { Intercropping effects on mustard aphid (Lipaphis } \\
\text { erysimi Kalenback) populations }\end{array}$ & $\begin{array}{l}\text { Singh and } \\
\text { Kothari } 1997\end{array}$ & India & 3 & 18 \\
\hline $\begin{array}{l}\text { Effects of intercropping with Spergula arvensis on } \\
\text { pests of Brussels sprouts }\end{array}$ & $\begin{array}{l}\text { Theunissen and } \\
\text { Den Ouden } 1980\end{array}$ & Netherlands & 3 & 22 \\
\hline $\begin{array}{l}\text { Intercropping cabbage and Indian mustard for } \\
\text { potential control of lepidopterous and other insects }\end{array}$ & $\begin{array}{l}\text { Bender, } \\
\text { Morrison and } \\
\text { Frisbie } 1999\end{array}$ & Texas & 4 & 28.5 \\
\hline $\begin{array}{l}\text { Flea beetle (Coleoptera: Chrysomelidae) } \\
\text { populations and crop yield in field pea and oilseed } \\
\text { rape intercrops }\end{array}$ & Weiss et al. 1994 & $\begin{array}{l}\text { North } \\
\text { Dakota }\end{array}$ & 5 & 30 \\
\hline $\begin{array}{l}\text { Role of intercropped red clover in inhibiting } \\
\text { European corn borer (Lepidoptera: Pyralidae) } \\
\text { damage to corn in Eastern Ontario }\end{array}$ & $\begin{array}{l}\text { Lambert et al. } \\
1987\end{array}$ & Ontario & 4 & 35 \\
\hline $\begin{array}{l}\text { Effects of plant density and diversity on the } \\
\text { population dynamics of a specialist herbivore, the } \\
\text { striped cucumber beetle, Acalymma vittata (Fab.) }\end{array}$ & Bach 1980 & Michigan & 3 & 100 \\
\hline $\begin{array}{l}\text { Effect of intercropping common bean with poor } \\
\text { hosts and nonhosts on numbers of immature } \\
\text { whiteflies (Homoptera: Aleyrodidae) in the Salama } \\
\text { Valley, Guatemala }\end{array}$ & Smith et al. 2001 & Guatemala & 4 & 153 \\
\hline $\begin{array}{l}\text { Reduced Empoasa fabae (Homoptera: } \\
\text { Cocadellidae) density in oat-alfalfa Intercrop } \\
\text { Systems }\end{array}$ & Lamp 1991 & Maryland & 4 & 231 \\
\hline $\begin{array}{l}\text { Effects of intercropping white cabbage with } \\
\text { clovers on pest infestation and yield }\end{array}$ & $\begin{array}{l}\text { Theunissen, } \\
\text { Booij and Lotz } \\
1995\end{array}$ & Netherlands & 4 & 546 \\
\hline
\end{tabular}




\section{Appendix 6: Popular companion planting recommendations}

Table 35. Examples of popularly circulated companion planting recommendations (from Primal Seeds 2002).

\begin{tabular}{|c|c|c|}
\hline Crop & Good Companions & Bad Companions \\
\hline Asparagus & Tomato, Basil, Parsley & Onion family \\
\hline Aubegine & Beans, Marigold, Catnip, Spinach, Tarragon & \\
\hline Beans, Bush & Rosemary, Pea, Cucumber, Radish, Petunia, Beetroot & Onion \\
\hline $\begin{array}{l}\text { Beans, } \\
\text { Climbing }\end{array}$ & Corn, Summer Savory, Radish & $\begin{array}{l}\text { Onion, Beets, Cabbage, } \\
\text { Sunflower, Kohlrabi }\end{array}$ \\
\hline Beets & Onion, Lettuce, beans, Brassicas, Sage & \\
\hline Brassicas & $\begin{array}{l}\text { To deter pests: Onion family, Chamomile, Nasturtium, Aromatic herbs, } \\
\text { esp. Catmint, Hyssop, Mint, Dill, Sage, Thyme, Lavender, Lemon } \\
\text { Balm. }\end{array}$ & $\begin{array}{l}\text { Strawberry, Tomato, Rue, } \\
\text { Climbing beans }\end{array}$ \\
\hline & Grows well with Celery, Beets, Chard, Lettuce, Spinach, Hemp. & \\
\hline Carrot & $\begin{array}{l}\text { Onion family and aromatic herbs may deter carrot root fly esp. } \\
\text { Coriander, Wormwood, Sage, Chives. Tomato, Flax, Chervil. }\end{array}$ & Dill, Celery, Fennel. \\
\hline Celery & Onion and Brassica families, Spinach, Tomato, Nasturtium & \\
\hline Chard & Dwarf beans, Onions, Kohlrabi & $\begin{array}{l}\text { Climbing beans, Mustard, } \\
\text { Charlock }\end{array}$ \\
\hline Corn & Bean, Squash, Pumpkin, Pea, Potato, Parsley, Amaranth, Dill & Tomato \\
\hline Cucumber & $\begin{array}{l}\text { Beans, Carrot, Onion, Radish, Tomato, Dill, Nasturtium, Lettuce, Corn, } \\
\text { Peas, Summer Savory }\end{array}$ & Strong herbs, Potato \\
\hline Fruit trees & Tansy, Nasturtium, Alfalfa, Nettles & Potato \\
\hline Grapes & Hyssop, Alfalfa & \\
\hline Lettuce & $\begin{array}{l}\text { Onion family, Carrot, Radish, Strawberry, Cucumber, Basil, Beetroot, } \\
\text { Chervil }\end{array}$ & \\
\hline Onion family & $\begin{array}{l}\text { Tomato, Lettuce, Brassicas, Strawberry, Chamomile, Pepper, Carrot, } \\
\text { Celery, Cucumber, Amaranth, Beetroot }\end{array}$ & Beans, Pea, Alfalfa, Asparagus \\
\hline Peas & $\begin{array}{l}\text { Lettuce, Beans, Cabbage, Radish, Swede, Celery, Cucumber, Corn, } \\
\text { Turnip }\end{array}$ & Onions \\
\hline Peppers & Tomato, Onion, Carrot, Amaranth, Tarragon, Okra & \\
\hline Potato & $\begin{array}{l}\text { Marigolds, Beans, Corn, Brassicas, Horseradish, Flax, Amaranth, Fat } \\
\text { hen }\end{array}$ & $\begin{array}{l}\text { Pumpkin, Squash, Tomato, } \\
\text { Cucumber, Sunflower, } \\
\text { Raspberry, Orach, Trees of the } \\
\text { prunus species }\end{array}$ \\
\hline Pumpkins & Corn, Marigold, Radish, Nasturtium & Potato \\
\hline Radish & Chervil, Squash, Peas, Beans, Cucumber & Hyssop \\
\hline Raspberry & Rue, Tansy & \\
\hline Roses & Garlic, Feverfew, Pennyroyal, Rue, Tansy & \\
\hline Spinach & Strawberry, Celery, Brassicas, Aubegine & \\
\hline Squash & Nasturtium, Corn, Marigold, Borage, Onion, Radish & Potato \\
\hline Strawberry & Lettuce, Onion, Bush beans, Borage, Spinach, Pyretheum & Brassicas \\
\hline Tomato & $\begin{array}{l}\text { Onion family, Basil, Parsley, White horehound, Mint, Nettles, } \\
\text { Bergamot, Nasturtium, Marigold, Borage, Carrot, Asparagus, } \\
\text { Cucumber, Celery, Amaranth }\end{array}$ & $\begin{array}{l}\text { potato, Fennel, Brassicas?, } \\
\text { Corn? }\end{array}$ \\
\hline Turnip & Pea & Potato \\
\hline
\end{tabular}




\section{Appendix 7: Soil test results for all study areas}
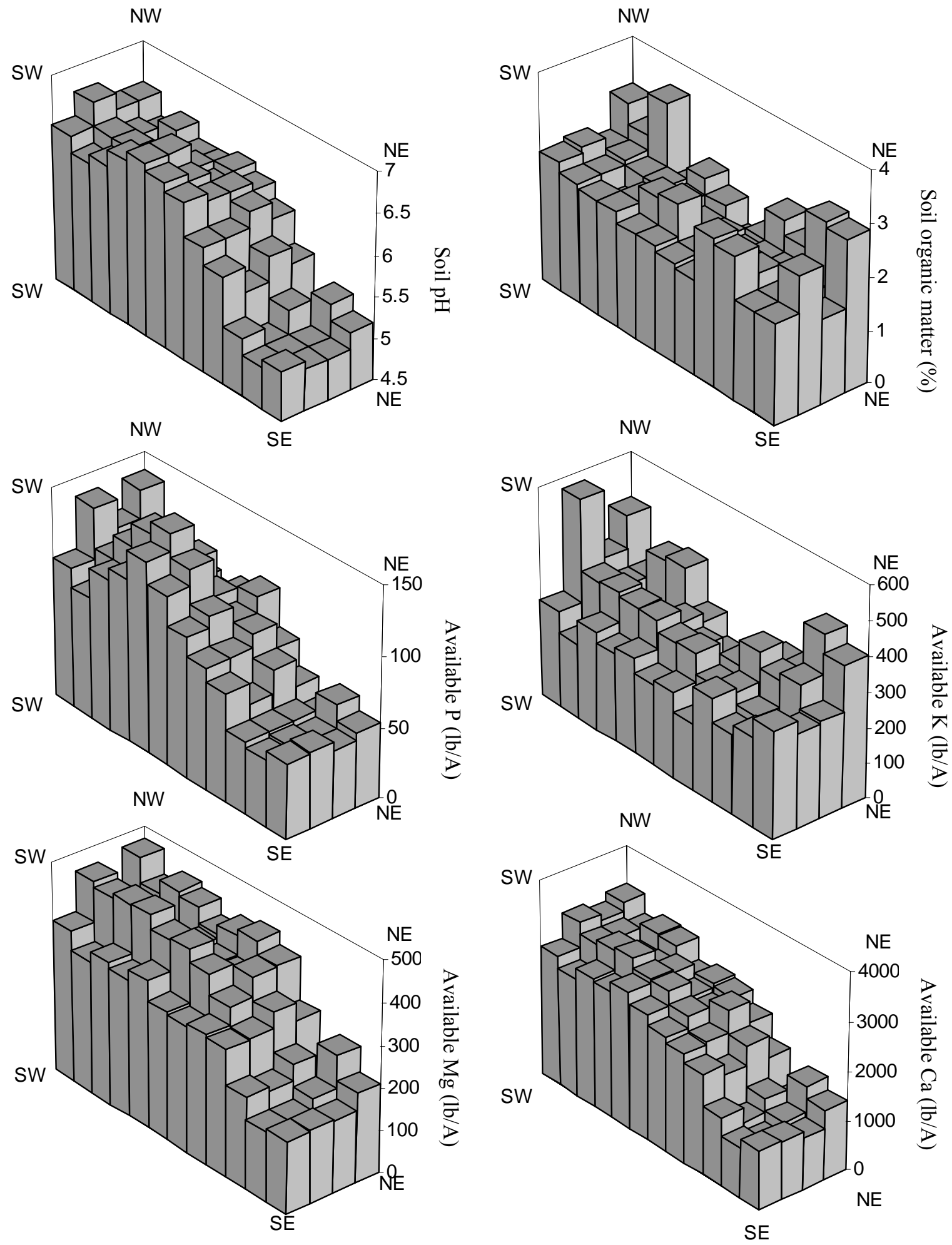

Figure 53. Soil test results from samples collected from the preliminary study area on 13 November, 2000. Each bar represents a single bed. Study area corners are marked by orthogonal abbreviation. 
Table 36. Analysis of composted dairy manure and leaf litter applied to preliminary study plots at approximately $3 \mathrm{~kg} / \mathrm{m}^{2}$ on 27 April, 2000.

\begin{tabular}{lcc}
\hline Parameter & $\%$ & $\begin{array}{c}\text { Application } \\
\text { rate }\left(\mathrm{g} / \mathrm{m}^{2}\right)\end{array}$ \\
\hline Total N & 0.39 & 12 \\
Total P & 0.26 & 7.8 \\
Total K & 0.45 & 14 \\
Moisture & 61 & 1800 \\
Ammonia & 0.04 & 1.2 \\
$\mathrm{Cu}$ & 0.002 & 0.06 \\
$\mathrm{Ca}$ & 0.19 & 5.7 \\
$\mathrm{Mg}$ & 0.18 & 5.4 \\
$\mathrm{C}: \mathrm{N}$ & \multicolumn{2}{c}{43.8} \\
\hline
\end{tabular}

Table 37. Soil test results from samples collected from the biointensive study on 15 April 2003, following study completion. Each value is the mean for a single replicate.

\begin{tabular}{lcccccc}
\hline Replicate & $\mathrm{pH}$ & $\begin{array}{c}\text { Soil organic } \\
\text { matter }(\%)\end{array}$ & $\begin{array}{c}\text { Available P } \\
(\mathrm{kg} / \mathrm{ha})\end{array}$ & $\begin{array}{c}\text { Available K } \\
(\mathrm{kg} / \mathrm{ha})\end{array}$ & $\begin{array}{c}\text { Available } \\
\mathrm{Mg}(\mathrm{kg} / \mathrm{ha})\end{array}$ & $\begin{array}{c}\text { Available Ca } \\
(\mathrm{kg} / \mathrm{ha})\end{array}$ \\
\hline 1 & 6.2 & 2.4 & 120 & 384 & 253 & 2874 \\
2 & 6.3 & 2.6 & 130 & 345 & 236 & 3158 \\
3 & 7.8 & 2.9 & 183 & 326 & 336 & 8561 \\
4 & 7.8 & 2.7 & 183 & 320 & 287 & 8776 \\
\hline
\end{tabular}

Table 38. Soil test results from samples collected from the tri-fan circle study on 15 April 2003, prior to transplanting crops for the second season. Each value is the mean for a single replicate.

\begin{tabular}{lcccccc}
\hline Replicate & $\mathrm{pH}$ & $\begin{array}{c}\text { Soil organic } \\
\text { matter }(\%)\end{array}$ & $\begin{array}{c}\text { Available P } \\
(\mathrm{kg} / \mathrm{ha})\end{array}$ & $\begin{array}{c}\text { Available K } \\
(\mathrm{kg} / \mathrm{ha})\end{array}$ & $\begin{array}{c}\text { Available } \\
\mathrm{Mg}(\mathrm{kg} / \mathrm{ha})\end{array}$ & $\begin{array}{c}\text { Available Ca } \\
(\mathrm{kg} / \mathrm{ha})\end{array}$ \\
\hline 1 & 5.4 & 0.8 & 84 & 142 & 584 & 2643 \\
2 & 6.2 & 2.3 & 86 & 259 & 262 & 3419 \\
3 & 6.1 & 2.5 & 80 & 233 & 274 & 3124 \\
\hline
\end{tabular}

